
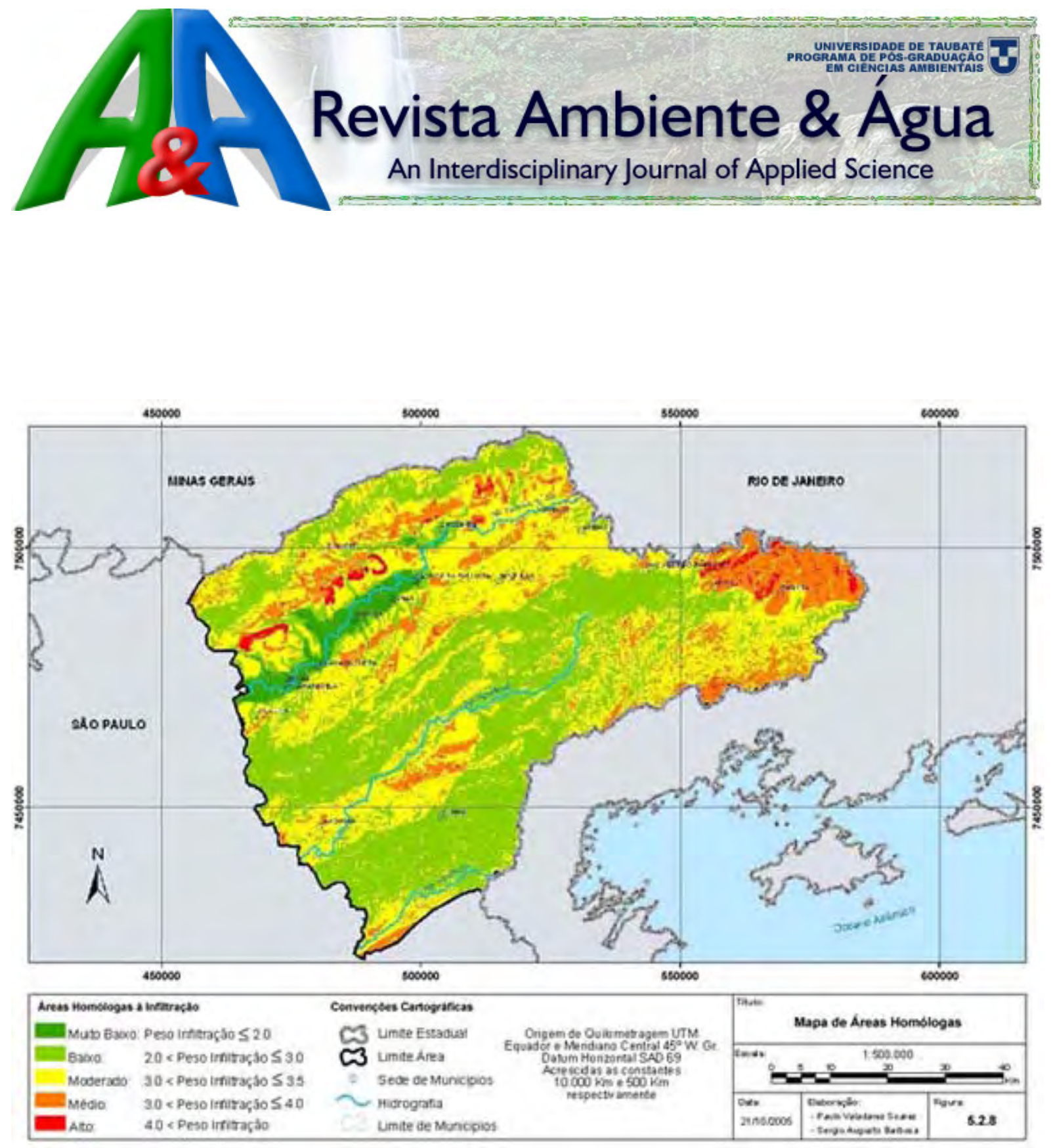

ISSN $=1980-993 \times$ (Online)

www.agro.unitau.br/ambi-agua

Edição 06 da Revista Ambiente \& Água - An Interdisciplinary Journal of Applied Science, Taubaté, v. 3, n. 1, p. 1-137, Abril 2008. (doi:10.4136/ambi-agua.v3.n1) 


\section{COMITÊ EDITORIAL}

\section{Editor}

Getulio Teixeira Batista

Instituto de Pesquisas Ambientais em Bacias Hidrográficas (IPABHi), Brasil

\section{Editores Associados}

Amaury Paulo de Souza

Universidade Federal de Viçosa (UFV), Brasil

Antonio Evaldo Klar

Universidade Estadual Paulista Júlio de Mesquita Filho, UNESP, Brasil

Dar Roberts

Universidade de Stanford; BA pela Universidade da Califórnia, EUA

Hans Raj Gheyi

Universidade Federal de Campina Grande (UFCG), Brasil

\section{Hélio Nóbile Diniz}

Instituto Geológico, Secretaria do Meio Ambiente do Estado de São Paulo (IG/SMA), Brasil

\section{João Vianei Soares}

Instituto Nacional de Pesquisas Espaciais (INPE), Brasil

Editor da Seção Editorial

Editora de Texto

Editora de Referência

Editor de Layout

Suporte Técnico
Luis A. Bartolucci

Florida International University (FIU), EUA

Marcelo dos Santos Targa

Universidade de Taubaté (UNITAU), Brasil

Nelson Wellausen Dias

Universidade de Taubaté (UNITAU), Brasil

Paul W. Mausel

Indiana State University (ISU), EUA

Paulo Renato Schneider

Universidade Federal de Santa Maria (UFSM), Brasil

Sebastião do Amaral Machado

Universidade Federal do Paraná (UFPR), Brasil

Silvio Jorge Coelho Simões

Universidade Estadual Paulista Júlio de Mesquita Filho (UNESP), Brasil

Yosio Edemir Shimabukuro

Instituto Nacional de Pesquisas Espaciais (INPE), Brasil

Nelson Wellausen Dias, PPGCA, UNITAU, Brasil

Maria de Jesus Ferreira Aires, GELP, UNITAU, Brasil

Liliane Castro, Biblioteca ECA/Civil, UNITAU, Brasil

Adam Querido Mazzei Ribeiro, LAGEO, UNITAU, Brasil

Marcio Vinicius Gagliotti, LAGEO, UNITAU, Brasil.

Ficha catalográfica elaborada pelo

SIBi - Sistema Integrado de Bibliotecas / UNITAU

Revista Ambiente \& Água - An Interdisciplinary Journal of Applied Science / Instituto de Pesquisas Ambientais em Bacias Hidrográficas. Taubaté. v. 3, n. 1 (2006) Taubaté: IPABHi, 2008.

Quadrimestral

ISSN 1980-993X

1. Ciências ambientais. 2. Recursos hídricos. I. Instituto de Pesquisas Ambientais em Bacias Hidrográficas. III. Título.

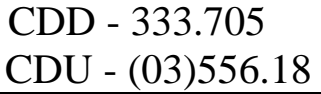




\section{ÍNDICE}

\section{CAPA}

Mapa de Potencialidade de Infiltração, em que as porções identificadas em vermelho representam as áreas com maior potencial para a infiltração.

Fonte: SOARES, P. V.; PEREIRA, S. Y.; SIMÕES, S. J. C.; BERNARDES, G. P.; BARBOSA, S. A. Mapa de infiltração do alto e médio Vale do Paraíba do Sul com base em elementos do meio físico e na precipitação. Ambi-Agua, Taubaté, v. 3, n. 1, p. 26-42, 2008. (doi:10.4136/ambi-agua.40)

\section{EDITORIAL}

Ambiente e Água - An Interdisciplinary Journal of Applied Science no seu terceiro ano de publicação (doi:10.4136/ambi-agua.37)

Getulio Teixeira Batista

\section{ARTIGOS}

Water balance in Cubatão-Sul river catchment, Santa Catarina, Brazil (doi:10.4136/ambi-agua.38)

Masato Kobiyama; Pedro Luiz Borges Chaffe

Mapping and monitoring land cover types in Corumbiara area, Brazilian Amazônia, using Landsat TM and JERS-1 SAR multitemporal data (doi:10.4136/ambi-agua.39)

Yosio E. Shimabukuro; Raimundo Almeida-Filho; Tatiana M. Kuplich; Ramon M. de Freitas

Mapa de infiltração do alto e médio Vale do Paraíba do Sul com base em elementos do meio físico e na precipitação (doi:10.4136/ambi-agua.40)

Paulo V. Soares; Sueli Y. Pereira; Silvio J. C. Simões; George de P. Bernardes; Sérgio

A. Barbosa

Desempenho agronômico de capim tifton 85 (cynodon spp) cultivado em sistemas alagados construídos utilizados no tratamento de água residuária de laticínios (doi:10.4136/ambi-agua.41)

Antonio T. de Matos; Sérgio S. Abrahão; Odilon G. Pereira

Fragilidade ambiental e uso do solo da bacia hidrográfica do Córrego Pindaíba, Uberlândia, MG, Brasil (doi:10.4136/ambi-agua.42)

Paula C. A. de Oliveira; Gelze S. S. C. Rodrigues; Silvio C. Rodrigues

Calibração de sondas TDR em condições de laboratório (doi:10.4136/ambi-agua.43)

Dione I. C. Milani; Maria H. F. Tavares; Clementina Scherpinski

Emprego de técnicas digitais para a concepção da base cartográfica da bacia hidrográfica do Córrego Cabuçu de Baixo, São Paulo, SP (doi:10.4136/ambiagua.44)

Rodrigo A. A. Nóbrega; Mario T. L. de Barros; José A. Quintanilha

Estudo dos impactos da ocupação humana na microbacia do rio Batedor na serra da Mantiqueira no município de Cruzeiro, SP, Brasil (doi:10.4136/ambi-agua.45)

Rubens T. Curvello; Getulio T. Batista; Marcelo S. Targa

Hydrogeology and hydrodynamics of Tremembé aquifer, São Paulo, Brazil (doi:10.4136/ambi-agua.46)

Helio N. Diniz; Jair Santoro; Getulio T. Batista; Nelson W. Dias; Marcelo S. Targa 


\title{
Ambiente e Água - An Interdisciplinary Journal of Applied Science in its third year of publication (doi:10.4136/ambi-agua.37)
}

\section{Getulio Teixeira Batista}

\author{
Professor of the Master Degree Program in Environmental Sciences of Taubaté University \\ Estrada Municipal Dr. José Luiz Cembranelli, 5.000; Bairro Itaim; 12.081-010 - Taubaté, SP \\ E-mail: ambi-agua@agro.unitau.br
}

This April 2008, volume 3, number 1 issue of Ambiente e Água - An Interdisciplinary Journal of Applied Science is a landmark for Ambi-Água to achieving national and international recognition. This year it is expected that the primary system for scientific journal evaluation in Brazil, QUALIS CAPES (http://qualis.capes.gov.br/webqualis/) will review the quality and geographical impact of Ambi-Água inasmuch as many Lattes curricula of scientists involved in Brazilian post-graduate programs show publications in Ambi-Água in the last two years. Batista (2007a) discussed details of CAPES evaluation procedure. In addition to the quality appraisal, CAPES also indicates the regional impact of scientific journals as local, national or international. Once a journal is evaluated by CAPES and has three years of on-time publications, CNPq, the major scientific support agency in Brazil, accepts applications for funding that journal. This may significantly improve the operational facilities of a granted journal.

Ambi-Água editorial board is proud to announce that since its first issue it has been circulating on-time. This has raised the confidence of the scientific community as reflected by the increasing number of manuscript submissions. In fact Ambi-Água has increased international interest indicated by four recent submissions from abroad that are currently undergoing peer review evaluation. We are continuously monitoring the journal's consultations since October 2007. From that time to February 2008 we received 6,230 visits that viewed 22,396 pages (3.59 pages/visit) from 89 countries and 742 cities from all continents. Scientists from 22 different universities or research institutions have already published in Ambi-Água. This number will go up to 32 when all submissions are considered.

Some uniqueness to Ambi-Água is worth mentioning: the scientific focus on environment and water resources, and keeping the interdisciplinary scope seems to have been welcomed by the scientific community. An important aspect of the editorial process is the time for manuscript evaluation. Normally, Ambi-Água has been operating on three month period at most from submission to manuscript approval or rejection. This has to be credited to the ad hoc peer review panel members that have been very diligent. Communication between authors and editor has been always prompt and effective to increase author's motivation and confidence. The use of SEER on-line editing system provided by IBICT (http://www.ibict.br/secao.php?cat=seer) allows the authors to continually follow their manuscript review process. This system allows users interface in English, Spanish and Portuguese. All authors' guidelines are presented in English and Portuguese and shortly will be available in Spanish as well.

Another positive aspect of Ambi-Água is its open access publishing policy powered by OAI-PMH as described by Batista (2007b). This greatly facilitates the indexing of AmbiÁgua by several data harvesters. A relative success has been achieved as a result of efforts to make this journal widely indexed and visible as can be seen in http://www.agro.unitau.br/ seer/files/tabela.htm. Another determination of the Editorial Board is to have in the near 
BATISTA, G. T. Ambiente e Água - An Interdisciplinary Journal of Applied Science in its third year of publication. Ambi-Agua, Taubaté, v. 3, n. 1, p. 3-4, 2008. (doi:10.4136/ambi-agua.37)

future the Digital Object Identifier (DOI ${ }^{\circledR}$ ) System (http://www.doi.org/) assigned to published articles.

\section{REFERENCES}

BATISTA, G. T. Geographical impact of scientific journals. Ambi-Agua, v. 2. n. 3, p. 12-18, 2007a. IPABHi, Taubaté, <http://www.agro.unitau.br/seer/index.php/ambi-agua/article/ view/85/123>. Access in Feb. 2008.

BATISTA, G. T. Scientific journal indexing. Ambi-Agua, v. 2. n. 2, p. 3-6, 2007b. IPABHi, Taubaté, <http://www.agro.unitau.br/seer/index.php/ambi-agua/article/view/59/80>. Access in Feb. 2008. 


ISSN = 1980-993X-doi:10.4136/1980-993X
www.agro.unitau.br/ambi-agua
E-mail: ambi-agua@agro.unitau.br
Tel.: (12) 3625-4116

\title{
Water balance in Cubatão-Sul river catchment, Santa Catarina, Brazil
} (doi:10.4136/ambi-agua.38)

\author{
Masato Kobiyama; Pedro Luiz Borges Chaffe \\ Department of Sanitary and Environmental Engineering, Federal University of Santa Catarina \\ Caixa Postal 476, Florianópolis-SC, CEP88040-900, Brasil \\ E-mail: kobiyama@ens.ufsc.br, chaffe@ens.ufsc.br
}

\begin{abstract}
The objective of the present study was to evaluate the water balance in the Cubatão-Sul river catchment $\left(403.83 \mathrm{~km}^{2}\right)$, Santa Catarina State, Brazil, which is very important for irrigated horticulture and drinking-water supply to the Great Florianópolis Region. The daily data obtained from the Poço Fundo hydrometeorological station and São José Meteorological station during the period between 1977 and 1994 were used for the analysis. A lumped and storage model HYCYMODEL was used for both water balance and evapotranspiration analyses and five additional methods were used for the evapotranspiration analysis. The results from the HYCYMODEL showed that the total discharge and the evapotranspiration in the catchment are approximately $62 \%$ and $44 \%$ of the annual rainfall $(1563 \mathrm{~mm})$, respectively. The total discharge consists on the direct runoff of $26 \%$ and the base flow of $74 \%$. The actual evapotranspiration estimated with the water budget method was practically equal to that obtained with the HYCYMODEL. And the values of the ratio of the annual actual evapotranspiration to the annual potential evapotranspiration are $0.39,0.58,0.65$ and 0.69 for Hamon method, modified Penman method, Blaney and Criddle method and Thornthwaite method, respectively. The increasing rate of the discharge over rainfall is larger than that of the evapotranspiration. When the annual rainfall is more than $930 \mathrm{~mm}$, the discharge is always larger than the evapotranspiration.
\end{abstract}

Keywords: Water balance; evapotranspiration; Cubatão-Sul river.

\section{Balanço hídrico na bacia do rio Cubatão-Sul, Santa Catarina, Brasil}

\section{RESUMO}

O objetivo do presente estudo foi avaliar o balanço hídrico na bacia do rio Cubatão-Sul (403,83 km²), Santa Catarina, Brasil, que é muito importante na irrigação e suprimento de água potável para a Região da Grande Florianópolis. Os dados diários de 1977 a 1994 usados na análise foram obtidos da estação hidrometeorológica do Poço Fundo e da estação meteorológica de São José. O modelo hidrológico concentrado HYCYMODEL foi usado para fazer o balanço hídrico e a análise de evapotranspiração. Outros cinco métodos também foram usados apenas para análise de evapotranspiração. Os resultados do HYCYMODEL mostraram que a vazão total e a evapotranspiração na bacia correspondem a aproximadamente $62 \%$ e $44 \%$ da chuva total média anual (1563 mm). A vazão total é dividida em aproximadamente $26 \%$ de escoamento direto e $74 \%$ de vazão de base. A evapotranspiração real estimada com 0 método do balanço hídrico foi praticamente igual à estimada com o HYCYMODEL. Os valores da razão da evapotranspiração real anual com a evapotranspiração potencial anual são de 0,39, 0,58, 0,65 e 0,69 para os métodos de Hamon, Penmand, Blaney e Criddle e o método de Thornthwaite, respectivamente. A taxa de aumento da vazão com a chuva é maior do que o 
da evapotranspiração. Quando a chuva anual ultrapassa $930 \mathrm{~mm}$, a vazão é sempre maior que a evapotranspiração.

Palavras-chave: Balanço hídrico; evapotranspiração; rio Cubatão-Sul.

\section{INTRODUCTION}

The hydrologic cycle consists in the hydrological processes that are mainly precipitation, runoff, evapotranspiration and soil-water storage. Each process must be evaluated by considering the interrelations among them. The estimation of evapotranspiration is relatively more difficult and complicated than those of precipitation and runoff. That is the reason why various methods have been proposed for the measurement and estimation of the evapotranspiration (Brutsaert, 1982; Pereira et al., 1997). The evapotranspiration estimation is very important in water resource management for hydroelectric power, drinking-water supply, irrigation, and fishery.

Evapotranspiration research is also connected with environmental concerns. While land cultivation extent has been increasing due to population growth, the environment has been degraded due to poor land development planning. Land use and land cover types influence the evapotranspiration mechanism that is characterized by water and heat transport, and consequently contribute to local and global climate change.

Thus, there is a social demand for catchment-level evapotranspiration research to account for water and environmental resources' impacts. This type of research can be better implemented based on water balance analysis that includes all the components of the hydrological processes.

Therefore, the objective of the present study was to evaluate the water balance in the Cubatão-Sul river catchment, Santa Catarina State, Brazil with emphasis on the evapotranspiration. This catchment is very important for irrigated horticulture and drinkingwater supply to the Great Florianópolis Region (Kobiyama and Oliveira, 1999).

\section{MATERIAL AND METHODS}

\subsection{Study area and hydrometeorological data}

The Cubatão-Sul watershed covers an area of $738 \mathrm{~km}^{2}$. Cubatão-Sul river catchment (CSRC) area studied covers $403.83 \mathrm{~km}^{2}$ and lies approximately between latitudes $27^{\circ} 35^{\prime} \mathrm{S}$ and $27^{\circ} 54^{\prime} \mathrm{S}$ and between longitudes $48^{\circ} 47^{\prime} \mathrm{W}$ and $49^{\circ} 03^{\prime} \mathrm{W}$, with altitudes varying from 100 to $1150 \mathrm{~m}$ (Figure 1). Poço Fundo hydrometeorological station (latitude $27^{\circ} 40^{\prime} \mathrm{S}$ and longitude $48^{\circ} 47^{\prime} \mathrm{W}$ ) is located at the middle of the Cubatão-Sul river basin toward the upper stream area of the watershed., The regional climate type is Cfa (humid subtropical with hot summer) according to Köppen classification. The natural vegetation is Atlantic Forest, dominated by Octea catharinensis (canela-preta), Octea pretiosa (canela sassafrás) and Aspidosperma olivaceum (pérola vermelha) species (Santa Catarina, 1986). The bedrock in the CSRC is granite, gneiss and sedimentary rock (Silva and Bortoluzzi, 1987).

The daily discharge and rainfall data from the Poço Fundo station for the period 19771994 were provided by the Empresa de Pesquisa Agropecuária e Extensão Rural de Santa Catarina S.A. (EPAGRI) and used for the water balance analysis. At the São José Meteorological station, which is about $20 \mathrm{~km}$ northeast from the Poço Fundo station, EPAGRI collects other meteorological parameter measurements: temperature $\left({ }^{\circ} \mathrm{C}\right)$, relative air humidity (\%), wind velocity $(\mathrm{km} / \mathrm{h})$ and daylight hours (h) that were also used for the evapotranspiration analysis. 


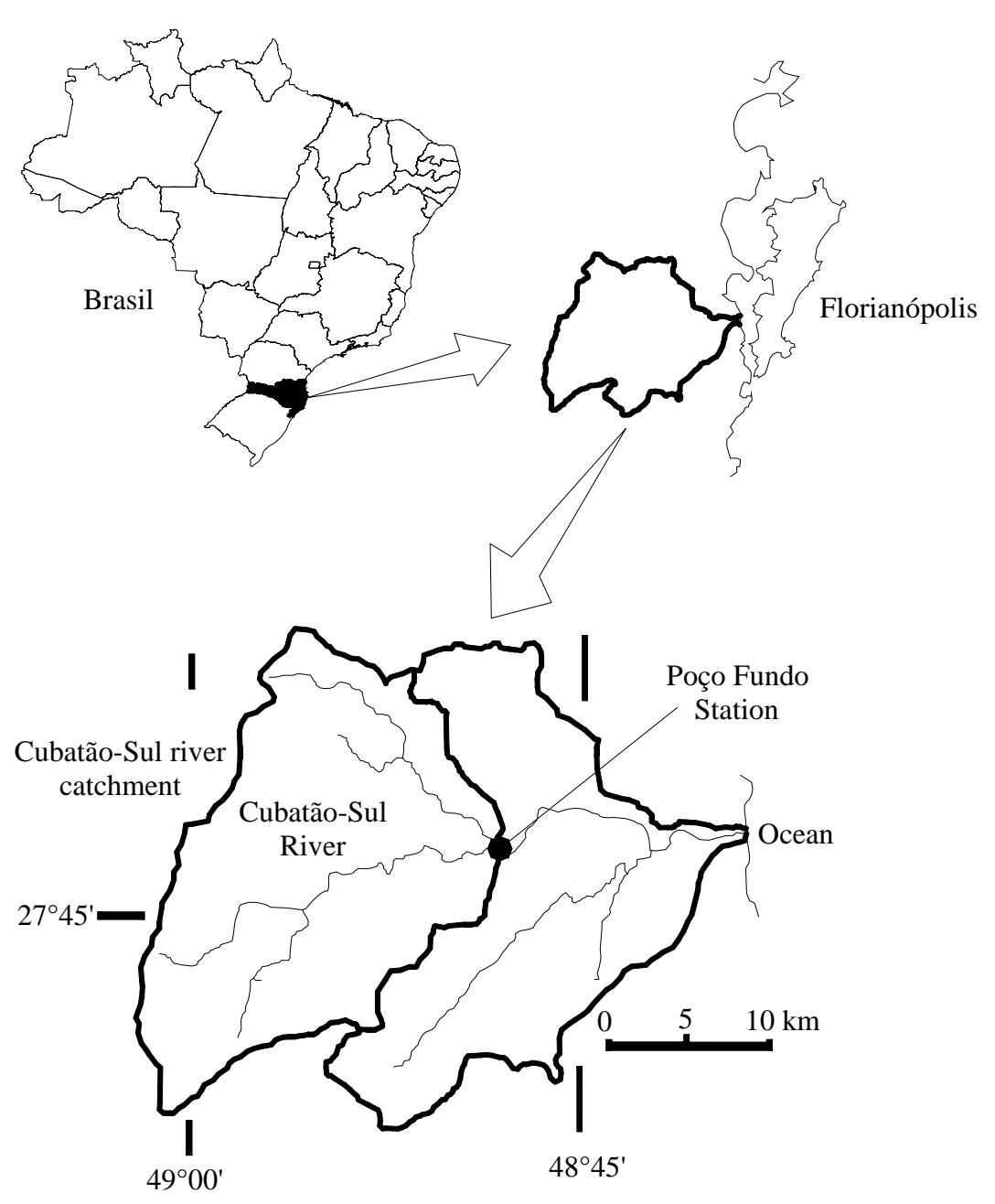

Figure 1. Location of the Cubatão-Sul river catchment area.

\subsection{Application of HYCYMODEL for annual water balance}

The HYCYMODEL proposed by Fukushima (1988) is a lumped and storage model. The model consists of 5 tanks related to the hillslope-channel system (Figure 2). A detailed description of the model can be seen in Fukushima (1988). A brief description follows:

With the ratio of impermeable area $(C)$, rainfall is divided into the channel rainfall $R_{c}(t)$ and the gross rainfall $R_{g}(t)$ where $t$ is the time. Tank I shows the interception process which is defined as:

$$
R_{n}(t)=A G \cdot R_{g}(t)-A I
$$

where $R_{n}(t)$ is the net rainfall and $A G$ and $A I$ are the interception parameters. The interception $E_{i}(t)$ is the difference between $R_{n}(t)$ and $R_{g}(t)$. Since $D_{16}$ and $D_{50}$ are defined as the effective top-soil depths in which the ratios of the contributing area are equivalent to $16 \%$ and $50 \%$, respectively, the standard deviation is:

$$
\sigma=\log \left(\frac{D_{50}}{D_{16}}\right)
$$


The variable $\xi$ is:

$$
\xi=\frac{\log \left\{\frac{\left[S_{u}(t-1)+R_{n}(t)\right]}{D_{50}}\right\}}{\sigma}
$$

Thus, the ratio of the contribution area is expressed by:

$$
m=\int_{-\infty}^{\xi} \frac{1}{\sqrt{2 \pi}} \exp \left(-\frac{\xi^{2}}{2}\right) d \xi
$$

Finally, the effective rainfall $R_{e}(t)$ can be determined with the storage $S_{u}(t-1)$ in Tank II and the net rainfall, i.e.:

$$
R_{e}(t)=m \cdot R_{n}(t)
$$

Tank III, IV and V represent the groundwater system, the subsurface water system and the channel system which determine the base flow $Q_{b}(t)$, the subsurface flow on hillslope $Q_{h}(t)$ and the direct runoff in channel $Q_{c}(t)$, respectively. In Tank II, III, IV and V, the relationship between the storage $S$ and the discharge $Q$ is expressed with the storage function:

$$
S=K \cdot Q^{P}
$$

where $K$ and $P$ are the storage function parameters. For Tanks II, III, IV and V, $K$ and $P$ are defined $K_{u}$ and $P_{u}, K_{b}$ and $P_{b}, K_{h}$ and $P_{h}$ and $K_{c}$ and $P_{c}$, respectively. As Tanks IV and V form the direct runoff, the values of $P_{h}$ and $P_{c}$ are 0.6. As Tank II has the linear phenomenon, the value of $P_{u}$ is 1.0. Following the suggestion of Fukushima (1988), the value of $P_{b}$ is 0.1 .

The transpiration ratio is:

$$
E_{t}(t)=\operatorname{Delta}\left\{P_{t a}+P_{t b} \cdot \sin \left[30^{\circ}-(I-I G)\right]\right\}
$$

where Delta, $P_{t a}, P_{t b}$ and $I G$ are the parameters and $I$ is the monthly number ( 1 to 12 ) corresponding to January to December. Transpiration during a drought decreases when the storage of Tank II smaller than $S_{b c}$. The critical discharge for transpiration $Q_{b c}$ corresponds to $S_{b c}$. The evapotranspiration $E(t)$ is the sum of $E_{i}(t), E_{t}(t)$ and the channel evaporation $E_{c}(t)$. 


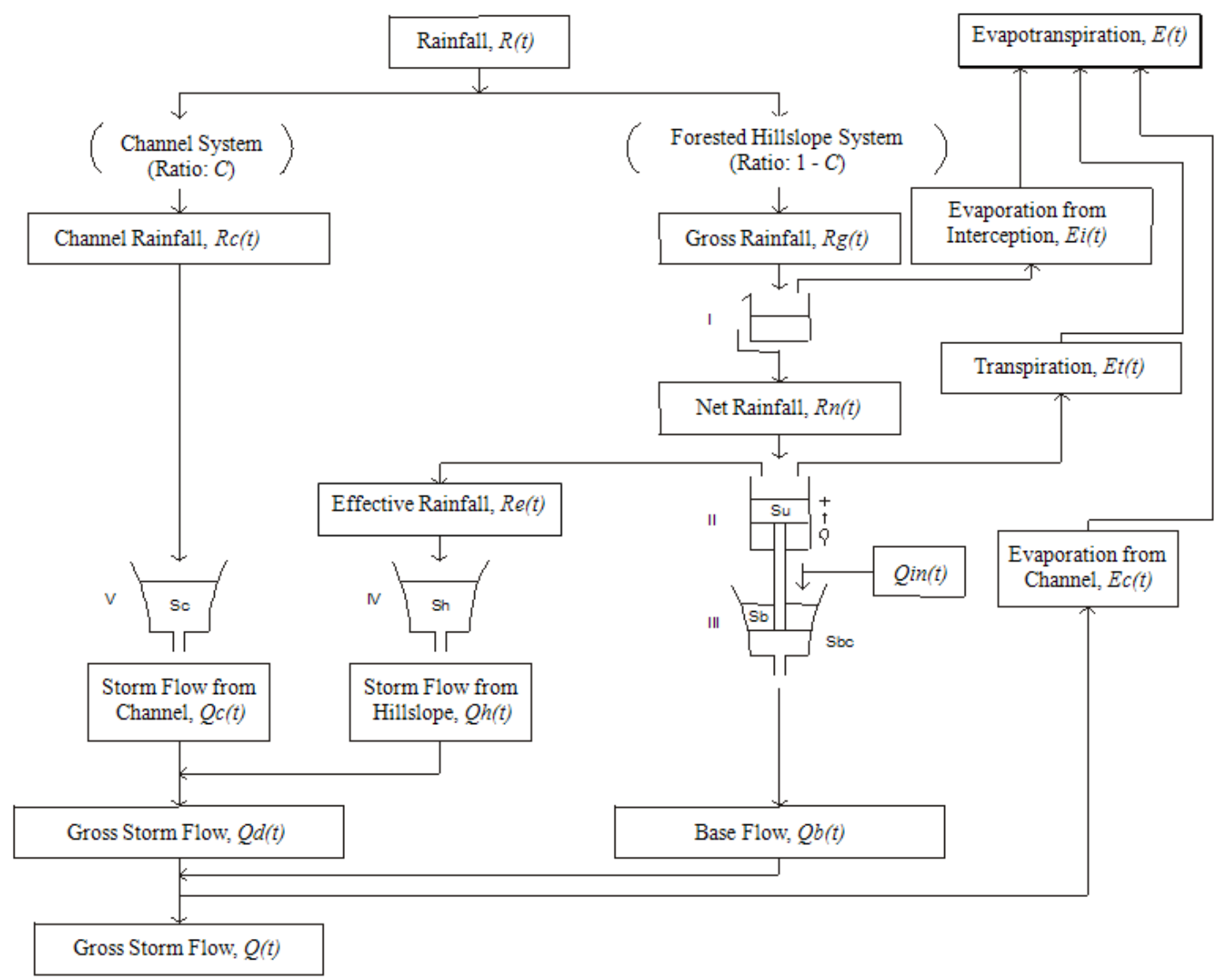

Figure 2. Flowchart of HYCYMODEL. Source: Fukushima (1988).

Kobiyama and Duarte (1997) running a simulation of 11-years hydrograph for the period 1974-1984 ascertained the applicability of this model for the rainfall-runoff processes of the Cubatão-Sul catchment and proposed the parameter values listed in Table 1. The present study used the same values for the parameters and simulated the water balance for the period 1977-1994. For the annual water balance analysis, the following equation was used:

$$
P=E+Q+d S
$$

where $P$ is the rainfall; $E P$ is the evapotranspiration; $Q$ is the discharge; and $d S$ is the change of soil-water storage. By the nature of the HYCYMODEL, EP consists of evaporation due to interception $E_{i}$, transpiration $E_{t}$ and the evaporation from the channel $E_{c}$.

Table 1. Values of the model parameters for the Cubatão-Sul catchment.

\begin{tabular}{cccccc}
\hline Parameter & Value & Parameter & Value & Parameter & Value \\
\hline$C$ & 0.030 & $K_{h}$ & 28 & $A l$ & 1.872 \\
$D_{10}$ & 10 & $K_{c}$ & 2 & $P_{t a}$ & 39 \\
$D_{50}$ & 66 & $P_{b}$ & 0.1 & $P_{t b}$ & 15 \\
$K_{u}$ & 20.1 & $Q_{b c}$ & 1.30 & $I G$ & 10 \\
$K_{b}$ & 4294 & $A G$ & 0.964 & Delta & 1 \\
\hline
\end{tabular}

Source: Kobiyama and Duarte (1997). 


\subsection{Estimation of evapotranspiration}

To estimate the catchment evapotranspiration 6 methods were applied: water budget method, Thornthwaite (1948) method, Hamon (1961) method, modified Penman method (Doorenbos and Pruitt, 1977), Blaney and Criddle (1966) method, and the HYCYMODEL.

The equation for the water budget method is:

$$
E=P-Q
$$

where $E P$ is the actual evapotranspiration in $\mathrm{mm} / \mathrm{month}, P$ is the precipitation in $\mathrm{mm} / \mathrm{month}$, and $Q$ is the runoff in $\mathrm{mm} / \mathrm{month}$. The change of water storage in the catchment during one month was neglected.

Thornthwaite (1948) proposed the following equation:

$$
E P^{*}=16(10 t / I)^{a}
$$

where $E P^{*}$ is the non-revised potential evapotranspiration in $\mathrm{mm} / \mathrm{month}, t$ is the mean monthly temperature in ${ }^{\circ} \mathrm{C}, \quad a$ is a constant $\quad\left(=0.000000675 I^{3}\right.$ $\left.0.0000771 I^{2}+0.01792 I+0.49239\right)$, and $I$ is the Thornthwaite's temperature efficiency index, being equal to the sum of 12 monthly values of heat index $i=(t / 5)^{1.514}$. Then this author used this value to compute the correct value with the following equation:

$$
E P=C_{1} \times E P^{*}
$$

where $E P$ is the potential evapotranspiration in $\mathrm{mm} / \mathrm{month}$ and $C_{1}$ is the correction factor which can be calculated based on UNESCO (1982) (Table 2).

Table 2. $C_{1}$ values for the Cubatão-Sul river catchment.

\begin{tabular}{ccccccccccccc}
\hline Month & Jan & Feb & Mar & Apr & May & Jun & Jul & Aug & Sep & Oct & Nov & Dec \\
\hline$C_{1}$ & 1.19 & 1.02 & 1.06 & 0.95 & 0.93 & 0.86 & 0.91 & 0.97 & 1.00 & 1.11 & 1.13 & 1.20 \\
\hline
\end{tabular}

Hamon (1961) pointed out that the Thornthwaite method overestimated the evapotranspiration in the summer and underestimated it in the winter and proposed the following equation:

$$
E P=1.4(n / 12)^{2} P t
$$

where $n$ is the daylight hours; $P t$ is the absolute humidity in $\mathrm{g} / \mathrm{m}^{3}$.

Doorenbos and Pruitt (1977) modified the Penman (1948) method and proposed a new equation:

$$
E P=C_{2}\left[W \cdot R A_{n}+(1-W) \cdot f(u) \cdot\left(e_{a}-e_{d}\right)\right]
$$

where $C_{2}$ is the correction factor; $W$ is the weighing factor related to a temperature; $R A_{n}$ is the net radiation in $\mathrm{mm} / \mathrm{day} ; f(u)$ is the function of the wind; $e_{a}$ is the saturation vapor pressure at the mean air temperature in $\mathrm{mmH}_{2} \mathrm{O}$; and $e_{d}$ is the saturation vapor pressure at mean dew point in $\mathrm{mmH}_{2} \mathrm{O}$. 
Villela and Mattos (1975) modified the equation of Blaney and Criddle (1966) with respect to the units:

$$
E P=(m t-0.5 T) p
$$

where $m t$ is the monthly mean temperature in ${ }^{\circ} \mathrm{C} ; T$ is the mean annual temperature in ${ }^{\circ} \mathrm{C} ; p$ is the percentage of the monthly daylight hours on the annual daylight hours.

The hydrometeorological data observed at Poço Fundo and São José stations during the period 1977-1994 were used for the evapotranspiration analysis.

\section{RESULTS AND DISCUSSION}

\subsection{Annual water balance}

Figure 3 shows the components of the total discharge. Due to the lack of hydrological data, the year 1991 was not considered in this study. Direct runoff and base flow for the period 1977-1994, related to the total discharge and based on mean values, are $26 \%$ and $74 \%$, respectively. This value for the base flow is in accordance with the value obtained by Hewlett (1982) who stated that about $70 \%$ of the total discharge is usually base flow in mountainous regions. Considering the direct runoff, the components from hillslope and channel are 81\% and $19 \%$, respectively.

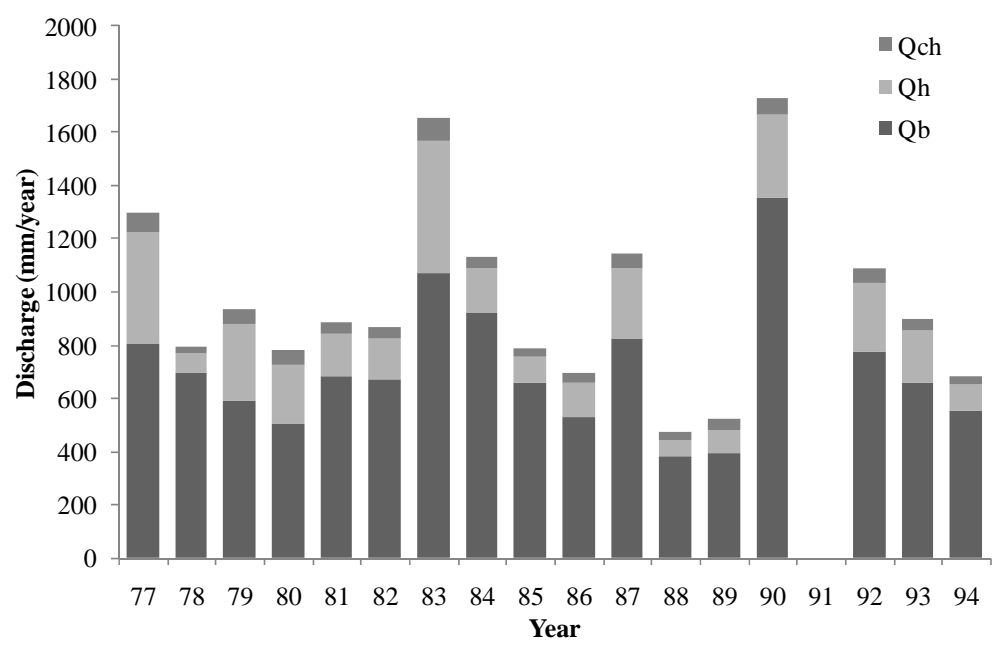

Figure 3. Components variation of total discharge for the period of 1977 to 1994 . $\left(Q_{b}=\right.$ base flow, $Q_{h}=$ direct runoff from hillslope, $Q_{c h}=$ direct runoff from channel).

Transpiration, evaporation by interception, and evaporation from the river to the total evapotranspiration values are 65\%, 33\% and 2\% for the period 1977 to 1994, respectively (Figure 4). According to Fujieda et al. (1997), the annual mean value of the transpiration is equal to that of the evaporation by interception in the Serra do Mar, São Paulo State. Comparing to this result, the ratio of transpiration in the CSRC is larger. It implies that, if the forest area is reduced in the CSRC the total discharge will increase significantly. 


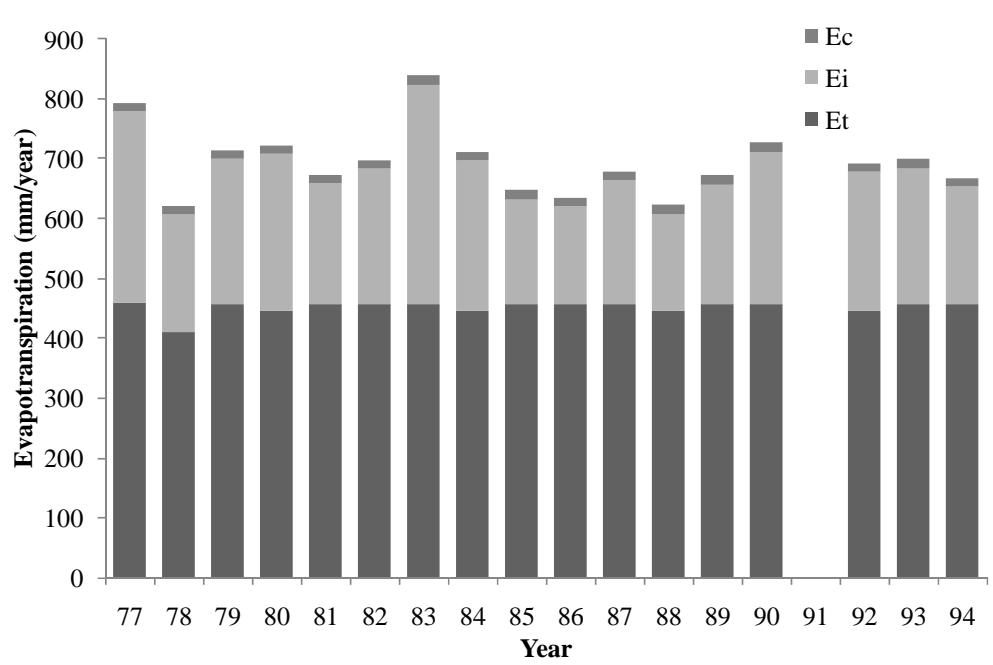

Figure 4. Components variation of evapotranspiration in the period 1977 to 1994 . $\left(E_{t}=\right.$ transpiration, $E_{i}=$ evaporation by interception, $E_{c}=$ evaporation from channel).

From the data of Figures 3 and 4, the ratios of the total discharge and the total evapotranspiration on the annual rainfall are $62 \%$ and $44 \%$, respectively (Table 3 ). The soilwater storage change is $-6 \%$. The mean total discharge of the CSRC is $12.3 \mathrm{~m}^{3} / \mathrm{s}$.

Table 3. Mean annual water balance of the Cubatão-Sul river catchment in the period 1977 to 1994.

\begin{tabular}{lcc}
\hline Component & (mm/year) & (\%) \\
\hline Rainfall $(R)$ & 1563 & 100.0 \\
\hline Total discharge $(Q)$ & 963 & 62 \\
Direct runoff $\left(Q_{d}\right)$ & 253 & 16 \\
Direct runoff from hillslope $\left(Q_{h}\right)$ & 206 & 13 \\
Direct runoff from channel $\left(Q_{c}\right)$ & 47 & 3 \\
Base flow $\left(Q_{b}\right)$ & 710 & 45 \\
\hline Evapotranspiration $(E)$ & 687 & 44 \\
Evaporation through interception $\left(E_{i}\right)$ & 229 & 15 \\
Transpiration $\left(E_{t}\right)$ & 445 & 28 \\
Evaporation from channel $\left(E_{c}\right)$ & 14 & 1 \\
\hline Change of the soil-water storage $(d S)$ & -87 & -6 \\
\hline
\end{tabular}

Figure 5 demonstrates the relationships between total discharge $Q$ and evapotranspiration $E$ to rainfall $P$. The increasing rate of $Q$ over $P$ is larger than that of $E$. In the case that $P$ is larger than $930 \mathrm{~mm} /$ year, approximately, $Q>E$ and, in the opposite scenario, $E$ could be larger than $Q$. 


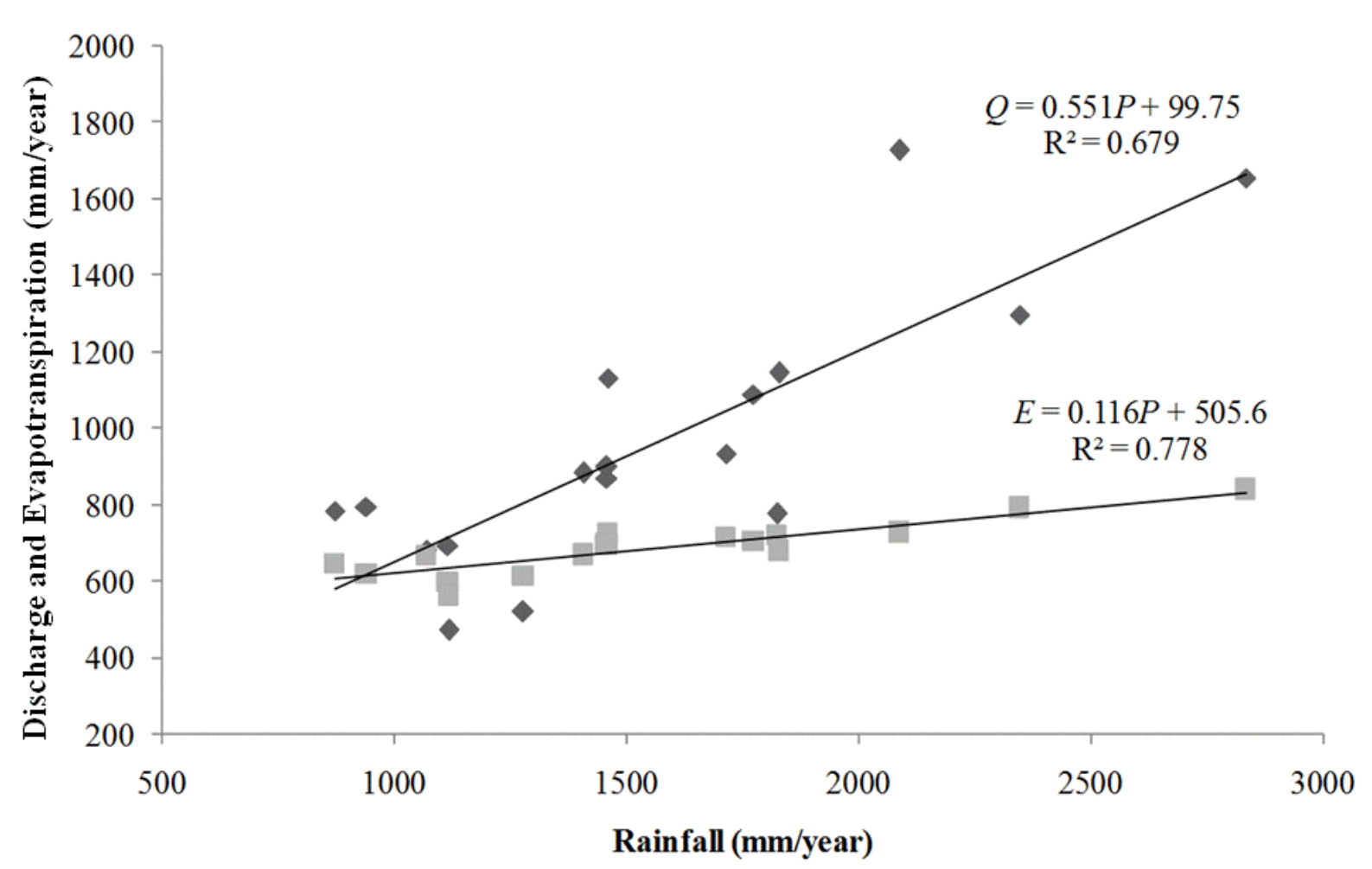

Figure 5. Relationship between discharge and evapotranspiration with rainfall.

\subsection{Annual evapotranspiration}

Table 4 shows the mean values of annual (actual or potential) evapotranspiration for the CSRC calculated using all six methods. According to the data obtained by EPAGRI, the mean annual precipitation in the catchment was $1563 \mathrm{~mm}$ for the study period. This value is smaller than that of the potential evapotranspiration calculated with the Hamon method. In practice, the values of the actual evapotranspiration, estimated with the water budget method and the HYCYMODEL, were the same.

Table 4. Mean annual evapotranspiration of the Cubatão-Sul river catchment for the study period.

\begin{tabular}{ccc}
\hline Method & $E(\mathrm{~mm} /$ year $)$ & $E / P(\%)$ \\
\hline Hamon & $1752^{*}$ & 112 \\
Modified Penman & $1197^{*}$ & 77 \\
Blaney and Criddle & $1058^{*}$ & 68 \\
Thornthwaite & $994^{*}$ & 64 \\
Water budget & $690^{\dagger}$ & 44 \\
HYCYMODEL & $690^{\dagger}$ & 44 \\
\hline
\end{tabular}

$*$ is potential evapotranspiration; ${ }^{\dagger}$ is actual evapotranspiration.

Fujieda et al. (1997) showed that the actual evapotranspiration is $30 \%$ of the annual precipitation in the Serra do Mar, São Paulo State. Compared with this value, the annual evapotranspiration in the CSRC can be considered high. With the values of the evapotranspiration calculated with the water budget method and the HYCYMODEL, the runoff ratio $(F)$, which is defined as the ratio of the annual runoff on the annual rainfall, was calculated as $62 \%$ in the CSRC approximately. 
The annual ratio of the actual evapotranspiration to the potential evapotranspiration calculated with the Hamon method, the modified Penman method, the Blaney and Criddle method, and the Thornthwaite method are 0.39, 0.58, 0.65 and 0.69 , respectively.

\subsection{Monthly evapotranspiration}

Figure 6 shows the change of monthly evapotranspiration calculated by all six methods. The graph patterns obtained with the modified Penman method, the Blaney and Criddle method and the Thornthwaite method are comparatively similar in the period analyzed (Figure 6(b), (c) and (d)). On the other hand, results of Hamon method and water budget method demonstrate high variation patterns (Figure 6 (a) and (e)).
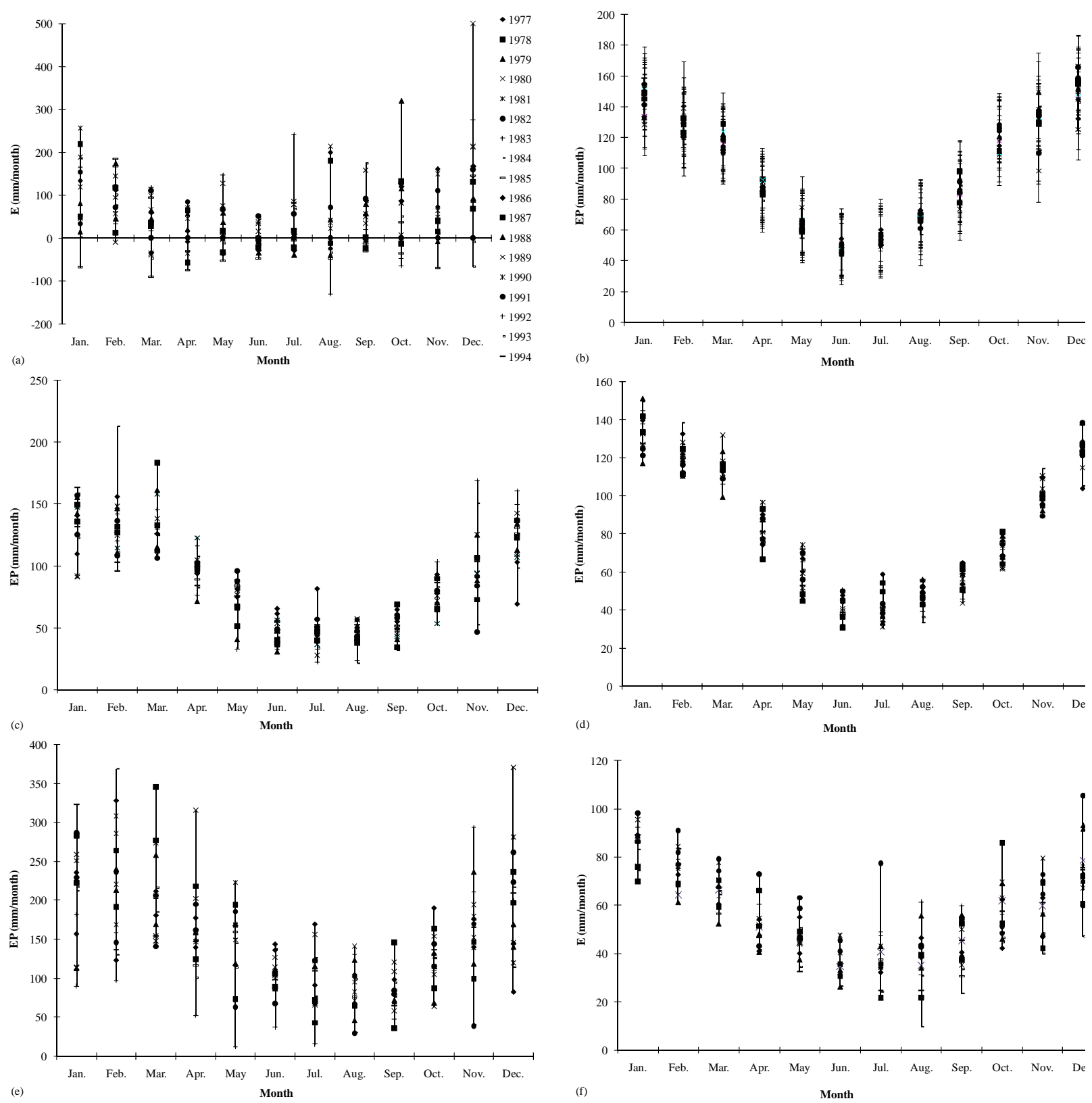

Figure 6. Monthly evapotranspiration of the Cubatão-Sul river catchment during the study period: (a) water budget method; (b) modified Penman method; (c) Blaney and Criddle method; (d) Thornthwaite method; (e) Hamon method; e (f) HYCYMODEL. 
In Figure 6(a) some monthly evapotranspiration values are negative. The occurrence of negative $\mathrm{E}$ values indicates that the monthly water budget method is not adequate for this catchment. That is why mean values were used instead.

The mean monthly evapotranspiration during the study period was calculated with each method. The changes of the mean monthly evapotranspiration obtained with the six methods are graphically shown in Figure 7. The graphs obtained with the Penman modified method, the Blaney and Criddle method and Thornthwaite method have similar patterns. The result with Hamon method is very different from the others. Observing the results of Table 4, it can be stated that Hamon method overestimates the potential evapotranspiration and that it is unrealistic for the CSRC situation.

Figure 7 shows clearly that evapotranspiration rate is highest in the summer. Winter was the season with the lowest monthly evapotranspiration shown by Blaney and Criddle method, Thornthwaite method, Hamon method and HYCYMODEL. Fall shows lower values with the water budget method and modified Penman method.

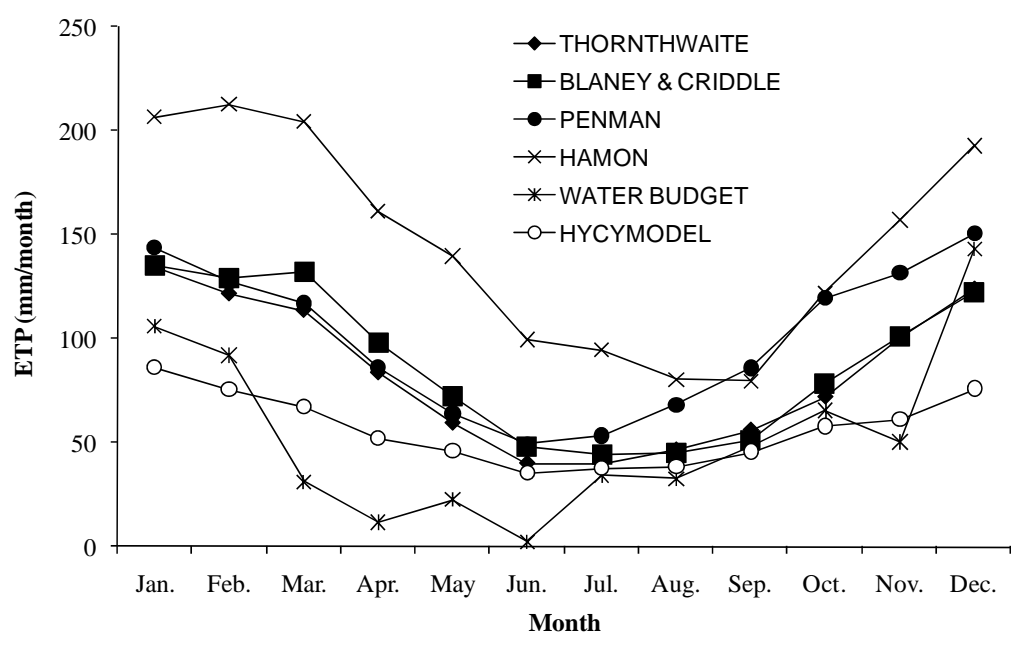

Figure 7. Comparison of mean monthly evapotranspiration change of the Cubatão-Sul river catchment during the study period using six methods.

\section{CONCLUSIONS}

In order to study the annual water balance of the Cubatão-Sul river catchment (403.83 $\mathrm{km}^{2}$ ), Santa Catarina State, Brazil, the data observed at the hydro-meteorological stations during the period 1977-1994 was analyzed with HYCYMODEL proposed by Fukushima (1988). The total discharge and the evapotranspiration are approximately $62 \%$ and $44 \%$ of the total rainfall, respectively. The base flow is about $74 \%$ of the total discharge, which agrees with the data of Hewlett (1982). The high ratio of transpiration to the evapotranspiration implies that, if deforestation occurs in the catchment, the total discharge will strongly increase.

The increasing rate of discharge over rainfall is larger than that of the evapotranspiration. When the annual rainfall is more than $930 \mathrm{~mm}$, the discharge is always larger than the evapotranspiration.

Using six methods (water budget method, Thornthwaite method, Hamon method, modified Penman method, Blaney and Criddle method and the HYCYMODEL), the monthly and annual evapotranspiration in the CSRC during the period 1977-1994 was evaluated. 
Although the annual values of the actual evapotranspiration estimated with the water budget method and the HYCYMODEL were similar, the monthly patterns obtained were different. The values of the ratio of the annual actual evapotranspiration to the annual potential evapotranspiration are 0.39, 0.58, 0.65 and 0.69 for Hamon method, Penman modified method, Blaney and Criddle method and Thornthwaite method, respectively.

The annual potential evapotranspiration value obtained with Hamon method is larger than that of the annual discharge. Therefore, this method is not suitable for this region.

These results will be useful for establishing water resources management strategies and land use guidelines for the Cubatão-Sul watershed.

\section{AKNOWLEDGEMENTS}

The authors are grateful to CNPq for providing a scholarship and Empresa de Pesquisa Agropecuária e Extensão Rural de Santa Catarina S.A. (EPAGRI) for providing hydrometeorological data of the Cubatão-Sul watershed.

\section{REFERENCES}

BRUTSAERT, W.H. Evapotranspiration into the atmosphere. New York: Springer, 1982. 316p.

BLANEY, H. F.; CRIDDLE, W. D. Determining consumptive use for water developments. In: Method for estimating evapotranspiration. New York: ASCE, 1966. p.35-64.

DOORENBOS, J.; PRUITT, W. O. Crop water requirement. Rome: FAO, 1977. 144p.

FUKUSHIMA, Y. A model of river flow forecasting for small forested mountain catchment. Hydrological Processes, Chichester, v. 2, p.167-185, 1988.

FUJIEDA, M.; KUDOH, T.; CICCO, V.; CARVALHO, J. L. Hydrological processes at two subtropical forest catchments: the Serra do Mar, São Paulo, Brazil. Journal of Hydrology, Amsterdam, v. 196, p. 26-46, 1997.

HAMON, W. R. Estimating potential evapotranspiration. Journal of Hydraulics Division ASCE, New York, v. 87 (HY3), p.107-119, 1961.

HEWLETT, J. D. Principles of Forest Hydrology. Athens: The University of Georgia Press, 1982. 183p.

KOBIYAMA, M.; DUARTE, C. Aplicação do modelo HYCYMODEL para análise de chuvavazão da bacia Cubatão-Sul no estado de Santa Catarina. In: BRAZILIAN SYMPOSIUM ON WATER RESOURCES, 12., 16-20 nov. 1997, Vitória, Proceedings... São Paulo: ABRH, 1997. p.589-596.

KOBIYAMA, M.; OLIVEIRA, S. M. Discharge and water quality of the Cubatão river, Santa Catarina State, Brazil. Revista do Setor de Ciências Agrárias UFPR, Curitiba, v. 18, p. 23-28, 1999.

PENMAN, H. L. Natural evaporation from open water, bare soil, and grass. Proceedings of Royal Society of London (Series A), London, v. 193, p. 120-145, 1948.

PEREIRA, A. R.; VILLA NOVA, N. A.; SEDIYAMA, G. C. Evapo(transpi)ração. Piracicaba: FEALQ/ESALQ/USP, 1997. 183p. 
SANTA CATARINA. Atlas de Santa Catarina. Rio de Janeiro: Aerofoto Cruzeiro, 1986.

SILVA, L. D.; BORTOLUZZI, C. A. (eds.) Mapa geológico do estado de Santa Catarina. Florianópolis: Secretaria de Ciência e Tecnologia, Minas e Energia, 1987.

THORNTHWAITE, C. W. An approach toward a rational classification of climate. Geography Review, Washington, v. 38, p. 55-94, 1948.

UNESCO. Guia metodologica para la elaboracion del balance hídrico de América del Sur. Montevideo: UNESCO, 1982. 130p.

VILLELA, S. M.; MATTOS, A. Hidrologia aplicada. São Paulo: McGraw-Hill do Brasil, 1975. 245p. 


ISSN = 1980-993X - doi:10.4136/1980-993X
www.agro.unitau.br/ambi-agua
E-mail: ambi-agua@agro.unitau.br
Tel.: (12) 3625-4116

\title{
Mapping and monitoring land cover types in Corumbiara area, Brazilian Amazônia, using Landsat TM and JERS-1 SAR multitemporal data
}

(doi:10.4136/ambi-agua.39)

\author{
Yosio E. Shimabukuro, Raimundo Almeida-Filho, Tatiana M. Kuplich, Ramon \\ M. de Freitas
}

\author{
Instituto Nacional de Pesquisas Espaciais (INPE) \\ Av. dos Astronautas, 1758, São José dos Campos, SP, 12227-010, Brasil \\ E-mail: \{yosio, rai, tmk, ramon\}@dsr.inpe.br
}

\begin{abstract}
This paper discusses the use of a Landsat Thematic Mapper (TM) and JERS-1 Synthetic Aperture Radar (SAR) time-series for mapping and monitoring land cover types in a test site in the region of Corumbiara, Rondônia State, western Brazilian Amazônia. In order to support JERS-1 data analysis, land cover maps were obtained by digital classification of Landsat TM images acquired from 1993 to 1997 period, following a procedure based on image segmentation, unsupervised classification, and post-classification image edition. The comparison of these products with JERS-1 temporal images shows that clear-cut areas are well-identified presenting a low backscattering response as expected. On the other hand, areas that have been cleared and even burned but with remaining forest material left on the ground present high backscattering response. Considering these observations and user interpretation expertise, temporal SAR images present an effective source of information for mapping and monitoring deforestation, especially in areas covered by clouds with restricted use of optical data.
\end{abstract}

Keywords: Landsat TM; JERS-1 SAR; land cover map; multitemporal analysis; digital classification; Amazonia region.

\section{Mapeamento e monitoramento dos tipos de cobertura da terra na área de Corumbiara, Amazônia brasileira, utilizando dados multitemporais do TM Landsat e do SAR JERS-1}

\section{RESUMO}

Este artigo discute o uso de uma série temporal de imagens do sensor TM do Landsat e do radar de abertura sintética (SAR) do JERS-1 para o mapeamento e monitoramento dos tipos de cobertura da terra numa área teste na região de Corumbiara, no Estado de Rondônia, oeste da Amazônia brasileira. Como suporte à análise dos dados do JERS-1, mapas da cobertura da terra foram obtidos por meio da classificação digital das imagens TM do Landsat adquiridas no período de 1993 a 1997, de acordo com um procedimento baseado na segmentação de imagem, classificação não supervisionada, e edição da classificação. A comparação desses produtos com as imagens multitemporais do JERS-1 mostra que as áreas cortadas são bem identificadas apresentando resposta baixa de retroespalhamento como esperado. Por outro lado, áreas desflorestadas e mesmo queimadas mas com restos de material 
da floresta deixadas no solo apresentam resposta alta de retroespalhamento. Considerando estas observações e a experiência dos fotointerpretes, as imagens temporais do SAR apresentam uma fonte de informações efetivas para o mapeamento e monitoramento do desflorestamento, especialmente em áreas cobertas por nuvens que restringem o uso de dados ópticos.

Palavras-chave: Landsat TM; JERS-1 SAR; mapa de cobertura da terra; análise multitemporal; classificação digital; região Amazônica.

\section{INTRODUCTION}

There is an increasing need for accurate mapping of forest conservation status. Since 1988 Brazilian Amazônia is monitored by the PRODES (Brazilian Estimate of Deforestation) Project (INPE, 2007), and results of this project have become available online, including yearly deforestation rates (http://www.obt.inpe.br/prodes/index.html). Maps of deforestation and rates of deforestation are produced by interpretation of Landsat Thematic Mapper (TM) images and, although the PRODES has been conducted successfully, it relies on optical remote sensing data, subject to the near-constant cloud coverage over the tropics.

In the Brazilian Amazônia, deforestation process can follow different methods, but it is common the removal of vegetation cover by the use of chain saws, with use of fire to complete the clearing process. The smoothed surface of the cleared terrains usually presents low radar return and, consequently, deforested areas will appear in dark shades in Synthetic Aperture Radar (SAR) images. However, where radar images are acquired before the clearing process has been concluded, presence of woody material on the ground will produce strong radar backscatters. Thus, contrary to the first case, uncompleted deforested areas will appear in light shades in radar scenes, as discussed by Stone and Woodwell (1988) and Almeida Filho et al. (2005). The mechanism of corner reflection between soil and trees left standing on the ground is responsible for the enhanced response, allowing the discrimination of this step of the deforestation process from the remaining land covers.

This study follows a previous one by Shimabukuro et al. (2007), which evaluated by statistical analysis the correlation among different land use/land cover classes identified in Landsat TM optical and SAR data acquired simultaneously in a study area. As results of this quantitative approach were very promising, we followed with a qualitative analysis of a multi-temporal JERS-1 time series, mainly for evaluating the discrimination ability of SAR images to specific deforestation steps. Thus, the present study aims to understand the role of the most significant terrain variables involved in remote deforestation mapping, thereby contributing to improve the use of SAR image as an operational system to map land use/land cover under the conditions and practices currents in the Brazilian Amazônia.

\section{STUDY AREA}

The study area is located in the south of Rondônia State, western Brazilian Amazônia (Figure 1), and comprises approximately $4,000 \mathrm{~km}^{2}$. The region is mainly covered by dense tropical forest that has been partially cleared over the past thirty years. Ten JERS-1 SAR and five Landsat TM images were acquired between 1993 and 1997 (Table 1) over this study area. 


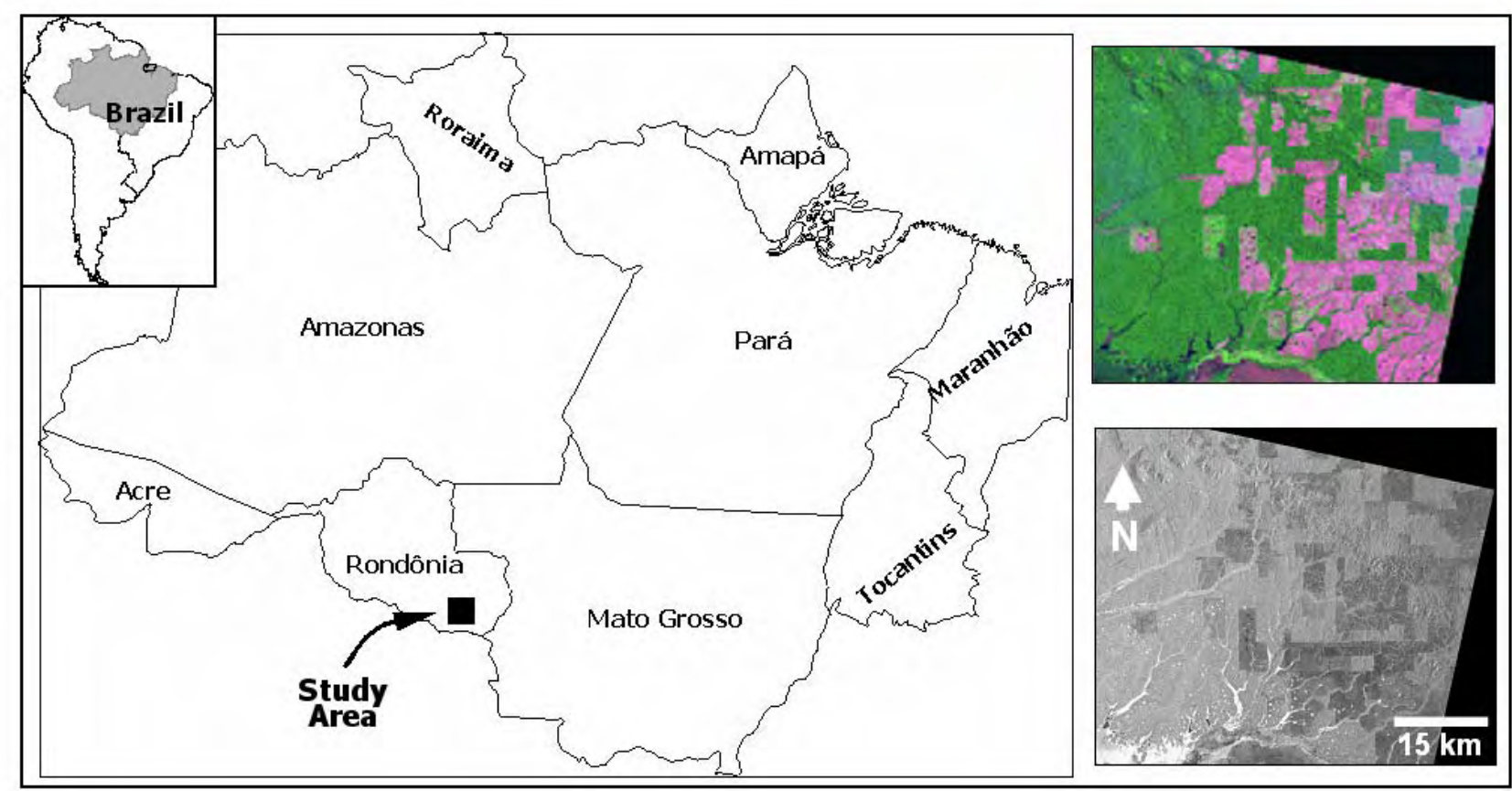

Figure 1. Location of the study area in Rondônia State, Brazilian Amazônia, and general characteristics of land use/land cover in the study area, as seen in a Landsat-TM color composite and a JERS-1 SAR image acquired in August 1997.

Table 1. JERS-1 SAR and Landsat TM images used in this study.

\begin{tabular}{l|l}
\hline \multicolumn{1}{c|}{$\begin{array}{c}\text { JERS-1 SAR } \\
\text { Images }\end{array}$} & \multicolumn{1}{c}{$\begin{array}{c}\text { Landsat TM } \\
\text { Images }\end{array}$} \\
\hline 30 September 1993 & 19 June 1993 \\
09 February 1994 & 09 August 1994 \\
04-August 1994 & 13 September 1995 \\
18 October 1995 & 13 July 1996 \\
25 May 1996 & 01 August 1997 \\
17 November 1996 & \\
29 March 1997 & \\
12 May 1997 & \\
25 June 1997 & \\
08 August 1997 & \\
\hline
\end{tabular}

\section{IMAGE PROCESSING AND INTERPRETATION}

The Landsat TM images were used to support the interpretation of the multitemporal SAR scenes. Based on satellite ephemeris, the 1993 TM image was geometrically corrected to the Universal Transverse Mercator (UTM) coordinate system, using a first-degree polynomial algorithm. This scene was used as reference to co-register the other TM images. In all cases, the co-registration accuracies were better than 0.8 pixel. The land cover map was obtained by digital classification of Landsat TM images following the procedure presented by Shimabukuro et al. (1998), which is based on image segmentation using a region growing algorithm, followed by unsupervised classification, and post-classification image editing. This 
procedure minimizes the omission and commission errors of the classification according to Almeida-Filho and Shimabukuro (2002). Land cover classes included: (i) primary forest, (ii) savanna, (iii) deforested (clear-cut) areas, and (iv) flooded vegetation. These image dataset allowed to estimate temporal changes in the land cover classes, such as the classes of burned grassland and burned forest converted to deforested areas, as well as the increment of deforested areas from one year to another.

The JERS-1 SAR operated in L-band frequency (wavelength of $23.5 \mathrm{~cm}$ ), with $\mathrm{HH}$ polarization and right-looking off-nadir angle of 35 degrees. The ground resolution was $18 \mathrm{~m}$ in both range and azimuth directions, and the swath width $75 \mathrm{~km}$. The ten JERS-1 images selected for this investigation were processed to standard level 2.1, i.e., 16 bits ground range, three looks and a pixel spacing of $12.5 \times 12.5 \mathrm{~m}$. Several adaptive and non-adaptive filters were tested to reduce speckle noise in the SAR images. The best results in terms of minimum loss of textural information and preservation of edges, estimated by visual inspection, were obtained with a 5 by 5 window Gamma Filter as implemented in ENVI software (Shi and Fung, 1994). All JERS-1 SAR images were then co-registered to the georeferenced TM images and resampled to the same spatial resolution (pixel $30 \mathrm{~m}$ x $30 \mathrm{~m}$ ). The August 1997 JERS-1 SAR DNs (digital number) were converted to backscatter coefficient $\left(\sigma^{\circ}\right)$ using Equation 1 (Rosenqvist, 1996; Shimada, 2001).

$$
\sigma^{\circ}=10 \log 10\left(\sum(\mathrm{DN}) 2 / \mathrm{n}\right)+\mathrm{CF}[\mathrm{dB}]
$$

where $\mathrm{DN}=$ digital number of image pixels; $\mathrm{n}=$ number of pixels sampled and $\mathrm{CF}=$ calibration factor. The calibration factor was -85.34 according to the processing date of the SAR image (Shimada, 2001).

Shimabukuro et al. (2007) showed that land use/land cover classes identified simultaneously in Landsat TM (soil, vegetation and shade faction images) and JERS-1 SAR images presented a very good relationship $\left(r^{2}=0.82\right)$. Based on these results, a JERS-1 multitemporal time series analysis was conducted, involving the mapping of deforestation in the study site. For this, a visual inspection of the SAR images was conducted, followed by the analysis of backscattering responses for each considered land use/land cover class identified simultaneously in the corresponding Landsat TM and SAR images. The availability of five JERS-1 SAR images, acquired over the period of November 1996 to August 1997 allowed performing an evaluation of this kind of data for detecting sequential deforestation areas.

\section{RESULTS AND DISCUSSION}

Figure 2 shows the distinctive backscattering $(\mathrm{dB})$ values of the corresponding land cover classes identified in the 1997 Landsat TM image. These coefficient values confirm a high contrast among forest (medium gray), flooded vegetation (bright gray), and cleared areas (dark gray), as showed in the JERS-1 SAR image acquired on 08 August 1997. Forest and flooded vegetation presents higher backscattering response as compared with savanna and clear cuts areas. These results indicate that possibility exists for discriminating forested areas and deforestation as required by the INPE's PRODES Project (INPE, 2007). Figure 3 compares the classes identified in the JERS-1 SAR image with its temporally corresponding Landsat TM image, showing that both are very similar in remote sensing information content. 


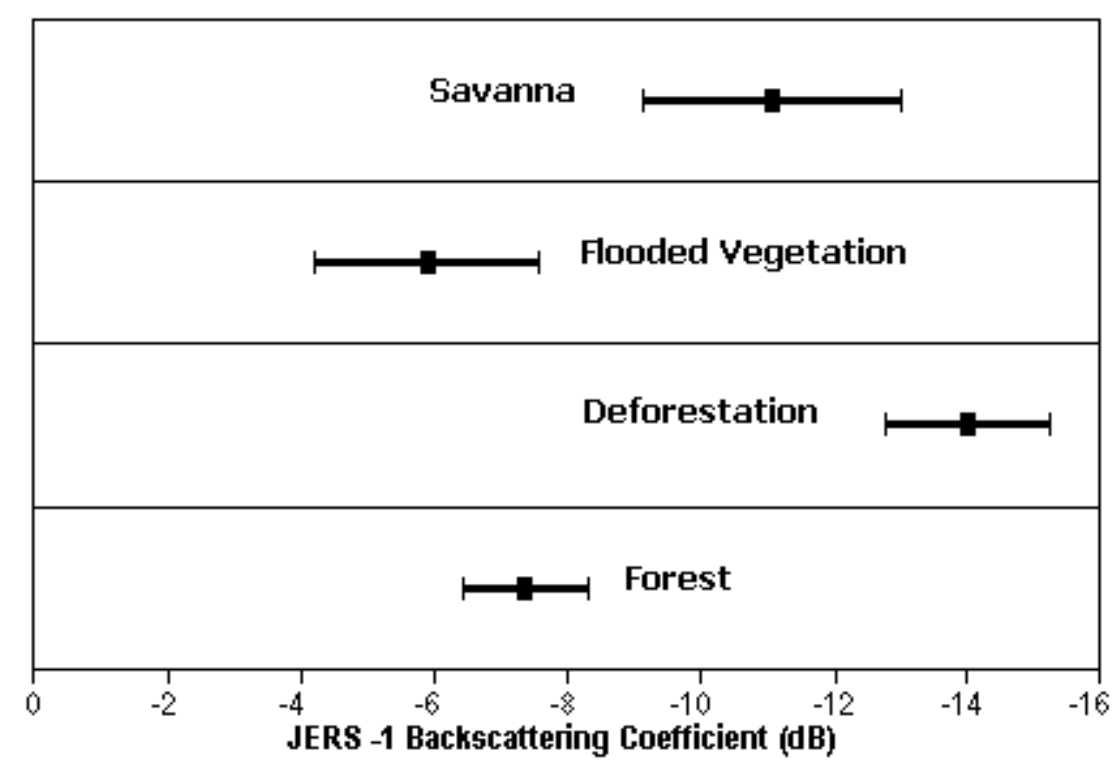

Figure 2. 1997 JERS-1 SAR Backscattering values for the samples of the land cover classes.
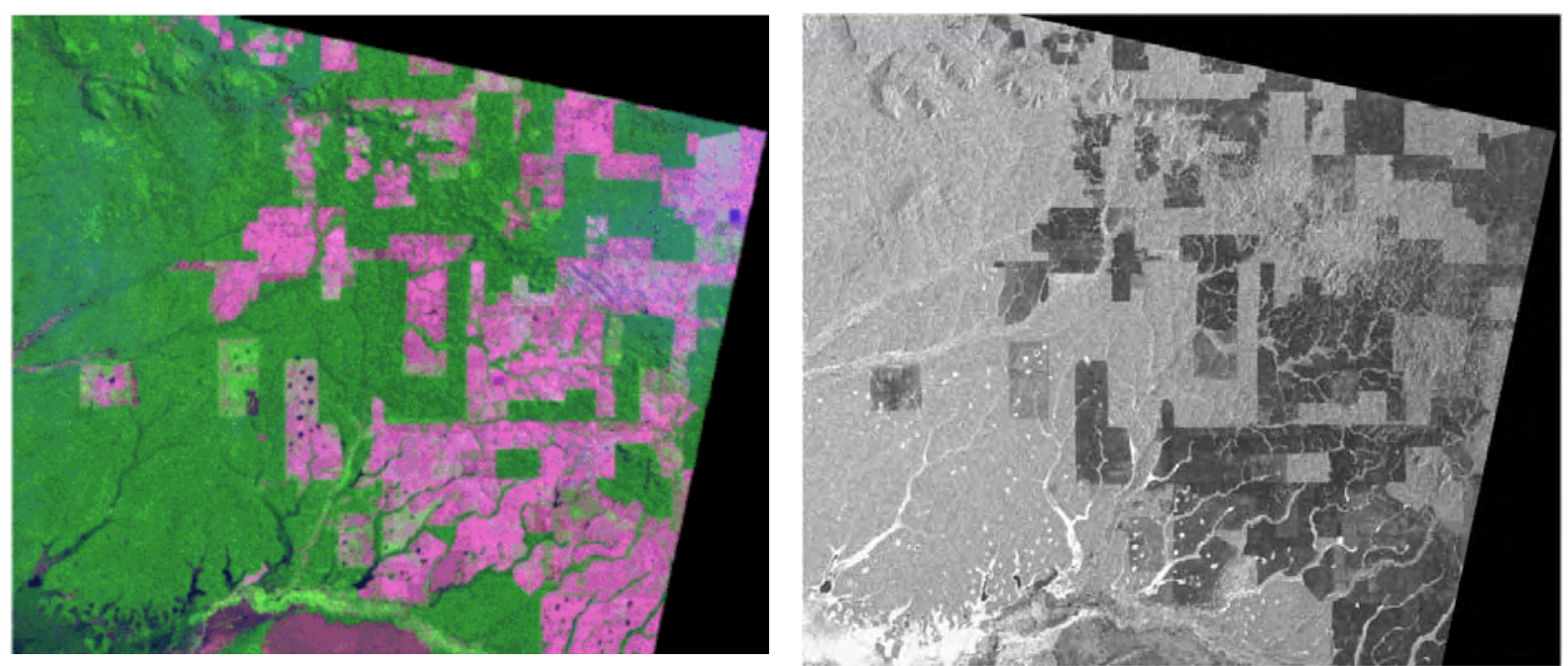

Figure 3. Landsat TM color composite (01 August 1997) and JERS-1 SAR image (08 August 1997).

Figure 4 shows the land use/land cover map of the study area derived from Landsat TM images acquired between 1993 to 1997 time period. This Figure presents a temporal map of the deforestation areas that occurred during this period, with the approximate time/year of clear-cutting, referred as "increment" as it "adds" to the areas already mapped as deforestation. This product is very similar to the one released by INPE's PRODES project (INPE, 2007) and was used to mask deforested areas in the SAR images. Table 2 shows the areas occupied by the land cover areas in the study area.

The areas recently burned, seen at the TM image acquired on 13 September 1995, as dark purple (in the TM image), appear as bright gray in the SAR data, being detectable easily by an interpreter (Figure 5). Although not presented here, in a careful inspection of the temporal JERS-1 SAR data, the history of clearings seen in Figure 5, with the approximate age of cleared areas, could also be observed. Then areas cleared initially by burning and with remaining biomass on the ground were seen as bright tones, while dark gray areas were 
related to bare soil (prepared for crop plantation), pastures or complete deforestation. In addition, the availability of 5 JERS-1 images, acquired between November 1996 and August 1997, allowed observing an increase of some deforested areas from 1996 to 1997 time period.

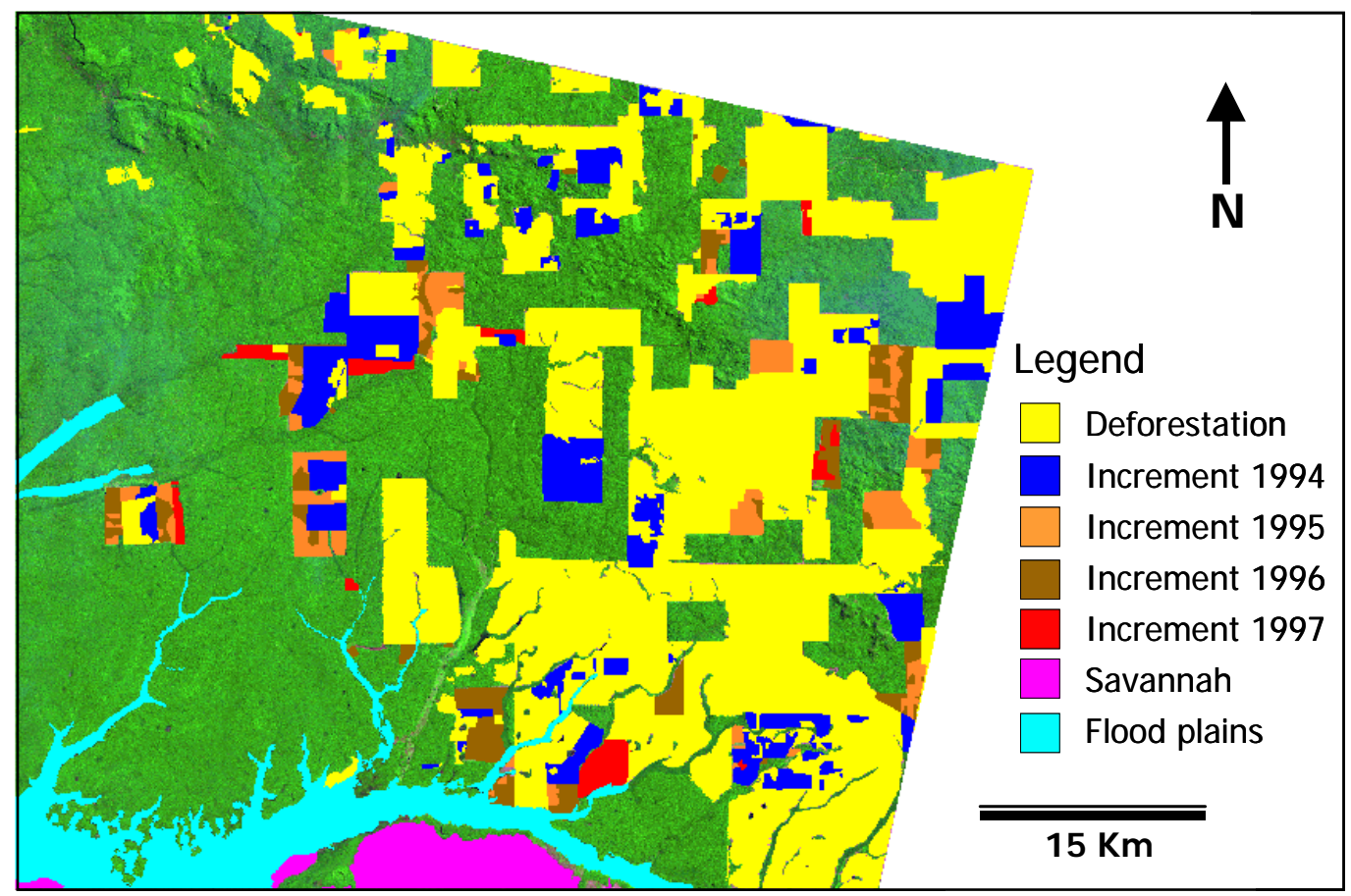

Figure 4. Land cover map of the study area based on classification of Landsat TM time series (Forest areas showed in green in the 1997 TM (R5 G4 B3) color composite image).

Table 2. Land cover areas estimated by multitemporal analyses of Landsat TM images.

\begin{tabular}{|c|c|c|c|c|c|}
\hline Classes & $\begin{array}{c}\text { TM- } 1993 \\
\left(\mathrm{Km}^{2}\right)\end{array}$ & $\begin{array}{c}\text { TM- } 1994 \\
\left(\mathrm{Km}^{2}\right)\end{array}$ & $\begin{array}{c}\text { TM- } 1995 \\
\left(\mathrm{Km}^{2}\right)\end{array}$ & $\begin{array}{c}\text { TM- } 1996 \\
\left(\mathrm{Km}^{2}\right)\end{array}$ & $\begin{array}{c}\text { TM- } 1997 \\
\left(\mathbf{K m}^{2}\right)\end{array}$ \\
\hline Forest & 2384.53 & 2215.36 & 2151.65 & 2085.65 & 2059.54 \\
\hline Deforestation & 925.70 & 925.70 & 925.70 & 925.70 & 925.70 \\
\hline Flooded areas & 194.40 & 194.40 & 194.40 & 194.40 & 194.40 \\
\hline Savanna & 57.72 & 57.72 & 57.72 & 57.72 & 57.72 \\
\hline Increment-94 & 0.00 & 169.24 & 169.24 & 169.24 & 169.24 \\
\hline Increment-95 & 0.00 & 0.00 & 63.71 & 63.71 & 63.71 \\
\hline Increment-96 & 0.00 & 0.00 & 0.00 & 66.01 & 66.01 \\
\hline Increment-97 & 0.00 & 0.00 & 0.00 & 0.00 & 26.11 \\
\hline
\end{tabular}

For an operational monitoring program of tropical forest, previous information on deforestation (as the maps produced by PRODES project) can be used to mask deforestation areas in SAR images, using SAR data as a base to map only new clear cuttings. Then a monitoring procedure can be sought with SAR images. The results show that SAR imagery is an alternative source of information for an operational project for deforestation monitoring especially for the areas with cloud cover restricting the use of optical images. 

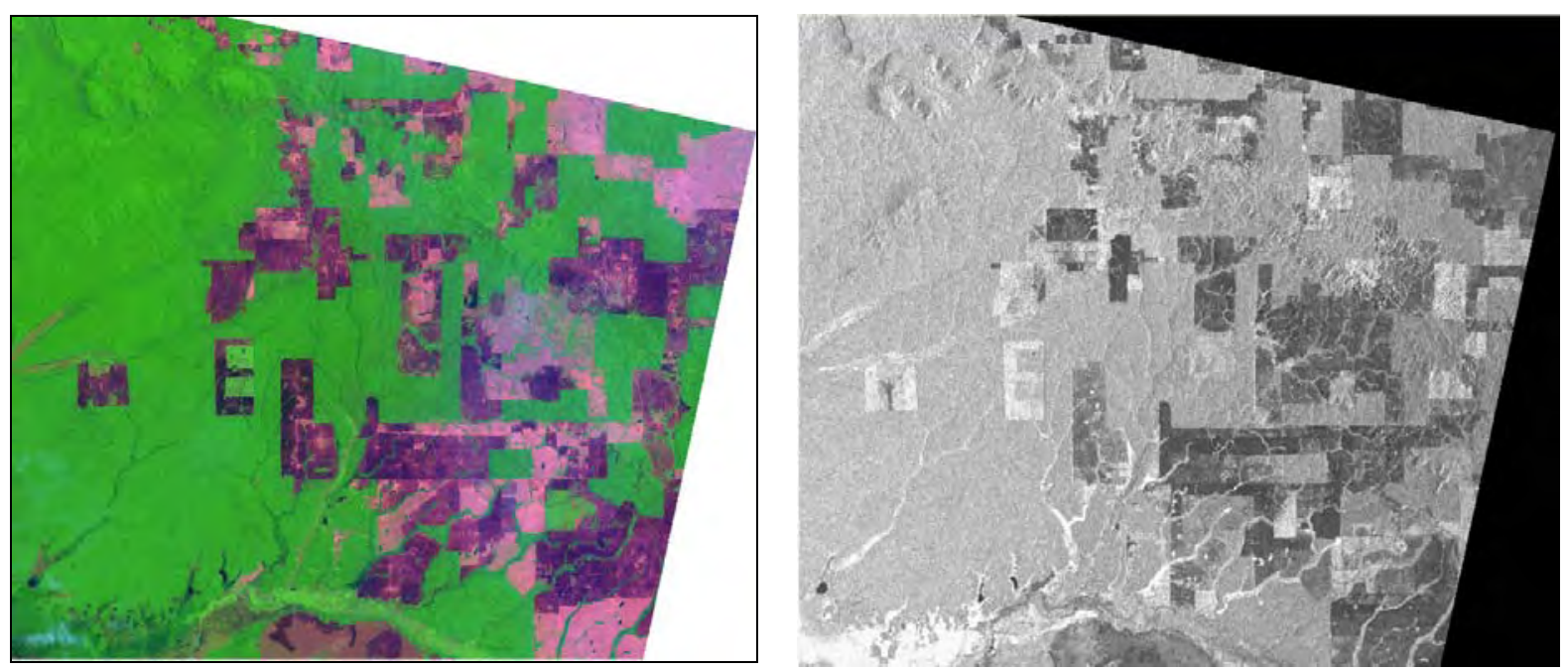

Figure 5. Landsat-TM color composite (13 September 1995) and JERS-1 SAR image (18 October 1995).

\section{CONCLUSIONS}

JERS-1 SAR images showed that deforested areas are well-identified due to a low backscattering response (as expected), while areas that have been cleared and even burned but with remaining forest material left on the ground present high backscattering response. Considering these observations and user interpretation expertise, it is evident that JERS-1 images may be used to map and monitor land cover changes in Amazônia. Then using an initial assessment of deforestation as available in the PRODES website, the JERS-1 SAR data is a useful source of information for monitoring deforestation activities in Amazônia, considering that its acquisition does not depend on weather condition.

\section{ACKNOWLEDGEMENT}

We acknowledge the Conselho Nacional de Desenvolvimento Científico e TecnológicoCNPq for research grants (305978/2006-3 and 306011/2006-9) and a scholarship grant (132140/2005-5). The Earth Observation Research and Application Center (EORC) of the Japan Aerospace Exploration Agency (JAXA) provided the JERS-1 SAR images within the framework of the Global Rain Forest Mapping (GRFM) Project. The National Institute for Space Research (INPE) provided the Landsat-TM images.

\section{REFERENCES}

ALMEIDA-FILHO, R.; SHIMABUKURO, Y. E. Digital processing of a Landsat-TM timeseries for mapping and monitoring degraded areas caused by independent gold miners, Roraima State, Brazilian Amazon. Remote Sensing of Environment, v. 79, p. 42-50, 2002.

ALMEIDA-FILHO, R.; ROSENQVIST, A.; SHIMABUKURO, Y. E.; SANTOS, J. R. Evaluation and perspectives of using multi-temporal L-band SAR data to monitor deforestation in the Brazilian Amazônia. IEEE Geoscience and Remote Sensing Letters, v. 2, n. 4, p. 409-412, 2005. 
INSTITUTO NACIONAL DE PESQUISAS ESPACIAIS. INPE. Projeto PRODES: monitoramento da floresta Amazônica Brasileira por satélite. 2007. Available: <www.obt.inpe.br/prodes>. Access: February 2008.

ROSENQVIST, A. Evaluation of JERS-1/SAR and Almaz/SAR backscatter for rubber and oil palm stands in West Malaysia. International Journal of Remote Sensing, v. 17, p. 191-202, 1996.

SHI, Z.; FUNG, K. B. A comparison of digital speckle filters. In: GEOSCIENCE AND REMOTE SENSING SYMPOSIUM - IGARSS'94, August 8-12 1994, Pasadena. Proceedings... Piscataway: IEEE Press, 1994. p. 2129-2133.

SHIMABUKURO, Y. E.; BATISTA, G. T.; MELLO, E. M. K.; MOREIRA, J. C.; DUARTE, V. Using shade fraction image segmentation to evaluate deforestation in Landsat Thematic Mapper images of the Amazon region. International Journal of Remote Sensing, v. 19, p. 535-541, 1998.

SHIMABUKURO, Y. E.; ALMEIDA-FILHO, R.; KUPLICH, T. M.; FREITAS, R. M. Quantifying optical and SAR image relationships for tropical landscape features in Amazônia. International Journal of Remote Sensing, v. 28, p 3831-3840, 2007.

SHIMADA, M. User’s Guide to NASDA’s SAR products. Ver.3. Tokyo: NASDA, 2001. 23p.

STONE, T. A.; WOODWELL, G. M. Shuttle imaging radar analysis of land use in Amazonia. International Journal of Remote Sensing, v. 9, p. 95-105, 1988. 


ISSN = 1980-993X - doi:10.4136/1980-993X
www.agro.unitau.br/ambi-agua
E-mail: ambi-agua@agro.unitau.br
Tel.: (12) 3625-4116

\title{
Mapa de infiltração do alto e médio Vale do Paraíba do Sul com base em elementos do meio físico e na precipitação
}

(doi:10.4136/ambi-agua.40)

\author{
Paulo Valladares Soares ${ }^{1}$, Sueli Yoshinaga Pereira ${ }^{2}$, Silvio Jorge Coelho Simões ${ }^{3}$, \\ George de Paula Bernardes ${ }^{3}$, Sérgio Augusto Barbosa ${ }^{4}$ \\ ${ }^{1}$ Fundação Florestal, 02377-000, São Paulo \\ E-mail: pvsoares1@yahoo.com.br \\ 2 Instituto de Geociências, Unicamp, 13083-870, Campinas \\ E-mail: sueliyos@ige.unicamp.br \\ ${ }^{3}$ Laboratório de Análise Geoespacial, UNESP, Campus de Guaratinguetá, 12516-410, Guaratinguetá \\ E-mail: simoes@feg.unesp.br,gpb@feg.unesp.br \\ ${ }^{4}$ Agência Nacional de Águas - ANA, 70610-200, Brasília, DF \\ E-mail: sergio.barbosa@ana.gov.br
}

\section{RESUMO}

Este trabalho apresenta um procedimento para a elaboração de um Mapa de Infiltração, com base nas ferramentas disponíveis em um sistema de informação geográfica. A região utilizada para a avaliação dessa metodologia foi uma parte da bacia do rio Paraíba do Sul, que corresponde a uma área de $7.600 \mathrm{~km}^{2}$. Os elementos do meio físico utilizados foram a litologia, o relevo, o solo e o uso e a cobertura da terra. Também, foi considerada a distribuição espacial da precipitação. Para cada tipo de elemento do meio físico aplicou-se um fator de ponderação de 1 a 5, que por sua vez corresponde a maior (5) ou menor (1) influência desse elemento para a capacidade de infiltração. Os resultados apontam que as melhores áreas de infiltração situam-se na região da Bocaina, nos contrafortes da Serra do Mar, na região entre Cunha e Lagoinha, e em parte dos terrenos colinosos relacionados à Bacia Sedimentar de Taubaté. Em uma realidade de recursos hídricos escassos tanto para ações não estruturais (conservação do solo, reflorestamento) e ações estruturais (estações de tratamento de água e esgoto e programas de redução de perda de água) a elaboração de um mapa que estabeleça a condição espacial da infiltração se constitui numa importante ferramenta de gestão e planejamento territorial, de modo a preservar os recursos hídricos.

Palavras-chave: processos de infiltração; elementos da paisagem; sistemas de informação geográfica.

\section{Map of infiltration of the Paraíba do Sul basin using physical elements and precipitation}

\section{ABSTRACT}

This paper presents a methodological approach to characterize the infiltrations conditions of a portion of Paraiba do Sul river basin $\left(7,600 \mathrm{~km}^{2}\right)$ using Geographic Information Systems tools. To each landscape feature (rock, structure, relief, soil, and land-use) and to the spatial distribution of precipitation, an infiltration potential scale factor that ranges from higher influence (5) to lower influence (1) was applied considering its geographical position. The results showed that higher infiltration capacity areas are located in Serra da Bocaina associated to Serra do Mar relief in the Northeast region and Southeast region as well associated to gentle hills and sandstones along the Paraíba do Sul river. The creation of an Infiltration Map may contribute to the development of long-term territorial plans and water 
SOARES, P. V.; PEREIRA, S. Y.; SIMÕES, S. J. C.; BERNARDES, G. P.; BARBOSA, S. A. Mapa de infiltração do alto e médio Vale do Paraíba do Sul com base em elementos do meio físico e na precipitação. Ambi-Agua, Taubaté, v. 3, n. 1, p. 26-42, 2008. (doi:10.4136/ambi-agua.40)

resource management plans in order to support future implementation of non-structural and structural measures at both regional and local scales.

Keywords: infiltration process; landscape features; geographical information system.

\section{INTRODUÇÃO}

Os processos de infiltração, retenção e percolação são responsáveis pela manutenção da bacia hidrográfica como um reservatório dinâmico do sistema hidrológico, o qual permite a armazenagem e transferência de água como, por exemplo, pela movimentação da água subterrânea em direção aos cursos de água nos períodos de estiagem. Para se ter uma compreensão sistêmica dos processos de infiltração é necessário considerar as conexões existentes entre a água, os elementos do meio físico e a dinâmica do uso da terra.

Entretanto, a maior parte dos estudos que tratam com os processos de infiltração da água no solo são baseados apenas em ensaios pontuais o que requerem uma grande quantidade de ensaios analisados para que se obtenha a sua representação espacial. Como procedimento alternativo, nos últimos anos, começam a ser desenvolvidos estudos que buscam avaliar a distribuição espacial da infiltração com base em parâmetros do meio físico tais como geologia, geomorfologia e pedologia (Brito et al., 2006).

Nessa direção, o objetivo deste trabalho é apresentar uma metodologia que possibilite definir áreas potenciais de infiltração com base em elementos do meio físico natural e modificado (rochas, relevos, solos e uso e cobertura da terra) e sua interação com a variação espacial da precipitação. O trabalho procurou ainda avaliar a capacidade de integração e interação de um sistema de informação geográfico no sentido de se obter um mapa de potencialidade à infiltração. Este estudo foi realizado em escala regional utilizando, como estudo de caso, parte da bacia do Rio Paraíba do Sul, compreendendo tanto a sua área mais preservada como sua área fortemente modificada por ações antrópicas.

\section{ASPECTOS TEÓRICOS}

O ciclo hidrológico descreve a dinâmica da água na natureza consistindo em um conjunto de fases, nos quais são representados os diferentes caminhos que a água percorre nas diferentes escalas de abordagem. Participam do ciclo vários processos hidrológicos, como: precipitação, evaporação, transpiração, infiltração, armazenamento superficial, escoamento superficial e sub-superficial e percolação. O ciclo hidrológico pode ser entendido como uma série de armazenagens de água conectadas por transferências. O tempo de permanência, que é a duração média de tempo que a água permanece em uma parte da hidrosfera ou local de armazenamento, antes de mover-se para outra parte, indica que estas transferências podem ser mais lentas (água subterrânea, por exemplo) ou mais rápidas como nos rios que exercem limitada função de armazenagem.

A variação no armazenamento é função das inter-relações dos elementos naturais e modificados da paisagem que compõem o meio físico (rochas e estruturas, relevo, declividade, solo, uso e cobertura da terra) quanto às condições espaciais da precipitação. Nesse sistema físico, visto de forma integrada, pode-se atribuir à bacia o papel de regulação e alteração na distribuição temporal dos volumes de água.

Conforme destacam Dunne e Leopold (1978), o processo de infiltração é o resultado de relações interdependentes na entrada de água na superfície do solo, na armazenagem e na transmissão de umidade do interior do solo. Com base nos princípios estabelecidos por Horton no final da década de 30 e início da década de 40 e largamente difundidos nos livros 
especializados de hidrologia como por exemplo, Bras (1990), a capacidade de infiltração pode ser definida como a taxa máxima com que um determinado solo pode absorver água em uma determinada condição. A umidade, a permeabilidade, a temperatura do solo, a profundidade da camada impermeável, o grau de compactação do solo e o tipo de uso da terra, estão entre os principais fatores que influenciam na capacidade de infiltração de um determinado solo.

Condições de textura, profundidade e umidade antecedente do solo são variáveis que exercem influência na quantidade de água que poderá ser estocada antes do solo atingir a saturação. Solos profundos, bem drenados e com textura grosseira apresentarão alta capacidade de infiltração, enquanto os solos rasos e mais argilosos mostrarão baixas taxas e volumes de infiltração. Essas condições estão fortemente relacionadas com as características geológicas, geomorfológicas e pedológicas de uma determinada região.

As alterações antrópicas na superfície do solo mudam a absorção, a infiltração, a qualidade e a quantidade de água subterrânea; também têm o papel de acelerar os processos de fluxo de superfície. A Figura 1 mostra a magnitude da intervenção humana e a capacidade de alterar a eficiência das armazenagens e transferências no interior do solo. Se a interferência se der em modificações de superfície ou de solo, ou em armazenagens, é provável que uma reação seqüencial provoque mudanças em todo o restante dos depósitos e transferências. Por outro lado, a diminuição da capacidade do solo para absorver as chuvas, devido a prováveis mudanças no uso e cobertura da terra, poderá afetar a distribuição de água por todas as etapas anteriores. Portanto, não é de estranhar que a atividade antrópica (particularmente as mudanças no uso da terra) cause grande impacto nos processos de infiltração, conforme mostra a Figura 1.

Apesar de sua fundamental importância no contexto do ciclo hidrológico e na manutenção da "saúde hídrica" de uma bacia hidrográfica, a infiltração é considerada como uma "caixa preta" e tende muitas vezes a ser desprezada nos cálculos dos balanços hídricos e nos estudos hidrológicos regionais. O procedimento usual de se quantificar a infiltração nos solos é por meio de ensaios pontuais com base nos diferentes procedimentos descritos na literatura (e.g. Rewls et al., 1993). Estimativas pontuais da infiltração podem ser obtidas de maneira mais sofisticada, como aquela apresentada por Kwicklis et al. (2005), envolvendo uma combinação de técnicas que incluem o uso da equação de Richard, modelagem numérica e métodos de balanço de massa utilizando cloro. Kwicklis et al. (2005) utilizam esse conjunto de técnicas para quantificar a infiltração e obter um mapa de infiltração em uma área em torno de $600 \mathrm{~km}^{2}$ na região de Los Alamos, Novo México, EUA.

Entretanto, no caso do Brasil, querer obter a espacialização da infiltração a partir de técnicas pontuais é muito difícil, em face do elevado custo dos ensaios, mesmo para áreas de pequenas dimensões (poucos $\mathrm{km}^{2}$ ), necessitando uma significativa quantidade de dados para gerar um mapa de boa qualidade a partir de técnicas de interpolação.

No caso de áreas de grandes dimensões (a partir de centenas de $\mathrm{km}^{2}$ ), a produção de um mapa de infiltração, a partir de ensaios quantitativos pontuais, torna-se inviável. Logo, devese buscar alternativas, com base em elementos do meio físico, que possam refletir, espacialmente, os processos de infiltração, tornando-os procedimentos qualitativos ou semiquantitativos. Uma proposta seria estabelecer mapas de infiltração com base na "classificação hidrológica de solos" (Ward e Eliot, 1995; Thompson, 1999), em que se define uma capacidade mínima de infiltração (em $\mathrm{mmh}^{-1}$ ) em função da sua textura. Um exemplo de mapa construído com base na classificação hidrológica dos solos foi aquele construído por Civita e Maio (1997), utilizando as ferramentas de um sistema de informação geográfico. 


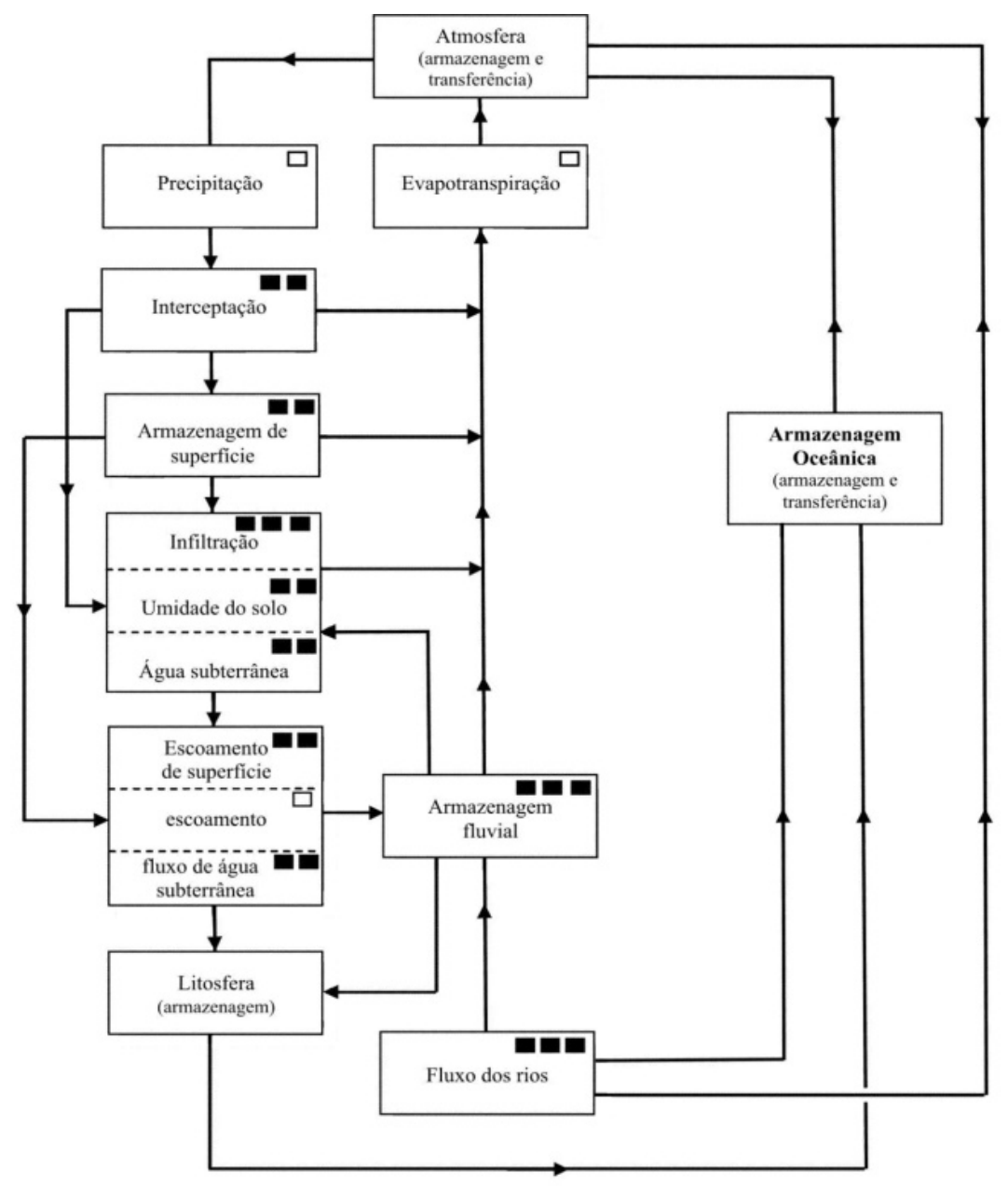

PONTOS DE INTERVENÇÃO HUMANA

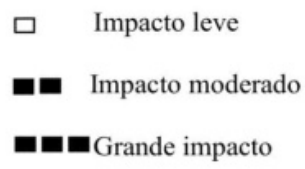

Figura 1. Representação do ciclo hidrológico mostrando os pontos de intervenção humana modificado de Drew (1994).

Embora os tipos de solos possam, de certa forma, refletir a capacidade de infiltração é importante lembrar que os processos de infiltração são controlados por diversos outros fatores como a precipitação, as características morfométricas do relevo, os tipos de rochas e suas estruturas, os tipos de vegetação, o uso e cobertura da terra, entre outros. Isso exige a construção de mapas de integração, como é o caso do "mapa de potencial de infiltração e recarga”, proposto por Gonçalves et al. (2007), que levaram em consideração diversos fatores do meio físico, uso da terra e características dos sistemas porosos e fraturados.

Outro caminho seria associar áreas de maior ou menor infiltração a partir do que foi designado por Brito et al. (2006) como "parâmetros hidrogeológicos". Esses autores consideraram quatro parâmetros (geologia, solo, declividade e áreas de inundação) e definiram diferentes pesos para cada um deles.

Finalmente, é preciso considerar que a relação entre a capacidade de infiltração e a capacidade de recarga dos aqüíferos nem sempre é direta e, como sugerem Kwicklis et al. (2005), diversos fatores podem complicar esta relação. Por exemplo, essa dificuldade pode 
ocorrer em regiões de aluviões, onde a direção de movimento da água de superfície e da água subterrânea nem sempre é clara ou em regiões compostas por rochas ígneas e metamórficas, onde a localização de fraturas armazenadoras de água pode ser uma tarefa bastante complexa necessitando de informações geoestruturais, hidrogeológicas e geofísicas.

\section{MATERIAIS E MÉTODOS}

Ao se analisar os mapas temáticos da área estudada, pode-se constatar a grande diversidade dos elementos do meio físico e das distintas formas de uso e ocupação da terra, evidenciando bem a complexidade mencionada acima. Uma maneira de resolver essa questão foi buscar estabelecer um grupo de especialistas com diferentes formações com o objetivo de avaliar cada elemento do meio físico selecionado. Inicialmente, buscou-se avaliar a importância relativa de cada elemento para a infiltração. Por exemplo, a geomorfologia teria mais importância que a pedologia, ou vice-versa? Em face da dificuldade em responder essa questão, assumiu-se que todos os elementos teriam o mesmo peso, ainda que isso pudesse mascarar uma maior importância relativa de um determinado elemento sobre outro. O grupo de especialista definiu para análise elementos do meio físico natural (rocha, solo, relevo e precipitação) e modificado (uso e cobertura da terra). Essa escolha se deve, principalmente, por dois fatores: a) a significativa importância desses elementos para o processo de infiltração; b) a base cartográfica disponível.

Para a produção do mapa final de infiltração levou-se em conta a base cartográfica existente no levantamento realizado durante a execução do Plano de Qualidade de Água para a porção paulista da bacia do Paraíba do Sul (CEIVAP, 2000). Infelizmente, existe uma discrepância de escala entre os levantamentos básicos efetuados. Para a região de estudo, a situação mais crítica são os levantamentos pedológicos e geomorfológicos. Em face disso, a escala de representação do mapa final de integração corresponde a mesma desses dois mapas (1:500.000).

Para as diferentes unidades (geológicas, geomorfológicas, pedológicas e de uso e cobertura do solo) e faixas (precipitação) atribuíram-se pesos que variam de um (1) a cinco (5) em que são analisados os comportamentos individuais de cada elemento aos processos de infiltração. Os pesos simbolizam a importância de cada tema (classes) para o sistema de análise conforme a sugestão da equipe de especialistas e a partir de informações bibliográficas. Esses números identificam o tipo de classe de um determinado mapa temático que ocorre em uma determinada unidade de terreno no interior da área de estudo. Quanto mais importante for uma classe em relação a determinado requisito, maior será seu peso para o referido requisito, indicando, portanto, condições mais favoráveis à infiltração (Tabela 1).

Tabela 1. Relação de qualificadores e seus respectivos pesos relativos.

\begin{tabular}{lc}
\hline \multicolumn{1}{c}{ Qualificadores } & Pesos Relativos \\
\hline Muito Baixa & 1 \\
Baixa & 2 \\
Regular & 3 \\
Boa & 4 \\
Muito Boa & 5 \\
\hline
\end{tabular}

Para executar a interação dos elementos do meio físico com seus respectivos pesos utilizaram-se as ferramentas de integração de dados do software ArcGIS ${ }^{\circledR}$. O procedimento 
para a geração do mapa de infiltração constou da aplicação de pesos segundo a característica específica de cada tema. O mapa final contém todos os cruzamentos espaciais realizados. No arquivo digital desse mapa foi calculada a média dos valores obtidos em todos os polígonos gerados, somando-se, para cada polígono, os pesos de infiltração dos temas e dividindo pelo número total de temas cruzados. Em seguida, foram definidos os intervalos entre os valores mínimos e os valores máximos encontrados na área de estudo. Dessa forma foi possível definir áreas homólogas em função da capacidade de infiltração tornando possível a espacialização e visualização de um mapa temático final.

\section{DESCRIÇÃO DA ÁREA DE ESTUDO}

A bacia do rio Paraíba do Sul está inserida nos territórios dos estados de São Paulo $\left(13.900 \mathrm{~km}^{2}\right)$, Rio de Janeiro $\left(20.900 \mathrm{~km}^{2}\right)$ e Minas Gerais $\left(20.700 \mathrm{~km}^{2}\right)$ onde vivem cerca de 14,3 milhões de pessoas em uma das mais importantes regiões industriais do país e onde se localizam várias cidades de médio e grande porte. A área de estudo (Figura 2), com aproximadamente $6.400 \mathrm{~km}^{2}$ de área total, compreende os municípios Cunha, Lagoinha, Roseira, Aparecida, Guaratinguetá, Potim, Canas, Lorena, Piquete, Cachoeira Paulista, Queluz, Lavrinhas, Cruzeiro, Silveiras, Areias, São José do Barreiro, Arapeí e Bananal.

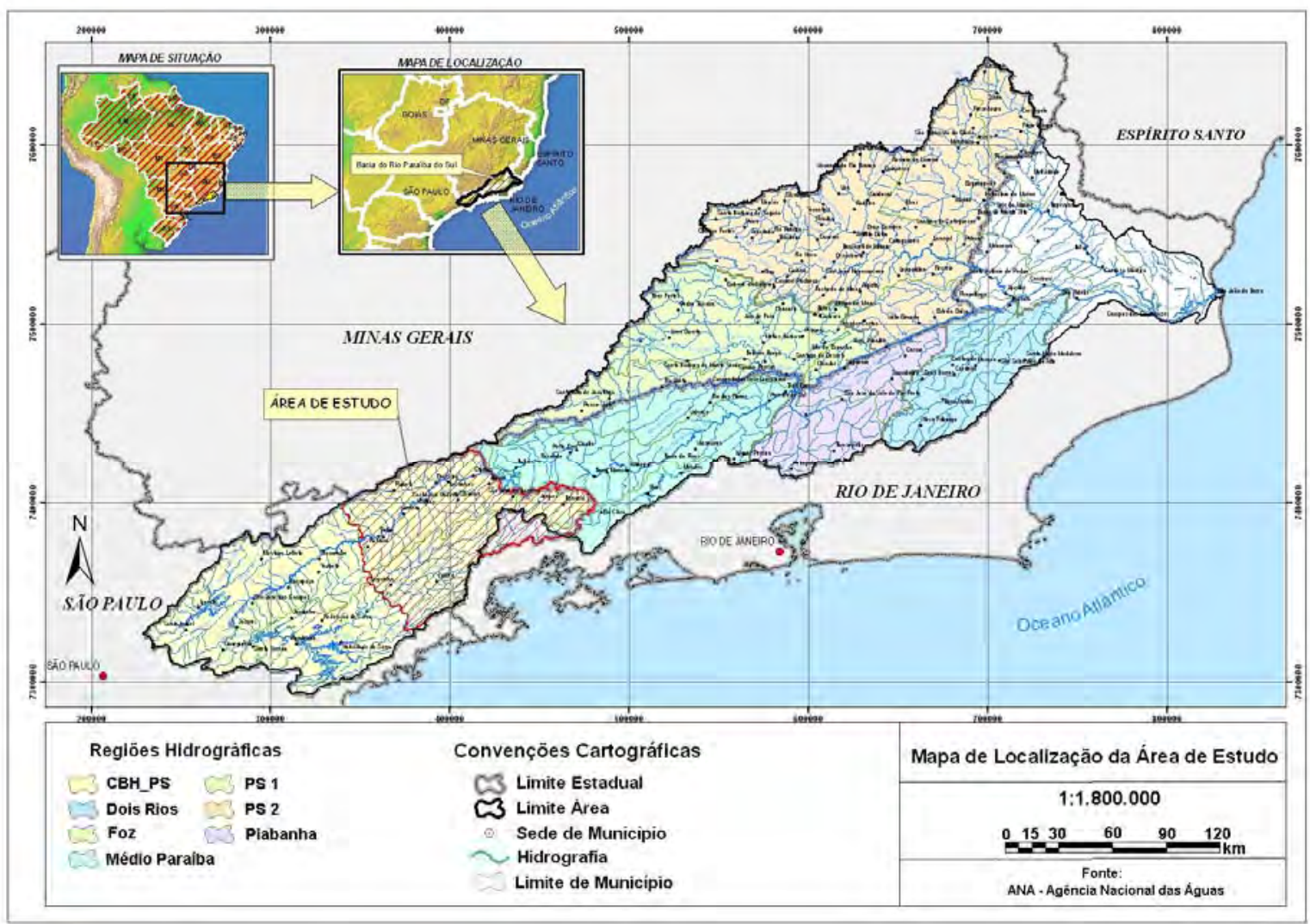

Figura 2. Regiões hidrográficas da bacia do rio Paraíba do Sul e localização da área de estudo.

A porção paulista da bacia, onde se localiza a área de estudo, pode ser dividida em quatro compartimentos com base nas características históricas, sociais, econômicas e ambientais: nascente, reservatório, urbano-industrial e agrícola-urbano-industrial (Figura 3). O compartimento nascente corresponde ao trecho onde estão inseridas as bacias hidrográficas 
que compõem os formadores do rio Paraíba do Sul (rio Paraibuna e rio Paraitinga). O compartimento reservatório é a região onde deságuam os formadores do rio Paraíba do Sul, constituindo o sistema de represa gerenciado pela CESP. O compartimento urbano-industrial constitui o eixo de maior desenvolvimento tecnológico e industrial da região, com processos acelerados e desordenados de urbanização, conurbação e altos índices de poluição hídrica. O compartimento agrícola-urbano-industrial corresponde ao último trecho da bacia hidrográfica do rio Paraíba do Sul no Estado de São Paulo e caracteriza-se, também, por pastagens degradadas, intensa fragmentação florestal, início de processos de conurbação e crescente atividade industrial. A área de estudo corresponde mais especificamente ao compartimento nascente e ao compartimento agrícola-urbano-industrial.

A região de estudo possui alta diversidade do meio físico, o qual é o resultado de uma evolução geológica complexa (IPT, 1981; Ross e Moroz, 1997). Na região é possível identificar três unidades geológicas-geomorfológicas bem distintas: a) rochas precambrianas associadas com relevos de morros e serras; b) sedimentos terciários associados a relevos suaves; e c), sedimentos quaternários associados a extensas planícies aluvionares. Esta grande diversidade geológica-geomorfológica tem contribuído para o desenvolvimento de diversas unidades pedológicas, tais como latossolos, argissolos, cambissolos e gleissolos melânicos (Oliveira et al., 1999). A grande variação altimétrica observada na área de estudo (entre 450 m e $2000 \mathrm{~m}$ ) favorece os processos orográficos sendo, em parte, responsável pela significativa variabilidade temporal (entre 1.300 e $2.400 \mathrm{~mm} / \mathrm{ano}$ ) e espacial das precipitações regionais (Silva, 1999; Simões e Barros, 2007).

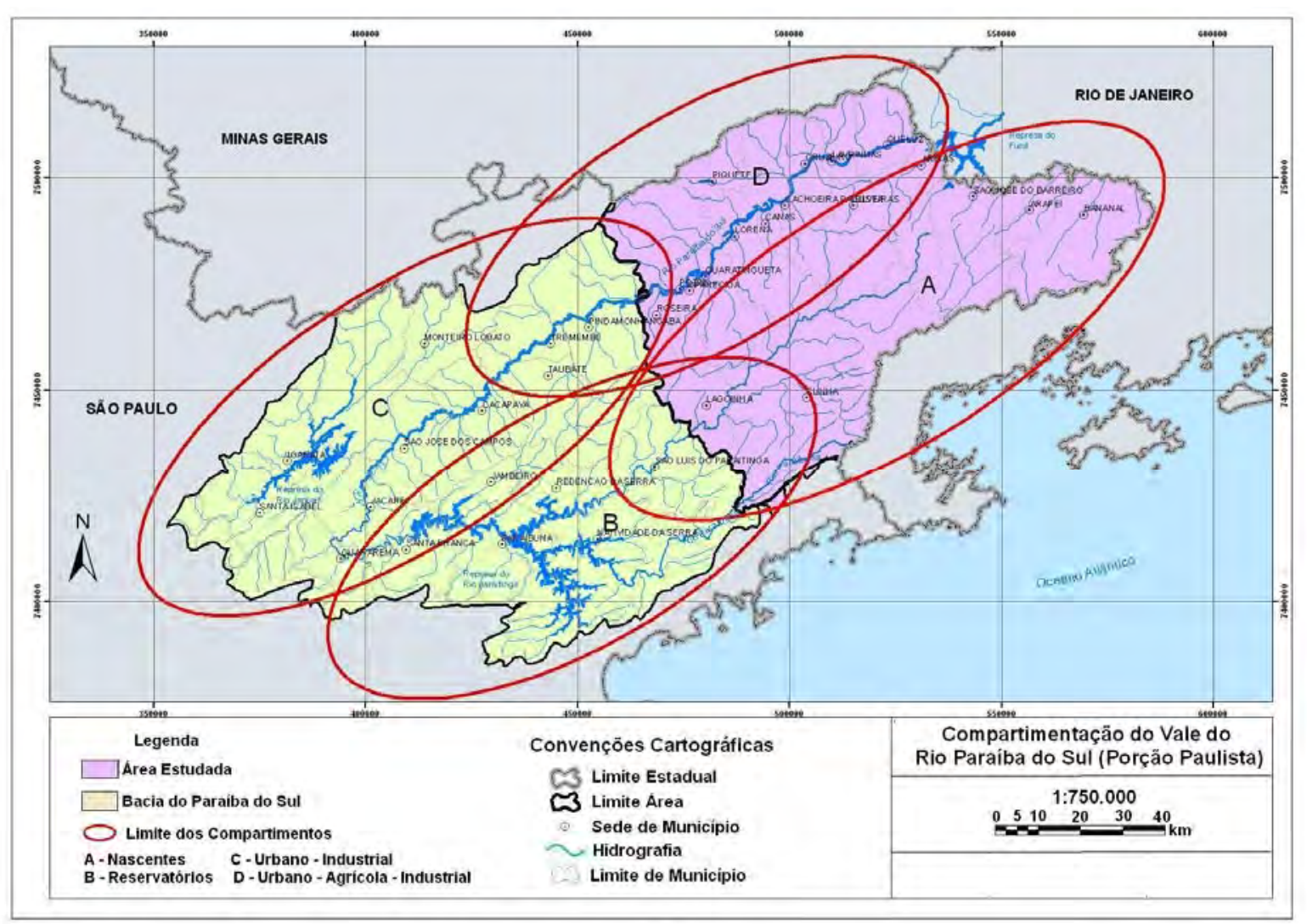

Figura 3. Compartimentação da bacia do Paraíba do Sul (porção paulista). A - nascente, B reservatório, C - urbano-industrial, D - urbano-agrícola-industrial. 
Em termos de distribuição espacial, as áreas de pastos/campos representam cerca de $50 \%$ da área total da bacia e pode-se constatar uma paisagem com elevado grau de fragmentação, na qual se destacam as áreas de mata nativa $(17,4 \%)$, capoeira $(13,4 \%)$, reflorestamento (9,0\%), pastagem de várzea (3,3\%), agricultura de várzea (1,0\%) áreas urbanizadas (2,9\%) e reservatórios (1,4\%), conforme levantamento realizado pelo CEIVAP (2000). Considerando a terminologia utilizada pela Ecologia da Paisagem, essas áreas se constituem no elemento matriz, enquanto os demais usos seriam pedaços (patches) inseridos na matriz (Forman e Godron, 1985; Forman, 1995).

\section{RESULTADOS}

\subsection{Geologia}

O mapa geológico utilizado foi produzido pelo IPT (1981), em escala 1:500.000, o qual é mostrado na Figura 4, para a área de estudo. Nesse mapa é possível identificar 9 unidades geológicas distintas. Na área de estudo, destacam-se duas grandes unidades: o embasamento cristalino, de idade precambriana, representado por granitos, migmatitos homogêneos e heterogêneos, quartzitos e filitos e a bacia sedimentar do Taubaté, composta por depósitos continentais flúvio-lagunares de idade terciária e sedimentos aluvionares de idade quaternária.

As rochas ígneas e metamórficas, como granitos e gnaisses, por serem impermeáveis, têm sua condição de infiltração dependendo completamente do comportamento do fraturamento. As melhores condições seriam fraturas abertas, em várias direções e com elevada densidade. No caso das rochas sedimentares, a porosidade e a permeabilidade são controladas pela composição das rochas favorecendo aquelas de composição arenosa.

As rochas com melhores condições de infiltração são os arenitos (peso 5) com lentes subordinadas de folhelhos. Em seguida, encontra-se o substrato granítico (peso 4) rico em minerais félsicos (claros) - como quartzo e feldspato - que propiciam mantos de alteração composto de sedimentos relativamente grosseiros e grau elevado de fraturamento e os migmatitos homogêneos (peso 3), com manto de alteração mais fino de composição arenoargilosa. Os aluviões, em geral, constituem-se nas condições menos favoráveis à infiltração (peso 1) com composição bastante variada (IPT, 1981).

\subsection{Pedologia}

O Mapa Pedológico do Estado de São Paulo (Oliveira et al., 1999), desenvolvido a partir do Sistema de Classificação de Solos da EMBRAPA, constitui-se no mais recente levantamento pedológico regional disponível para o estado e foi utilizado como base para a área de estudo. Regionalmente, seis unidades pedológicas bem distintas foram identificadas (Figura 5).

Para se avaliar as condições de infiltração desses solos, levou-se em consideração, além da classificação proposta por Oliveira et al., (1999), a classificação hidrológica dos solos com base na sua capacidade de infiltração (Ward e Elliot, 1995). Nessa classificação são definidas quatro classes avaliadas em condições de saturação dos solos, a saber: a) solos com alta capacidade de infiltração, consistindo de solos profundos e com drenagem boa à excessiva (na área de estudo correspondem aos latossolos); b) solos com capacidade de infiltração moderada com profundidades relativamente rasas e textura variável (na área de estudo, correspondem aos cambissolos); c) solos com baixa capacidade de infiltração, consistindo de camadas impermeáveis que dificultam o movimento descendente da água (na região de estudo correspondem aos argissolos); d) solos com capacidade de infiltração muito baixa consistindo de solos argilosos com elevado potencial de agregação, ou com nível freático próximo à 
SOARES, P. V.; PEREIRA, S. Y.; SIMÕES, S. J. C.; BERNARDES, G. P.; BARBOSA, S. A. Mapa de infiltração do alto e médio Vale do Paraíba do Sul com base em elementos do meio físico e na precipitação. Ambi-Agua, Taubaté, v. 3, n. 1, p. 26-42, 2008. (doi:10.4136/ambi-agua.40)

superfície (na área de estudo corresponderiam aos cambissolos húmicos e aos gleissolos melânicos).

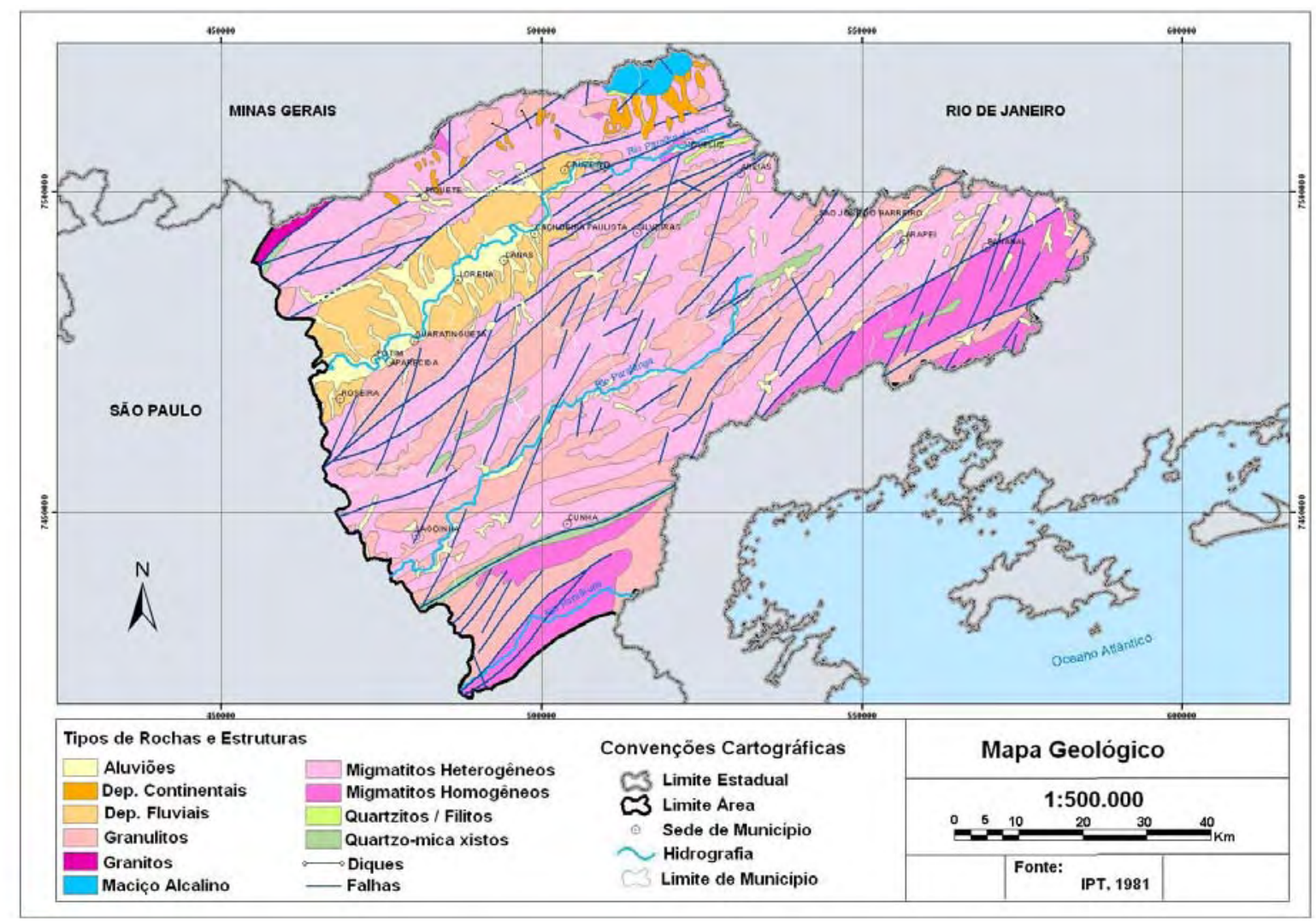

Figura 4. Mapa Geológico da área de estudo (IPT, 1981) mostrando as diferentes unidades litológicas e as principais direções de lineamento regionais.

Os latossolos vermelho-amarelos são os que apresentam as melhores condições de infiltração (peso 5) em face de ser bem desenvolvidos, não apresentarem minerais primários e terem boa condição de drenagem. Os cambissolos háplicos e húmicos, ainda que tenham horizonte B pouco espesso receberam pesos de infiltração 4 e 3, respectivamente. Um aspecto que facilita o processo de infiltração nos cambissolos é a presença de minerais primários facilmente alteráveis. Os argissolos vermelho-amarelo com horizonte B textural, enriquecidos em argila foram considerados como tendo baixa condição de infiltração (peso 2). Os gleissolos melânicos, ricos em argila e matéria orgânica e com nível freático próximo à superfície representam as condições menos favoráveis à infiltração (peso 1) representando condições de descarga de aqüífero. 
SOARES, P. V.; PEREIRA, S. Y.; SIMÕES, S. J. C.; BERNARDES, G. P.; BARBOSA, S. A. Mapa de infiltração do alto e médio Vale do Paraíba do Sul com base em elementos do meio físico e na precipitação. Ambi-Agua, Taubaté, v. 3, n. 1, p. 26-42, 2008. (doi:10.4136/ambi-agua.40)

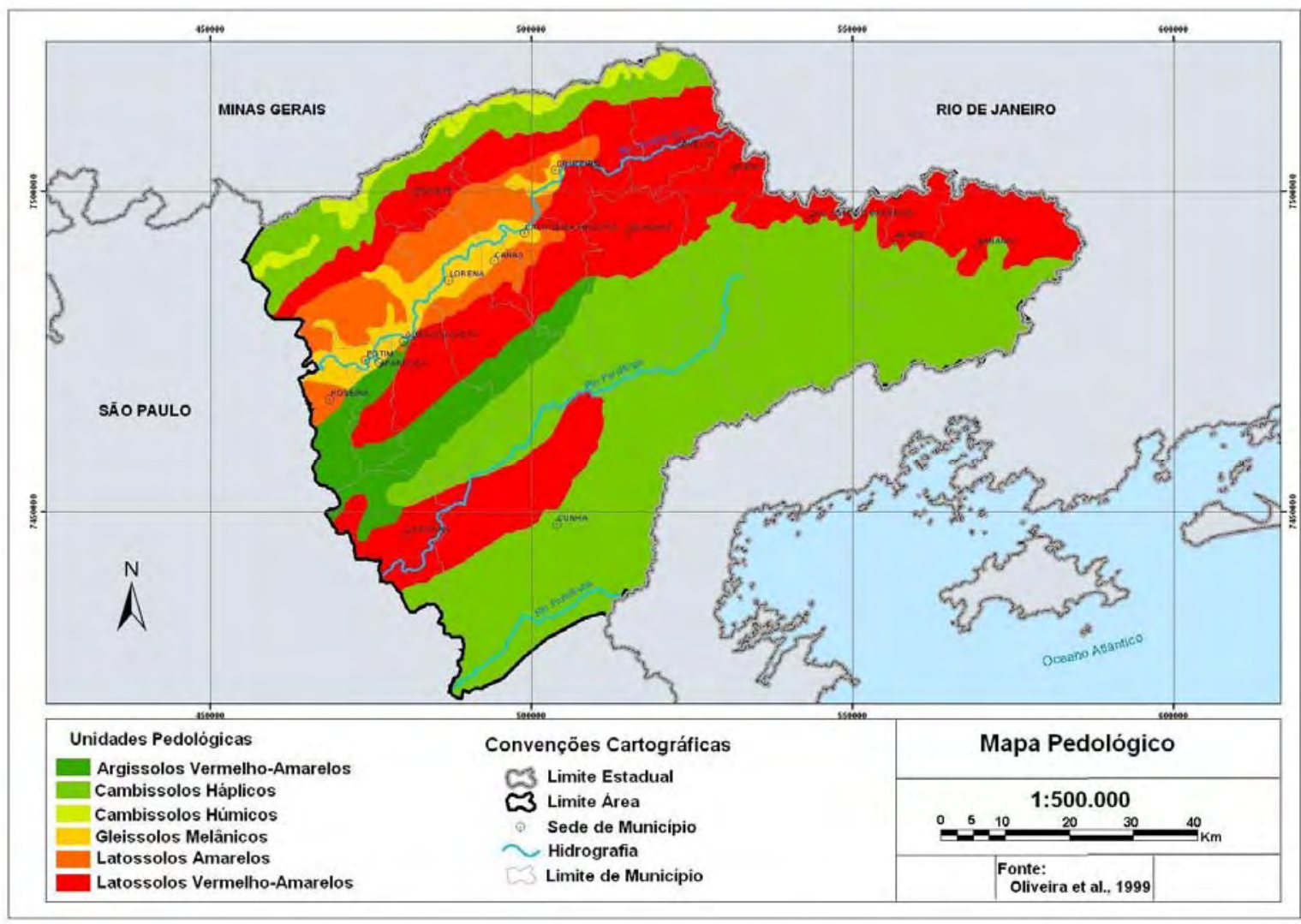

Figura 5. Mapa Pedológico da área de estudo no qual foram identificados seis unidades distintas. Fonte: Oliveira et al. (1999).

\subsection{Geomorfologia}

A região de estudo está inserida na Província Geomorfológica do Planalto Atlântico, caracterizando-se pelas zonas do Planalto Paraitinga, Planalto Bocaina, Médio Vale do Paraíba e parte da Serra da Mantiqueira conforme Ross e Moroz (1997). A análise dos elementos do relevo foi realizada tomando-se como base o Mapa Geomorfológico do Estado de São Paulo nas escalas 1:1.000.000 (Ponçano et al., 1981) e 1:500.000 (Ross e Moroz, 1997) (Figura 6).

Em face da escala de representação, preferiu-se utilizar o mapa geomorfológico o qual representa as diferentes unidades de relevo, contendo informações sobre a morfologia, a morfometria, a litologia entre outros. Dessa maneira, consegue-se expressar melhor a diversidade e as feições do relevo na região do que utilizando apenas a declividade.

Para a região de estudo foram identificadas doze unidades geomorfológicas, variando de planícies aluvionares (com baixíssima declividade) até relevos de serras (com declividades superiores a $100 \%)$.

Os relevos de colinas amplas, topos e extensos e aplainados, drenagem de baixa intensidade e vales abertos representam as melhores condições de infiltração (peso 5). Os relevos de morrotes baixos e morros paralelos foram considerados como tendo boas condições de infiltração (peso 4), particularmente por apresentarem topos arredondados e vales que variam de fechados a abertos. Em uma situação intermediária, encontram-se os relevos constituídos de morrotes e espigões com drenagem de média a alta densidade e vales fechados (peso 3). Os relevos de escarpas com topos angulosos, drenagem de alta densidade e vales fechados possuem condições pouco favoráveis à infiltração (peso 2). Os terrenos baixos e 
SOARES, P. V.; PEREIRA, S. Y.; SIMÕES, S. J. C.; BERNARDES, G. P.; BARBOSA, S. A. Mapa de infiltração do alto e médio Vale do Paraíba do Sul com base em elementos do meio físico e na precipitação. Ambi-Agua, Taubaté, v. 3, n. 1, p. 26-42, 2008. (doi:10.4136/ambi-agua.40)

planos nas margens dos rios e sujeitos a inundação representam as condições menos favoráveis a infiltração (peso 1).

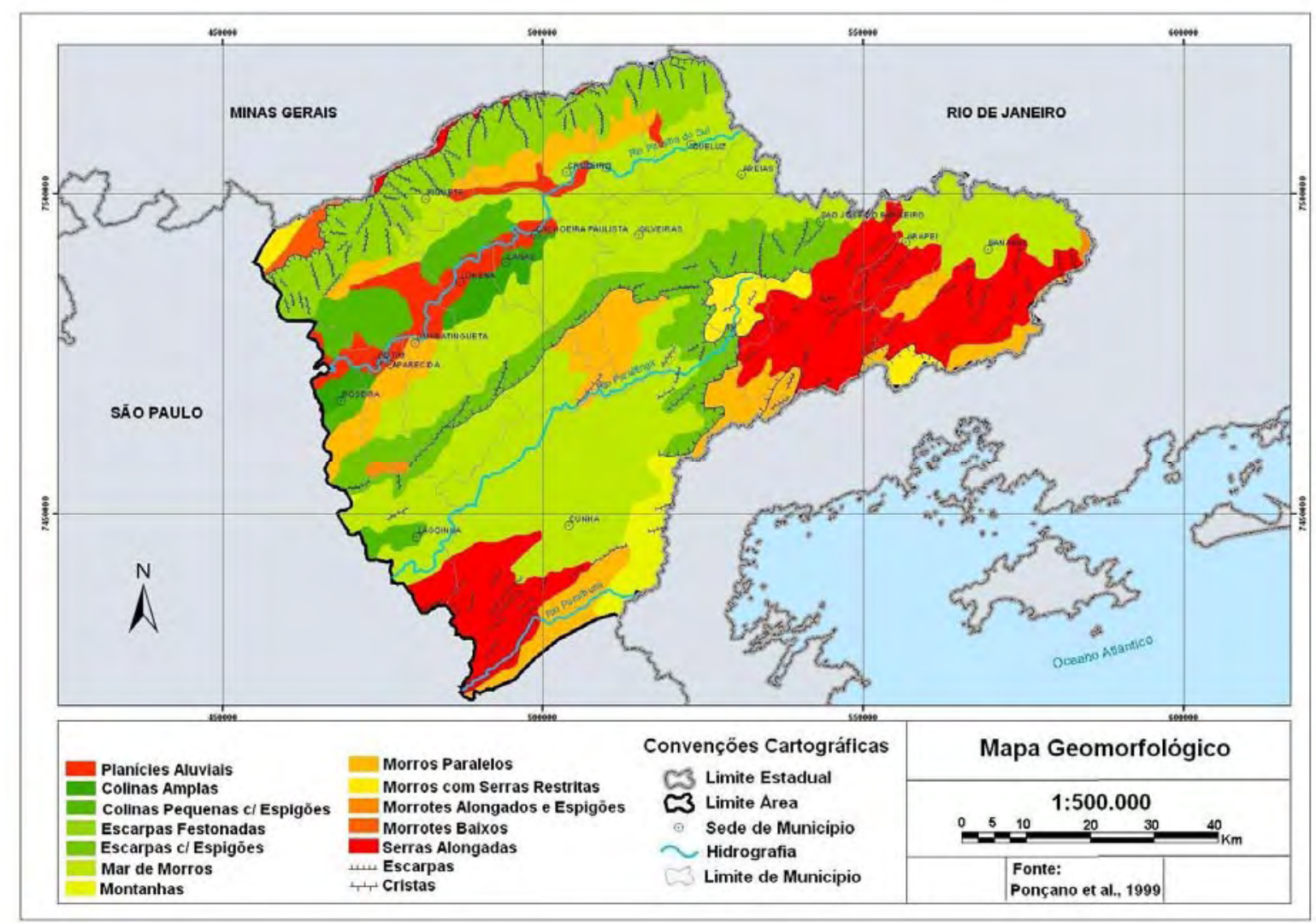

Figura 6. Mapa Geomorfológico mostrando a grande diversidade de tipos de relevos encontrados na área de estudo.

Fonte: Ponçano et al. (1981).

\subsection{Precipitação}

A região sudeste do Brasil apresenta grande diversidade no seu regime de chuvas, em face de ser uma zona de transição entre o regime tropical e o de média latitude (Rao e Hada, 1990). Além dessa diversidade, o padrão de precipitação da região do Vale do Paraíba é fortemente influenciado pelo efeito orográfico das chuvas devido à presença das serras do Mar e da Mantiqueira, que acrescentam maior complexidade aos processos climatológicos da região.

Uma das melhores maneiras de representar a variabilidade espacial da precipitação em uma região constituída de relevos íngremes é pelo método das isoietas, que é indicado para regiões com elevada diversidade topográfica (Thompson, 1999). Com base na configuração das isoietas da região de estudo, pode-se observar, a partir da Figura 7, que as precipitações mais elevadas - assim como as maiores diferenças nas precipitações - estão associadas às Serras da Mantiqueira (1300 a $2200 \mathrm{~mm}$ ) e a Serra do Mar (1300 a $2800 \mathrm{~mm}$ ). Em contraste, a região plana conhecida como Vale do Paraíba possui os menores índices de precipitação anual da bacia oscilando entre 1200 e 1300 mm. Portanto, a Figura 7 mostra claramente a importância do efeito orográfico sobre a distribuição espacial das precipitações.

No que concerne à infiltração, a utilização da pluviosidade média anual como entrada de água no sistema de bacias hidrográficas, está associada à idéia de que as maiores alturas de precipitação possuem maior probabilidade de contribuir para o processo de infiltração. Dessa 
maneira foram estabelecidas oito faixas de pluviosidade para a região considerada. Entre os maiores valores de precipitação média anual (peso 5) e os menores (peso 1) estabeleceram-se faixas intermediárias, as quais foram definidas de forma arbitrária.

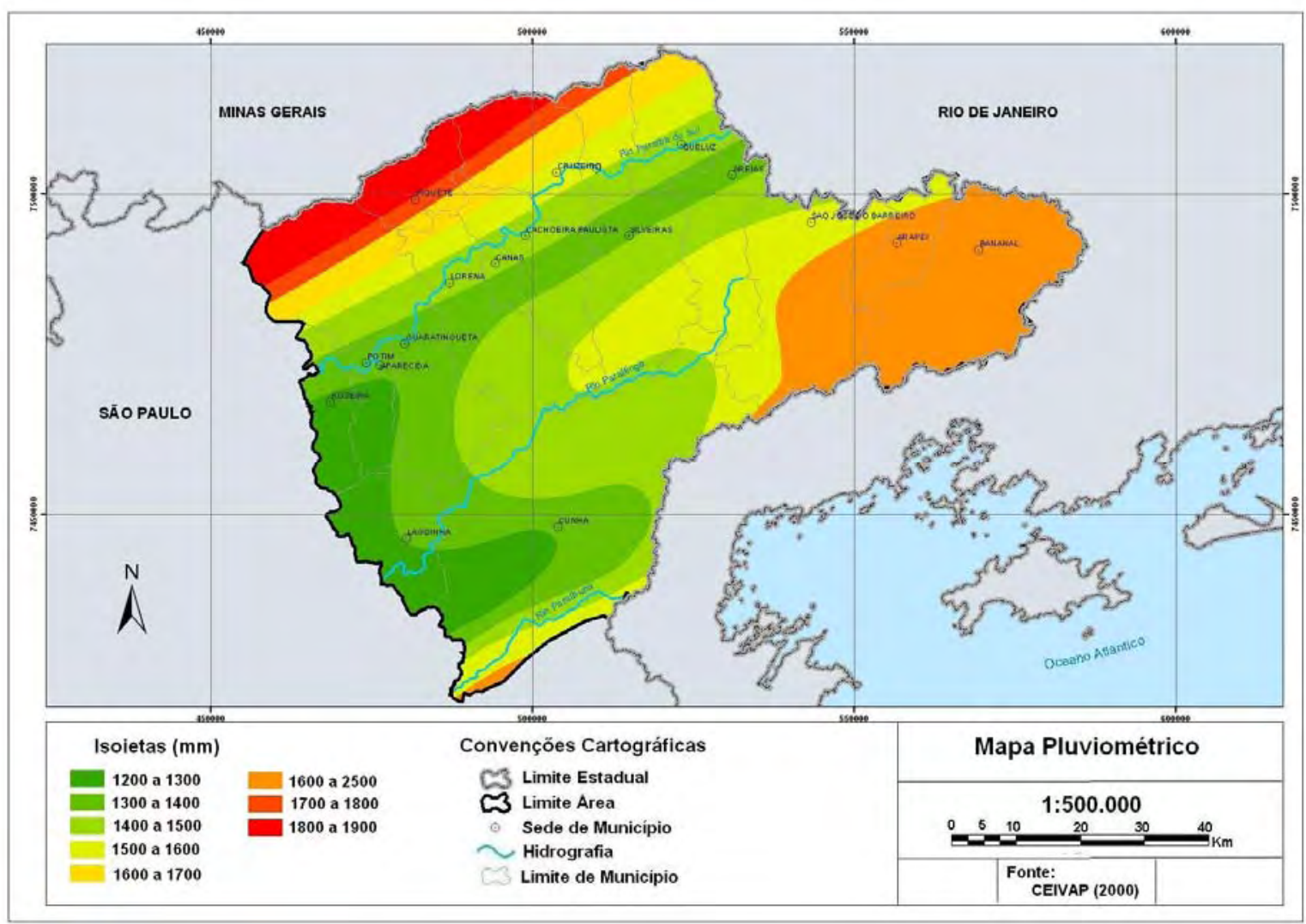

Figura 7. Mapa de Pluviometria, área de estudo construído a partir do método de isoietas.

Fonte: CEIVAP (2000).

\subsection{Uso e Cobertura da Terra}

Entre todos os critérios, o uso e cobertura da terra é aquele onde é possível se estabelecer a melhor correlação com os processos de infiltração, em face da grande quantidade de trabalhos existentes na literatura, inclusive com dados quantitativos.

Por outro lado, a definição das classes de uso da terra é um processo que envolve certa subjetividade e está fortemente correlacionado à escala de trabalho proposta. Neste estudo utilizou-se a metodologia adotada pelo Instituto Florestal no qual o Mapa de Uso e Cobertura Vegetal Natural foi elaborado por meio da interpretação de imagens do satélite LANDSAT 7 (Figura 8) e produzido dentro do Plano de Qualidade de Água da Bacia do Rio Paraíba do Sul, porção paulista (CEIVAP, 2000).

Assim, utilizou-se como base as classes de uso e cobertura propostas por Pereira et al. (1988) sendo elas: urbanização, pastagem, capoeira, reflorestamento e mata. Como era de se esperar, a formação vegetal constituída de matas com estrutura complexa e elevada biodiversidade possui as melhores condições de infiltração (peso 5), seguidas pelas áreas homogêneas de plantio de reflorestamento (peso 4). As florestas secundárias em estágio inicial de recuperação apresentando porte arbustivo até arbóreo representam situação intermediária (peso 3). As áreas de pastagem mal manejadas ligadas às atividades agropastoris extensivas receberam peso 2. As áreas com condições menos favoráveis de infiltração (peso 1) estão associadas aos núcleos urbanos e zonas de expansão urbana, caracterizadas pela presença de muitos lotes e impermeabilização da estrutura urbana. 
SOARES, P. V.; PEREIRA, S. Y.; SIMÕES, S. J. C.; BERNARDES, G. P.; BARBOSA, S. A. Mapa de infiltração do alto e médio Vale do Paraíba do Sul com base em elementos do meio físico e na precipitação. Ambi-Agua, Taubaté, v. 3, n. 1, p. 26-42, 2008. (doi:10.4136/ambi-agua.40)

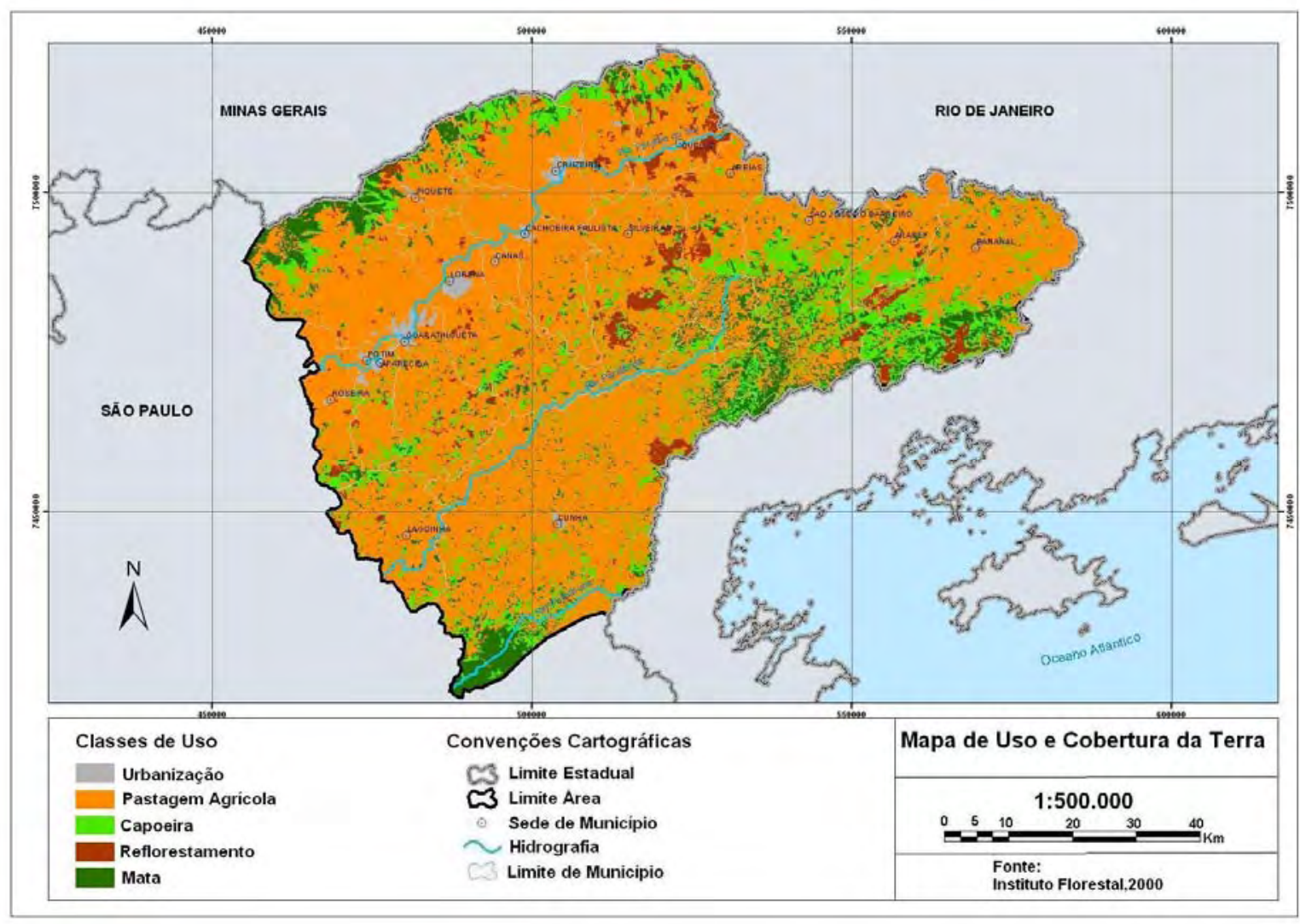

Figura 8. Mapa de Uso e Cobertura da Terra identificando as cinco principais classes encontradas na região.

Fonte: CEIVAP (2000).

\subsection{Mapa de Potencialidade a Infiltração}

Embora as classes dentro dos planos de informação possam responder de forma individual, suas características quanto à capacidade de infiltração estão ligadas à integração dos elementos do meio físico e constituem-se numa interessante forma de análise na distribuição espacial das condições de infiltração.

Pelo procedimento metodológico descrito no item 3, a identificação de regiões com boa capacidade de infiltração representam aquela que tem a melhor conjugação de possibilidades para que a água permaneça e se infiltre no perfil de solo. O mapa da Figura 9 representa as regiões com maior ou menor facilidade de infiltração com base nos elementos analisados.

A partir da Figura 9, observa-se que o extremo nordeste da área, correspondendo à Serra da Bocaina, apresenta a maior área contínua com boa capacidade de infiltração. Isso pode ser explicado por um conjunto de fatores positivos como elevadas precipitações médias anuais (1800 a $1900 \mathrm{~mm})$, relevos predominantes de morros e morrotes, declividades médias baixas (3 a 12\%), predominância de solos homogêneos e com boa drenagem (latossolos vermelhoamarelos) e alto grau de fraturamento. Áreas expressivas com boas condições de infiltração ainda ocorrem nos contrafortes da Serra do Mar, na região entre Cunha e Lagoinha e em parte dos terrenos colinosos que acompanham o rio Paraíba do Sul, na porção norte da área. Nos contrafortes da Serra do Mar, as áreas de boa condição de infiltração englobam as nascentes dos rios Paraibuna e Paraitinga. 
SOARES, P. V.; PEREIRA, S. Y.; SIMÕES, S. J. C.; BERNARDES, G. P.; BARBOSA, S. A. Mapa de infiltração do alto e médio Vale do Paraíba do Sul com base em elementos do meio físico e na precipitação. Ambi-Agua, Taubaté, v. 3, n. 1, p. 26-42, 2008. (doi:10.4136/ambi-agua.40)

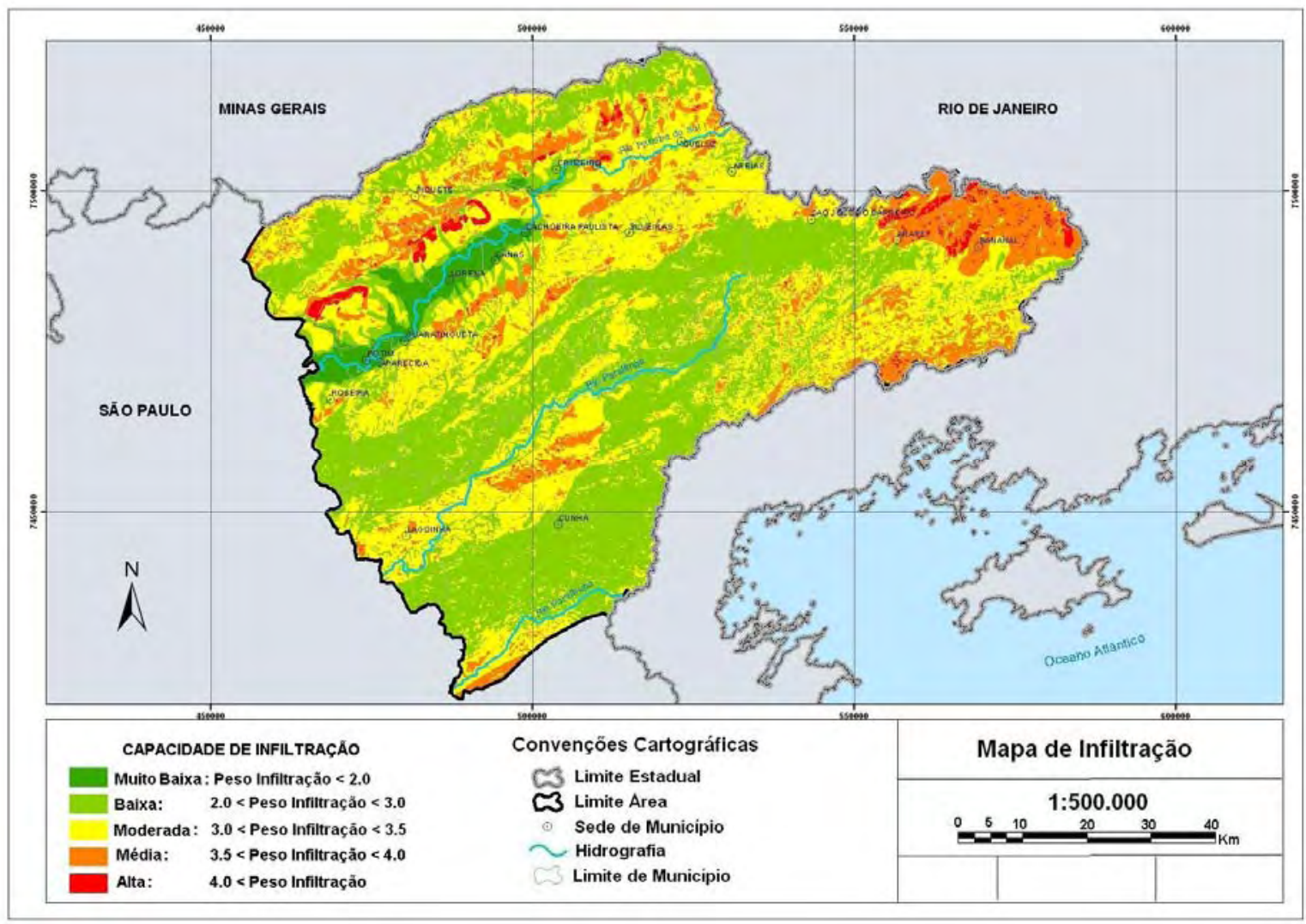

Figura 9. Mapa de Potencialidade de Infiltração, em que as porções identificadas em vermelho representam as áreas com maior potencial para a infiltração.

As áreas com boa capacidade de infiltração ocorrem de forma fragmentada e são caracterizadas por fatores como pluviometria média (1400 a $1600 \mathrm{~mm})$ e relevos predominantemente constituídos de serras e solos de B textural incipiente (cambissolos). De uma maneira geral, essas condições não seriam muito favoráveis à infiltração. Entretanto, as condições de uso e cobertura da terra são muito favoráveis, pois nessa região se concentra a maior parte dos fragmentos de mata da área de estudo. Na região entre Cunha e Lagoinha (centro-sul da área), existe uma "mancha" que apresenta uma boa capacidade de infiltração. Nessa região, as precipitações são relativamente baixas (1400 a 1500 mm). Entretanto, diversos condicionantes do meio físico são favoráveis à infiltração, tais como: o predomínio de morros e morrotes, as baixas declividades (3-12\%), a presença de granitóides muito fraturados e a presença de latossolos vermelho-amarelos. Na porção norte da área, ocorre uma estreita faixa de terrenos com boa infiltração. Essa área está inserida em elementos da paisagem com condições favoráveis de infiltração tais como: relevos colinosos, baixas declividades (3-12\%) e latossolos vermelho-amarelos.

As condições menos favoráveis de infiltração ocorrem em diversas áreas no interior da região estudada, tais como: no extremo sul (região entre Cunha e São Luis do Paraitinga), no extremo norte (Serra da Mantiqueira), em uma longa faixa SW-NE, dividindo a área ao meio (Serra do Quebra Cangalha) e na porção noroeste (planície aluvionar do rio Paraíba do Sul). Na região da Serra do Quebra Cangalha, a precipitação média anual é relativamente baixa (1200 a $1400 \mathrm{~mm})$. O relevo é formado predominantemente por uma escarpa estabelecendo um divisor de águas entre a região compreendida entre a Serra do Mar e a Serra do Quebra Cangalha e entre a Serra da Mantiqueira e a Serra do Quebra Cangalha. As declividades são relativamente elevadas (30 a 100\%) e os relevos estão em uma zona de transição entre os 
latossolos e os cambissolos. Na planície aluvionar do Rio Paraíba do Sul, as condições de infiltração são muito reduzidas devido às condições de baixa permeabilidade dos solos predominantes (gleissolos melânicos), os quais são ricos em argila e matéria orgânica. Esses solos estão, na sua maioria, em condições próximas à saturação (solos hidromórficos) e, considerando o modelo de circulação de água adotado neste trabalho, essas áreas se constituem descarga de aqüífero.

De uma maneira geral, a região entre a Serra do Quebra Cangalha e a Serra do Mar apresenta condições de infiltração variando de boa a moderada. O mapa da Figura 9 mostra claramente a importância dessa faixa — ou compartimento — como área de produção e disponibilização de água para o sistema Paraíba do Sul.

\section{CONCLUSÃO}

Este trabalho faz uso de elementos do meio físico, natural e modificado (rochas, estruturas, relevo, solos e uso e cobertura da terra) e precipitação para definir áreas com maior potencial de infiltração, considerando dois importantes compartimentos da bacia do rio Paraíba do Sul (porção paulista). No compartimento nascente (A), as áreas com melhores condições de infiltração ocorrem de forma fragmentada, estando associadas, principalmente, aos fragmentos de matas e às elevadas precipitações médias, ainda que os solos sejam relativamente incipientes. No compartimento urbano-agrícola-industrial (D), as áreas mais favoráveis estão associadas aos terrenos colinosos que acompanham o rio Paraíba do Sul, que estão associados aos sedimentos predominantemente arenosos, ainda que as médias de precipitação sejam relativamente baixas. A região da Bocaina apresenta uma grande área contínua favorável à infiltração, mas que deságua a jusante da represa do Funil, não contribuindo para os dois compartimentos analisados.

Os resultados apontam que os elementos do meio físico naturais e modificados interferem fortemente no processo de infiltração e, na maioria dos casos, necessitam ser avaliados integradamente e não de maneira isolada.

Espera-se que os resultados obtidos neste trabalho possam contribuir como uma ferramenta de gestão e de planejamento territorial visando à preservação dos recursos hídricos na bacia do rio Paraíba do Sul, assim como orientar na implementação de medidas estruturais (como obras de engenharia de drenagem) e medidas não estruturais (como o melhor planejamento do uso da terra no interior da bacia).

\section{AGRADECIMENTOS}

À Fundação de Amparo à Pesquisa do Estado de São Paulo / FAPESP, pelos recursos obtidos através do Programa de Políticas Públicas (Processo 2000/13714-1).

\section{REFERÊNCIAS}

BRAS, R. Hydrology: an introduction to hydrologic science. Reading: Addison-Wesley, 1990. 643p.

BRITO, M. G.; COSTA, C. N.; ALMEIDA, J. A.; VENDAS, D.; VERDIAL, P. H.; Characterization of maximum infiltration using GIS tools. Engineering Geology, Amsterdam, v. 85, p.14-18, 2006. 
CIVITA, M. V.; MAYO, M. Mapping groundwater vulnerability in areas impacted by flash food disasters. In: ESRI EUROPEAN USER CONFERENCE, 13., 1998, Firenze. Proceedings... Disponível em: <http://www.wca-infonet.org/servlet/BinaryDownloader Servlet?filename =1066722282491_wdse12.pdf> . Acesso em: 20 jan. 2008.

COMITÊ DA BACIA DO RIO PARAÍBA DO SUL. CEIVAP Projeto qualidade das águas e controle da poluição hídrica na Bacia do Rio Paraíba do Sul. Relatório Final. São Paulo: Governo de São Paulo / CBH - Rio Paraíba do Sul e Serra da Mantiqueira, 2000. 256p. 1 CD-ROM.

DREW, D. Processos interativos homem-meio ambiente, 3.ed. Rio de Janeiro: Bertrand, 1994. 224p.

DUNNE, T.; LEOPOLD, L. B. Water in environmental planning. San Francisco: W.H. Freeman, 1978. 818p.

FORMAN, R. T. Land mosaics: the ecology of landscape and regions. New York: Cambridge University Press, 1995. 632p.

FORMAN, R. T.; GODRON, M. Landscape ecology. New York: John Willey, 1985. 619p.

GONÇALVES, T. D.; CAMPOS, J. E. G.; BATISTA, G. B.; DINIZ, H. N.; TARGA, M. S. Metodologia para elaboração de mapas hidrogeológicos: estudo de caso da bacia hidrográfica do rio da Palma, DF, Brasil. Revista Ambiente e Água, v. 2, n.2, p. 47-68. 2007.

INSTITUTO TECNOLÓGICO DO ESTADO DE SÃO PAULO (IPT). Mapa geológico do Estado de São Paulo. São Paulo: IPT, 1981. 126p. 1 Mapa, n. 6. Escala 1:500.000.

KWICKLIS, E.; WITKOWSKI, M.; BIRDSELL, K.; NEWMAN, B.; WALTHER, D.; Development of an infiltration map for the Los Alamos area, New Mexico. Madison: Vadoze Zone Journal, v. 4, p. 672-693, 2005.

OLIVEIRA, J. B.; CAMARGO, M. N.; ROSSI, M.; CALDERANO FILHO, B. Mapa Pedológico do Estado de São Paulo. Campinas: Instituto Agronômico de Campinas (IAC), 1999. 1 Mapa. Escala 1:500.000.

PEREIRA, M. N.; NOVO, E. M. L. M.; KURKDJIAN, M. L. N. O.; D’ALGE, J. C. L. Atualização do uso da terra do município de São José dos Campos através de dados de sensoriamento remoto. São José dos Campos: INPE- DPA, 1988. p. 71.

PONÇANO, W. L.; CARNEIRO, C. D. R.; BISTRICHI, C. A.; ALMEIDA, F. F. M.; PRANDINI, F. L. Mapa Geomorfológico do Estado de São Paulo, São Paulo: IPT, 1981. 94p. 1 Mapa. Escala 1:500.000

RAO, V. B.; HADA, K. Characteristics of rainfall over Brazil: annual variation and connections with the Southern oscillation. Berlin: Theoretical \& Applied Climatology, v. 42, p. 81-91, 1990.

REWIS, W. J.; AHUJA, L. R.; BRAKENSIEK, D. L.; SHIRMOHAMMADI, A. Infiltration and soil water movement. In: MAIDMENT D. R. (ed.) Handbook of hydrology. New York: McGraw Hill, 1993. p. 5.1 - 5.51. 
SOARES, P. V.; PEREIRA, S. Y.; SIMÕES, S. J. C.; BERNARDES, G. P.; BARBOSA, S. A. Mapa de infiltração do alto e médio Vale do Paraíba do Sul com base em elementos do meio físico e na precipitação. Ambi-Agua, Taubaté, v. 3, n. 1, p. 26-42, 2008. (doi:10.4136/ambi-agua.40)

ROSS, J. L. S.; MOROZ, I. C. Mapa Geomorfológico do Estado de São Paulo. Revista do Departamento de Geografia, São Paulo, v. 10, p. 41-56, 1997.

SIMÕES, S .J .C.; BARROS, A.P., Regional hydroclimatic variability and Brazil's 2001 energy crisis. Bradford: Management of Environmental Quality, v.18, n.3, p.263273. 2007.

SILVA, J. U. L., A dinâmica atmosférica e a distribuição das chuvas na região nordeste paulista. 1999, 212f. Tese (Doutorado em Geociências) - Instituto de Geociências e Ciências Exatas, Universidade Estadual Paulista, Rio Claro, 1999.

THOMPSON, S. Hydrology for water management. Rotterdam: A. A. Balkema, 1999. 362p.

WARD, A. D.; ELLIOT, W. J. Environmental hydrology. Boca Raton: Lewis Publishers, 1995. 462p. 


ISSN = 1980-993X - doi:10.4136/1980-993X
www.agro.unitau.br/ambi-agua
E-mail: ambi-agua@agro.unitau.br
Tel.: (12) 3625-4116

\title{
Desempenho agronômico de capim tifton 85 (cynodon spp) cultivado em sistemas alagados construídos utilizados no tratamento de água residuária de laticínios \\ (doi:10.4136/ambi-agua.41)
}

\author{
Antonio Teixeira de Matos"; Sérgio Silva Abrahão²; Odilon Gomes Pereira ${ }^{3}$ \\ ${ }^{1}$ Engenheiro Agrícola, D.S., Professor do Departamento de Engenharia Agrícola, Universidade Federal de \\ Viçosa, bolsista do CNPq \\ E-mail: atmatos@ufv.br \\ ${ }^{2}$ Engenheiro Agrícola, M.Sc. em Engenharia Agrícola, Departamento de Engenharia Agrícola, UFV \\ E-mail: sergio@ctazm.org.br \\ ${ }^{3}$ Agrônomo, D.S., Professor do Departamento de Zootecnia, Universidade Federal de Viçosa, UFV \\ E-mail: odilon@ufv.br
}

\section{RESUMO}

O objetivo, com a realização deste trabalho, foi estudar o desempenho do capim tifton 85 (Cynodon spp), cultivado em Sistemas Alagados Construídos (SACs) e submetido a diferentes taxas de aplicação de carga orgânica (TCOs), proporcionadas pela aplicação de misturas de águas residuárias da indústria de laticínios (ARL) com água, nas condições climáticas de Viçosa, MG. A infra-estrutura experimental foi constituída por cinco SACs com fluxo subsuperficial horizontal: tanques de 0,40 × $0,75 \times 3,00 \mathrm{~m}$ (profundidade, largura e comprimento), impermeabilizados e preenchidos com $0,33 \mathrm{~m}$ de profundidade de brita zero. A ARL foi aplicada numa vazão média de $60 \mathrm{~L}^{-1 i a^{-1}}$ e tempo de residência hidráulica de 4,8 dias e TCOs de 66, 130, 190, 320 e $570 \mathrm{~kg} \mathrm{ha}^{-1}$. dia $^{-1}$ de DBO. O capim tifton 85 se adaptou bem aos SACs, apresentando bom enraizamento, alta produtividade e grande capacidade de remover nutrientes ( $\mathrm{N}, \mathrm{P}$ e K) e sódio da ARL, cujos valores estiveram, respectivamente, entre 216 e 544, 24 e 61, 115 e 204 e 4,3 e 10,9 kg.ha ${ }^{-1}$.

Palavras-chave: águas residuárias; leitos cultivados; processamento do leite.

\section{Agronomic performance of tifton 85 (cynodon spp) grass cultivated in constructed wetlands used in milk processing wastewater treatment}

\begin{abstract}
The present work was carried out in order to study the performance of the tifton 85 (Cynodon spp) grass cultivated in wetlands (SACs) and submitted to different organic load application rates (TCOs) of milk processing wastewater (ARL), in the climatic conditions of Viçosa MG. The experimental structure was constituted by five SACs with horizontal subsuperficial flow, using tanks of $0.40 \times 0.75 \times 3.00 \mathrm{~m}$ (depth, width and length) filled with $0.33 \mathrm{~m}$ depth of fine stones. The ARL was applied in average flow of $60 \mathrm{~L}^{-d_{a y}{ }^{-1}}$, hydraulic time residence of 4.8 days and TCOs of 66, 130, 190, 320 and $570 \mathrm{~kg} \mathrm{ha}^{-1}$.day ${ }^{-1}$ of DBO. The tifton 85 grass adapted well to SACs, presenting good rooting ${ }_{2}$ high yield and capacity of nutrients (N, P and K) and sodium removal of the ARL, whose values were, respectively, between 216 - 544, 24 61, 115 - 204 and $4.3-10.9$ kg.ha ${ }^{-1}$.
\end{abstract}

Keywords: wastewater; wetland; milk processing. 


\section{INTRODUÇÃO}

Nas últimas décadas, tem sido crescente o interesse por Sistemas Alagados Construídos (SACs), por se tratar de tecnologia simples, de baixo custo, fácil operação e manutenção para o tratamento de grande diversidade de produtos líquidos, ricos em material orgânico susceptível à biodegradação (Brasil et al., 2007). Esses sistemas oferecem benefícios ambientais consideráveis, tais como sua integração a parques e sistemas recreacionais, possibilitando o desenvolvimento de animais silvestres, harmonizando-se com a paisagem natural e proporcionando a produção de efluentes de boa qualidade, que poderão ser utilizados para outros fins ou lançados em corpos hídricos receptores.

Os SACs são sistemas projetados para utilizar plantas cultivadas em substratos (solo, areia, brita ou cascalho), onde, naturalmente, sob condições ambientais adequadas, ocorrem processos físicos, químicos e bioquímicos de tratamento das águas residuárias. Segundo Paganini (1997), as espécies vegetais a serem selecionadas devem ser perenes, ter alta tolerância ao excesso de água e a ambientes eutrofizados, ser de fácil propagação e crescimento rápido, ser de fácil colheita e manejo e possuir alta capacidade de remoção de nutrientes e poluentes. Além disso, devem apresentar denso sistema radicular, ser pouco susceptível a pragas e doenças e ser passível de cortes sucessivos e freqüentes.

A escolha deve incluir espécies com grande capacidade de extração de nutrientes, que se desenvolvam bem em ambientes encharcados, com rusticidade suficiente e alto poder de dominação (capacidade de se sobressair em relação a outras plantas), além de apresentar valor nutricional para alimentação animal.

Grande número de espécies vegetais, quase que exclusivamente aquáticas, têm sido cultivadas em SACs, no Brasil, sendo utilizadas as seguintes macrófitas: Juncus sp. (Sousa et al., 2000), Echimochloa polytachya (Sezerino e Philippi, 2003), Typha sp. (Hussar, 2001; Campos et al., 2002; Valentim, 2003; Brasil et al., 2005), Zizaniopsis bonariensis (Campos et al., 2002), Eleocharis sp. e Scirpus sp. (Valentim, 2003) e arroz (Oriza sativa L.) (Nogueira, 2003). Entretanto, pouco ainda se sabe sobre quais seriam as espécies mais indicadas e como deveria ser o seu manejo, qual o desempenho dos sistemas e o potencial para remoção de diferentes compostos, no tratamento de diferentes águas residuárias em SACs.

O capim tifton 85, uma das espécies do gênero Cynodon, possui boas características de produção e elevada capacidade de crescimento, apresentando grande potencial de uso como forrageira nas condições subtropicais e tropicais. Seu relvado atinge até $1 \mathrm{~m}$ de altura e é forrageira resistente a cortes freqüentes. A matéria seca produzida, em boas condições de manejo e adubação, é de boa qualidade, permitindo bom desempenho animal na produção de leite e carne. Muito embora tenham sido realizados poucos trabalhos de pesquisa com essa gramínea no Brasil, ela tem demonstrado um bom desempenho, quando avaliada (Cecato e Bortolo, 1999).

Stefanutti et al. (1999) avaliaram o comportamento do capim tifton 85 em rampas de tratamento de esgoto doméstico e consideraram esse capim eficiente na remoção de nutrientes aplicados no solo, considerando-o apropriado para cultivo nesses sistemas de tratamento, por apresentar fechamento homogêneo e mais denso, além de apresentar recuperação mais rápida após o corte.

Queiroz et al. (2004), estudando o desempenho de quatro espécies forrageiras (capim quicuio da Amazônia, capim braquiária, capim coastcross e capim tifton 85) cultivadas em rampas e submetidas à aplicação de água residuária da suinocultura, pelo método do escoamento superficial, verificaram que, dentre as gramíneas forrageiras avaliadas, o capim tifton 85 foi o que se mostrou mais adequado para cultivo em rampas de tratamento de águas 
residuárias da suinocultura por escoamento superficial devido à alta produtividade e capacidade de extração de nutrientes alcançadas, além da rápida recuperação após o corte, com boa cobertura do solo e o impedimento ao desenvolvimento de poucas espécies invasoras no local.

Por existir pouca informação sobre o desempenho agronômico de espécies de vegetais quando cultivadas em SACs, em diferentes taxas de carga orgânica, no presente trabalho tevese como objetivo estudar o desempenho de Sistemas Alagados Construídos, cultivados com capim tifton 85 (Cynodon spp), submetidos a diferentes taxas de aplicação de carga orgânica proporcionadas pela aplicação de águas residuárias da indústria de laticínios (ARL), nas condições climáticas de Viçosa, MG.

\section{MATERIAL E MÉTODOS}

O experimento foi conduzido na Área Experimental de Hidráulica, Irrigação e Drenagem do Departamento de Engenharia Agrícola da UFV, em Viçosa, MG. Para a realização dos estudos, foram utilizadas águas residuárias brutas provenientes da Usina de Beneficiamento de Leite da Fundação Arthur Bernardes (Laticínios da FUNARBE), localizada no Campus da UFV.

A infra-estrutura experimental foi constituída por cinco leitos de sistemas alagados construídos (SACs) com fluxo subsuperficial horizontal. Cada SAC foi constituído por um tanque de $0,40 \times 0,75 \times 3,00 \mathrm{~m}$ (profundidade, largura e comprimento), impermeabilizado, preenchido com substrato de brita zero, declividade de base de $0,5 \%$ no sentido longitudinal do tanque e profundidade do leito filtrante de 0,33 m.

Para facilitar o pegamento das mudas de capim, os SACs foram previamente saturados com água residuária proveniente da suinocultura da UFV, posteriormente foi feito o plantio, utilizando-se propágulos vegetativos (rizomas+caule) com, aproximadamente, 0,30 m de comprimento. A densidade de plantio foi, em média, 14 propágulos. $\mathrm{m}^{-2}$ e o plantio ocorreu em apenas uma etapa, no dia 16 de abril de 2005.

Após o plantio dos propágulos, deu-se continuidade ao fornecimento da água residuária proveniente da suinocultura nos SACs com e sem vegetação, com uma freqüência de 3 vezes por semana, até o dia 3 de agosto de 2005. A partir do dia 4 de agosto de 2005, passou-se a aplicar, na mesma freqüência, apenas água "limpa” do manancial (AM) e no dia 19 de agosto de 2005 deu-se a partida de operação nos SACs com aplicação diária da água residuária do laticínio (ARL).

A água residuária afluente aos SACs foi aplicada de forma a se promover o seu escoamento de forma subsuperficial, com vazão média de $60 \mathrm{~L} \cdot \mathrm{dia}^{-1}$ e tempo de residência hidráulica igual a 4,8 dias nos tanques. As taxas de carga orgânicas aplicadas (TCOs) em cada tratamento foram de 66, 130, 190, 320 e $570 \mathrm{~kg} \cdot \mathrm{ha}^{-1} \cdot \mathrm{dia}^{-1}$ de DBO, denominados respectivamente de CT-66, CT-130, CT-190, CT-320 e CT-570, respectivamente. As diferentes cargas orgânicas dos afluentes foram obtidas por meio de misturas da água residuária de laticínio (ARL) bruta, que tinha DBO de aproximadamente 2.500 mg.L ${ }^{-1}$, com água "limpa" do manancial (AM). Os tratamentos foram aplicados até 9 de dezembro, ocasião em que foi feito o segundo corte do capim e encerrado o experimento.

As principais características físicas, químicas e bioquímicas da água residuária do laticínio (ARL) e da água "limpa" de manancial (AM), utilizadas para a dosagem das TCOs estão apresentadas na Tabela 1. A coleta da biomassa, realizada após ter sido realizado um corte de uniformização dos estandes de plantas, foi efetuada em duas ocasiões diferentes, num intervalo de 45 dias, aproximadamente, sendo constituída pelo corte das plantas de toda área 
de cada SAC, que foi subdividida em três subáreas (início, meio e fim), numa altura entre 5 e $10 \mathrm{~cm}$ acima do meio suporte. Para a quantificação da concentração de nutrientes e sódio no tecido vegetal, amostras do segundo corte do capim tifton 85 foram submetidas à digestão nítrico-perclórico, seguida da quantificação do N-total pelo método semimicro Kjeldahl, do Ptotal por espectrofotometria e $\mathrm{K}$ e $\mathrm{Na}$ por fotometria de chama. O valor do conteúdo de proteína bruta foi obtido por multiplicação da concentração de N-total por 6,25, conforme recomendado por Silva (1998). As análises laboratoriais foram realizadas em conformidade com recomendações de Kiehl (1985), sendo efetuadas nos laboratórios de Solo e Resíduos Sólidos e de Química dos Resíduos do Departamento de Engenharia Agrícola da UFV.

Tabela 1. Características físicas, químicas e bioquímicas da água residuária do laticínio (ARL) e da água "limpa" de manancial (AM) utilizadas para a dosagem das TCOs (média dos valores medidos nas seis amostragens efetuadas).

\begin{tabular}{lccc}
\hline Variáveis & Unidade & \multicolumn{2}{c}{$\begin{array}{c}\text { ARL } \\
\text { Média e Desvio Padrão }\end{array}$} \\
\hline pH & --- & $3,78 \pm 0,47$ & $6,94 \pm 0,17$ \\
CE & $\mu S . \mathrm{cm}^{-1}$ & $994 \pm 110$ & $89 \pm 14$ \\
DBO & $\mathrm{mg} \cdot \mathrm{L}^{-1}$ & $2790 \pm 633$ & $12 \pm 4$ \\
DQO & $\mathrm{mg} \cdot \mathrm{L}^{-1}$ & $5143 \pm 328$ & $20 \pm 6$ \\
SS & $\mathrm{mg} \cdot \mathrm{L}^{-1}$ & $702 \pm 100$ & $3 \pm 3$ \\
$\mathrm{ST}$ & $\mathrm{mg} \cdot \mathrm{L}^{-1}$ & $2407 \pm 442$ & $104 \pm 41$ \\
SD & $\mathrm{mg} \cdot \mathrm{L}^{-1}$ & $1705 \pm 479$ & $101 \pm 43$ \\
$\mathrm{~N}-$ Total & $\mathrm{mg} \cdot \mathrm{L}^{-1}$ & $89,54 \pm 17,3$ & $3,33 \pm 5,7$ \\
P-Total & $\mathrm{mg} \cdot \mathrm{L}^{-1}$ & $22,51 \pm 5,1$ & $0,12 \pm 0,17$ \\
Potássio & $\mathrm{mg} \cdot \mathrm{L}^{-1}$ & $66,36 \pm 23,9$ & $3,77 \pm 1,5$ \\
Sódio & $\mathrm{mg} \cdot \mathrm{L}^{-1}$ & $107,72 \pm 98,4$ & $8,43 \pm 4,2$ \\
\hline
\end{tabular}

No final do período de avaliação dos SACs, foram feitas medidas da profundidade atingida pelas raízes da planta dentro dos SACs.

Os resultados foram interpretados quantitativamente, utilizando-se, para isso, o ajuste de equações matemáticas, escolhidas com base no valor do coeficiente de determinação $\left(\mathrm{R}^{2}\right)$, desde que houvesse lógica para o tipo de comportamento descrito.

\section{RESULTADOS E DISCUSSÃO}

Observou-se que os SACs que receberam maiores TCOs (CT-320 e CT-570) apresentaram menor altura média de planta na zona de entrada e maior na zona de saída (Figura 1a). Contrariamente, os SACs que receberam menores valores de TCO (CT-66 e CT130) apresentaram maior altura média de planta na zona de entrada e menor na zona de saída. O SAC que recebeu TCO intermediária (CT-190) apresentou maior altura média de plantas.

A variação da altura média do capim tifton 85 ao longo dos SACs, em função da TCO aplicada, está, provavelmente, relacionada com o estágio de degradação/decomposição da matéria orgânica ao longo desses tanques. Nos SACs que receberam maiores TCOs, houve maior acúmulo de matéria orgânica na zona de entrada, tornando esta área saturada com esse material, o que constituiu um ambiente francamente redutor e, conseqüentemente, com baixa disponibilidade de nutrientes assimiláveis pelo capim. Nesse caso, admite-se que à medida que o líquido foi se encaminhando para a zona de saída, condições mais oxidantes passaram a ser encontradas e, com isso, maior passou a ser a disponibilidade de nutrientes para as plantas. Já no caso dos SACs que receberam menores taxas de carga orgânica, o aporte de matéria 
orgânica na zona de entrada foi menor e, provavelmente, possibilitou a disponibilização de nutrientes para as plantas em todo o SAC, pelo menos até o período final de monitoramento dos SACs.

Na Figura 1b está ilustrado o aspecto típico da zona radicular do capim tifton 85, desenvolvidas durante o período do experimento, em que se pode observar um desenvolvimento axial e relativamente profundo $(30 \mathrm{~cm})$ das raízes no sistema radicular das plantas, entretanto, verificou-se que a maior densidade de raízes se encontrava concentrada entre a superfície do substrato e a profundidade de $10 \mathrm{~cm}$. As profundidades máximas alcançadas pelas raízes, nesta pesquisa, demonstraram compatibilidade da espessura de 0,30 $\mathrm{m}$ do substrato do meio suporte com o desenvolvimento radicular dessas espécies vegetais.

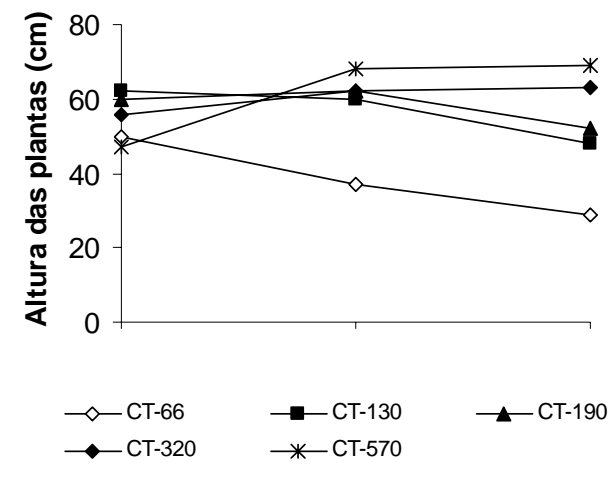

a

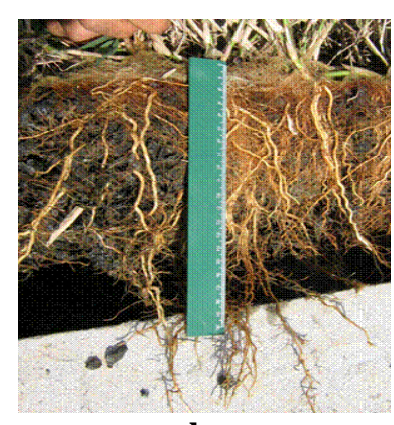

b

Figura 1. Altura média de plantas ao longo do comprimento (início, meio e final) dos SACs, medida 45 dias após a $1^{\text {a }}$ amostragem dos estandes (a), e aspecto típico da zona radicular do capim tifton 85 (b).

As profundidades máximas alcançadas e o tipo de crescimento das raízes principais demonstrou boa adaptação do capim tifton 85 em SACs funcionando em regime de fluxo subsuperficial. O maior desenvolvimento radicular, em profundidade, possibilitando exploração de maior seção molhada dos SACs, é uma característica importante para a seleção de espécies a serem cultivadas em SACs, já que parte importante da absorção de nutrientes (notadamente Ca e Mg) se dá por interceptação radicular (Vargas et al., 1983).

Na Figura 2 está apresentada a curva de produtividade acumulada de matéria seca em função das TCOs, obtida a partir das duas amostragens efetuadas em cada SAC. Ao observar essa Figura, verificou-se que a produtividade de matéria seca aumentou com o acréscimo na TCO aplicada nos SACs. Entretanto, verificou-se, também, tendência de decréscimo na produtividade de matéria seca, quando os valores de TCO se aproximaram de $500 \mathrm{~kg} . \mathrm{ha}^{-1}$.dia ${ }^{-1}$ de DBO. Com base nesses resultados, suspeita-se que a aplicação de TCOs muito superiores a $570 \mathrm{~kg} . \mathrm{ha}^{-1}$.dia ${ }^{-1}$ de DBO poderão prejudicar a produtividade de matéria seca do capim tifton 85, quando cultivado em SACs submetidos a condições semelhantes às de condução deste experimento. 


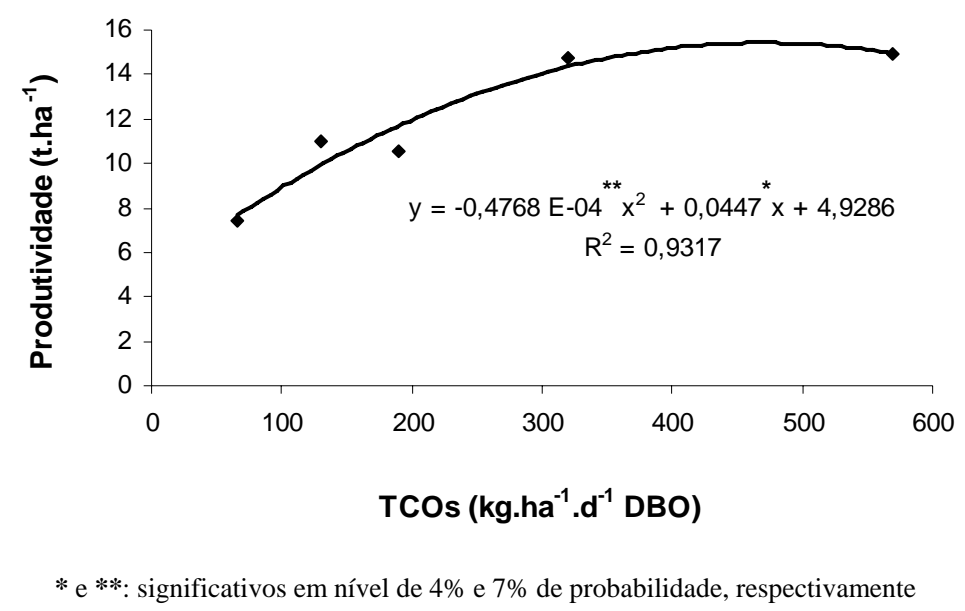

Figura 2. Produtividade acumulada de matéria seca do capim tifton 85, em função das taxas de carga orgânica superficial (TCOs) aplicadas.

Oliveira (1999), em sistema de cultivo convencional (adubação química e irrigação) verificou aumento linear na produtividade de matéria seca do capim tifton 85 , que variou de 3,13 a 12,32 t.ha-1 ${ }^{-1}$ respectivamente, aos 14 e 70 dias após a rebrota. Cultivando da mesma forma, Postiglion e Messias (1998) obtiveram produtividade anual (média de três anos consecutivos), de 10,71 t.ha ${ }^{-1}$ de capim tifton 85. Queiroz et al. (2004) obteve produtividade de 17,7 t.ha $^{-1}$ em tifton 85 fertirrigado com água residuária da suinocultura (aplicação de 800 kg.ha ${ }^{-1} \cdot$ dia $^{-1}$ de DBO). Neste experimento, a produtividade máxima estimada foi de 15,4 t.ha ${ }^{-1}$, obtida com uma TOC de $469 \mathrm{~kg} \cdot \mathrm{ha}^{-1}$. dia ${ }^{-1}$, valor superior ao obtido em cultivos convencionais (adubação química do solo), porém abaixo do obtido por Queiroz et al. (2004) com a aplicação de maior TOC de água residuária da suinocultura, água residuária sabidamente mais rica em nutrientes do que a ARL.

Nas Figuras 3 a 6, estão apresentados os dados experimentais, as curvas e as equações ajustadas de concentração de N, P, K e Na na parte aérea do capim tifton 85 como função da TCO aplicada nos SACs. Verifica-se que houve tendência de aumento na concentração de Ntotal, P-total e $\mathrm{Na}$, na parte aérea do capim tifton 85, com o aumento nas TOCs. Considerando-se relativamente altas as concentrações de sódio no afluente aos SACs e que o potássio sofre a concorrência desse cátion, prejudicando sua absorção pelas plantas, suspeitase que o decréscimo na absorção de potássio possa estar associado, dentre outros fatores, ao aumento na disponibilidade de sódio nos SACs, com o aumento das TCOs aplicadas. Sabe-se que as plantas podem absorver $\mathrm{Na}$ em substituição ao $\mathrm{K}$, para que exerçam funções fisiológicas semelhantes nas plantas. 


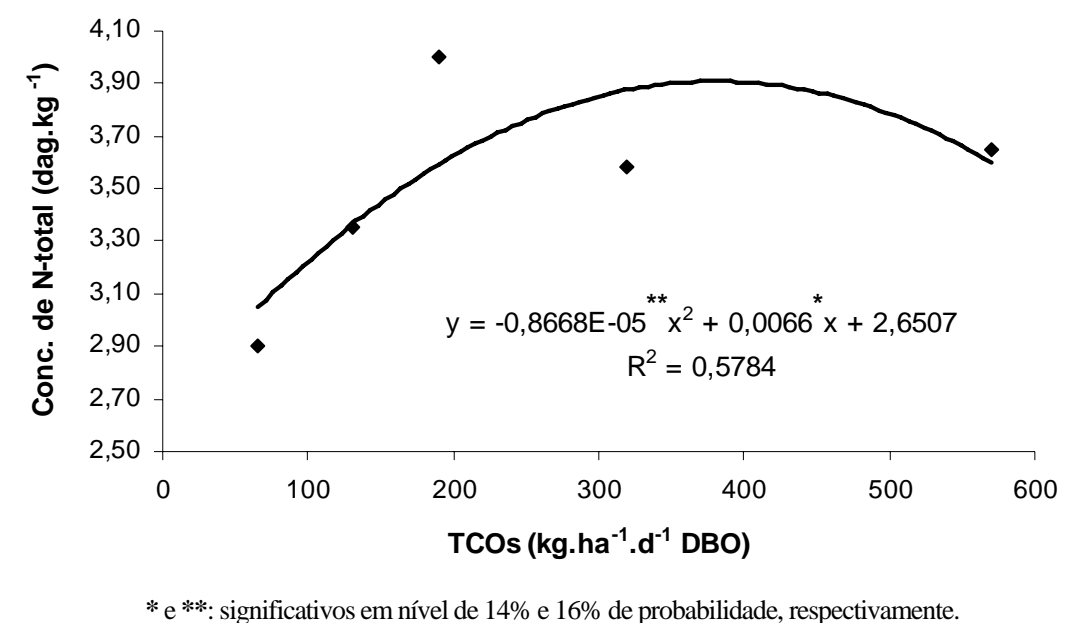

Figura 3. Variação da concentração de N-total na parte aérea do capim tifton 85, em função das taxas de carga orgânica superficial (TCOs) aplicadas.

No que se refere ao nitrogênio, o aumento na concentração ocorreu até TOCs em torno de $400 \mathrm{~kg} \cdot \mathrm{ha}^{-1} \cdot \mathrm{dia}^{-1}$, com ligeira diminuição na concentração desse nutriente a partir dessa taxa. Em relação ao fósforo e o sódio, não foi obtido um ponto de concentração máxima nas faixas de TOCs avaliadas.

A concentração média de P-total foi de 0,36 dag. $\mathrm{kg}^{-1}$. Queiroz (2000), trabalhando com o capim tifton 85 submetido à aplicação de água residuária da suinocultura e água da rede de abastecimento, obteve valores médios de 0,37 e 0,34 dag. $\mathrm{kg}^{-1}$, respectivamente, de concentração de P-total nas folhas.

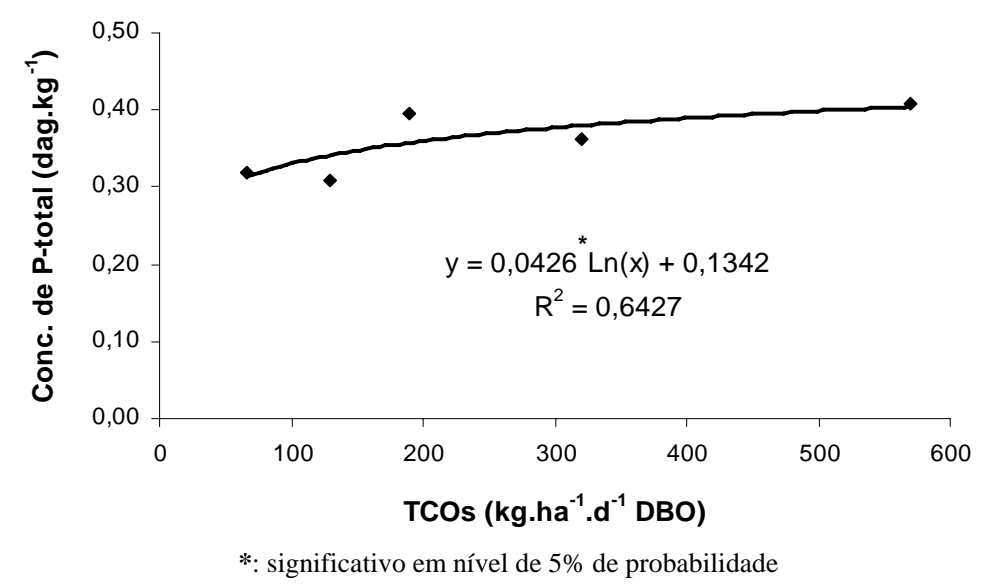

Figura 4. Variação da concentração de P-total na parte aérea do capim tifton 85, em função das taxas de carga orgânica superficial (TCOs) aplicadas.

De acordo com Gomide (1986), a concentração de potássio na faixa de 1,5 a 2,0 dag. $\mathrm{kg}^{-1}$ na parte aérea das plantas pode ser considerada normal para forrageiras e que valores mais elevados indicam absorção de luxo desse nutriente. Com base nisso, pode-se afirmar que o capim tifton 85 tendeu a apresentar concentrações abaixo do normal, tendo sido estimada uma concentração mínima, de 1,3 dag. $\mathrm{kg}^{-1}$, quando foi aplicada uma TOC de $378 \mathrm{~kg} \cdot \mathrm{ha}^{-1}$.dia ${ }^{-1}$. 


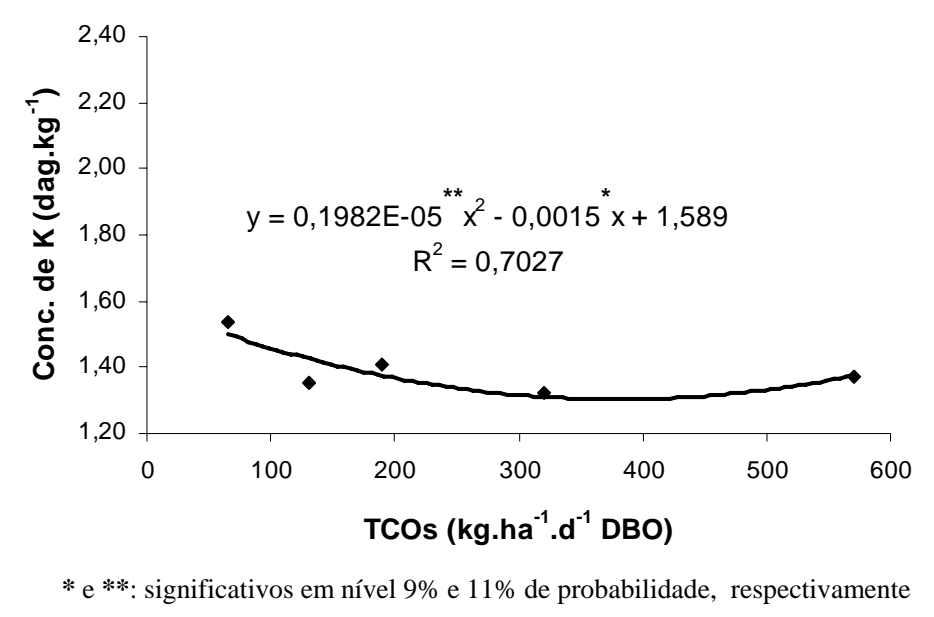

Figura 5. Variação da concentração de $K$ na parte aérea do capim tifton 85, em função das taxas de carga orgânica superficial (TCOs) aplicadas.

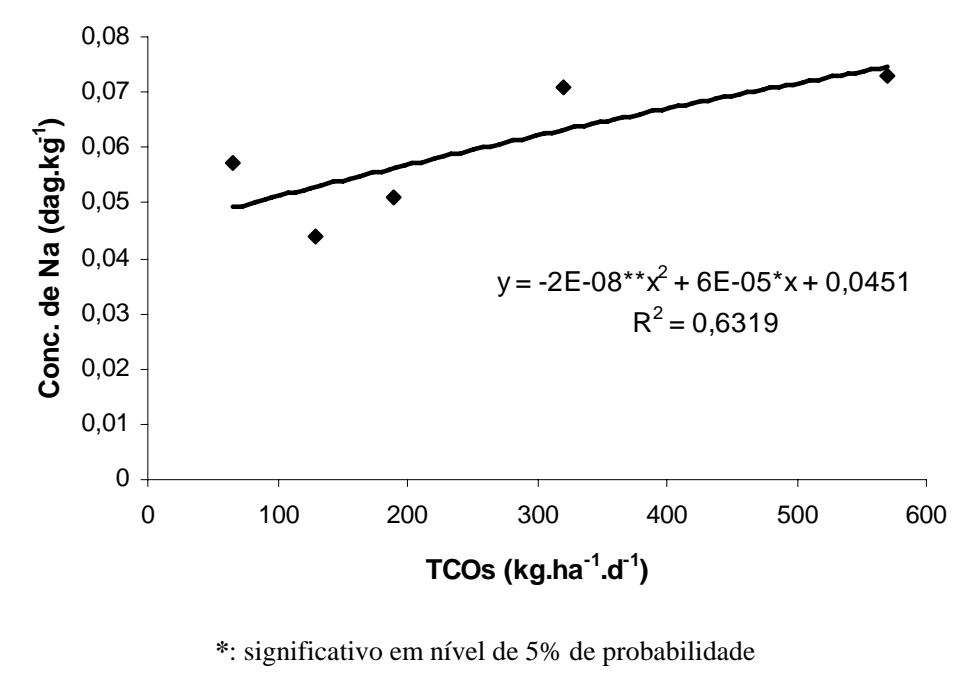

Figura 6. Variação da concentração de Na na parte aérea do capim tifton 85, em função das taxas de carga orgânica superficial (TCOs) aplicadas.

Oliveira (1999) verificou que os conteúdos de proteína bruta, P, K, Ca e Mg reduziram linearmente com a idade de rebrota do capim tifton 85 cultivado convencionalmente (adubação química mais irrigação), sendo de 15,60 e 4,50 dag. $\mathrm{kg}^{-1}$, 0,98 e 0,39 dag.kg-1, 3,97 e 1,28 dag. $\mathrm{kg}^{-1}, 0,56$ e 0,37 dag. $\mathrm{kg}^{-1}$ e 0,37 e 0,29 dag. $\mathrm{kg}^{-1}$, aos 14 e 70 dias de idade, respectivamente. Os conteúdos de proteína bruta obtidos neste trabalho ficaram na faixa de 18 a 25 dag. $\mathrm{kg}^{-1}$, valores muito superiores aos obtidos por Oliveira (1999) no capim tifton 85, aos 14 dias após a sua rebrota. No que se refere a $\mathrm{P}$ e K, os valores ficaram pouco acima dos obtidos pelo mesmo autor no capim tifton 85, aos 70 dias após a rebrota. Entretanto isso não é indicativo de deficiência desses nutrientes na ARL, tendo em vista que o corte foi efetuado aos 45 dias, tempo mais próximo dos 70 dias do que dos 14 dias após a rebrota do capim.

Na Tabela 2 estão apresentados os valores de remoção de N-total, P-total, K e Na pelas plantas, em função das TCOs aplicadas em cada tratamento, calculados utilizando-se os 
valores de concentração média de $\mathrm{N}, \mathrm{P}, \mathrm{K}$ e Na obtidos no segundo corte e de produtividade do capim no período de cultivo (19/08 a 09/12).

Tabela 2. Valores de remoção de N, P, K e Na pelo capim tifton 85 em função das taxas de carga orgânica superficial (TCOs) aplicadas.

\begin{tabular}{|c|c|c|c|c|}
\hline \multirow{2}{*}{ TCOs $\left(k \cdot h a^{-1} \cdot\right.$ dia $\left.^{-1}\right)$} & \multicolumn{4}{|c|}{ Remoção (kg.ha ${ }^{-1}$ ) } \\
\hline & $\mathbf{N}$ & $\mathbf{P}$ & $\mathbf{K}$ & $\overline{\mathrm{Na}}$ \\
\hline 66 & 216 & 24 & 115 & $\overline{4,3}$ \\
\hline 130 & 368 & 34 & 148 & 4,8 \\
\hline 190 & 421 & 41 & 148 & 5,4 \\
\hline 320 & 530 & 53 & 195 & 10,4 \\
\hline 570 & 544 & 61 & 204 & 10,9 \\
\hline Média & 416 & 43 & 162 & 7,2 \\
\hline
\end{tabular}

Considerando-se que os valores apresentados na Tabela 2 são relativos a apenas 112 dias de cultivo do capim, pode se considerar que os resultados obtidos sejam muito significativos, já que em um ano de cultivo nos SACs (mantendo-se mesmo intervalo entre cortes e constante a concentração dos elementos químicos no capim), a remoção de nutrientes pode

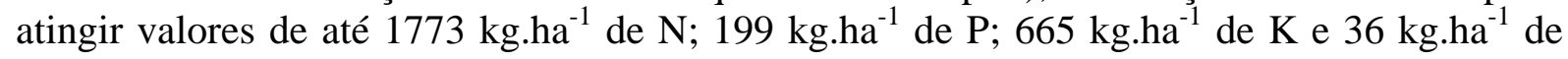
Na.

Tendo em vista que nas maiores TCOs aplicadas não houve problemas para o desenvolvimento do capim, tendo havido até aumento de produtividade, e que nessas condições houve maior remoção de nutrientes e sódio da ARL, pode-se afirmar que taxas de até $570 \mathrm{~kg} \cdot \mathrm{ha}^{-1} \cdot \mathrm{dia}^{-1}$ de DBO podem ser aplicadas visando-se obter eficiente tratamento dessa água residuária.

\section{CONCLUSÕES}

Com base nos resultados obtidos, pode-se concluir que:

- o capim tifton 85 se adaptou bem aos sistemas alagados construídos, com a aplicação da ARL, em TCOs de 66 a 570 kg.ha ${ }^{-1} \cdot \mathrm{dia}^{-1}$, com desenvolvimento axial e bom aprofundamento das raízes, não apresentando problemas fisiológicos ou nutricionais;

- o capim tifton 85 apresentou grande produtividade média de matéria seca e proteína bruta e relativamente grande capacidade de remover nutrientes e sódio da ARL, devendo ser considerado como opção para cultivo em SACs, caso se deseje a produção de forrageiras de grande valor nutricional para alimentação animal;

- TCOs de até $570 \mathrm{~kg} \cdot \mathrm{ha}^{-1}$.dia ${ }^{-1}$ de DBO podem ser aplicadas visando-se obter eficiente tratamento da água residuária de laticínios.

\section{REFERÊNCIAS BIBLIOGRÁFICAS}

BRASIL, M. S.; MATOS, A. T.; SOARES, A. A.; FERREIRA, P. A. Qualidade do efluente de sistemas alagados construídos, utilizados no tratamento de esgoto doméstico. Revista Brasileira de Engenharia Agrícola e Ambiental, Campina Grande, v.9, p. 133-137, 2005. 
BRASIL, M. S.; MATOS, A. T.; SOARES, A. A. Plantio e desempenho fenológico da taboa (Thypha sp.) utilizada no tratamento de esgoto doméstico em sistema alagado construído. Engenharia Sanitária e Ambiental, Rio de Janeiro, v.12, p. 266-272, 2007.

CAMPOS, J. C.; FERREIRA, J. A.; MANNARINO, C. F.; SILVA, H. R.; BORBA, S. M. P. Tratamento do chorume do aterro sanitário de Piraí (RJ) utilizando wetland. In: SIMPÓSIO ÍTALO-BRASILEIRO DE ENGENHARIA SANITÁRIA, 6., 2002, Vitória. Anais... Vitória: ABES, 2002. 1 CD-ROM.

CECATO, U.; BORTOLO, M. Importância econômica das espécies forrageiras na produção animal. Gênero Cynodon. In: II Curso de Produção e Utilização de Pastagens Módulo I. Maringá: CPAF, 1999. p.15-20.

GOMIDE, J. A. Adubação fosfatada e potássica de plantas forrageiras. In: PEIXOTO, A. M.; MOURA, J. C.; FARIA, V. P. (eds.). Pastagens: fundamentos da exploração racional. Piracicaba: FEALQ, 1986. p.155-164.

HUSSAR, G. J. Avaliação do desempenho de leitos cultivados no tratamento de águas residuárias de suinocultura. 2001, 118f. Dissertação (Mestrado em Engenharia Agrícola) - FEAGRI-UNICAMP, Campinas, 2001.

KIEHL, E. J. Fertilizantes orgânicos. São Paulo: Ceres, 1985, 492p.

NOGUEIRA, S. F. Balanço de nutrientes e avaliação de parâmetros biogeoquímicos em áreas alagadas construídas para o tratamento de esgoto, 2003, 137f. Dissertação (Mestrado em Energia na Agricultura) - Centro de Energia Nuclear na Agricultura, Piracicaba, 2003.

OLIVEIRA, M. A. Morfogênese, análise de crescimento e valor nutritivo do capim-tifton 85 (Cynodon ssp) em diferentes idades de rebrota, 1999, 94f. Dissertação (Mestrado em Zootecnia) - DZO/Universidade Federal de Viçosa, Viçosa, 1999.

PAGANINI, W. S. Disposição de esgotos no solo (Escoamento à superfície). São Paulo: AESABESP, 1997. 232p.

POSTIGLIONI, S. R.; Messias, D. C. Potencial forrageiro de quatro cultivares do gênero Cynodon na região de Campos Gerais do Paraná. In: REUNIÃO ANUAL DA SOCIEDADE BRASILEIRA DE ZOOTECNIA. 35., 1998, Botucatu. Anais... Botucatu: SBZ, 1998. p.439-441.

QUEIROZ, F. M. Avaliação de gramíneas forrageiras para o tratamento de águas residuárias da suinocultura. 2000, 91f. Dissertação (Mestrado em Engenharia Agrícola) - DEA/Universidade Federal de Viçosa, Viçosa, 2000.

QUEIROZ, F. M.; MATOS, A. T.; PEREIRA, O. G.; OLIVEIRA, R. A.; LEMOS, A. F. Características químicas do solo e absorção de nutrientes por gramíneas em rampas de tratamento de águas residuárias da suinocultura. Engenharia na Agricultura, Viçosa, v.12, n.2, p. 77-90, 2004. 
SEZERINO, P. H.; PHILIPPI, L. S. Filtro plantado com macrófítas (Wetlands) como tratamento de esgotos em unidades residenciais - Critérios para dimensionamento. In: CONGRESSO BRASILEIRO DE ENGENHARIA SANITÁRIA E AMBIENTAL. 22., 2003, Joinville. Anais... Joinville: ABES/AIDIS, 2003. 1 CD-ROM.

SILVA, D. J. Análise de alimentos (métodos químicos e biológicos). 2.ed. Viçosa: Imprensa Universitária, UFV, 1998. 165p.

SOUSA, J. T.; VAN HAANDEL, A. C.; COSENTINO, P. R. S.; GUIMARÃES, A. V. A. Pós-tratamento de efluente de reator UASB utilizando sistemas "wetlands" construídos. Revista Brasileira de Engenharia Agrícola e Ambiental, Campina Grande, v.4, n.1, p.87-91, 2000.

STEFANUTTI, R.; MATTIAZZO, M. E.; CORAUCCI FILHO, B.; NOUR, E. A. A.; FIGUEIREDO, R. F. Comportamento de duas forrageiras sob diferentes taxas de aplicação de esgotos sanitários utilizando o método do escoamento superficial. In: CONGRESSO BRASILEIRO DE ENGENHARIA AGRÍCOLA. 28., 1999, Pelotas. Anais... Pelotas: UFPEL, 1999. 1 CD-Rom.

VALENTIM, M. A. A. Desempenho de leitos cultivados (“construted wetland") para tratamento de esgoto: contribuições para concepção e operação. 2003, 210f. Tese (Doutorado em Engenharia Agrícola) - FEAGRI - Faculdade de Engenharia Agrícola/UNICAMP, Campinas, 2003.

VARGAS, R. M. E.; MEURER, E. J.; ANGHINONI, I. Mecanismos de suprimento de fósforo, potássio, cálcio e magnésio às raízes de milho em solos do Rio Grande do Sul. Revista Brasileira de Ciência do Solo, Viçosa, v.7, p. 143-148, 1983. 


ISSN = 1980-993X - doi:10.4136/1980-993X
www.agro.unitau.br/ambi-agua
E-mail: ambi-agua@agro.unitau.br
Tel.: (12) 3625-4116

\title{
Fragilidade ambiental e uso do solo da bacia hidrográfica do Córrego Pindaíba, Uberlândia, MG, Brasil (doi:10.4136/ambi-agua.42)
}

\author{
Paula Cristina Almeida de Oliveira ${ }^{1}$; Gelze Serrat de Souza Campos Rodrigues ${ }^{2}$; \\ Silvio Carlos Rodrigues ${ }^{3}$ \\ ${ }^{1}$ Mestranda - Bolsista CNPq - Universidade Federal de Uberlândia \\ E-mail: paulinhageo@yahoo.com.br \\ ${ }^{2}$ Doutora em Geografia - Fundação Estadual do Meio Ambiente \\ E-mail: gelcampos@ig.ufu.br \\ ${ }^{3}$ Prof. Dr. Universidade Federal de Uberlândia. Avenida João Naves de Ávila, 2121, sala 1 H16. \\ CEP: 38.408-100 - Uberlândia, MG \\ E-mail: silgel@ufu.br
}

\section{RESUMO}

Este trabalho estudou a fragilidade ambiental na bacia hidrográfica do córrego Pindaíba por meio da análise das interações dos componentes naturais e antrópicos existentes na área estudada. O objetivo principal desta pesquisa foi identificar e mapear a fragilidade ambiental existente na bacia hidrográfica do Córrego Pindaíba. Os objetivos específicos consistiram na caracterização física e no uso e ocupação do solo da referida bacia hidrográfica. Para a realização da pesquisa foram feitos vários trabalhos de campo em toda a extensão da bacia. Para a confecção da base cartográfica foram utilizadas as cartas topográficas de Taboca e Pau-Furado na escala de 1:25.000. Posteriormente, a base foi vetorizada no software Cartalinx. Os mapas temáticos de geologia, geomorfologia e do uso do solo foram compilados com base no software Arcview 3.2. O mapa de fragilidade também foi criado no software Arcview 3.2, utilizando-se o módulo Geoprocessing Wizard. Para a avaliação da fragilidade do relevo, aplicada ao planejamento ambiental, utilizou-se a metodologia de Ross (1990, 1994) que atribui valores às variáveis do meio ambiente de acordo com suas potencialidades. Como resultado, obteve-se a identificação das principais ações naturais e antrópicas atuantes na bacia e um mapa com as áreas de fragilidade da bacia. Esses resultados indicam que devem ser feitas alterações no uso da terra, adequando-se os tipos de cultura à morfologia da área, levando-se em consideração não só os recursos naturais, mas também as necessidades de seus moradores.

Palavras-chave: Fragilidade ambiental; bacia hidrográfica; planejamento ambiental.

\section{Environmental fragility and land use of the Pindaíba Creek Hydrographic Basin, Uberlândia, MG, Brazil}

\section{ABSTRACT}

This paper presents an environmental analysis of the fragility of Pindaíba Creek Hydrographic Basin using the analysis of natural and anthropic components interactions in the study area. The main objective of this research was to identify and map the environmental fragility of this basin. The specific objectives consisted in the physical characterization of land use and land cover. To accomplish this research, several field campaigns were conducted throughout the basin. The cartographic base was compiled using the Taboca and Pau Furado charts at 1:25.000 scale that were digitized using the software Cartalinx. The thematic maps 
of geology, geomorphology, and land use were compiled using the software Arcview 3.2. The fragility map was also derived based on the software Arcview 3.2 using the tool Geoprocessing Wizard. The methodology developed by Ross $(1990,1994)$ was used for the evaluation of the landscape fragility. This methodology attributes values to environment variables according to their potentialities. Results allowed the identification of major natural and anthropic actions in the study area represented in a map of fragility potential. These results indicate that land use has to be changed in order to adjust to the landscape morphology, considering not only natural resources, but also the needs of the people who live in the study area.

Keywords: environmental fragility; hydrographic basin; environmental planning.

\section{INTRODUÇÃO}

Ao longo da história, o homem evoluiu, acumulando conhecimentos; suas necessidades básicas e curiosidades estimularam o interesse por novas descobertas, por melhor conhecer a si próprio, bem como o universo que o cerca. Entretanto, essa evolução de conhecimentos e aprendizados não trouxe apenas resultados positivos, pois as alterações propiciadas pela aplicação desses novos conhecimentos trouxeram reflexos sobre a forma de funcionamento dos processos naturais.

O meio ambiente tornou-se uma das grandes preocupações da humanidade, que busca aliar a evolução de suas tecnologias com preservação do meio ambiente, visto que a intensidade das ações antrópicas sobre o meio físico acelera a velocidade dos processos naturais, alterando seu comportamento.

Na região do Triângulo Mineiro, a paisagem do Cerrado sofreu significativas alterações com a introdução da moderna agricultura, onde a vegetação natural foi quase totalmente substituída por pastagens e culturas agrícolas. Essa agricultura se tornou uma das atividades que causaram os maiores impactos ambientais no Cerrado, principalmente, pelo fato de essas áreas possuírem um relevo com formas pouco dissecadas e suaves, que facilitam a mecanização agrícola. As transformações na dinâmica da paisagem atingiram também as bacias hidrográficas, onde os eventos de origem antrópica interferem diretamente na dinâmica desse sistema, influenciando sua quantidade e qualidade, devido à intensa pressão causada pela utilização desordenada de seus componentes.

A bacia hidrográfica do córrego Pindaíba se localiza próxima à área urbana de Uberlândia e está situada na direção de expansão do município, fazendo parte da bacia hidrográfica do Rio Araguari (Figura 1).

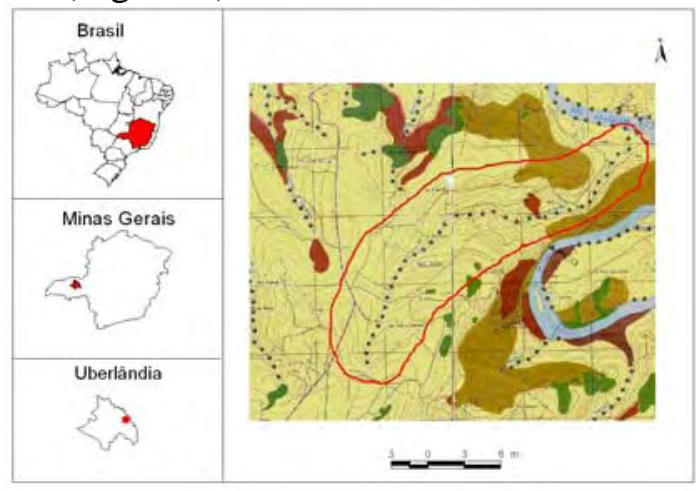

Figura 1. Localização da bacia hidrográfica do córrego Pindaíba. 
A bacia hidrográfica do córrego Pindaíba, além de apresentar uma grande diversidade no uso da terra e dos recursos hídricos, foi afetada parcialmente pela construção do lago da Usina Hidrelétrica Capim Branco I.

A análise geográfica da bacia hidrográfica do córrego Pindaíba torna-se necessária para o entendimento dos processos naturais e suas relações com as atividades antrópicas. Este trabalho justifica-se pela necessidade de compreender a dinâmica natural da referida bacia, tendo em vista os diferentes níveis de intervenção humana nela.

Marques (2001, p.45) diz que "a visão holística da paisagem e a necessidade da compreensão das relações entre o homem, a natureza e a sociedade criaram novas visões e enfoques para as pesquisas ambientais".

As bacias hidrográficas têm se tornado um importante instrumento para o gerenciamento das atividades de uso e conservação dos recursos naturais. Segundo Botelho e Silva (2004, p.184) é consenso entre os pesquisadores que a bacia hidrográfica é o espaço de planejamento e gestão das águas onde se procura compatibilizar as diversidades demográficas, sociais, culturais e econômicas das regiões.

Baccaro et al. (2004) afirmam que a bacia do rio Araguari necessita de um planejamento que vise ao desenvolvimento sustentável das atividades futuras e também ao monitoramento das atividades em andamento.

O objetivo principal desta pesquisa é identificar e mapear a fragilidade ambiental existente na bacia hidrográfica do córrego Pindaíba. Os objetivos específicos consistem na caracterização física e na caracterização do uso e ocupação do solo da referida bacia hidrográfica.

Na elaboração da pesquisa foram consideradas algumas definições relacionadas ao planejamento ambiental, à hidrográfica e à fragilidade ambiental.

Para Santos (2004), o planejamento ambiental surgiu da necessidade da organização do uso da terra em resposta ao aumento da demanda do uso irracional dos recursos energéticos, biológicos, terras e água.

Gomez Orea (1978 apud Botelho, 1995) define planejamento ambiental como sendo "um processo de tomada de decisões que implicam numa reflexão sobre as condições econômicas, sociais e ambientais que orientam qualquer decisão futura".

Já Gallopin (1981 apud Botelho, 1995) define planejamento como uma proposta de implementação de medidas para melhorar a qualidade de vida presente e futura dos seres humanos, pela preservação e do melhoramento do meio ambiente.

Segundo Santos (2004, p.28),o planejamento ambiental fundamenta-se na interação e integração dos sistemas que compõem o ambiente. Tem o papel de estabelecer as relações entre os sistemas ecológicos e os processos da sociedade, das necessidades socioculturais a atividades e interesses econômicos, a fim de manter a máxima integridade possível dos seus elementos componentes.

A bacia hidrográfica ou bacia de drenagem é entendida como uma área da superfície da Terra drenada por um rio principal e seus tributários sendo limitada pelos divisores d’água. (Botelho, 2004).

No Brasil, foi apenas a partir da década de 80 do século passado que se atenuaram os estudos e trabalhos relacionados com a bacia hidrográfica como unidade de planejamento. A bacia de drenagem exerce um importante papel no que se refere à evolução do relevo uma vez que os cursos d'água constituem importantes modeladores da paisagem. (Guerra e Cunha, 1996). 
Nessa perspectiva, planejamento ambiental em bacias hidrográficas torna-se extremamente importante, pois atua como instrumento para minimizar a ação de impactos ambientais decorrentes da ação antrópica.

Para se avaliar o potencial de fragilidade de um determinado ambiente natural é necessário considerar as características genéticas e as atividades antrópicas desenvolvidas nesse ambiente.

Conforme Spörl e Ross (2004, p.40), a identificação dos ambientes naturais e suas fragilidades potenciais e emergentes proporcionam uma melhor definição das diretrizes e ações a serem implementadas no espaço físico territorial, servindo de base para o zoneamento e fornecendo subsídios à gestão do território.

Nesse sentido, Kawakubo et al. (2005, p. 2203) afirmam que:

"O mapa de fragilidade ambiental constitui uma das principais ferramentas utilizadas pelos órgãos públicos na elaboração do planejamento territorial ambiental. O mapeamento da fragilidade ambiental permite avaliar as potencialidades do meio ambiente de forma integrada, compatibilizando suas características naturais com suas restrições."

O mapeamento da fragilidade ambiental em bacias hidrográficas assume um importante papel no que tange ao planejamento territorial, pois orienta o tipo de uso mais adequado, visando à redução dos impactos causados pela ocupação desordenada.

\section{MATERIAIS E MÉTODOS}

Foram realizados vários trabalhos de campo em toda a extensão da bacia, com o objetivo de caracterizá-la, bem como identificar as principais ações naturais e antrópicas.

Para a confecção da base cartográfica foram utilizadas as cartas topográficas de Taboca (SE 22-Z-B-VI-4 NE) e Pau-Furado (SE 22-Z-B-VI-4 NO) na escala de 1:25.000 (IBGE, 1984). Posteriormente, a imagem foi vetorizada no software Cartalinx.

Os mapeamentos temáticos foram derivados de dados secundários elaborados por diversos autores. Como a fonte original era diferente da utilizada neste mapeamento, foram utilizadas as legendas originais com as devidas simplificações devido à necessidade de adaptação ao processo de análise da fragilidade da paisagem. O mapa de geologia foi adaptado do Mapa Geológico do Município de Uberlândia elaborado por Nishiyama (1998) na escala de 1.100.000, o mapa geomorfológico foi adaptado do Mapa Geomorfológico da Bacia do Rio Araguari, realizado por Baccaro et al. (2004). O mapa de uso do solo foi adaptado dos mapas do Plano de Controle Ambiental AHE Capim Branco I (CCBE, 2005).

A confecção dos mapas temáticos foi realizada no software Arcview 3.2. O mapa de fragilidade também foi criado no software Arcview 3.2, utilizando o módulo Geoprocessing Wizard.

Para analisar a fragilidade do relevo, Ross (1990) estabeleceu uma ampliação das concepções de Tricart (1977). Essa nova proposta indica que as unidades ecodinâmicas podem estar em equilíbrio dinâmico ou em desequilíbrio, suprimindo a classificação intergrade proposta por Tricart. Assim, os ambientes são classificados em estáveis, quando estão em equilíbrio dinâmico e classificados em ambientes instáveis, quando estão em desequilíbrio.

Para aplicar a metodologia da fragilidade ao planejamento ambiental, Ross $(1990,1994)$ propõe a classificação dos graus de fragilidade, atribuindo valores a eles, de forma que, quanto maior a classe de fragilidade, maior é o valor atribuído a ela. 


\section{RESULTADOS E DISCUSSÃO}

\subsection{Caracterização física da área de estudo}

Com suas nascentes na Serra da Canastra, a Bacia Hidrográfica do Rio Araguari possui 22.186 km² de área, e abrange o território de 20 municípios de Minas Gerais. O município de Uberlândia situa-se na mesorregião do Triangulo Mineiro e Alto Paranaíba, e segundo dados da Prefeitura Municipal de Uberlândia, de 2006, a população estimada é de 600 mil habitantes, distribuídos em uma área de aproximadamente 4.115 km² (Prefeitura..., 2007).

\subsubsection{Clima}

De acordo com Silva e Assunção (2004), o município de Uberlândia, segundo a classificação de Köppen, está inserido no contexto dos climas do tipo Aw, ou seja, possui inverno seco e verão chuvoso, dominado predominantemente pelos sistemas intertropicais e polares. A temperatura média varia de 19 a $27^{\circ} \mathrm{C}$ e a pluviosidade média fica em torno de $1500 \mathrm{~mm} /$ ano.

\subsubsection{Geologia}

A bacia hidrográfica do córrego Pindaíba apresenta basaltos da Formação Serra Geral, de idade Mesozóica, arenitos da Formação Marília e migmatitos do Embasamento Cristalino (Nishiyama, 1989), de acordo com a Figura 2.

As nascentes estão sobre a Formação Marília. Os basaltos da Formação Serra Geral afloram principalmente às margens do córrego. Essa formação é responsável pelas pequenas corredeiras e quedas d'água existentes ao longo do córrego sendo observado em afloramentos rochosos. Os gnaisses afloram em forma de matacões no médio curso, em uma área de contato com o basalto, e os migmatitos afloram no baixo curso do córrego, em uma área de relevo mais íngreme.

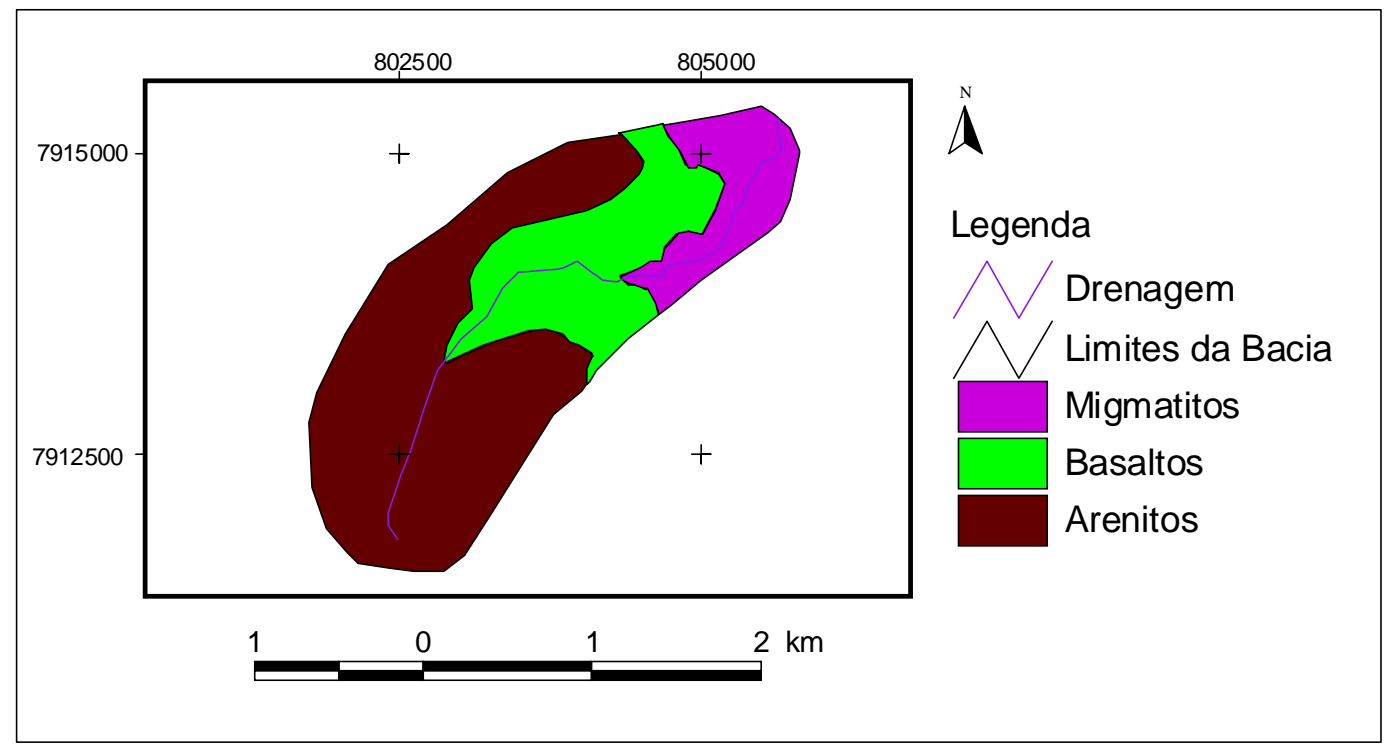

Figura 2. Mapa Geológico da bacia hidrográfica do córrego Pindaíba. Autor: Oliveira (2006).

\subsubsection{Geomorfologia}

Baccaro (1989) afirma que a área do município de Uberlândia está classificada em três categorias: área de relevo dissecado, que corresponde às áreas com topos aplainados entre 700 
e 900 metros, áreas com relevo intensamente dissecado, que apresenta uma porção mais elevada com topos aplainados, pertencentes a uma grande chapada que se estende por toda a região e áreas de relevo com topo plano, que correspondem a uma área de topos planos e largos e vales espaçados entre si com pouca ramificação de drenagem e vertentes entre 3 e $5^{\circ}$ de inclinação.

Segundo a Figura 3, a bacia hidrográfica do córrego Pindaíba está inserida na Unidade Morfoestrutural da Bacia Sedimentar do Paraná, na unidade geomorfológica do Cânion do Araguari, sendo caracterizada como uma área de relevo intensamente dissecado, apresentando vertentes abruptas e forte entalhamento dos vales e relevos bem encaixados.

A unidade Cânion do Araguari apresenta um forte entalhamento dos vales e das vertentes, além de perfis de vertentes com rupturas côncavas, segmentos convexos, paredões rochosos e terraços fluviais.

O córrego Pindaíba não possui afluentes, ele nasce em uma área de patamares planos, num vale amplo, que se torna estreito com presença de cachoeiras e corredeiras, após entrar na área de cânions. Na área de estudo, os terraços são utilizados para produção agrícola, principalmente a banana e hortifrutigranjeiros, e as áreas mais inclinadas são utilizadas para pastagens.

Os sulcos e ravinas estão presentes ao longo de toda a bacia, como também a ocorrência de assoreamento das margens do córrego, principalmente próximo à sua foz (Oliveira, 2006).

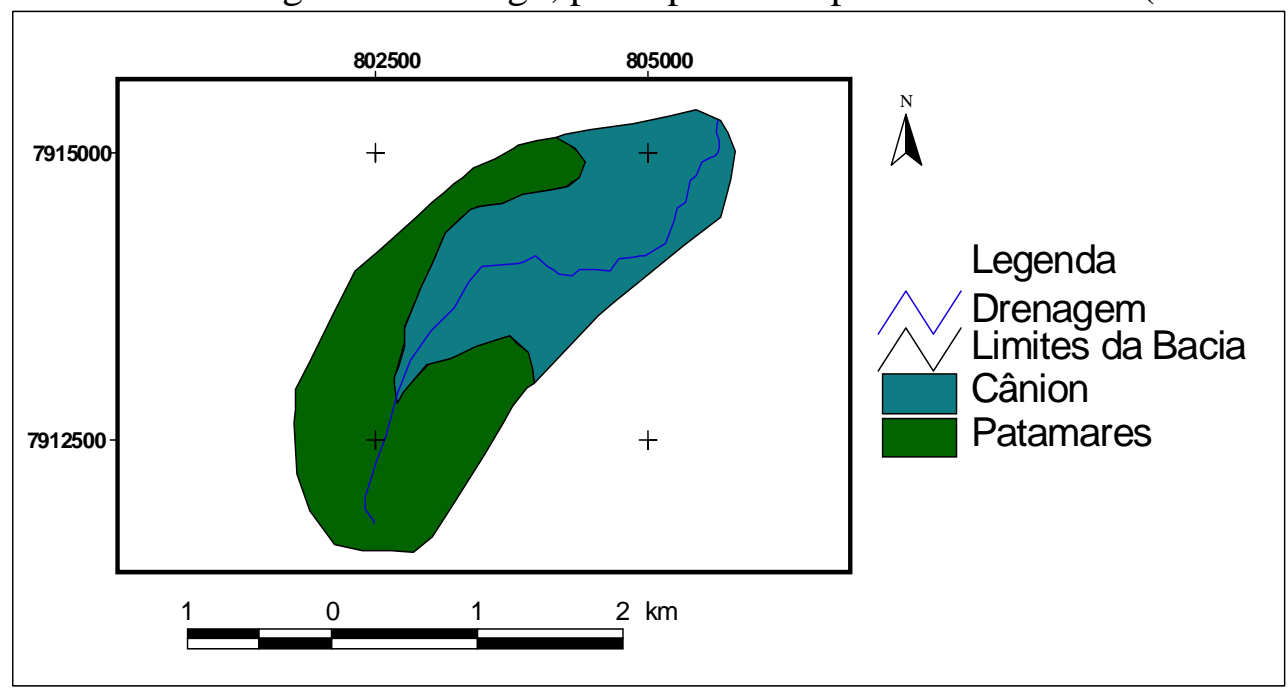

Figura 3. Mapa Geomorfológico da bacia hidrográfica do córrego Pindaíba. Autor: Oliveira (2006).

\subsubsection{Cobertura Vegetal}

A cobertura vegetal do município está inserida nos Domínios Morfoclimáticos dos Cerrados, (Ab’Sáber, 2003) e, segundo Giffoni e Rosa (2007), os principais tipos fisionômicos existentes são mata ciliar ou galeria, cerrado, campo limpo, campo sujo e cerradão.

A cobertura vegetal da bacia do córrego Pindaíba apresenta um estado de avançada degradação. A vegetação típica do Cerrado foi quase totalmente extinta, dando lugar à pastagem e culturas temporárias de hortifrutigranjeiros. Nas margens do córrego, estão presentes, de forma descontínua, espécies de médio e grande porte, da Mata de Galeria e Mata Mesofítica, intercaladas com pastagens e culturas.

Os trechos com vegetação em regeneração e Mata Mesofítica se encontram sob as áreas de cânion. Mais expressivamente nas áreas de patamares se concentram a produção de 
berinjela e quiabo; culturas anuais como banana e cana-de-açúcar e pastagem melhorada, segundo a Figura 4.

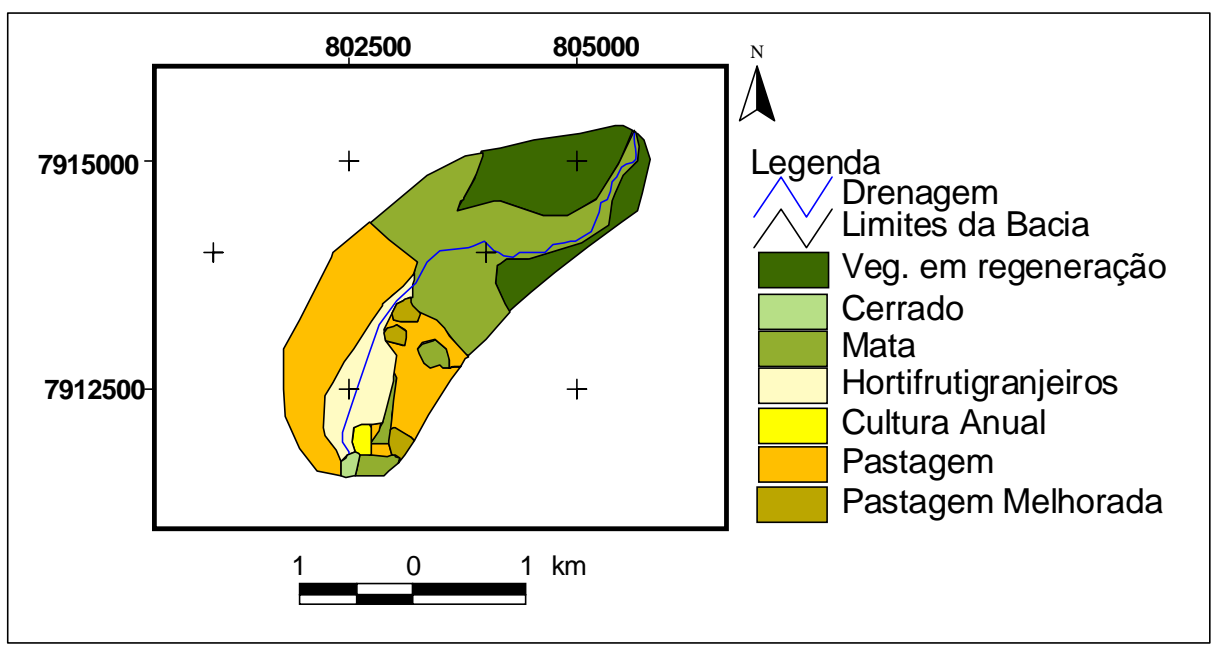

Figura 4. Mapa de Uso e Ocupação da Terra da bacia hidrográfica do córrego Pindaíba.

Fonte: CCBE (2005). Autor: Oliveira (2006).

\subsubsection{Solos}

Os solos existentes no município de Uberlândia são o Latossolo Vermelho-Amarelo (LVa), o Latossolo Vermelho Distrófico (LVd), o Gleissolo (Gxbe), o Argissolo VermelhoAmarelo eutrófico (Pvae) e o Cambissolo (Cxd1) (Embrapa, 1982 apud Atehortúa, 2004).

\subsubsection{Bacia Hidrográfica do Córrego Pindaíba}

A bacia hidrográfica do córrego Pindaíba apresenta níveis de degradação bastante elevados.

A nascente principal do córrego está localizada em área antropizada, situada sob as raízes de uma gameleira, e se encontra parcialmente cercada e coberta por telhas para evitar o pisoteio do gado e de animais de pequeno porte. As nascentes secundárias se formam sob um campo hidromórfico, com vegetação rasteira e resquícios de pastagem e milho, o que significa que a área já foi cultivada.

No geral, a área das nascentes apresenta um estado de degradação avançado. A nascente principal apresenta indícios de culturas de pequeno porte, e o solo apesar de possuir gramíneas nas margens é exposto. A nascente principal foi parcialmente canalizada para abastecer a sede da Fazenda Pindaíba. O campo hidromórfico que abriga as nascentes secundárias também apresenta vestígios de culturas e a vegetação circundante às nascentes é pouco expressiva

Logo após as nascentes, o córrego apresenta um longo trecho de vegetação secundária de médio porte. Ambas as margens são ocupadas por culturas como chuchu, berinjela, quiabo, banana e algumas árvores frutíferas (Figura 5). Nessa propriedade, existe o sistema de rotação de culturas, sendo que a banana é produzida em grande escala. A água é bombeada e consumida pelas atividades da fazenda. Outra atividade desenvolvida nessa propriedade é a criação de gado. 


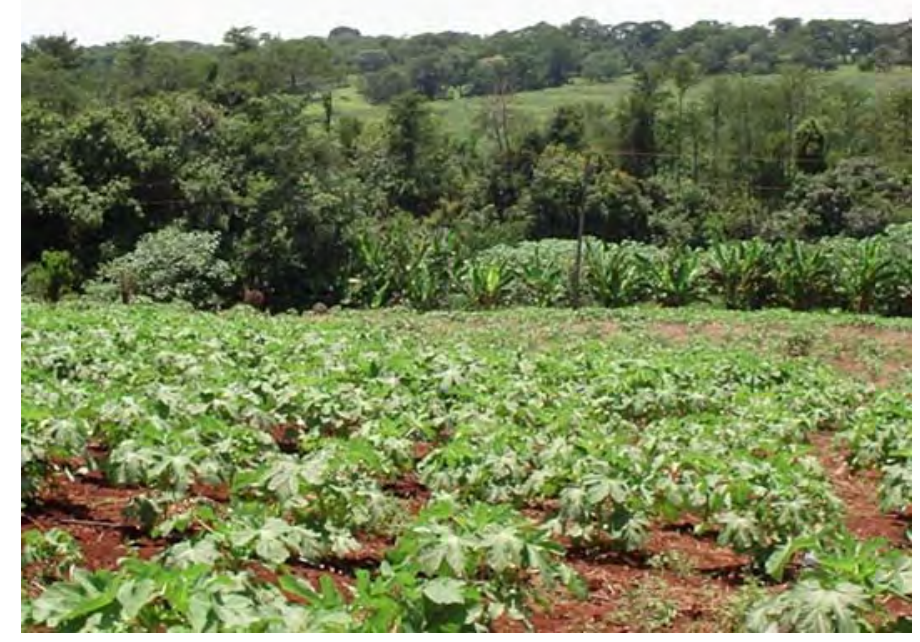

Figura 5. Plantação de quiabo, seguida do bananal em segundo plano e mata ciliar ao fundo.

Autor: Oliveira (2006).

Nas terras da Fazenda Tenda e Laje, o córrego já apresenta um vale fechado e o relevo mais inclinado. A superfície é recoberta por uma escassa camada de serrapilheira e algumas árvores frutíferas. O fato de estar desprotegida favorece a erosão e o transporte de sedimentos para o córrego, provocando assoreamento. Nessa fazenda, o córrego apresenta duas represas artificiais para abastecimento da fazenda e irrigação da lavoura. Na saída de água da primeira represa, o curso do córrego foi desviado e, posteriormente, canalizado, sendo que no curso desviado existe uma cachoeira artificial.

A Fazenda Laje apresenta o trecho do córrego mais protegido. As margens abrigam uma vegetação densa com árvores de médio e grande porte. Os solos são latossolos vermelhos cobertos por serrapilheira. O córrego apresenta trechos com afloramentos de basalto, onde aparecem corredeiras e quedas de pequeno porte, com boa vazão.

Nessa área, o relevo é mais inclinado e o solo é coberto por pastagens, visto que a atividade principal da fazenda é a criação de gado. A água é captada por uma bomba d'água para abastecimento da fazenda. Devido à declividade do terreno e à cobertura vegetal representada por pastagens, em alguns trechos próximos às margens do córrego aparecem alguns pontos com ravinas.

Na divisa entre a Fazenda Laje e a fazenda subseqüente, também denominada Pindaíba, a dinâmica do córrego já foi alterada. Existe um barramento do córrego, formando uma cachoeira artificial feita para a retirada de água com auxilio de uma bomba (Figura 6). A margem esquerda apresenta vegetação de pequeno porte e indícios de pisoteio de gado.

A vegetação ciliar da margem direita foi retirada, dando lugar à pastagem e à plantação de banana. 


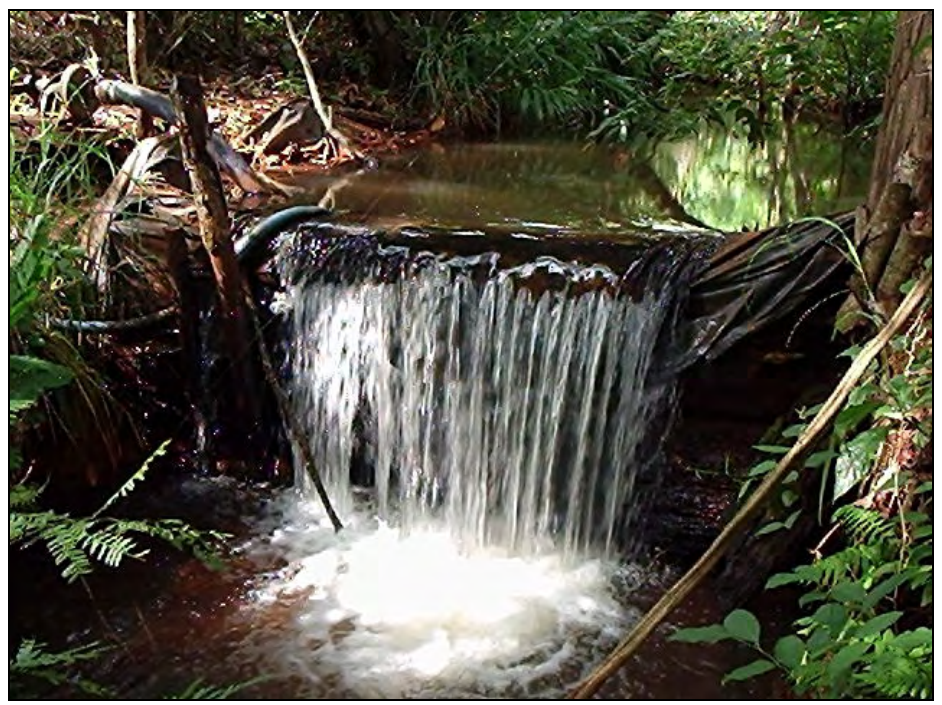

Figura 6. Queda artificial feita para captação de água.

Autor: Oliveira (2006).

A jusante, na Fazenda Nossa Senhora da Abadia, o córrego apresenta vários afloramentos de basalto, e uma queda natural de aproximadamente seis metros de altura. A vegetação ciliar apresenta dossel superior a 10 metros de altura e o córrego se apresenta bastante assoreado e suas margens apresentam indícios de pisoteio de animais. Após a cachoeira, o curso do córrego foi desviado. O curso artificial abastece duas represas, uma para abastecimento e outra destinada à criação de peixes (Figura 7). Posteriormente, o curso desviado se encontra com o canal normal.

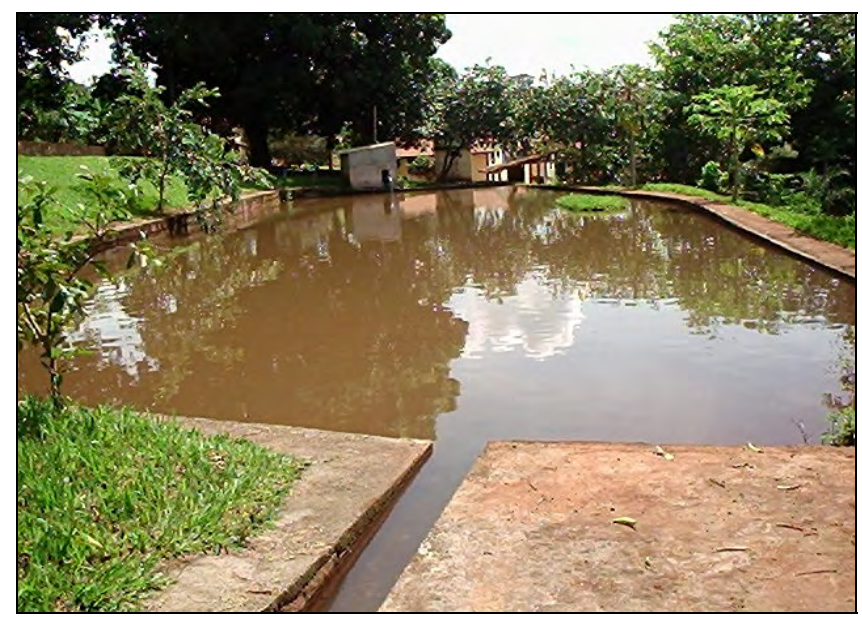

Figura 7. Represamentos formados a partir do curso desviado do córrego.

Autor: Oliveira (2006).

O curso normal do córrego também abastece duas represas, que por sua vez estão bastante assoreadas. Suas margens encontram-se bastante degradadas, com solo exposto e algumas arvores frutíferas na margem esquerda, e vegetação rasteira e solo exposto na margem direita.

No médio curso, na fazenda também denominada Pindaíba, o córrego foi alterado para abastecer duas represas artificiais que são utilizadas para irrigação. A atividade principal nessa propriedade é o cultivo de banana, além de maracujá e chuchu. O relevo é bastante 
inclinado, os solos possuem vegetação rasteira e o córrego apresenta ainda algumas corredeiras e árvores de médio porte e bambuzais. Por se tratar de uma área de contato, apresenta vários afloramentos de basaltos e gnaisses.

No curso inferior, próximo à sua foz, o córrego apresenta o maior nível de degradação. Nesse local, a vegetação natural é bastante escassa, com poucas árvores, onde predominam as pastagens. O relevo se apresenta mais dissecado, com formas convexas, aflorando migmatitos do Embasamento Pré-Cambriano.

A formação do lago da usina hidrelétrica Capim Branco I provocou alterações na dinâmica do córrego. A foz, que se encontrava em elevado grau de degradação, com a vegetação natural substituída por pastagem e erosão nas margens, teve alguns metros submersos pela água do lago. Porém depois da formação do lago, as margens continuam sem a proteção da vegetação natural, cobertas apenas por pastagem. Nas margens do córrego é constante a presença de animais.

\subsection{Fragilidade Ambiental}

Para a determinação das classes de fragilidade ambiental, foram consideradas as variáveis geologia, geomorfologia e uso da terra, em que valores de 1 a 5 foram atribuídos a eles, de acordo com seu grau de proteção (Rodrigues, 2000). Quanto maior a classe de fragilidade, que está diretamente ligada a potencialidade da variável de potencializar processos erosivos, maior é o valor atribuído a ela.

Em relação à geologia, a Formação Serra Geral foi classificada como tendo uma baixa fragilidade, sendo que o valor atribuído a ela foi 1. A Formação Marilia possui valor 2 por ter fragilidade considerada baixa - média. O Embasamento Cristalino possui a fragilidade média, com valor 3.

No que se refere às unidades geomorfológicas, os patamares são identificados como áreas de média fragilidade, com valor 3 e as áreas de Cânion são identificadas como áreas de fragilidade alta, de valor 5 . Nesse caso considerou-se que as maiores inclinações potencializam a ocorrência de processos erosivos e movimentos de massa.

Quanto ao potencial de fragilidade propiciado pela vegetação, as áreas ocupadas com mata e cerrado tiveram a fragilidade classificada como baixa, com valor 1. Já as áreas com vegetação em regeneração possuem fragilidade baixa - média, com valor 2 . As áreas com cultura anual e pastagem melhorada apresentam fragilidade média com valor 3 . As áreas de pastagem são de fragilidade média alta, valor 4. Já as áreas ocupadas com hortifrutigranjeiros possuem fragilidade alta com valor 5 . Nesse caso considera-se que a maior cobertura vegetal propicia a proteção à superfície, e que a maior proximidade com as condições naturais incorporam maior proteção em relação às áreas que sofreram atuação antrópica.

Foi estabelecido que a classe de fragilidade baixa possui valores entre 4 e 5 , já a classe de fragilidade baixa - média possui valores entre 6 e 7, a classe de fragilidade média possui valores entre 8 e 9 , a classe de fragilidade media - alta possui valores entre 10 e 11 e a classe de fragilidade alta possui valores entre 12 e 13 (Tabela 1). 
Tabela 1. Análise Geral das Classes de Fragilidade da Bacia Hidrográfica do Córrego Pindaíba.

\begin{tabular}{ccccc}
\hline Unidade Geológica & Unidade Geomorfológica & Uso da Terra & Valor & $\begin{array}{c}\text { Classe de } \\
\text { Fragilidade }\end{array}$ \\
\hline Formação Marilia & Patamares & Mata & 5 & Baixa \\
Formação Marilia & Patamares & Vegetação em & 6 & Baixa - média \\
Formação Marilia & Regeneração & 7 & Baixa - média \\
Formação Marilia & Patamares & Pastagem Melhorada & 7 & Baixa - média \\
Formação Marilia & Cânion & Mata & 7 & Baixa - média \\
Embasamento Cristalino & Cânion & Cerrado & 7 & Baixa - média \\
Formação Serra Geral & Patamares & Mata & 6 & Baixa - média \\
Formação Serra Geral & Patamares & Mata & 7 & Baixa - média \\
Formação Marilia & Patamares & Vegetação em & Regeneração & Média \\
Formação Marilia & Patamares & Pastagem & 8 & Média \\
Formação Serra Geral & Patamares & Hortifrutigranjeiros & 9 & Média \\
Formação Serra Geral & Patamares & Pastagem Melhorada & 8 & Média \\
Formação Marilia & Patamares & Pastagem & 9 & Média \\
Formação Marilia & Cânion & Veg. em Regeneração & 8 & Média \\
Embasamento Cristalino & Cânion & Cultura Anual & 9 & Média \\
Formação Marilia & Patamares & Vegetação em & 9 & Média \\
Formação Marilia & Cânion & Regeneração & 9 & Pastagem Melhorada \\
Formação Marilia & Cânion & Pastagem & 10 & Média - alta \\
Formaçâo Serra Geal & Cânion & Hortifrutigranjeiros & 11 & Média - alta \\
\hline For Olivén & Patamares & Hortifrutigranjeiros & 10 & Média-Alta \\
\hline
\end{tabular}

Fonte: Oliveira (2006).

Para se chegar ao resultado final das classes de fragilidade existentes na bacia foram realizados cruzamentos entre todas as unidades e, posteriormente, a somatória dos valores atribuídos a essas unidades. Dessa forma, identificaram-se quatro classes de fragilidade na bacia hidrográfica do córrego Pindaíba (Figura 8).

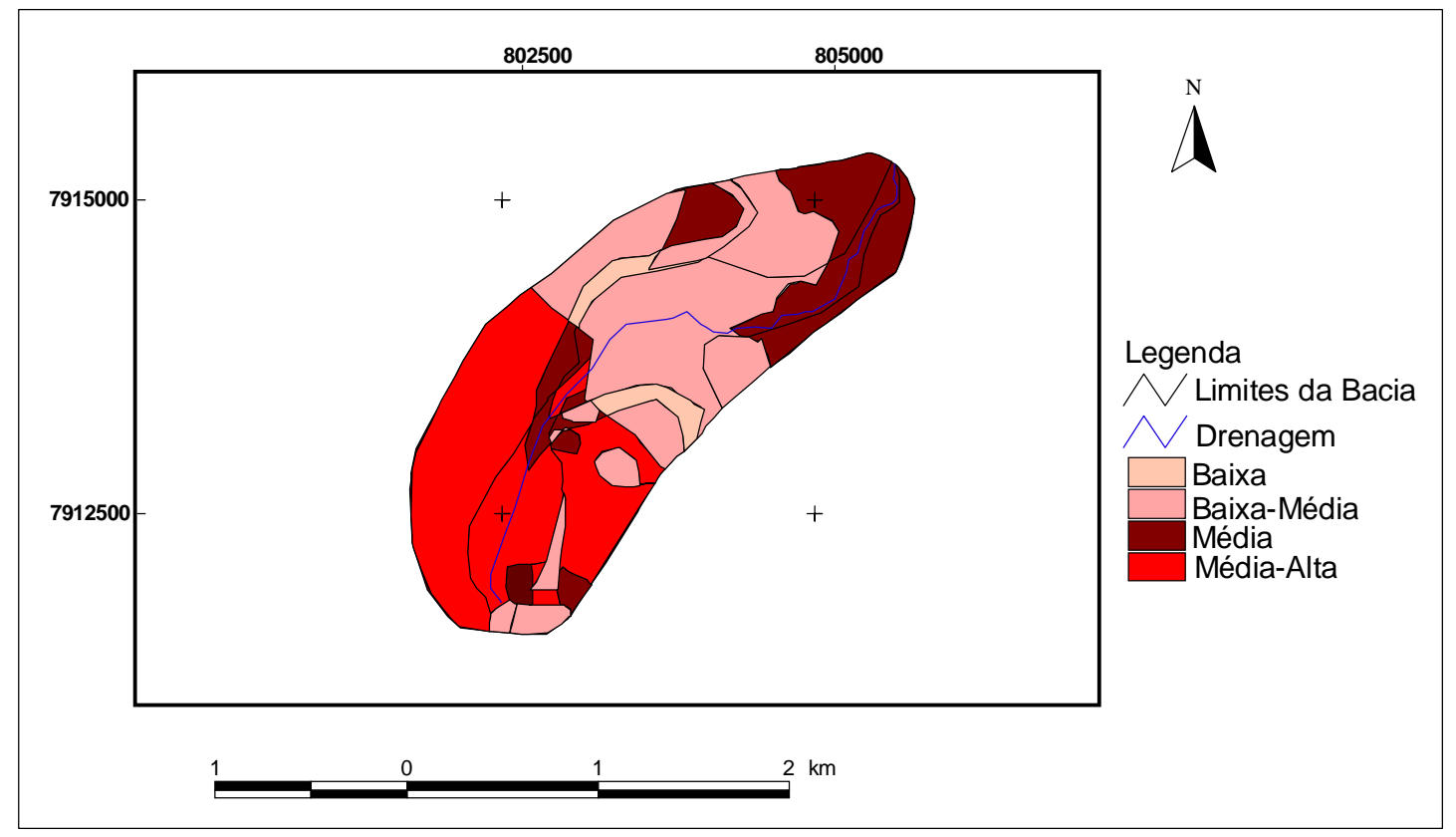

Figura 8. Fragilidade do Relevo da Bacia Hidrográfica do Córrego Pindaíba.

Autor: Oliveira (2006). 
A bacia hidrográfica do córrego Pindaíba apresenta cenários diferentes de degradação. Os agentes responsáveis por essa degradação partem de ações isoladas, que, em conjunto provocam impactos maiores, alterando a configuração natural da bacia.

A área das nascentes devem sofrer um processo de adequação às normas ambientais, como indica o parágrafo II do artigo $3^{\circ}$ do Código Florestal Brasileiro (Lei 4.771/65) (Brasil, 1965), que considera Área de Preservação Permanente o raio mínimo de 50 metros de largura que circunda as nascentes e olhos d'água, ainda que intermitentes. Além de serem cercadas para garantir a recuperação, essa área deve ser reflorestada com espécies nativas para que a cobertura vegetal seja retomada, e assim atue como um freio natural que impeça a compactação do solo, bem como a erosão pluvial, e ainda proteja as margens do córrego, evitando o assoreamento e garantindo a preservação desse curso d'água. As espécies podem ser conseguidas no Horto Florestal da Secretaria de Meio Ambiente da Prefeitura Municipal de Uberlândia, gratuitamente.

Um outro problema comum em toda a extensão da bacia são os represamentos e os desvios no curso do córrego para irrigação das lavouras. Esse fato pode ser considerado o mais relevante causador de degradação na bacia, uma vez que modifica a vazão natural do córrego. Cada propriedade deve utilizar a água de forma sustentável, respeitando o regime natural do córrego. Isso inclui a retomada do curso normal do córrego, reduzindo o número de barragens ao longo do canal.

A bacia hidrográfica do córrego Pindaíba deve ser explorada de acordo com suas potencialidades e sua capacidade de uso, visando a um constante equilíbrio do meio natural em detrimento das atividades antrópicas.

Várias ações devem ser realizadas para que o córrego se mantenha preservado. Porém tais ações devem ser tomadas e realizadas em conjunto por todos aqueles que utilizam a bacia, uma vez que é do interesse de todos preservá-la.

Conforme previsto no parágrafo IX do artigo $2^{\circ}$ do Comitê da Bacia Hidrográfica do Rio Araguari (Minas Gerais, 1998), sugere-se a criação do Comitê da Bacia Hidrográfica do Córrego Pindaíba, que contará com representantes do poder público, usuários da bacia e interessados, que serão responsáveis pela criação de projetos para a utilização sustentável da bacia, a fiscalização e aplicação da legislação vigente.

\section{CONCLUSÕES}

Este diagnóstico ambiental procurou compreender a dinâmica da bacia hidrográfica do córrego Pindaíba pelos processos naturais e das ações antrópicas. Salienta-se que as intervenções humanas são responsáveis pelo alto nível de alteração e degradação do meio natural. Em diferentes pontos da bacia, o uso do solo e os impactos por ele gerados são os mesmos.

A identificação das áreas com maior fragilidade do relevo indica que devem ser feitas alterações no uso da terra, adequando os tipos de cultura à morfologia da área. Assim, a bacia hidrográfica do córrego Pindaíba necessita de um planejamento que abranja não só os recursos naturais, mas também que inclua as necessidades de seus moradores.

Nos patamares, sugere-se a inserção das culturas consideradas com média, média-alta e alta fragilidade, como cultura anual, pastagem melhorada, pastagem e hortifrutigranjeiros devido também à feição geológica em que essa unidade está inserida. Nas áreas de cânion devido às formas mais aguçadas, sugere-se para o uso da terra mata e cerrado, que são consideradas de baixa e baixa-média fragilidade. As pequenas áreas atualmente ocupadas por 
pastagem e hortifrutigranjeiros nessa feição geomorfológica devem ser destinadas a áreas onde a vegetação natural possa se regenerar.

\section{REFERÊNCIAS}

AB'SABER, Aziz Nacib. Os domínios de natureza no Brasil: potencialidades paisagísticas. São Paulo: Ateliê Editorial, 2003. 160p.

ATEHORTÚA. M. R. Análise comparativa da geomorfológica, solos e uso da terra nos Municípios de Puerto López (Colômbia) e Uberlândia (Brasil). 2004. 180f. Dissertação (Mestrado em Geografia) - Instituto de Geografia, Universidade Federal de Uberlândia, Uberlândia. 2004.

BACCARO.C. A. D. Estudos geomorfológicos do Município de Uberlândia. Revista Sociedade e Natureza, Uberlândia, n. 1, v.1. p. 17-21, junho 1989.

BACCARO, C. A. D.; MEDEIROS, S. M.; FERREIRA, I. L.; RODRIGUES, S. C. Mapeamento geomorfológico da Bacia do Rio Araguari. In: LIMA, S. C; SANTOS, R. J. (Orgs.) Gestão ambiental da Bacia do Rio Araguari: rumo ao desenvolvimento sustentável. Uberlândia: Universidade Federal de Uberlândia, Instituto de Geografia. Brasília: CNPq, 2004. p. 1-20.

BOTELHO, R. G. M. Planejamento ambiental em microbacia hidrográfica. In: GUERRA, Antônio José Teixeira; CUNHA, Sandra Baptista. (Orgs.). Erosão e conservação de solos: conceitos temas e aplicações. Rio de Janeiro: Bertrand Brasil, 1995. p. 269-293.

BOTELHO R. G. M.; SILVA, A. S. da. Bacia hidrográfica e qualidade ambiental. In: VITTE, Antonio Carlos; GUERRA, Antonio José Teixeira. Reflexões sobre a geografia física no Brasil. Rio de Janeiro: Bertrand Brasil, 2004. p. 153-188.

BRASIL. Lei 4.771, de 15 de setembro de 1965. Institui o Novo Código Florestal. Disponível em: < http://www.planalto.gov.br/CCIVIL/LEIS/L4771.htm>. Acesso em: junho 2007.

MINAS GERAIS. Decreto 39.912 de 22 de Setembro de 1998. Institui o Comitê de Bacia Hidrográfica do Rio Araguari. Disponível em: <http://aguas.igam.mg.gov.br/ 2008nacbh/comites/cbhpn2/decreto.pdf> Acesso em: junho 2007.

BRASIL. Decreto 39.912 de 22 de Setembro de 1998. Institui o Comitê de Bacia Hidrográfica do Rio Araguari.

CONSÓRCIO CAPIM BRANCO ENERGIA. Planos de controle ambiental AHE Capim Branco I. Monitoramento do uso e ocupação do solo, cobertura vegetal e fontes de degradação dos recursos hídricos - Relatório de conclusão da fase II (Mapeamento simultâneo às obras). Araguari: CCBE, set. 2005. 57 p.

GIFFONI, S. N.; ROSA, R. Mapeamento dos remanescentes da cobertura vegetal natural do Município de Uberlândia no ano de 2002. In: SIMPÓSIO BRASILEIRO DE SENSORIAMENTO REMOTO, 13., 21 a 26 de abril de 2007, Florianópolis. Anais... São José dos Campos: INPE, 2007. p. 1679-1686. 1 CD -ROM

GUERRA, A. J. T.;CUNHA, S. B. Degradação ambiental. In: GUERRA, A. J. T.;CUNHA, S. B. (orgs.). Geomorfologia e meio ambiente. Rio de janeiro: Bertrand Brasil, 1996. 
INSTITUTO BRASILEIRO DE GEOGRAFIA E ESTATÍSTICA. Cartas topográficas. Folhas SE 22-Z-B-VI-4 NE; SE 22-Z-B-VI-4 NO. Rio de Janeiro: IBGE, 1984. 1 mapa. Escala 1:25.000.

KAWAKUBO, F. S.; MORATO, R. G.; CAMPOS, K. C.; LUCHUARI, A.; ROSS, J. L. S. Caracterização empírica da fragilidade ambiental utilizando geoprocessamento. In: SIMPÓSIO BRASILEIRO DE SENSORIAMENTO REMOTO, 12., 16 a 21 de abril 2005, Goiânia. Anais... São José dos Campos: INPE, 2005. p. 2203-2210. 1 CD -ROM

MARQUES, A. S. Ciência geomorfológica. In: CUNHA, Sandra Baptista da; GUERRA, Antonio José Teixeira. Geomorfologia, uma atualização de bases e conceitos. Rio de Janeiro: Bertrand Brasil, 2001. p. 23-50.

NISHIYAMA, L. Geologia do Município de Uberlândia e áreas adjacentes. Revista Sociedade e Natureza, Uberlândia, n. 1, v. 1, p. 9-16, junho 1989.

NISHIYAMA, L. Procedimentos de mapeamento geotécnico como base para análises e avaliações ambientais do meio, em escala 1:100000: aplicação no município de Uberlândia - MG. 1998. Tese (Doutoramento em Geotécnica) - FFLCH, Universidade de São Paulo, São Paulo, 1998.

OLIVEIRA, P. C. A. de. Diagnóstico ambiental e análise da fragilidade do relevo da Bacia Hidrográfica do Córrego Pindaíba, Uberlândia - Minas Gerais. 2006. Monografia (Graduação em Geografia) - Instituto de Geografia, Universidade Federal de Uberlândia, Uberlândia, 2006.

PREFEITURA MUNICIPAL DE UBERLÂNDIA. Banco de dados integrados - BDI. 2007. Disponível em: <http://www3.uberlandia.mg.gov.br/home_bdi.php>. Acesso em: jun. 2007.

RODRIGUES, Silvio Carlos. Análise da fragilidade do relevo: abordagem empíricoexperimental. Revista Sociedade e Natureza, Uberlândia, n. 12, p. 167-189, jan./jun. 2000.

ROSS, J. L. S. Geomorfologia: ambiente e planejamento. 5. ed. São Paulo: Contexto, 1990. $84 \mathrm{p}$.

ROSS, J. L. S. Análise empírica da fragilidade dos ambientes naturais e antropizados. Revista do Depto de Geografia - FFLCH-USP, São Paulo, n. 8, p. 63-74, 1994.

SANTOS, R. F. dos. Planejamento ambiental: teoria e prática. São Paulo: Oficina de Textos, 2004. 184 p.

SILVA, E. M.; ASSUNÇÃO, W. L. O Clima na cidade de Uberlândia. Revista Sociedade e Natureza, Uberlândia, n. 30, v. 16, p. 91-107, jun. 2004.

SPÖRL, C.; ROSS, J. L. S. Análise comparativa a fragilidade ambiental com aplicação de três modelos. Revista GEOUSP - Espaço e Tempo, São Paulo, n. 15, p.39-49, 2004.

TRICART, J. Ecodinâmica. Rio de Janeiro: FIBGE / SUPREN, 1977. 


ISSN = 1980-993X-doi:10.4136/1980-993X
www.agro.unitau.br/ambi-agua
E-mail: ambi-agua@agro.unitau.br
Tel.: (12) 3625-4116

\title{
Calibração de sondas TDR em condições de laboratório
}

(doi:10.4136/ambi-agua.43)

\author{
Dione Inês Christ Milani' ${ }^{1}$ Maria Hermínia Ferreira Tavares²; Clementina \\ Scherpinski ${ }^{3}$ \\ ${ }^{1}$ Faculdades Assis Gurgaz - Mestre em Engenharia Agrícola \\ E-mail: dioneicmilani@hotmail.com \\ ${ }^{2}$ Universidade Estadual do Oeste do Paraná - Docente do Programa de Pós-Graduação em Engenharia \\ Agrícola \\ E-mail: mhstavar@certto.com.br \\ ${ }^{3}$ Universidade Estadual do Oeste do Paraná - Mestre em Engenharia Agrícola \\ E-mail: scherpinski@unioeste.br
}

\section{RESUMO}

Dentre os métodos indiretos para a determinação da umidade volumétrica do solo $\left(\theta_{\mathrm{v}}\right)$, a técnica da Reflectometria no Domínio do Tempo (TDR) tem recebido crescente atenção. Como toda técnica, apresenta vantagens e desvantagens, entre elas a maior desvantagem é a necessidade de calibração. No estudo aqui apresentado, foram obtidos valores da constante dielétrica aparente do solo $\left(\mathrm{K}_{\mathrm{a}}\right)$ e umidade volumétrica $\left(\theta_{\mathrm{v}}\right)$ para um Latossolo Vermelho, por meio de um experimento de laboratório e utilizadas dezessete sondas de TDR, sendo duas sondas originais e quinze confeccionadas pela própria equipe. $\mathrm{O}$ trabalho objetivou: a) calibrar as dezessete sondas, em condições de laboratório, comparando-se seis modelos de regressão para cada sonda; b) verificar a viabilidade do emprego das sondas manufaturadas. Constatou-se que o melhor ajuste de regressão para todas as sondas foi a equação polinomial cúbica e que as sondas montadas pela equipe apresentaram desempenho semelhante ao das sondas originais.

Palavras-chave: constante dielétrica aparente; calibração; Reflectometria no Domínio do Tempo; umidade volumétrica do solo.

\section{TDR probes calibration in laboratory conditions}

\section{ABSTRACT}

Among the indirect methods to evaluate the volumetric soil water content $\left(\theta_{v}\right)$, the Time Domain Reflectometry (TDR) technique is receiving growing attention. As any technique, it presents advantages and disadvantages: the most serious disadvantage is the calibration necessity. At the present study, values of apparent dielectric constant $\left(\mathrm{K}_{\mathrm{a}}\right)$ and volumetric water content $\left(\theta_{\mathrm{v}}\right)$ for a Red Latosol were obtained in a laboratory experiment, using seventeen probes of TDR, from which two were original and fifteen were manufactured by the staff. This study aimed: a) to calibrate the seventeen probes, in laboratory conditions, comparing six regression models for each probe; b) to verify the viability to use the manufactured probes. It was found out that the best regression model was the cubic polynomial model and that the manufactured probes presented performances comparable to the original ones.

Keywords: apparent dielectric constant; calibration; Time Domain Reflectometry; volumetric soil water content. 


\section{INTRODUÇÃO}

Existem vários métodos indiretos para a determinação do conteúdo da água do solo, dentre eles a TDR (Reflectometria no Domínio do Tempo), pela qual o tempo de trânsito de uma onda eletromagnética por uma haste colocada no solo fornece a constante dielétrica aparente do solo $\left(K_{a}\right)$, dada pela Equação 1:

$$
K_{a}=\left(\frac{t \times c}{2 L}\right)^{2}
$$

na qual $t$ é o tempo de deslocamento (em s) da onda eletromagnética, $c$ é a velocidade da luz $\left(3.0 \times 10^{8} \mathrm{~m} / \mathrm{s}\right)$ e $L$ é o comprimento da haste da sonda $(\mathrm{em} \mathrm{m})$.

Existem vantagens e desvantagens no uso da técnica da TDR: para Tommaselli e Bacchi (2001), a vantagem é a rapidez na obtenção da umidade e a desvantagem é a dependência do tipo de solo (mineral ou orgânico), materiais magnéticos e a calibração trabalhosa. Os fatos das sondas TDR poderem ser acopladas a multiplexadores (Coelho et al., 2006) ou a outros tipos de sensores, tais como penetrômetros (Manieri et al., 2007), constituem excepcional vantagem da técnica da TDR. Segundo Noborio (2001), a TDR proporciona a repetibilidade das leituras, a não destruição da região amostrada, a não emissão de radiações ionizantes, portabilidade e facilidade de acoplamento a dispositivos coletores de dados, tendo como desvantagem o custo elevado.

Para diminuir os custos, sondas nacionais têm sido desenvolvidas. Villwock et al. (2004) construíram e avaliaram sondas, em condições de campo e laboratório, mostrando a boa qualidade das sondas montadas pela equipe local, a um custo nove vezes menor do que o custo das sondas originais importadas. Outra iniciativa para a diminuição de custos foi o desenvolvimento de aplicativos nacionais para a aquisição e gerenciamento dos dados (Tavares et al., 2006), uma vez que os programas importados apresentam alto custo.

Para Topp et al. (1980), a relação empírica entre a constante dielétrica aparente $K_{a}$ e o conteúdo volumétrico da água $\theta_{v}$ é independente do tipo do solo, de sua densidade, da temperatura e do conteúdo de sais solúveis. Esses autores consideram que, para freqüências entre 1 e $20 \mathrm{GHz}$, a única variável que afeta a resposta dielétrica do solo é o conteúdo da água no solo, com um peso relativo de cerca de $90 \%$. Assim, a constante dielétrica aparente $\mathrm{K}_{\mathrm{a}}$ pode ser usada para determinar $\theta_{v}$.

As pesquisas existentes demonstram que há constante procura de um modelo universal de calibração para os equipamentos TDR, devendo-se, entretanto, levar em consideração a composição atípica de alguns solos. Segundo Roth et al. (1990), há variações na curva de calibração para solos que apresentam maior susceptibilidade aos campos magnéticos, como por exemplo, os solos com altos teores de óxidos de ferro. Segundo Tommaselli e Bacchi (2001), os trabalhos realizados a respeito do assunto levaram a três tipos de abordagem na formulação dos modelos das curvas de calibração: abordagens empíricas, semi-empíricas e físicas.

Em um trabalho pioneiro, Topp et al. (1980) estudaram a relação empírica entre $\mathrm{K}_{\mathrm{a}}$ e $\theta_{\mathrm{v}}$ (umidade volumétrica) para quatro solos minerais e encontraram como ajuste um único modelo linear cúbico. Tommaselli e Bacchi (2001) salientam que os modelos indicados pelos fabricantes dos equipamentos TDR devem ser abandonados, já que desconsideram as peculiaridades dos solos, devendo-se realizar novas calibrações. Esse autor encontra como melhor ajuste modelos cúbicos para cinco solos diferentes, tanto para os dados de cada um 
dos solos tratados isoladamente, assim como para o conjunto dos dados tratados de forma conjunta. Os modelos cúbicos de calibração foram obtidos também por outros autores (Tommaselli e Bacchi, 2001; Villwock et al., 2004).

Os objetivos deste trabalho foram: a) calibrar dezessete sondas de TDR, das quais duas eram originais e quinze fabricadas pela equipe; b) verificar a viabilidade do emprego das sondas manufaturadas. Os dados foram obtidos em condições de laboratório, em um Latossolo Vermelho com alto teor de argila e procurando-se a melhor equação de regressão, de forma a garantir maior precisão na obtenção da umidade volumétrica.

\section{MATERIAL E MÉTODOS}

O experimento foi realizado com um Latossolo Vermelho, coletado no Núcleo Experimental de Engenharia Agrícola da Universidade Estadual do Oeste do Paraná, na cidade de Cascavel, com coordenadas geográficas $24^{0} 58^{\prime}$ de latitude Sul e $26^{0}$ de longitude Oeste de Greenwich. A caracterização dos atributos físicos e químicos do solo estudado é apresentada na Tabela 1.

Tabela 1. Atributos físicos e químicos do Latossolo Vermelho empregado no experimento (camada de $5,0$ a $25,0 \mathrm{~cm})$.

\begin{tabular}{lrlr}
\hline Atributo & \multicolumn{1}{c}{ Valor } & Atributo & \multicolumn{1}{c}{ Valor } \\
\hline Areia & $3,0 \%$ & $\mathrm{pH}\left(\mathrm{CaCl}_{2}\right)$ & 5,80 \\
Silte & $27,9 \%$ & $\mathrm{C}$ & $23,22 \mathrm{mgdm}^{-3}$ \\
Argila & $69,1 \%$ & $\mathrm{P}$ & $5,70 \mathrm{mgdm}^{-3}$ \\
Densidade do solo & $1,31 \mathrm{Mgm}^{-3}$ & $\mathrm{Fe}$ & $68,10 \mathrm{mgdm}^{-3}$ \\
Densidade de partículas & $2,92 \mathrm{Mgm}^{-3}$ & $\mathrm{~K}^{+}$ & $0,14 \mathrm{cmoldm}^{-3}$ \\
Porosidade Total & $55,0 \%$ & $\mathrm{Ca}^{2+}$ & $7,73 \mathrm{cmoldm}^{-3}$ \\
Macroporosidade & $10,4 \%$ & $\mathrm{Mg}^{2+}$ & $4,60 \mathrm{cmoldm}^{-3}$ \\
Microporosidade & $44,6 \%$ & $\mathrm{H}^{+3} \mathrm{Al}^{3+}$ & $4,61 \mathrm{cmoldm}^{-3}$ \\
Umidade volumétrica na capacidade de & $0,405 \mathrm{~m}^{3} \mathrm{~m}^{-3}$ & & \\
campo & & & \\
Umidade volumétrica no ponto de & $0,253 \mathrm{~m}^{3} \mathrm{~m}^{-3}$ & & \\
murcha permanente & & & \\
\hline
\end{tabular}

Foram utilizadas sondas de três hastes, cujos comprimentos variaram de $17,0 \mathrm{~cm}$ a 42,0 $\mathrm{cm}$, fabricadas segundo Villwock et al. (2004) e acopladas a um equipamento TDR modelo TRASE 6050X1, da Soil Moisture Equipment Corp*, o qual foi empregado de acordo com as instruções do fabricante (Soil Moisture Equipment Corporation, 1998).

O solo foi coletado na camada de 5,0 a 25,0 cm de profundidade, seco ao ar por 144 horas e peneirado com peneira de $2 \mathrm{~mm}$, obtendo-se assim TFSA (terra fina seca ao ar). Depois de peneirado, o solo foi colocado em oito cilindros de PVC, com capacidade individual de 15 litros, sendo compactado de modo a manter sua densidade o mais uniforme possível. Após 24 horas, os cilindros foram pesados para a obtenção do valor da densidade de

*Referência ao fabricante não implica indicação por parte dos autores. 
solo úmido $\rho_{u}$, após o que as sondas TDR foram cuidadosamente introduzidas no solo de cada cilindro, procurando-se evitar a formação de lacunas de ar entre as hastes e o solo, o que poderia comprometer as leituras.

Após cada leitura com o equipamento TDR, foram retiradas quatro amostras deformadas de solo de cada cilindro, as quais foram pesadas e levadas à estufa por 24 horas para a obtenção da umidade gravimétrica $\mu$, a qual foi empregada no cálculo da umidade volumétrica $\theta_{v}$, conforme a Equação 2:

$$
\theta_{v}=\frac{\rho_{u}}{\frac{1}{\mu}+1}
$$

Em função do volume de solo colocado em cada cilindro $\left(0,015 \mathrm{~m}^{3}\right)$, foram utilizados $250 \mathrm{ml}$ de água em cada umedecimento. A cada operação de umedecimento, o solo era colocado em um recipiente cilíndrico maior, sendo a água pulverizada e misturada. Depois de umedecido e homogeneizado, o solo era novamente compactado nos cilindros, os quais eram hermeticamente fechados, evitando-se assim perda de água por evaporação. As leituras foram sempre realizadas em intervalos de 24 horas, obtendo-se nove níveis diferentes de umidade.

Foi realizada uma leitura por sonda para cada recipiente, totalizando quatro repetições para cada nível de umidade. Os números 1 a 15 referem-se às sondas fabricadas, enquanto os números 16 e 17 foram reservados para as sondas originais.

A Figura 1 mostra três exemplares de sondas utilizadas neste experimento, sendo a central uma sonda original e as laterais sondas manufaturadas pela equipe.

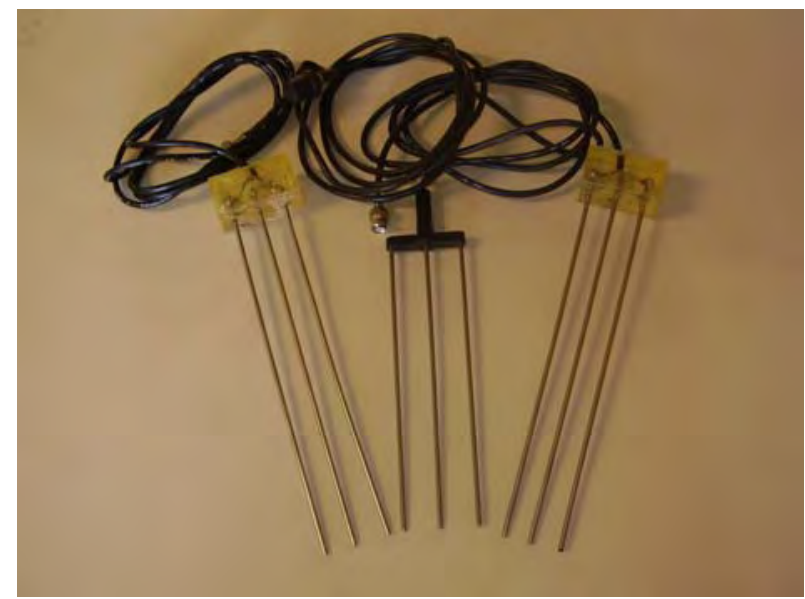

Figura 1. Exemplares de sondas TDR utilizadas no experimento.

O teste de Scott-Knott foi aplicado no nível de 5\% de significância, comparando-se os resultados das médias e separando-se as variáveis em grupos distintos.

\section{RESULTADOS E DISCUSSÃO}

O intervalo de umidade volumétrica obtido nas condições do trabalho foi de 22,0\% a $36,0 \%$. Os comportamentos da constante dielétrica aparente do solo para as diferentes sondas podem ser comparados na Figura 2. Podemos observar que a sonda 2 apresentou a maior variabilidade e que todas as sondas mostraram comportamento semelhante, sempre com o 
valor médio de cada leitura superando a mediana e indicando uma variação maior com o aumento de $K_{a}$.

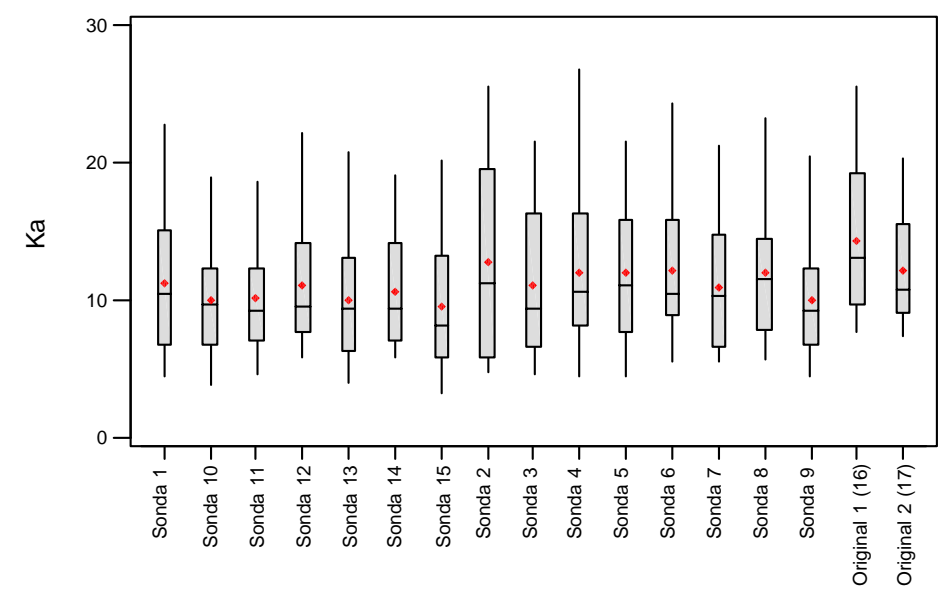

Figura 2. Variação de $K_{a}$ para as diferentes sondas. As médias estão indicadas em vermelho.

O comprimento de cada sonda, número de pontos ajustados, desvio padrão, resultado do teste de semelhança e o valor de $p$ da análise de variância da equação de regressão cúbica ajustada podem ser visualizados na Tabela 2, sendo a diferença entre o número de pontos ajustados decorrente da falta de leitura em determinadas ocasiões. No teste de semelhança, letras iguais significam sondas iguais em média. $\mathrm{O}$ valor de $\mathrm{p}$ mostrou-se significativo para todas as regressões.

Os resultados do desvio padrão foram relativamente grandes, porém, semelhantes, pois a variação de umidade entre cada medida, utilizando $250 \mathrm{ml}$ de água para cada intervalo, foi pré-estabelecida. O teste de Scott-Knott mostrou que as sondas 2, 4, 5, 6, 8, 16 e 17 foram iguais, em média, entre si, enquanto que as sondas $1,3,7,9,10,11,12,13$, 14 e 15 formaram outro grupo de sondas semelhantes. A análise de variância mostrou que os dados tiveram regressão significativa.

Foram ajustados seis modelos de regressão para cada sonda, sendo eles: linear, quadrático, cúbico, logarítmico, potencial e exponencial. O modelo polinomial cúbico foi o que melhor se ajustou às regressões, sendo a única exceção a sonda 7 , para a qual o melhor modelo ajustado foi o potencial, apresentando, porém pequena diferença em relação ao modelo cúbico. As sondas 14 e 16 mostraram os melhores coeficientes $\mathrm{R}^{2}$, com valores 0,9415 e 0,9427 respectivamente. A sonda 7 obteve o menor coeficiente $\mathrm{R}^{2}$ mas, mesmo assim, seu resultado pode ser considerado ótimo. Os coeficientes de determinação $\mathrm{R}^{2}$ e $\overline{R^{2}}$ mostraram-se bons em todos os casos. A Tabela 3 mostra o melhor ajuste de regressão, bem como o coeficiente de determinação $R^{2}$ e o coeficiente de determinação ajustado $\overline{R^{2}}$, o qual leva em consideração o número de dados ajustados para cada sonda. 
MILANI, D. I. C.; TAVARES, M. H. F.; SCHERPINSKI, C. Calibração de sondas TDR em condições de laboratório. Ambi-Agua, Taubaté, v. 3, n. 1, p. 68-75, 2008. (doi:10.4136/ambi-agua.43)

Tabela 2. Dados relevantes para cada sonda.

\begin{tabular}{cccccc}
\hline Sonda & $\begin{array}{c}\text { Comprimento } \\
(\mathbf{c m})\end{array}$ & $\begin{array}{c}\mathbf{N}^{\mathbf{o}} \mathbf{\text { de pontos }} \\
\text { ajustados }\end{array}$ & Desvio Padrão & Teste de Scott-Knott & Valor de $\boldsymbol{p}$ \\
\hline 1 & 17,4 & 36 & 4,788 & $\mathrm{a}$ & 0,000 \\
2 & 17,3 & 24 & 6,977 & $\mathrm{~b}$ & 0,000 \\
3 & 17,4 & 32 & 4,935 & $\mathrm{a}$ & 0,000 \\
4 & 17,3 & 35 & 5,346 & $\mathrm{~b}$ & 0,000 \\
5 & 22,1 & 36 & 4,800 & $\mathrm{~b}$ & 0,000 \\
6 & 21,7 & 33 & 4,655 & $\mathrm{~b}$ & 0,000 \\
7 & 22,2 & 34 & 4,327 & $\mathrm{a}$ & 0,000 \\
8 & 22,1 & 26 & 5,267 & $\mathrm{~b}$ & 0,000 \\
9 & 32,0 & 35 & 4,170 & $\mathrm{a}$ & 0,000 \\
10 & 31,9 & 34 & 3,895 & $\mathrm{a}$ & 0,000 \\
11 & $31,9 \mathrm{~cm}$ & 34 & 3,743 & $\mathrm{a}$ & 0,000 \\
12 & $41,4 \mathrm{~cm}$ & 27 & 4,054 & $\mathrm{a}$ & 0,000 \\
13 & $41,4 \mathrm{~cm}$ & 34 & 4,271 & $\mathrm{a}$ & 0,000 \\
14 & $41,6 \mathrm{~cm}$ & 35 & 3,792 & $\mathrm{a}$ & 0,000 \\
15 & $41,6 \mathrm{~cm}$ & 35 & 4,365 & $\mathrm{a}$ & 0,000 \\
16 & $20,0 \mathrm{~cm}$ & 36 & 5,399 & $\mathrm{~b}$ & 0,000 \\
17 & $30,0 \mathrm{~cm}$ & 35 & 3,700 & $\mathrm{~b}$ & 0,000 \\
\hline
\end{tabular}

Tabela 3. Modelos ajustados e respectivos coeficientes de determinação para cada sonda.

\begin{tabular}{|c|c|c|c|}
\hline Sonda & Modelo & $R^{2}$ & $\overline{R^{2}}$ \\
\hline 1 & $\theta=-4 \mathrm{E}-05 \mathrm{~K}_{\mathrm{a}}^{3}+0.0014 \mathrm{~K}_{\mathrm{a}}{ }^{2}-0.0081 \mathrm{~K}_{\mathrm{a}}+0.2492$ & 0.83358 & 0.81798 \\
\hline 2 & $\theta=-3 \mathrm{E}-05 \mathrm{~K}_{\mathrm{a}}^{3}+0.0012 \mathrm{~K}_{\mathrm{a}}^{2}-0.0089 \mathrm{~K}_{\mathrm{a}}+0.2578$ & 0.86195 & 0.84125 \\
\hline 3 & $\theta=-3 \mathrm{E}-05 \mathrm{~K}_{\mathrm{a}}^{3}+0.0008 \mathrm{~K}_{\mathrm{a}}^{2}-0.0004 \mathrm{~K}_{\mathrm{a}}+0.2203$ & 0.85632 & 0.84093 \\
\hline 4 & $\theta=-3 \mathrm{E}-05 \mathrm{~K}_{\mathrm{a}}^{3}+0.0012 \mathrm{~K}_{\mathrm{a}}^{2}-0.0082 \mathrm{~K}_{\mathrm{a}}+0.2577$ & 0.7794 & 0.75810 \\
\hline 5 & $\theta=-7 \mathrm{E}-05 \mathrm{~K}_{\mathrm{a}}^{3}+0.0029 \mathrm{~K}_{\mathrm{a}}^{2}-0.0279 \mathrm{~K}_{\mathrm{a}}+0.3231$ & 0.80565 & 0.78742 \\
\hline 6 & $\theta=-8 \mathrm{E}-05 \mathrm{~K}_{\mathrm{a}}^{3}+0.0035 \mathrm{~K}_{\mathrm{a}}^{2}-0.0378 \mathrm{~K}_{\mathrm{a}}+0.37$ & 0.84578 & 0.82983 \\
\hline 7 & $\theta=-2 \mathrm{E}-05 \mathrm{~K}_{\mathrm{a}}^{3}+0.0006 \mathrm{~K}_{\mathrm{a}}^{2}+0.0022 \mathrm{~K}_{\mathrm{a}}+0.2133$ & 0.68873 & 0.65760 \\
\hline 8 & $\theta=-2 \mathrm{E}-05 \mathrm{~K}_{\mathrm{a}}^{3}+0.0002 \mathrm{~K}_{\mathrm{a}}^{2}+0.0114 \mathrm{~K}_{\mathrm{a}}+0.1657$ & 0.78724 & 0.75823 \\
\hline 9 & $\theta=-2 \mathrm{E}-05 \mathrm{~K}_{\mathrm{a}}^{3}+0.0007 \mathrm{~K}_{\mathrm{a}}^{2}+0.0018 \mathrm{~K}_{\mathrm{a}}+0.2162$ & 0.84492 & 0.82991 \\
\hline 10 & $\theta=2 \mathrm{E}-05 \mathrm{~K}_{\mathrm{a}}^{3}-0.0006 \mathrm{~K}_{\mathrm{a}}^{2}+0.0155 \mathrm{~K}_{\mathrm{a}}+0.1734$ & 0.81869 & 0.80056 \\
\hline 11 & $\theta=-8 \mathrm{E}-05 \mathrm{~K}_{\mathrm{a}}^{3}+0.0023 \mathrm{~K}_{\mathrm{a}}^{2}-0.0124 \mathrm{~K}_{\mathrm{a}}+0.246$ & 0.84784 & 0.83262 \\
\hline 12 & $\theta=2 \mathrm{E}-05 \mathrm{~K}_{\mathrm{a}}^{3}-0.0011 \mathrm{~K}_{\mathrm{a}}^{2}+0.0255 \mathrm{~K}_{\mathrm{a}}+0.1223$ & 0.76353 & 0.73269 \\
\hline 13 & $\theta=-7 \mathrm{E}-05 \mathrm{~K}_{\mathrm{a}}^{3}+0.002 \mathrm{~K}_{\mathrm{a}}^{2}-0.0101 \mathrm{~K}_{\mathrm{a}}+0.2477$ & 0.83882 & 0.82270 \\
\hline 14 & $\theta=7 \mathrm{E}-05 \mathrm{~K}_{\mathrm{a}}^{3}-0.0027 \mathrm{~K}_{\mathrm{a}}^{2}+0.0417 \mathrm{~K}_{\mathrm{a}}+0.0615$ & 0.94273 & 0.93719 \\
\hline 15 & $\theta=-1 \mathrm{E}-05 \mathrm{~K}_{\mathrm{a}}^{3}+0.0004 \mathrm{~K}_{\mathrm{a}}^{2}+0.005 \mathrm{~K}_{\mathrm{a}}+0.2106$ & 0.85953 & 0.84594 \\
\hline 16 & $\theta=-2 \mathrm{E}-05 \mathrm{~K}_{\mathrm{a}}^{3}+0.0006 \mathrm{~K}_{\mathrm{a}}^{2}+0.0029 \mathrm{~K}_{\mathrm{a}}+0.181$ & 0.94149 & 0.93600 \\
\hline 17 & $\theta=2 \mathrm{E}-05 \mathrm{~K}_{\mathrm{a}}^{3}-0.0008 \mathrm{~K}_{\mathrm{a}}^{2}+0.0215 \mathrm{~K}_{\mathrm{a}}+0.1107$ & 0.86014 & 0.84661 \\
\hline
\end{tabular}


A Figura 3 traz os gráficos de dispersão dos resultados, os quais relacionam os valores de constante dielétrica aparente do solo com os teores de umidade volumétrica. Os gráficos mostram comportamento semelhante para as sondas, sendo o comportamento cúbico mais evidente na Figura 3b do que na Figura 3a.

(a)

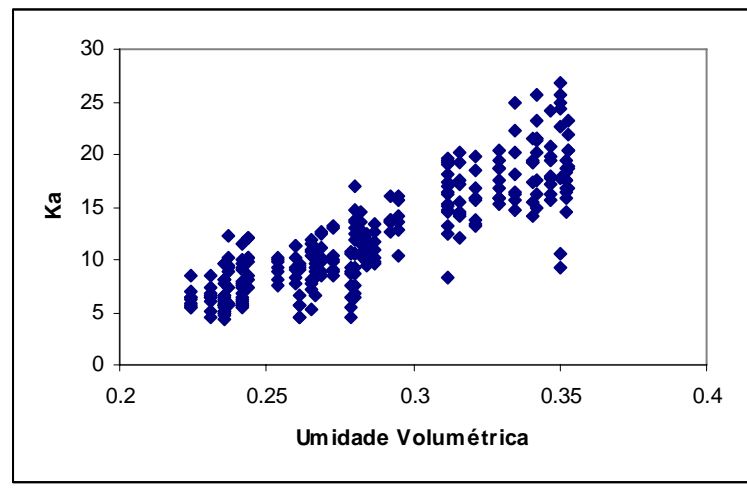

(b)

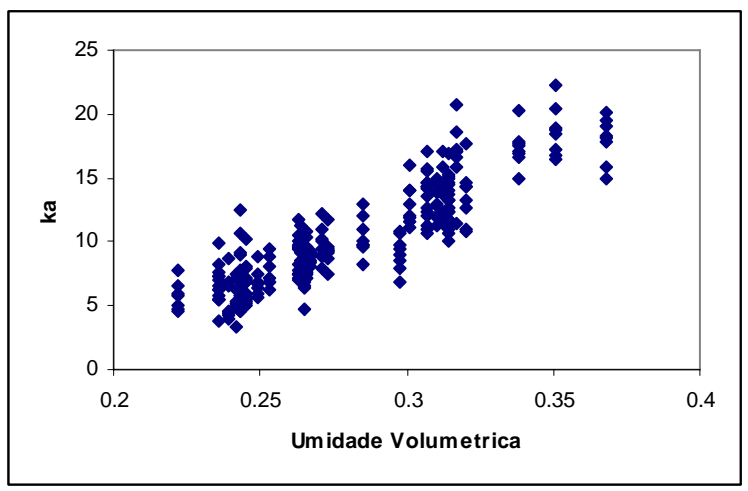

Figura 3. Gráficos de dispersão de $K_{\mathrm{a}}$ versus Umidade Volumétrica para: a) Sondas 1 a 8 e sonda 16; b) Sondas 9 a 15 e sonda 17 .

\section{CONCLUSÕES}

1) O modelo que melhor se ajustou às dezessete sondas foi o modelo polinomial cúbico, comprovando os resultados obtidos por outros autores;

2) Os coeficientes das equações de calibração de todas as sondas mostraram-se semelhantes, indicando a viabilidade de emprego das sondas manufaturadas.

\section{AGRADECIMENTOS}

Aos Profs. Drs. Décio Lopes Cardoso e Miguel Angel Uribe Opazo, pela colaboração prestada;

À Prof ${ }^{\mathrm{a}}$. Rosangela Villwock, pelo auxílio na confecção das sondas;

À Fundação Banco do Brasil, pelo apoio na aquisição do equipamento de TDR;

Ao Conselho Nacional de Desenvolvimento Científico e Tecnológico (CNPq) pela concessão da bolsa de mestrado a Dione Inês Christ Milani.

\section{REFERÊNCIAS}

COELHO, E. F.; VELlAME, L. M.; FILHO, M. A. C.; LEDO, C. A. S. Desempenho de modelos de calibração de guias de onda acopladas a TDR e a multiplexadores em três tipos de solos. Revista Brasileira de Ciência do Solo, Viçosa, v. 30, n. 1, p. 23-30, 2006.

MANIERI, J. M.; VAZ, C. M. P.; MARIA, I. C. Sonda espiral de TDR para a medida da umidade no perfil do solo. Revista Brasileira de Ciência do Solo, Viçosa, v. 31, n. 2, p. 191-198, 2007.

NOBORIO, K. Measurement of soil water content and electrical conductivity by time domain reflectometry: a review. Computers and Electronics in Agriculture, Washington, v. 31, n. 3, p. 213-237, 2001. 
ROBINSON, D. A.; JONES S. B.; WRAITH, J. M.; OR, D.; FRIEDMAN, S. P. A Review of Advances in Dielectric and Electrical Conductivity Measurement in Soils Using Time Domain Reflectometry. Vadose Zone Journal, Madison, v. 2, n. 4, p. 444-475, 2003.

ROTH, C. H.; SCHULIN, R.; FLUHLER, H.; ATTINGER, W. Calibration of time-domain reflectometry for water content measurement using composite dielectric approach. Water Resources Research, v. 26, n. 10, p. 2267-2273, 1990.

SOILMOISTURE EQUIPMENT CORPORATION. Trase-Operating Instructions. Santa Barbara: S.E.C., 1998. 119 p.

TAVARES, M. H. F.; BUSATTA, O. J.; VILAS BOAS, M. A.; ORO, A. L. T. Desenvolvimento de aplicativo para um equipamento TDR. Irriga, Botucatu, v. 11, n. 4, p. 543-552, 2006.

TOMMASELLI, J. T. G.; BACCHI, O. O. S. Calibração de um equipamento de TDR para medida de umidade de solos. Pesquisa Agropecuária Brasileira, Brasília, v. 36, n. 9, p. 1145-1154, 2001.

TOPP, G. C.; DAVIS, J. L.; ANNAN, A. P. Electromagnetic determination of soil water content: measurements in coaxial transmission lines. Water Resources Research, Washington, v. 16, n. 3, p. 574-582, 1980.

VILLWOCK, R.; TAVARES, M. H. F.; VILAS BOAS, M. A. Calibração de um equipamento TDR em condições de campo. Irriga, Botucatu, v. 9, p. 82-88, 2004. 


ISSN = 1980-993X - doi:10.4136/1980-993X
www.agro.unitau.br/ambi-agua
E-mail: ambi-agua@agro.unitau.br
Tel.: (12) 3625-4116

\title{
Emprego de técnicas digitais para a concepção da base cartográfica da bacia hidrográfica do Córrego Cabuçu de Baixo, São Paulo, SP, Brasil
} (doi:10.4136/ambi-agua.44)

\author{
Rodrigo Affonso de Albuquerque Nóbrega ${ }^{1}$; Mario Thadeu Leme de Barros ${ }^{2}$; \\ José Alberto Quintanilha ${ }^{1}$ \\ Escola Politécnica da Universidade de São Paulo - ${ }^{1}$ Lab. de Geoprocessamento do Depto. de Eng. de \\ Transportes e ${ }^{2}$ Departamento de Engenharia Hidráulica e Sanitária \\ E-mail: rodrigo.nobrega@poli.usp.br; mtbarros@usp.br; jaquinta@usp.br
}

\section{RESUMO}

O emprego de bases cartográficas confiáveis como material de apoio a projetos de planejamento e gestão espacial é de caráter primordial ao seu sucesso. Todavia, a escassez e a desatualização desse material tem levado à adoção de metodologias alternativas, na busca de soluções mais rápidas e menos onerosas para elaboração dessas informações, sem que haja o comprometimento da qualidade. Nesse contexto, o presente trabalho mostra a viabilidade da construção de uma base cartográfica voltada para as aplicações em hidrologia, mais especificamente, como base para um Sistema de Suporte à Decisão para Gerenciamento de Bacia Urbana - SSDURB. A metodologia aqui apresentada reúne técnicas de extração manual das feições do terreno, bem como técnicas automáticas de fotogrametria. Como produtos, foram obtidas ortofotos e cartas altimétricas, com eqüidistância de 5 metros para as regiões montanhosas com cobertura florestal e de 1 metro para as demais áreas, priorizando as áreas de várzea para análise de pontos de alagamento. Análises finais mostram a viabilidade do emprego da metodologia proposta e a alta qualidade dos produtos.

Palavras-chave: modelo digital de terreno; ortofoto; hidrologia urbana; gestão de recursos hídricos; água urbana.

\section{Application of digital techniques to generate a cartographic database of Córrego do Cabuçu de Baixo basin, São Paulo, SP, Brazil}

\section{ABSTRACT}

The use of appropriate cartography database is extremely important to support projects of planning and land management. However, the absence of maps, or the amount of obsolete maps, has been leading to the adoption of alternative methodologies aiming to faster and less onerous solutions for the development of cartography databases, without compromising quality. Regarding this problem, the present paper reports on the viability of constructing a cartographic database designed for applications in hydrology, more specifically, as a base for a Decision Support System for Urban Basin Management - DSSURM. The methodology combines techniques of manual terrain features extraction, as well as automatic techniques of photogrammetry. Digital orthophotos and contour maps were generated. The coarser 5 meters interval was used for the mountainous regions and forest, and the finer 1 meter interval for other regions, floodplains were prioritized for mapping flooding areas. The final analyses show the viability of the methodology as well as the high quality of the cartographic products.

Keywords: digital terrain modeling; orthophoto; urban hydrology; hydro resources management; urban water. 


\section{INTRODUÇÃO}

Os problemas relativos à água no meio urbano são hoje extremamente preocupantes e envolvem questões econômicas, sociais e ambientais complexas, principalmente em grandes cidades, nas chamadas megacidades, como São Paulo, Rio de Janeiro, etc. O equacionamento e a solução desses problemas envolvem profissionais de diferentes áreas do conhecimento e necessitam de muito planejamento, muito estudo, para que as soluções propostas sejam de fato eficientes.

A inclusão de questões relativas à água urbana nos Planos de Bacia Hidrográfica, instrumento base do Sistema de Gerenciamento de Recursos Hídricos no Brasil e nos Planos Diretores das cidades é fundamental para que se possa avançar em soluções. Os programas e projetos de água urbana estão diretamente relacionados à melhoria do meio e do padrão de vida do homem urbano. Nesse sentido, é fundamental o desenvolvimento de ferramentas de planejamento e gestão municipal que possa enfocar, principalmente, a pequena bacia hidrográfica urbana. A urbanização e a gestão municipal praticamente desfiguraram as pequenas bacias hidrográficas e, infelizmente, muitos dos problemas existentes nas áreas urbanas advêm da falta de planejamento e de gestão feitas com base na bacia hidrográfica.

A Escola Politécnica da Universidade de São Paulo (EPUSP), via seu Departamento de Engenharia Hidráulica e Sanitária (PHD), propôs ao Fundo Setorial de Recursos Hídricos (CT-HIDRO) dois projetos voltados às questões da água urbana e ambos estudaram os problemas sob a ótica da pequena bacia urbana. Um desses projetos trata do desenvolvimento de uma ferramenta de planejamento e de gestão urbana, chamada de Sistema de Suporte à Decisão para Gerenciamento de Bacia Urbana - SSDURB (Barros, 2004a e 2004b). O outro projeto trata de ações mais específicas, chamado Plano de Bacia Urbana (Barros, 2005). Esse sistema de suporte à decisão (SSD) permite a um usuário processar diferentes tipos de modelos matemáticos de quantidade e qualidade da água para simular diferentes cenários de ocupação e uso do solo. Acoplado a esse SSD foi desenvolvido um banco de dados detalhado, com informações dos mais variados tipos, todas relacionadas com a água urbana.

O SSDURB foi montado para a bacia do córrego Cabuçu de Baixo em São Paulo, região que caracteriza muito bem os problemas de água que a cidade enfrenta. A disponibilidade de informações confiáveis é a base de sustentação de um SSD. Nesse sentido, o projeto se preocupou em montar um banco de dados para servir de referência para outras áreas urbanas.

Segundo Choi et al. (2005), avanços recentes em tecnologia da informação, incluindo hardware, software e internet, têm fornecido soluções para diferentes aspectos da modelagem hidrológica. Atualmente, velocidade e capacidade de armazenamento dos computadores, redes e software de análise espacial permitem a simulação hidrológica distribuída, tornando possível a consideração da variação espacial. Sistemas de informações geográficas (SIG) tiveram um forte impacto na modelagem hidrológica e no desenvolvimento de modelos (Xu et al., 2001). Ferramentas SIG são comumente usadas em sistemas de suporte à decisão para preparação de dados, operação e modelagem de sistemas hidrológicos e tornaram-se ferramentas essenciais para o desenvolvimento de sistemas de suporte à decisão espacial para o gerenciamento de bacias. (Tayler et al., 1999; Lohani et al., 2002; Watson et al., 2002; Wilson et al., 2000). Em particular, Choi et al. (2005) descrevem um SSD desenvolvido em ambiente web-GIS para entrada de dados, apresentação de mapas e delineamento dos contornos de bacias online. Zerger e Wealands (2004) descrevem o desenvolvimento de um SDS que integra resultados de modelos hidrodinâmicos, SIG e sistemas gerenciadores de banco de dados. Dymond et al. (2004) usam um SSD em ambiente web-GIS para integrar modelos hidrológicos e econômicos com diferentes resoluções espaciais e temporais. 
A base cartográfica e altimétrica para aplicação de modelos hidrológicos, hidráulicos e de qualidade da água em pequenas áreas urbanas é uma informação essencial. Superfícies tridimensionais representam dados de elevação. Essas superfícies podem ser geradas usando diferentes abordagens, dependendo do software ou da representação de dados, vetorial ou matricial, utilizada (Rainis, 2004). Uma revisão de diferentes tipos de algoritmos pode ser encontrada em Skidmore (1989), Dunn e Hickey (1998) e Burrough e McDonnell (1998).

As imagens de satélites de sensoriamento remoto na região óptica (visível e infravermelho próximo) do espectro eletromagnético não apresentavam potencial de aplicação para áreas urbanas com os sensores de média resolução ( $30 \mathrm{~m})$. No entanto, com o advento dos sensores imageadores de maior resolução espacial, como o IKONOS (1m), QuickBird (0,6m), HRG/SPOT-5 (2,5m) e, mais recentemente, o HRC/CBERS-2b (2,7m), abriram-se novas perspectivas para o uso dessas imagens para análises urbanas.

Distorções geométricas causadas pela forma de obtenção das imagens (visadas fora do nadir), instabilidade da plataforma e rotação e curvatura da Terra são comuns em imagens captadas por satélites de sensoriamento remoto.

Áreas urbanas com edificações de diferentes alturas introduzem distorções adicionais (objetos pequenos sobre as edificações, muros e divisas entre as edificações, não são completamente ortorretificados, devido à falta de exatidão do modelo digital de terreno (MDT) (Zhou et al., 2005).

A ortorretificação é uma das maneiras de se reduzir essas distorções. Entende-se por ortofoto uma imagem que sofreu um processo de ortorretificação, o qual é responsável pela correção causada pelo efeito do terreno, pela orientação da aeronave e pelo efeito de projeção cônica natural do sistema de lentes da câmara (Church, 1976, apud McGlone, 2004). Para corrigir as elevações, é necessário o uso de modelos digitais de terreno (MDT), obtidos a partir de técnicas de fotogrametria digital aplicadas às estereo-imagens de alta resolução espacial, semelhantes àquelas usadas em fotografias aéreas (Gooch and Chandler, 1998; Chandler, 1999).

Existe uma grande variedade de formas para obtenção de um modelo digital de terreno (MDT). Zeilhofer (2001) destaca o levantamento topográfico em campo, restituição fotogramétrica e a interferometria a partir de dados de sistemas imageadores de radar. Para Jacobsen (2001), a correlação automática de imagens e o imageamento por laser (Light Detector And Ranging - LiDAR) estão entre as técnicas de modelagem digital mais empregadas na atualidade. Embora haja uma forte tendência ao emprego dessas técnicas, por utilizarem tecnologia de ponta e possibilitarem o levantamento rápido e preciso do terreno, o custo dessa atualização tecnológica as tornam inacessíveis para grande parte dos projetos atuais.

Como alternativas mais tradicionais, existe o emprego de cartas topográficas digitalizadas ou o uso de fotografias aéreas (ou imagens de satélites). O emprego de cartas topográficas pode ser uma boa solução, poupando o trabalho de levantamento em campo (Zeilhofer, 2001). Todavia, a qualidade do MDT estará diretamente ligada à qualidade da carta topográfica de origem. Embora, em geral, as cartas topográficas sejam produzidas segundo critérios que garantam a precisão, a atualização das bases cartográficas no Brasil não é feita regularmente, elevando o risco de se trabalhar com dados incorretos. Eficientes e precisas, a adoção de fotografias aéreas para restituição da superfície topográfica acaba elevando os custos do projeto, uma vez que esse processo é manual e depende da habilidade e da acuidade visual do operador.

No contexto da cartografia digital, pela facilidade de seu emprego em programas de geoprocessamento e pelos benefícios oferecidos, as ortofotos vêm ganhando destaque, segundo Queiroz Filho (1993). O processo de ortorretificação foi proposto por Russel Bean, 
do serviço geológico norte-americano - USGS, em meados de 1955, utilizando na época recursos ópticos/mecânicos e a habilidade do operador na compensação da variação do relevo para produzir as ortofotos. Atualmente, a ortorretificação utiliza basicamente rotinas de processamento digital de imagem e a influência do relevo é compensada automaticamente pelo uso do modelo digital do terreno. Uma revisão detalhada sobre o processo de ortorretificação pode ser encontrada no capítulo 13 "Photogrammetric products" de McGlone (2004). Nesse capítulo são discutidos vários produtos cartográficos digitais, dados gerados por sistemas de informações geográficas e a visualização 3D.

Wechsler (2007) examinou a natureza e a importância do gerenciamento de incertezas nos modelos digitais de terreno (MDT) em hidrologia. Essa revisão discute o que o autor chama de "áreas fundamentais" da modelagem digital de terrenos e que afetam o uso de MDT em aplicações hidrológicas. Essas áreas fundamentais incluem: a) erros no MDT; b) parâmetros topográficos freqüentemente derivados dos MDT e algoritmos associados à geração desses MDT; c) a influência da escala do MDT imposta pela resolução da malha utilizada; d) a interpolação no MDT; e) as modificações inseridas no terreno para gerar superfícies MDT hidrologicamente viáveis.

Outro aspecto relevante na escolha do método de MDT envolve a análise da forma com que as informações do terreno são representadas. Os modelos clássicos são a malha regular (GRID) e a malha de triângulos irregulares (TIN). O modelo GRID, por exemplo, apresenta grande facilidade de implementação e execução, todavia não permite representar detalhes com dimensões inferiores ao espaçamento da malha. A adoção de uma malha densa pode comprometer o desempenho do sistema e gerar redundância em regiões planas ou de declividade constante. O TIN, embora necessite de aplicativos mais sofisticados para execução, permite a representação do relevo em detalhes, pois permite adaptar a dimensão dos triângulos às irregularidades naturais e artificiais do terreno. Maiores detalhes podem ser vistos em McGlone (2004) e Maune (2007).

Na prática, o levantamento de dados na bacia do Cabuçu de Baixo evidenciou um problema crônico, infelizmente, comum em projetos de recursos hídricos: a falta de informações cartográficas confiáveis e atualizadas. O objetivo deste artigo é apresentar uma metodologia alternativa desenvolvida para a geração da superfície topográfica e o seu emprego na produção de ortofotos para subsidiar a coleta de informações planimétricas, com qualidade compatível com a modelação matemática do SSDURB.

Dadas às restrições de recursos e de tempo, a técnica de mapeamento aqui apresentada demonstrou ser muito adequada às análises feitas pelo SSDURB. A base cartográfica gerada, constituída por cartas altimétricas e ortofotos digitais, possibilitou que o projeto fosse subsidiado por informações precisas, tendo em vista os objetivos do SSD. Além disso, a altimetria permitiu a elaboração de pranchas tridimensionais que em muito contribuíram para análise espacial de propostas de intervenção na bacia, executadas posteriormente (Barros, 2005).

\section{MATERIAIS E MÉTODOS}

\section{1. Área de Estudo}

A área de estudo em questão, corresponde à bacia do córrego Cabuçu de Baixo, localizada no extremo norte do município de São Paulo-SP, compreendida entre as latitudes $23^{\circ} 24^{\prime} 30^{\prime \prime}$ S e $23^{\circ} 30^{\prime} 30^{\prime \prime}$ S e as longitudes $46^{\circ} 37^{\prime} 30^{\prime \prime}$ W e $46^{\circ} 43^{\prime \prime} 50^{\prime \prime}$ W, em uma área de aproximadamente $42 \mathrm{Km}^{2}$ e perímetro de aproximado de $45 \mathrm{~km}$ (Figura 1). A Bacia do Cabuçu de Baixo é formada à montante pelas sub-bacias dos Córregos do Bananal, Guaraú, 
Itaguaçu e Bispo e à jusante pelo Córrego do Cabuçu de Baixo. Ao Norte, sua extensão abrange parte da Serra da Cantareira, limitada pelas divisas entre os municípios de São Paulo, Mairiporã e Caieiras. Ao sul, a bacia sofre um estreitamento até sua jusante no Rio Tietê. Sua extensão territorial abrange principalmente os bairros da Freguesia do Ó, Vila Nova Cachoeirinha, Vila Brasilândia, Horto Florestal e Parada de Taipas. Maiores detalhes podem ser vistos em Barros (2004b).

Devido à abrangência da bacia, a cobertura do solo pode ser dividida, a priori, em três grupos principais: área totalmente urbanizada, área em urbanização e área em mata nativa. Todavia, a escala das imagens utilizadas (fotografias aéreas 1:8.000) permite que seja realizada uma classificação mais criteriosa do padrão de cobertura de solo, em especial na mancha urbana, caracterizada por regiões residenciais de diferentes níveis sociais.

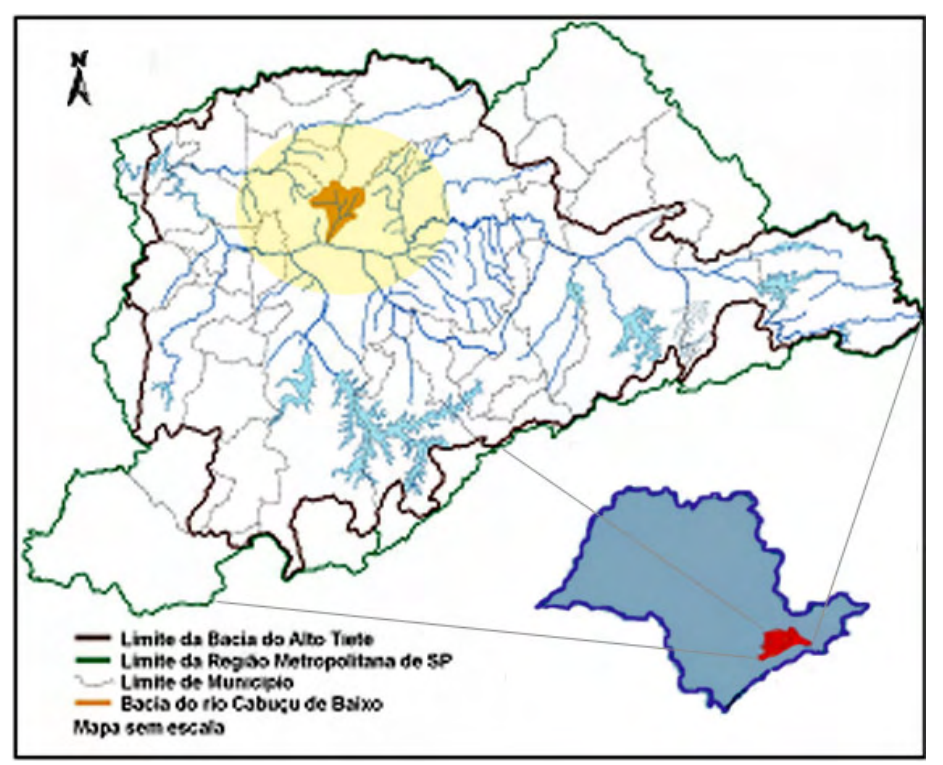

Figura 1. Ilustração sem escala da localização da área do projeto. Destaque para a Região Metropolitana de São Paulo no detalhe menor e para a Bacia do Córrego do Cabuçu no detalhe maior.

Desconsiderando os fatores sociais e econômicos envolvidos, a heterogeneidade da mancha urbana na bacia pode ser notada pelas diferenças no padrão das edificações (aglomeração, dimensão e forma), no sistema viário (pavimentação, largura e traçado) e na redução da arborização. Somados à complexidade do relevo nas áreas de periferia, o padrão de cobertura do solo interfere diretamente na modelagem digital do terreno por estereoscopia, podendo mascarar a superfície real do terreno (Figura 2). 


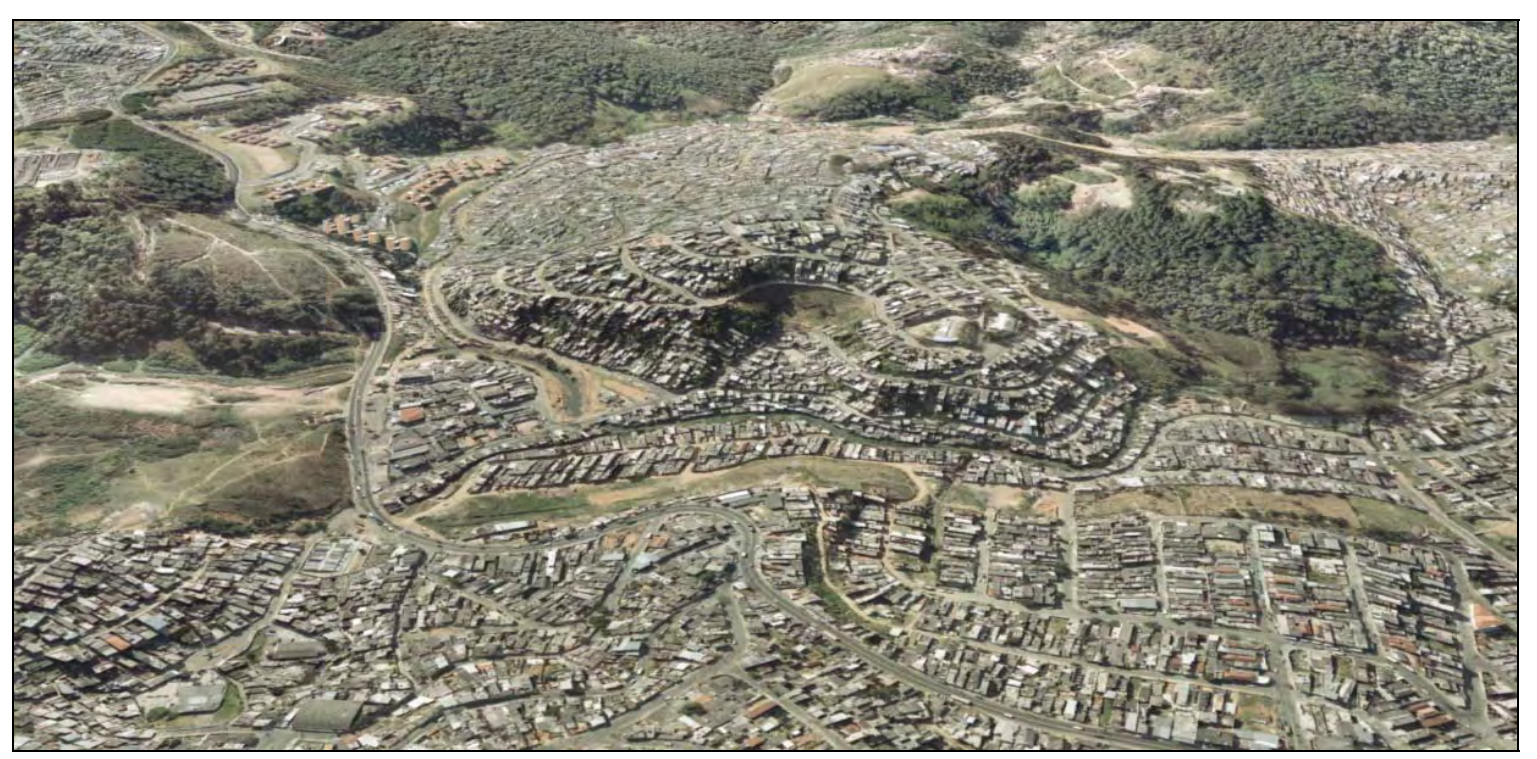

Figura 2. Vista panorâmica ilustrando a complexa heterogeneidade da ocupação do solo em um trecho da bacia.

\subsection{A Escolha do Método}

Neste projeto, a escolha dentre os diferentes métodos para aquisição do MDT levou em consideração fatores como o custo, o tempo e a qualidade. Visando solucionar tal problema, optou-se em utilizar uma solução híbrida, baseada no processo de restituição fotogramétrica digital, recorrendo a processos manuais e automáticos para a criação e modelagem do relevo, remotamente, em ambiente virtual tridimensional.

No entanto, a escolha do método envolveu também a análise da forma com que as informações do terreno seriam representadas. O modo interativo com que o MDT seria constituído, bem como a facilidade de adaptação do TIN às feições do terreno foram fatores limitantes na escolha do modelo adotado.

\subsection{Recursos Utilizados}

Para o desenvolvimento do projeto foi utilizado um conjunto de 68 fotografias áreas (escala 1:8000), fazendo o recobrimento estereoscópico de toda a extensão territorial da bacia, as quais foram obtidas em setembro de 2003. A sobreposição longitudinal média das fotografias é de $60 \%$ e a lateral (sobreposição entre faixas de vôo adjacentes) é de 40\%, estabelecidas previamente no planejamento do vôo. Embora o termo fotografia seja mencionado com freqüência, vale ressaltar que elas foram adquiridas em meio analógico (filme aéreo) e, posteriormente, digitalizadas por meio de um scanner fotogramétrico. As imagens digitais foram padronizadas em RGB 24 bit com 900 dpi, gerando arquivos da ordem de $210 \mathrm{MB}$ por imagem.

Foram levantados 29 pontos de controle em campo, os quais foram definidos previamente em uma etapa de planejamento, avaliando estratégias de distribuição e de freqüência em função da precisão requerida para as medidas tridimensionais ao longo do conjunto de imagens. Para o levantamento, utilizaram-se receptores GPS de padrão geodésico (portadora L1). Foram adotadas feições já existentes no terreno e presentes nas fotografias, como sinalização de trânsito, calçada e muro como referência para as medidas. A alta resolução espacial dessas imagens e a pequena diferença de tempo entre as datas do vôo e do levantamento em campo facilitaram o processo de identificação dessas feições em campo sem que houvesse o comprometimento da qualidade. 
Todos os processamentos foram realizados em um microcomputador padrão PC com processador de $1 \mathrm{GHz}, 2 \mathrm{~GB}$ de RAM e HD de 110 GB. Para auxílio na visualização e medição tridimensional, foi utilizado um estereoscópio (Screenscope) instalado junto ao monitor, dispensando o emprego de recursos gráficos mais sofisticados.

As etapas de aerotriangulação, modelagem digital do terreno, ortorretificação e mosaicagem foram desenvolvidas no sistema Socet Set ${ }^{\circledR}$ V.4.31 da LH System, gentilmente cedido pela Wild Comercial Importadora Ltda. para este trabalho.

\subsection{Preparação das Imagens}

Para o projeto do SSD do Cabuçu de Baixo, inicialmente foi proposto o emprego de um MDT extraído a partir de cartas topográficas do GEGRAN (Grupo Executivo da Grande São Paulo), datadas da década de 70, obtidas por restituição fotogramétrica, bem como imagens do satélite IKONOS II de outubro de 2002, como apoio visual. Em condições normais de ocupação e uso do solo, essa diferença entre as datas não deveria comprometer o estudo, porém a Bacia do Cabuçu de Baixo é tomada por constantes processos de urbanização, acarretando em constantes movimentações do terreno (cortes, aterros, retificação e canalização de córregos).

Visando reduzir o risco de haver eventuais incompatibilidades entre o MDT e a real situação de terreno, a metodologia adotada neste trabalho remeteu ao emprego da aerofotogrametria, utilizando imagens aéreas mais recentes. O fluxograma (Figura 3) ilustra a seqüência das etapas envolvidas.

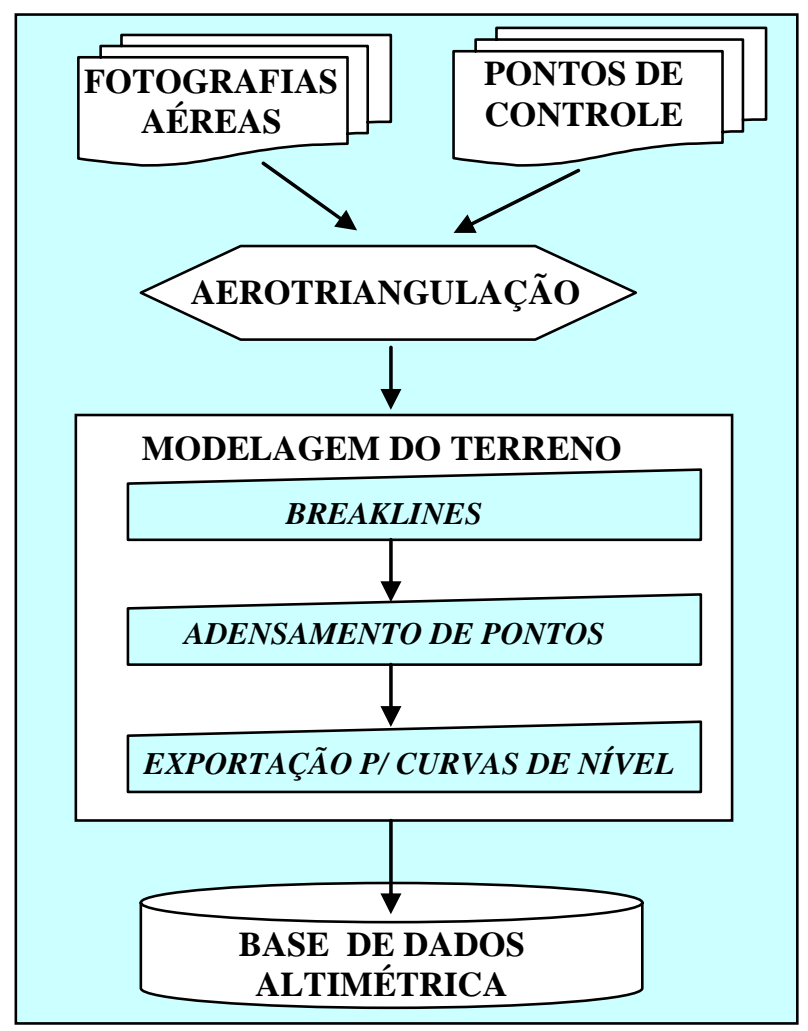

Figura 3. Fluxograma das etapas envolvidas na modelagem digital do terreno.

A preparação das fotografias aéreas para visualização dos modelos estereoscópicos exigiu um processo denominado aerotriangulação, o qual envolveu a amarração das imagens (orientação relativa), utilizando pontos de ligação e, posteriormente, a amarração desse conjunto de imagens aos pontos de controle levantados em campo (orientação absoluta). Ao 
final da aerotriangulação foi possível inferir a acurácia obtida para a medição das feições das imagens em 3D. Uma abordagem detalhada sobre o processo de aerotriangulação pode ser encontrada em McGlone (2004).

Foram utilizados cerca de 1147 pontos de enlace e 29 pontos de controle. Baseado na qualidade da leitura desses pontos, bem como na sua distribuição geométrica, o erro quadrático médio (EQM) final da aerotriangulação foi de $0,44 \mathrm{~m}, 0,48 \mathrm{~m}$ e $0,28 \mathrm{~m}$, respectivamente para os eixos Este, Norte e Elevação. A precisão alcançada mostrou-se compatível à precisão requerida para o modelo de altimetria proposto no trabalho.

\subsection{Modelagem Digital do Terreno}

Uma vez aerotrianguladas as imagens, foi possível iniciar a modelagem digital do terreno utilizando, por sua vez, recursos gráficos que permitem a visualização tridimensional do terreno e das feições nele presentes. Inicialmente, foram restituídas as principais feições que interferem na forma do relevo. Os vetores criados em primeira instância correspondem às linhas de quebra do terreno, denominados como breaklines. Embora fundamentais para o MDT, as breaklines apenas permitem reproduzir a forma aproximada do relevo.

Todavia, os recursos disponíveis no aplicativo utilizado permitiram a visualização simultânea das feições restituídas e das curvas de nível interpoladas em tempo real (Figura 4). Essa visualização facilitou a localização de regiões com densidade insuficiente de breaklines ou regiões cujo MDT não fosse suficientemente representativo.

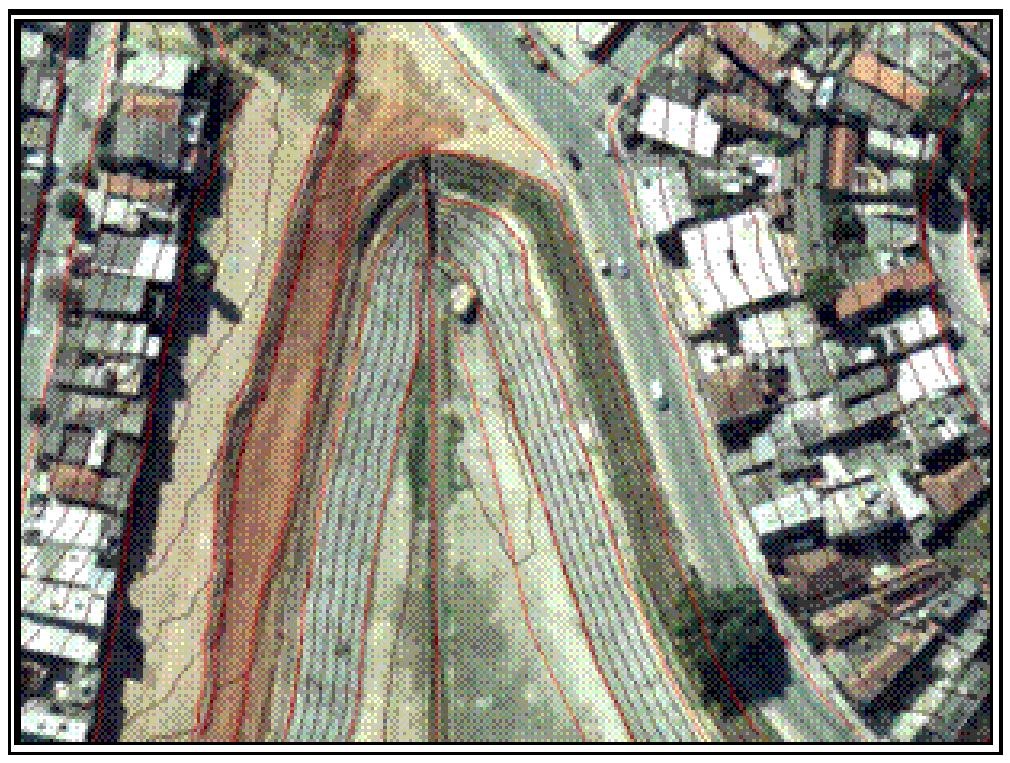

Figura 4. Visualização das breaklines (linhas em vermelho) utilizadas para criar e refinar o MDT em sobreposição a uma ortofoto e as curvas de nível com intervalo de 1 metro no "piscinão" do Guaraú.

Em uma segunda etapa, a modelagem do terreno foi desenvolvida por meio de um adensamento maior de pontos. Em geral, as regiões com pouca variação do terreno, ou com declividades constantes, necessitaram de um número menor de pontos de adensamento. Ao contrário, regiões de relevo mais acidentado foram as maiores candidatas a receber esses pontos. De forma análoga à restituição das breaklines, os pontos foram adicionados manualmente como vértices dos triângulos (Figura 5), pela visualização estereoscópica das imagens. Nesse momento, foram sobrepostas as breaklines, as curvas de nível interpoladas e a malha TIN. 
NÓBREGA, R. A. A.; BARROS, M. T. L. DE; QUINTANILHA, J. A. Emprego de técnicas digitais para a concepção da base cartográfica da bacia hidrográfica do Córrego Cabuçu de Baixo, São Paulo, SP. Ambi-Agua, Taubaté, v. 3, n. 1, p. 76-90, 2008. (doi:10.4136/ambi-agua.44)

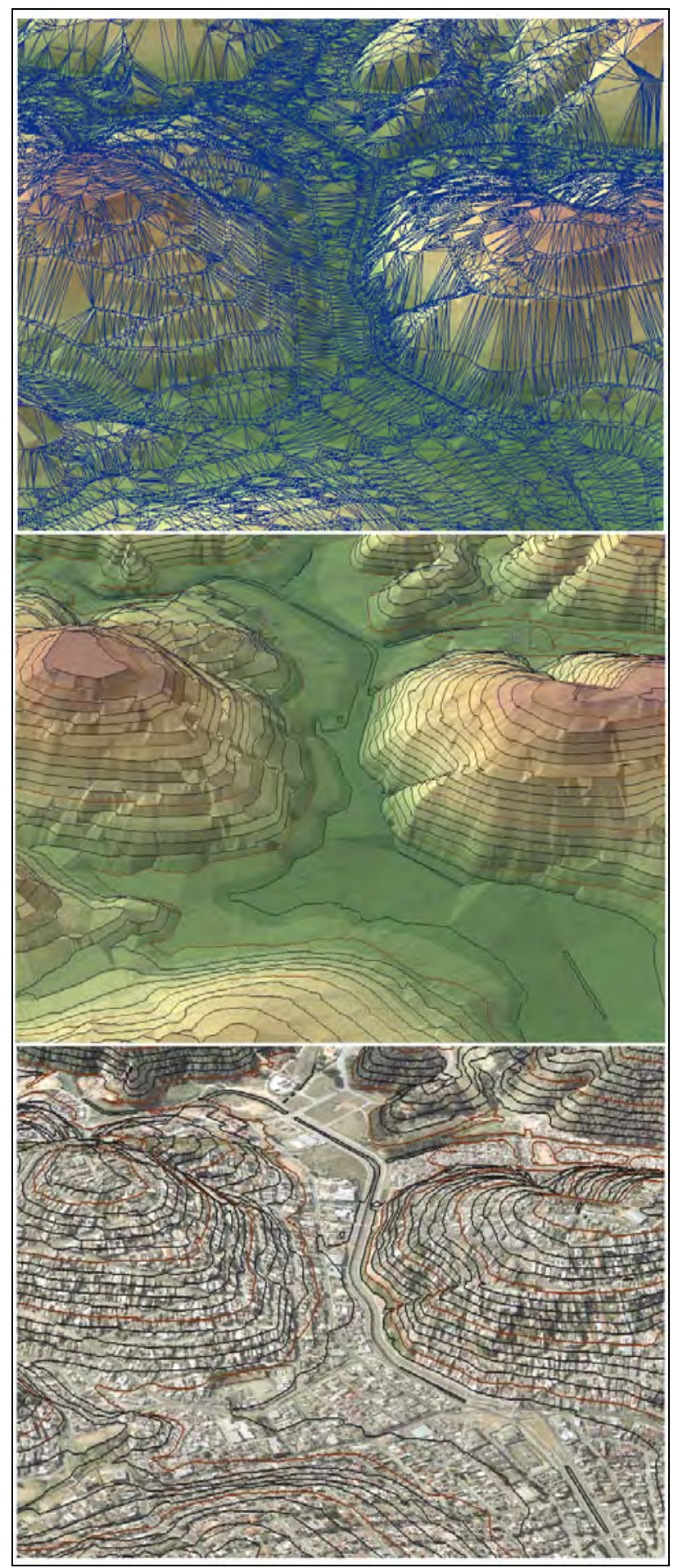

Figura 5. Etapas utilizadas na construção do MDT. Acima: MDT representado por TIN; ao centro: MDT suavizado e sobreposto à altimetria; abaixo: sobreposição com ortofoto em perspectiva.

A interpolação das curvas de nível, nesse caso, apenas forneceu um apoio visual ao operador. Para tanto, reduziu-se gradualmente o intervalo entre as curvas até atingir 1 metro, a fim de representar de forma fiel as feições naturais e artificiais do relevo. A cada ponto adicionado, as curvas foram recalculadas e, em tempo real, mostradas sobre o modelo 
estereoscópico. Assim, interativamente, o MDT foi constituído, apoiado sempre na análise visual do operador, até que toda a extensão da bacia fosse coberta (Figura 6).

Finalizada a construção do MDT, foi necessária sua exportação para que pudesse ser carregado no SSD. Nessa etapa, a opção foi gerar um arquivo vetorial contendo curvas de nível em formato DXF. Esse processo foi realizado em duas etapas, primeiramente um arquivo contendo toda a extenção da bacia com curvas de nível espaçadas a cada 5 metros. Em seguida, um segundo arquivo foi gerado, contendo curvas de nível espaçadas a cada metro, limitadas às proximidades dos rios e suas várzeas, as quais deverão ser adotadas posteriormente para estudos mais detalhados das regiões de alagamento.

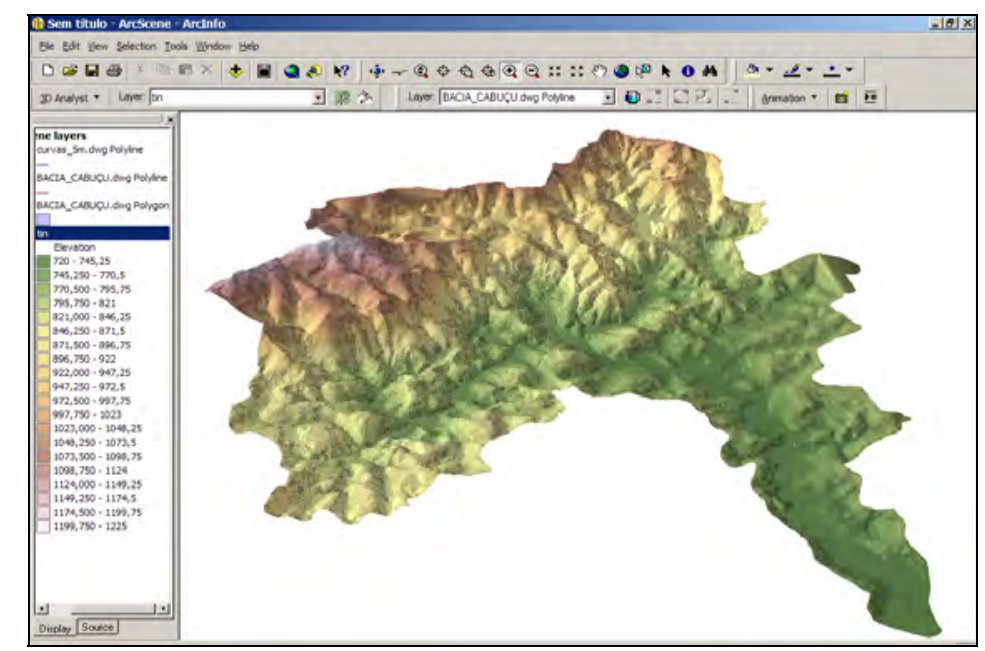

Figura 6. Ilustração do MDT completo da bacia com exagero vertical duplicado no Esri ArcScene ${ }^{\circledR}$.

\subsection{Ortorretificação e Mosaicagem}

A introdução de ortofotos visou subsidiar a carência de informações cartográficas para emprego no SSD. O emprego das ortofotos traz como uma das principais vantagens a total compatibilidade entre as feições presentes nas imagens e a superfície topográfica, uma vez que ambos têm como origem as mesmas fotografias aéreas.

O processo de ortorretificação baseou-se na correção, não uniforme, de distorções geométricas das fotografias, a fim de homogeneizar as diferenças existentes em escala, causadas pela projeção cônica delas e pela variação do relevo. Em tese, modelar o efeito causado pela projeção cônica das fotografias implica conhecimento dos parâmetros que definem a geometria da imagem, como distância focal, altura de vôo e características internas do sensor. As diferenças em escala das imagens causadas pelas irregularidades do terreno são corrigidas a partir do MDT.

Ainda, antes do processamento das ortofotos, as fotografias aéreas sofreram um processo de balanceamento radiométrico, responsável pela homogeneização das tonalidades, do brilho e do contraste delas (Nóbrega, 2002; Nóbrega e Quintanilha, 2004), a fim de minimizar eventuais discrepâncias que podem ser facilmente realçadas nos mosaicos.

Dessa forma, de posse de todos os parâmetros necessários e das imagens balanceadas, foram criadas as ortofotos, priorizando as regiões centrais de cada fotografia. Critérios de verificação da qualidade foram adotados após o processamento de cada ortofoto, como a verificação de regiões excessivamente distorcidas, a ligação entre ortofotos adjacentes e a sobreposição com dados vetoriais, como breaklines e curvas de nível.

O passo seguinte foi a mosaicagem das ortofotos, visando à obtenção de uma imagem única, conservando as propriedades geométricas das ortofotos originais. Nesse processo, 
foram adotadas linhas de corte, inseridas manualmente nas regiões de sobreposição entre duas ortofotos adjacentes. Foram eleitas as feições referentes ao nível do solo, a fim de evitar os efeitos de distorção pela diferença de projeção.

Uma vez mosaicadas, as ortofotos deram origem a um arquivo digital de aproximadamente 1,5 GB, incompatível com a grande maioria dos microcomputadores e aos aplicativos atuais. Nesse caso, a solução foi adotar uma articulação de folhas para recortar o mosaico em imagens menores. O planejamento da articulação levou em consideração a minimização do número de imagens, a facilidade operacional e a capacidade de processamento dos recursos computacionais já existentes no projeto do SSD. Assim, foram geradas 26 imagens (Figura 7) em formato GeoTiff de 228 MB cada, identificadas seqüencialmente por códigos alfanuméricos pré-determinados.

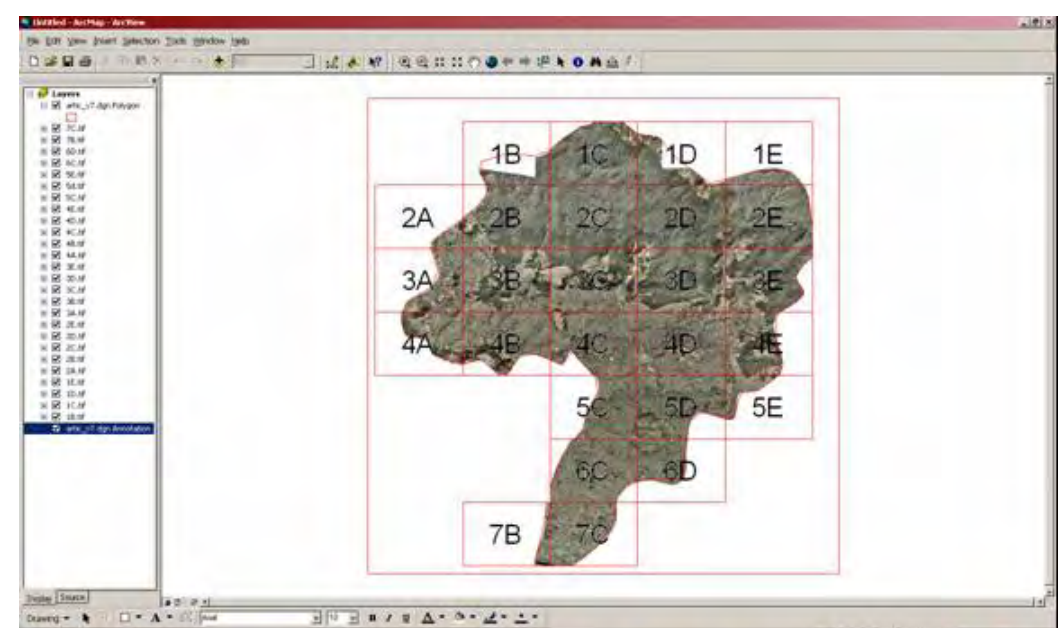

Figura 7. Visualização das imagens finais e da articulação no Esri Arcview $^{\circledR}$.

\section{RESULTADOS E DISCUSSÃO}

Como produto final, foi gerado um MDT de toda a extensão da bacia hidrográfica do Cabuçu. Para emprego no SSDURB, o MDT foi convertido em curvas de nível, disponibilizado em formato vetorial, de acordo com as características requeridas pelo sistema.

A proposta visou também à concepção de ortofotos digitais, as quais foram compiladas a partir das fotografias aéreas utilizadas e do MDT criado. A alta resolução das fotografias aéreas, a precisão geométrica da aerotriangulação, o balanceamento radiométrico e a fidelidade com que as feições do terreno foram representadas no MDT possibilitaram que as ortofotos fossem geradas com uma resolução espacial de $0,2 \mathrm{~m}$ e as feições representadas de modo contínuo, sem quebras.

A análise da precisão do MDT foi realizada comparando-se as altitudes pontos de controle levantados em campo pelos receptores GPS padrão geodésico e as correspondentes altitudes fornecidas pelo MDT. Essa análise foi desenvolvida pelo aplicativo Socet Set e foram considerados apenas os pontos internos à área coberta pelo MDT. Alguns pontos, por estarem localizados nas bordas do MDT, apresentaram resíduos elevados e foram desconsiderados na análise. A análise final mostrou que a média das diferenças foi de 0,5303m com um desvio padrão de 0,8025 e EQM de 0,9377 m. A maior diferença detectada entre os 14 pontos foi de 1,2633 m, o que nos leva a afirmar que, apesar do baixo grau de aderência entre o MDT e a superfície topográfica da bacia, esses resultados foram suficientes 
NÓBREGA, R. A. A.; BARROS, M. T. L. DE; QUINTANILHA, J. A. Emprego de técnicas digitais para a concepção da base cartográfica da bacia hidrográfica do Córrego Cabuçu de Baixo, São Paulo, SP. Ambi-Agua, Taubaté, v. 3, n. 1, p. 76-90, 2008. (doi:10.4136/ambi-agua.44)

para seu uso na aplicação desenvolvida. A Tabela 1 mostra os resultados da análise para os 14 pontos internos á área de interesse.

Tabela 1: Comparação entre altitudes dos pontos de controle e aquelas obtidas via MDT.

\begin{tabular}{c|c|c}
\hline $\mathbf{N}^{\mathbf{0}}$ de pontos & $\begin{array}{c}\text { Identificador do } \\
\text { Ponto }\end{array}$ & $\begin{array}{c}\text { Diferença em altitude } \\
\mathbf{( Z )} \\
(\mathbf{m})\end{array}$ \\
\hline 1 & $\mathrm{P} 06$ & 1,2633 \\
2 & $\mathrm{P} 07$ & 0,1324 \\
3 & $\mathrm{P} 01$ & 1,6637 \\
4 & $\mathrm{P} 04$ & $-0,2138$ \\
5 & $\mathrm{P} 08$ & 0,1258 \\
6 & $\mathrm{P} 09$ & $-1,0345$ \\
7 & $\mathrm{P} 10$ & 1,3090 \\
8 & $\mathrm{P} 11$ & 0,8185 \\
9 & $\mathrm{P} 12$ & 0,5592 \\
10 & $\mathrm{P} 13$ & 0,5449 \\
11 & $\mathrm{P} 14$ & 1,0289 \\
12 & $\mathrm{P} 17$ & $-0,8114$ \\
13 & $\mathrm{P} 18$ & 0,9544 \\
14 & $\mathrm{P} 21$ & 1,0845 \\
\hline
\end{tabular}

A sobreposição das informações altimétricas produzidas com o MDT e das ortofotos afirma a qualidade desses produtos como suporte para as análises visuais e automáticas, se comparados a outras fontes de informação, como a sobreposição entre as curvas de nível da base cartográfica do GEGRAN de 1977 e uma imagem do satélite IKONOS II de 2002 (Figura 8).

Por fim, um mosaico geral foi produzido, permitindo a visualização contínua de toda a extensão da bacia hidrográfica pela junção das 26 ortofotos existentes.
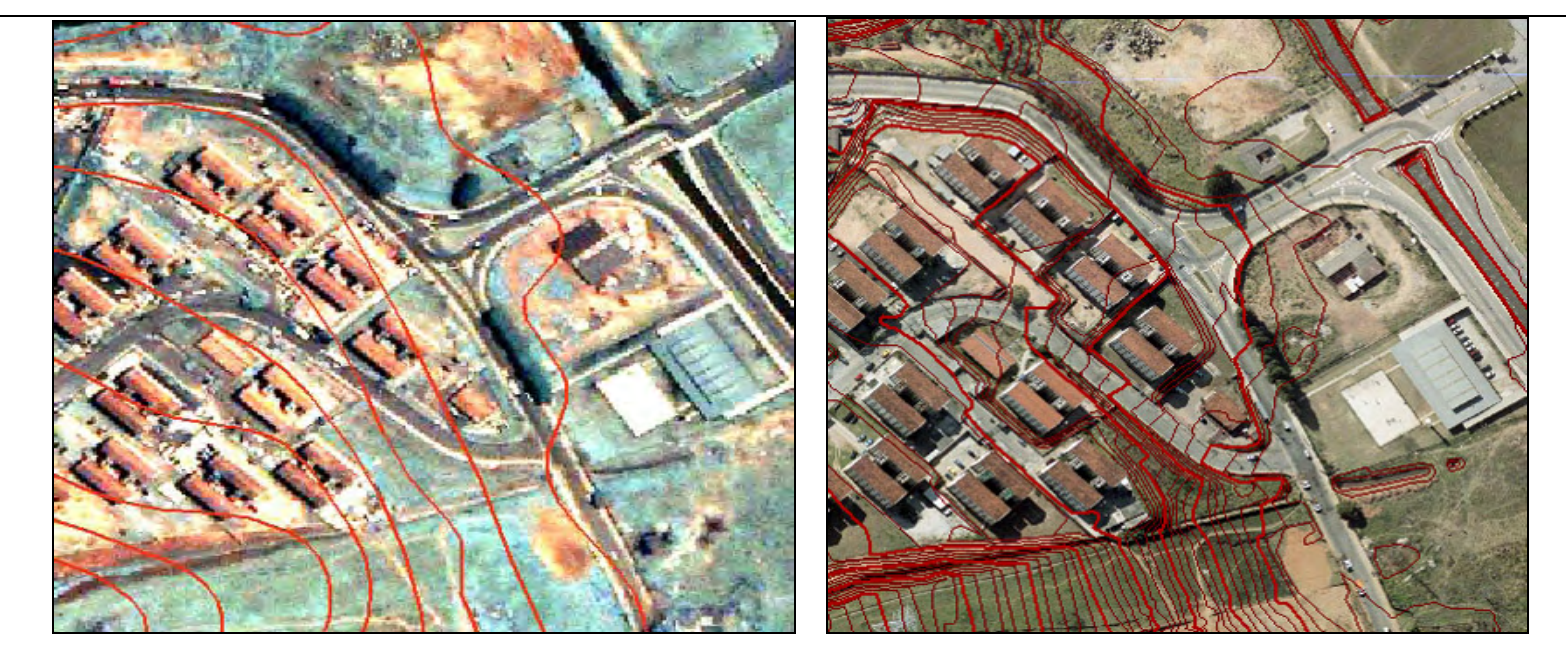

Figura 8. Acima: Curvas de nível GEGRAN 5m (1978) sobrepostas à imagem IKONOS II (outubro de 2002). Abaixo: Curvas de nível $1 \mathrm{~m}$ sobrepostas à ortofoto, ressaltando a movimentação do terreno com o empreendimento construído.

\section{CONCLUSÃO}

O artigo apresenta uma metodologia alternativa desenvolvida para a geração da superfície topográfica e o seu emprego na produção de ortofotos para subsidiar a coleta de 
informações planimétricas, em qualidade compatível com a modelação matemática do SSDURB.

Dadas às restrições de recursos e de tempo, a técnica de mapeamento aqui apresentada demonstrou ser muito adequada às análises feitas pelo SSDURB. A base cartográfica gerada, constituída por cartas altimétricas e ortofotos digitais, possibilitou que o projeto fosse subsidiado por informações precisas, tendo em vista os objetivos do SSD. Além disso, a altimetria permitiu a elaboração de pranchas tridimensionais que em muito contribuíram para análise espacial de propostas de intervenção na bacia, executadas posteriormente (Barros, 2005).

A utilização de um mesmo MDT para geração das ortofotos proporcionou um bom relacionamento entre as feições do terreno, ilustradas na imagem, e representadas pelas curvas de nível. Tais informações são de extrema importância ao SSD, pois permitem, por exemplo, revelar detalhes existentes em áreas sujeitas à inundação.

As vantagens que a adoção de um MDT obtido a partir de uma base cartográfica precisa e atualizada trouxeram ao SSD, foram bastante significativas do ponto de vista operacional. Do ponto de vista econômico, sabe-se que a introdução de um projeto de fotogrametria agrega valores (financeiros) elevados, o que muitas vezes inviabiliza o empreendimento. No entanto, a metodologia proposta nesse trabalho procurou trilhar uma forma diferenciada para suprir as necessidades do SSD. O modelo proposto preservou a precisão nos detalhes semelhante à de uma restituição fotogramétrica manual, e utilizou recursos automáticos disponíveis no aplicativo, em busca da redução no tempo de execução e, conseqüentemente, no custo.

\section{AGRADECIMENTOS}

Os autores agradecem à Escola Politécnica da Universidade de São Paulo, ao CNPq (Conselho Nacional de Desenvolvimento Cientifico e Tecnológico), à Wild Comercial Importadora Ltda. e aos membros da equipe envolvidos no Projeto Gerenciamento Integrado de Bacias Hidrográficas em Áreas Urbanas, Projeto CIAMB 02, 01/97, 03/01-2 PADCT III e aos revisores da revista Ambi-Água pelas sugestões e contribuições.

\section{REFERÊNCIAS}

BARROS, M. T. L. Gerenciamento Integrado de Bacias Hidrográficas em Áreas Urbanas. CNPq, EPUSP. 2004a. Disponível em: <http://www.phd.poli.usp.br/cabucu>. Acesso em: 19 março 2008

BARROS, M. T. L. Gerenciamento Integrado de Bacias Hidrográficas em Áreas Urbanas. São Paulo: CNPq, EPUSP, 2004b. Vol. 1. 52 p.

BARROS, M. T. L. Plano de Bacia Urbana - Relatório Final. São Paulo: EPUSP, FUSP, FINEP, CNPq, 2005.

BURROUGH, P.; MCDONNELL, R. Principles of Geographic Information Systems. New York: Oxford University Press, 1998. 333 p.

CHANDLER, J. Effective application of automated digital photogrammetry for geomorphological research. Earth Surface Processes and Landforms, v. 24, p. 51-63, 1999.

CHOI, J.-Y.; ENGEL, B. A.; THELLER, L.; HARBOR, J. Utilizing web-based gis and sdss for hydrological land use change impact assessment. Transactions of the American Society of Agricultural Engineers, v. 48, n. 2, p. 815-822, 2005. 
DYMOND, R. L.; REGMI, B.; LOHANI, V. K.; DIETZ, R. Interdisciplinary Web-Enabled Spatial Decision Support System for Watershed Management. Journal of Water Resource, Planning, and Management, v. 130, n. 4, p. 290-300, 2004.

DUNN, M.; HICKEY, R. The effect of slope algorithms on slope estimates within a GIS, Cartography, v. 27, p. 9-15, 1998.

GOOCH, M. J.; CHANDLER, J. H. Optimization of strategy parameters used in automated digital elevation model generation. In: DONOGHUE, D. N. M. (Ed.). International archives of photogrammetry and remote sensing. ISPRS, Data Integration: Systems and Techniques, Cambridge, v. 32, n. 2, p. 88- 95, 1998.

JACOBSEN, K. New developments in digital elevation modeling. Geoinformatics, v. 4, n. 5, p. 18-21, 2001.

LOHANI, V.; KIBLER, D. F.; CHANAT, J. Constructing a problem solving environment tool for hydrologic assessment of land use change. Journal of American Water Resources Association, v. 38, n. 2, p. 439-452, 2002.

MCGLONE, C. (Ed.) Manual of photogrammetry. 5.ed. Bethesda: American Society for Photogrammetry and Remote Sensing, 2004. 1151p.

MAUNE, D. F. Digital elevation model technologies and applications: the DEM user manual. 2.ed. Bethesda: American Society for Photogrammetry and Remote Sensing, 2007. 655 p.

NÓBREGA, R. A. A. Análise do balanceamento de imagens aplicado a fotogrametria. 2002. 119p. Dissertação (Mestrado em Engenharia de Transportes - Área de Informações Espaciais/Geoprocessamento) - Escola Politécnica da Universidade de São Paulo, São Paulo. 2002.

NÓBREGA, R. A. A., QUINTANILHA, J. A. Comparative analysis of automatic digital image balancing and standard histogram enhancement techniques in remote sensing images. Revista Brasileira de Cartografia. Curitiba - PR: , v.56, n.1, p.55 - 64. 2004.

QUEIROZ FILHO, A. P. Ortofoto digital para atualização cartográfica em um sistema de informações geográficas. 1993. 132 p. Dissertação (Mestrado em Engenharia de Transportes - Área de Informações Espaciais/Geoprocessamento) - Escola Politécnica da Universidade de São Paulo, São Paulo, 1993.

RAINIS, R. Estimating sediment yield using Agricultural Non-Point Sources (AGNPS) model: the effects of slope information from different GIS software. Journal of Spatial Hydrology, v. 4, n. 2, 2004.

SKIDMORE, A. A. Comparison of techniques for calculating gradient and aspect from a gridded digital elevation model. International Journal of Geographical Information Science, v. 3, p. 323-334, 1989.

TAYLER, K.; WALKER, G.; ABEL, D. A framework for model integration in spatial decision support systems. International Journal of Geographical Information Science, v. 13, n. 6, p. 533- 555, 1999. 
XU, Z. X.; ITO, K.; SCHULTZ, G. A.; LI, J. Y. Integrated hydrologic modeling and GIS in water resources management. Journal of Computing in Civil Engineering, v. 15, n. 3, p. 217-223, 2001.

WATSON, L. T.; LOHANI, V. K.; KIBLER, D. F.; DYNOND, R. L.; N.RAMAKRISHNAN, N.; SHAFFER, C. F. Integrated computing environments for watershed management. Journal of Computing in Civil Engineering, v. 16, n. 4, p. 259-268, 2002.

WECHSLER, S. P. Uncertainties associated with digital elevation models for hydrological applications: a review. Hydrology and Earth System Sciences, v. 11, p. 1481-1500, 2007.

WILSON, J. P.; MITASOVA H.; WRIGHT, D. J. Water resource applications of geographic information systems. URISA Journal, v. 12, n.2, p. 61-79, 2000.

ZEILHOFER, P. Modelação do relevo e obtenção de parâmetros fisiográficos na Bacia do Rio Cuiabá. Revista Brasileira de Recursos Hídricos, v. 6, n. 3, p. 95-109, 2001.

ZERGER, A.; WEALANDS, S. Beyond Modelling: Linking Models with GIS for Flood Risk Management. Natural Hazards, v. 33, p.191-208, 2004.

ZHOU, G.; CHEN, W.; KELMELIS, J. A.; ZHANG, D. A Comprehensive Study on Urban True Orthorectification. IEEE Transactions on Geoscinecce and Remote Sensing, v. 43, n. 9, p. 2138-2147, 2005. 


ISSN = 1980-993X - doi:10.4136/1980-993X
www.agro.unitau.br/ambi-agua
E-mail: ambi-agua@agro.unitau.br
Tel.: (12) 3625-4116

\title{
Estudo dos impactos da ocupação humana na microbacia do rio Batedor na Serra da Mantiqueira no município de Cruzeiro, SP, Brasil (doi:10.4136/ambi-agua.45)
}

\author{
Rubens Torres Curvello ${ }^{1}$; Getulio Teixeira Batista ${ }^{2}$; Marcelo dos Santos Targa ${ }^{2}$ \\ ${ }^{1}$ Aluno de Mestrado em Ciências Ambientais da Universidade de Taubaté (UNITAU) \\ E-mail: rtcurvello@hotmail.com \\ ${ }^{2}$ Professor do Programa de Pós-Graduação em Ciências Ambientais da Universidade de Taubaté \\ (UNITAU) \\ E-mail: \{getulio; mtarga\}@agro.unitau.br
}

\section{RESUMO}

Estudos de bacias hidrográficas como unidades territoriais integradoras da gestão de recursos hídricos são necessários para garantir o uso sustentável dos recursos naturais dessas bacias. A implantação do Comitê das Bacias Hidrográficas do Paraíba do Sul, em 1994, estimulou o levantamento de informações essenciais para o planejamento da gestão e manejo das bacias integrantes da Bacia do Paraíba do Sul situada em uma região industrializada e de acelerado desenvolvimento. O rio Batedor, localizado no município de Cruzeiro, SP, deságua no rio Passa Vinte, contribuinte do Paraíba do Sul. Sua foz é localizada nas coordenadas $22^{\circ} 31^{\prime} 0,63^{\prime}$ 'S e $45^{\circ} 01^{\prime} 2,07^{\prime}$ 'O. Sua nascente, distante cerca de $8,5 \mathrm{~km}$ de sua foz, encontrase próxima ao pico do Itaguaré, a $2.308 \mathrm{~m}$ de altitude, na Serra da Mantiqueira, divisa entre São Paulo e Minas Gerais. Para a caracterização da rede hidrográfica da bacia do Batedor e das formas de ocupação do solo foram utilizadas imagens do satélite Landsat e mapas planoaltimétricos analisados com técnicas de sensoriamento remoto e de geoprocessamento. Esse trabalho teve por objetivo estudar os impactos do uso do solo e dos recursos hídricos na bacia do rio Batedor e gerar material de apoio para educação ambiental. A bacia do rio Batedor apresenta boa disponibilidade hídrica, não apresenta risco de enchentes, está situada em área de muitas nascentes, nas encostas da Serra da Mantiqueira, e possui cursos jovens, com pouca sinuosidade. Nessa bacia ocorre ocupação irregular de áreas para moradias, desenvolvimento de agricultura de subsistência principalmente da bananicultura em locais declivosos e margens do rio, pastagens degradadas, que denotam a inadequação do uso do solo à legislação ambiental. Com a redução da cobertura florestal da bacia houve agravamento dos processos erosivos o que causou o assoreamento da calha do rio e alterou as características de qualidade e quantidade regularizada de água dessa bacia, hoje responsável pelo abastecimento de $70 \%$ do consumo da cidade de Cruzeiro, SP.

Palavras-chave: Bacia hidrográfica; Rio Batedor; Geoprocessamento; Impacto ambiental; Educação ambiental; SIG.

\section{Study of human occupation impacts in the Batedor river basin in the Mantiqueira Mountain in the municipality of Cruzeiro, SP, Brazil}

\section{ABSTRACT}

The study of hydrographic basins as territorial units integrating the management of hydric resources is essential to guarantee sustainable use of natural resources in these basins. The establishment of the Paraíba do Sul hydrographic basins committee, in 1994, determined the need for management planning and action integration in the Paraíba do Sul basin which 
incorporates a variety of industries and intense land use. The Batedor river, in the municipality of Cruzeiro, SP, flows into the Passa Vinte which is an affluent of Paraíba do Sul river. Its mouth is located at $22^{\circ} 31^{\prime} 0.63^{\prime}$ S and $45^{\circ} 01^{\prime} 2.07^{\prime \prime} \mathrm{W}$. Its farthest water contributing source lies about $8.5 \mathrm{~km}$, near the Itaguaré peak 2,308 $\mathrm{m}$ high, in the Mantiqueira Mountain on the border of São Paulo and Minas Gerais States. To characterize land use in the Batedor hydrographic basin, Landsat imagery and topographic charts were analyzed based on remote sensing and geoprocessing techniques. This paper describes the study of impacts related to land and water resources use in the Batedor river basin and the generation of educational environmental material. Results have shown that this basin has good water supply, has no flooding risk and has several springs running down the Mantiqueira Moutain slopes that form young creeks with few meanders. Irregular human occupation for housing and subsistence agriculture, mainly banana plantations can be seen in deep slopes and riparian areas, as well as degraded pastures that indicate inappropriate land use and no conformance to pertinent legislation. The decrease in forest vegetation cover can cause severe erosion with significant soil loss and sediment deposition in the river, thus reducing water quality and quantity during the dry season. This basin is currently responsible for $70 \%$ of the Cruzeiro, SP water supply.

Keywords: Hydrographic Basin; Batedor River; Geoprocessing; Environmental Impact; Environmental Education; GIS.

\section{INTRODUÇÃO}

Para a gestão dos recursos hídricos vitais à manutenção da qualidade de vida da sociedade, surgiram várias ações, dentre as quais se destacam a implantação inovadora do Comitê das Bacias Hidrográficas do Paraíba do Sul, em 1994 e, em nível nacional, a criação da lei 9433/97 que institui a Política Nacional de Recursos Hídricos.

O gerenciamento e a preservação da Bacia do Rio Paraíba do Sul que abrange uma área industrial entre as mais desenvolvidas do país, com 57 mil $\mathrm{Km}^{2}$ e cerca de cinco milhões de habitantes deve ser feito com base em estudos para o manejo e a conservação das microbacias que compõem a bacia do Paraíba do Sul.

Conforme já demonstraram Aulicino et al. (2000), o uso de técnicas de Geoprocessamento e Sensoriamento Remoto é importante para o planejamento geográfico, pela disponibilização e integração de dados fundamentais para o zoneamento e manejo sustentável de bacias hidrográficas e, especialmente na investigação da adequação do uso do solo em áreas de preservação permanente.

O município de Cruzeiro, SP, com 331 quilômetros quadrados e aproximadamente 80 mil habitantes, situado próximo às vertentes da Serra da Mantiqueira apresenta diversos mananciais com importância relevante para a Bacia do Rio Paraíba do Sul. O rio Batedor, localizado nesse município (Figura 1) é responsável por 70\% do abastecimento de água, com uma vazão de captação de 600 m³/h, conforme outorga do DAEE (São Paulo, 2005).

Segundo a classificação de Setzer (1966), o clima da área de estudo é caracterizado por inverno seco e verão chuvoso, com temperatura média do mês mais frio inferior a $18^{\circ}$ e a do mês mais quente superior a $22^{\circ} \mathrm{C}$, com índice pluviométrico variando entre 1.100 e $1.700 \mathrm{~mm}$ anuais, e com estação seca entre os meses de abril e setembro.

A Serra da Mantiqueira é formada por escarpas elevadas e morros, nos quais o planalto mineiro termina diante do Vale do Paraíba, e encontra-se dividida nesta zona em duas porções: Serra da Mantiqueira Oriental e Serra da Mantiqueira Ocidental. A Serra da 
Mantiqueira Oriental é formada por escarpas festonadas, originárias de relevos mais íngremes entre o planalto de Campos do Jordão (SP) e sua continuação até o maciço de Itatiaia (RJ), terminando a oeste, na altura da localidade de Monteiro Lobato (SP). A partir daí, a configuração geológica da Serra da Mantiqueira muda, passando a ser considerada Serra da Mantiqueira Ocidental (Ponçano et al., 1981).

A bacia hidrográfica do rio Batedor encontra-se nas vertentes da Serra da Mantiqueira, em área correspondente à Área de Preservação Ambiental (APA) da Mantiqueira, estabelecida por meio do Decreto $n^{0}$ 91304, de 03 de junho de 1985 com a finalidade de proteger e preservar uma das maiores cadeias montanhosas da região sudeste do Brasil.

Os dobramentos antigos ou escudos cristalinos como a Serra da Mantiqueira possuem solos litólicos, com horizontes A ou "O” (orgânico) seguido pela rocha matriz, o que indica pouca infiltração e muito escoamento superficial, dando origem a inúmeros cursos d'água (Vieira, 1975).

O solo da bacia hidrográfica do Batedor é formado, no curso superior, por neossolo litólico com afloramento de rocha e cambissolo háplico distrófico com argila de atividade baixa. Nos cursos médios e inferiores é formado por latossolo vermelho e amarelo distrófico com camadas litólicas (Oliveira et al., 1999).

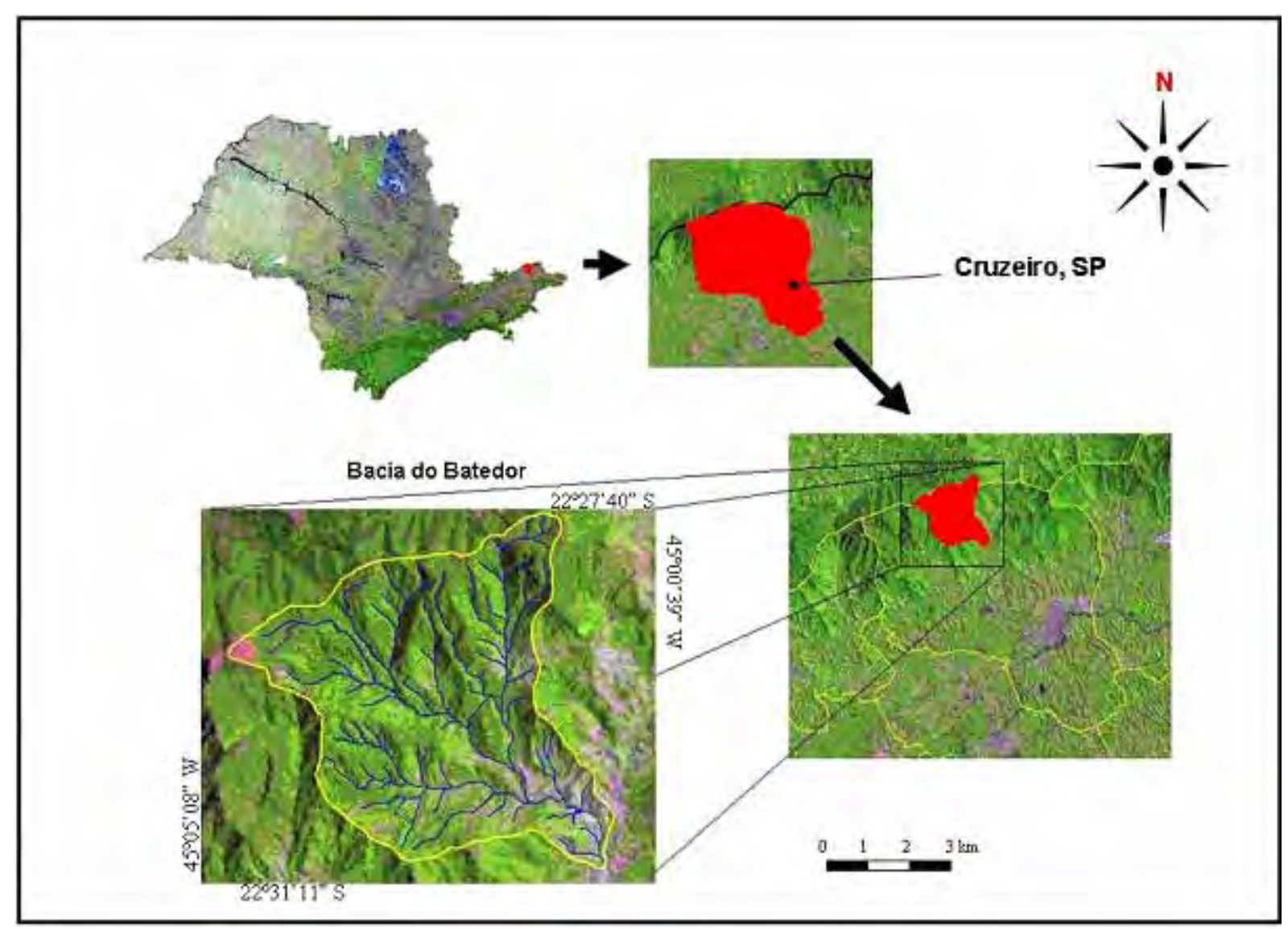

Figura 1. Localização da Bacia do rio Batedor com seus principais formadores sobre imagem CBERS 2 (Satélite Sino-Brasileiro de Recursos Terrestres), sensor CCD, órbita: 153, ponto 125, adquirida em $24 / 08 / 2005$.

O relevo é um importante fator que pode influenciar bastante na profundidade dos solos. Assim, a sua profundidade aumenta quando diminui a declividade (Vieira, 1975). A formação vegetal original dessa bacia é Floresta Ombrófila Mista que ocorre em áreas de clima quente e 
úmido sem período biologicamente seco, com ocorrência exclusiva no Planalto Meridional Basileiro acima de 500/600 metros de altitude (IBGE, 2004).

A preservação e proteção das águas da bacia do rio Batedor com objetivo de garantir o abastecimento da cidade de Cruzeiro, SP, teve início em 1964, quando o poder púbico municipal desapropriou 758 alqueires correspondentes à fazenda do Batedor por meio dos Decretos $n^{\circ}$ 145/1964 e $n^{\circ}$ 146/1964 (Cruzeiro, 1964). Contudo, após a data do decreto ocorreram ocupações irregulares na bacia do rio Batedor, pois foram realizadas à margem da legislação urbanística, ambiental, civil, penal e registrária (Pinto, 2003).

A ocupação irregular da bacia e a implantação de atividades agrícolas como o cultivo de banana, milho e hortaliças com técnicas e métodos impróprios vêm afetando a microbacia do Batedor pelo uso competitivo pela água e nutrientes, além de fomentar o desmatamento, em áreas de encostas, nascentes e margens. Esses usos e ocupação também aumentam o risco de escorregamento, pois a supressão da mata nativa faz com que a velocidade do escoamento das águas das chuvas seja aumentada, o que causa voçorocas e assoreamento do leito do rio Batedor, além de pôr em risco a vida da população local.

Outra ação importante para a conservação do ambiente e em especial dos mananciais foi a criação das Áreas de Proteção Ambiental (APAs), por meio da Lei n ${ }^{\circ}$ 6902/1981, regulamentada pelo Decreto ${ }^{\circ}$ 99.274/1990 e que compõe o Sistema Nacional de Unidades de Conservação (SNUC), instituído pela Lei 9985/2000.

A Bacia hidrográfica do rio Batedor encontra-se quase totalmente situada dentro dos limites da APA da Serra da Mantiqueira, excluindo uma pequena parte a sudeste da bacia, como pode ser observado na Figura 2.

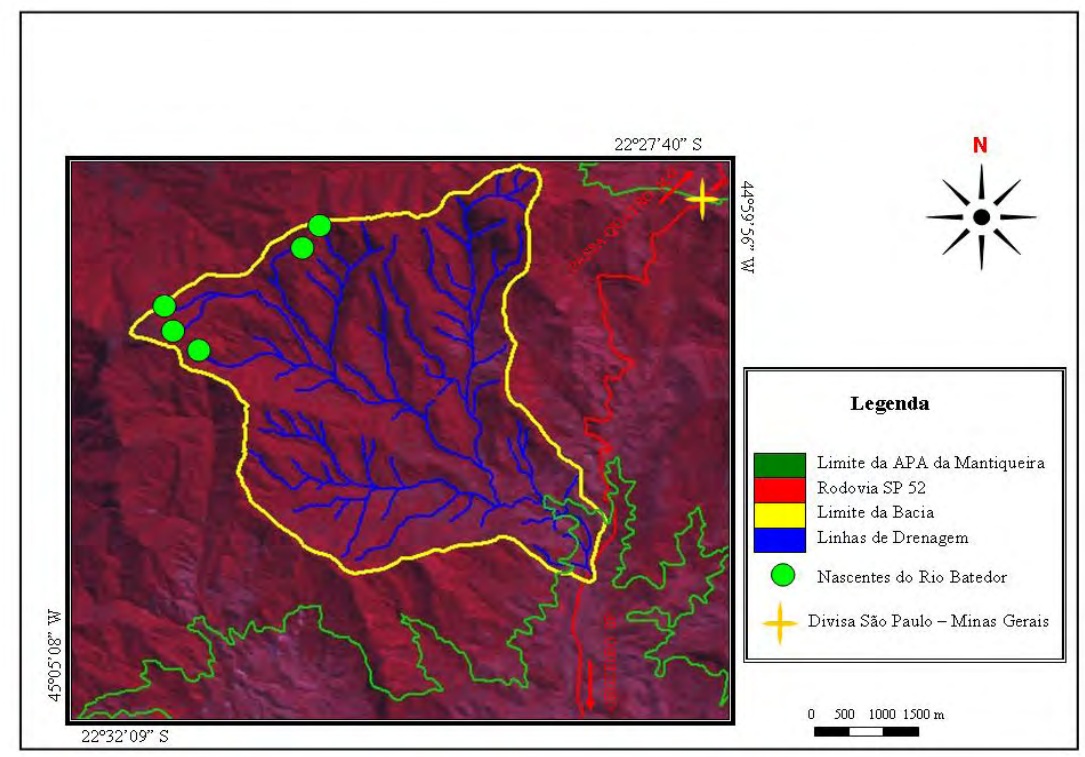

Figura 2. Localização da bacia do Batedor em relação aos limites da APA da Mantiqueira, mostrando as principais nascentes e formadores.

Embora exista uma legislação ambiental relativa às Unidades de Conservação, a Lei Federal 9985/2000 ou Lei SNUC, em seu Artigo 15, admite a ocupação humana em APAs quando define: A Área de Proteção Ambiental é uma área em geral extensa, com certo grau de ocupação humana, dotada de atributos abióticos, bióticos, estéticos ou culturais especialmente importantes para a qualidade de vida e o bem-estar das populações humanas, e tem como objetivos básicos proteger a diversidade biológica, disciplinar o processo de ocupação e assegurar a sustentabilidade do uso dos recursos naturais. 
Pela necessidade de se preservar o remanescente de floresta tropical ombrófila úmida contidos no maciço da Mantiqueira, foi criada a APA da Serra da Mantiqueira, por meio do Decreto $\mathrm{n}^{\circ}$ 91304, de 03 de junho de 1985, abrangendo vários municípios do Estados de Minas Gerais, do Rio de Janeiro e de São Paulo, entre eles, o município de Cruzeiro no estado de São Paulo. O objetivo desse trabalho foi estudar os impactos do uso do solo e dos recursos hídricos na bacia do rio Batedor e gerar material de apoio para educação ambiental.

\section{MATERIAL E MÉTODO}

Inicialmente, foram digitalizadas as cartas topográficas folhas Lorena e Virgínia, edição do IBGE de 1971, Datum Horizontal Córrego Alegre, na escala 1:50.000, para localização da área estudada com o uso do Sistema de Processamento de Informações Georreferenciadas (SPRING), que é um aplicativo para processamento de imagens e de SIG (Sistema de Informações Geográficas) (Câmara et al., 1996), instalado no Laboratório de Geoprocessamento, Sensoriamento Remoto e Informática Rural da Universidade de Taubaté (LAGEO).

Foi criado um projeto correspondente a um retângulo, com as coordenadas $22^{\circ} 33^{\prime}$ 41,73” S $45^{\circ} 07^{\prime} 22,98^{\prime}$ ' O, e $22^{\circ} 25^{\prime}$ 47,04” S, 44 58' 10,94”O e, em seguida, a partir dessas coordenadas foi delimitada a bacia hidrográfica do rio Batedor, observando-se os divisores de água a partir das curvas de nível representadas nas cartas topográficas usando-se funções do aplicativo SPRING.

As linhas de drenagem foram digitalizadas com base nas cartas topográficas para a caracterização de diversos parâmetros da bacia. Como características físicas foram determinados o Coeficiente de compacidade (Kc), o Fator de forma (Kf), a Densidade de drenagem, o Comprimento do talvegue, a Sinuosidade do rio e a Ordem dos cursos d'água, conforme metodologia descrita em Villela e Matos (1975) usando-se as Equações 1 a 3.

$$
K c=\frac{P}{\sqrt{A}} * 0,28
$$

em que $K c$ é o coeficiente de compacidade; $P$ é o perímetro da bacia em km; $A$ é a área da bacia em $\mathrm{km}^{2}$.

$$
K f=\frac{A}{L^{2}}
$$

em que $K f$ é o fator de forma, adimensional; $L$ é o comprimento axial da bacia em km.

$$
D d=\frac{\overline{L t}}{A}
$$

em que $D d$ é a Densidade de drenagem em $\mathrm{km} / \mathrm{km}^{2} ; L t$ é o comprimento total dos cursos d’água da bacia em km; $A$ é a área da bacia hidrográfica em $\mathrm{km}^{2}$.

Os limites da bacia foram sobrepostos a uma imagem georreferenciada do satélite CBERS 2 (Satélite Sino-Brasileiro de Recursos Terrestres), sensor CCD, órbita 153, ponto 125, adquirida em 24/08/2005, em composição colorida de três bandas espectrais, $2(0,52-$ 0,59 $\mu \mathrm{m}$, Verde), 3, (0,63-0,69 $\mu \mathrm{m}$, Vermelho) e 4 (0,77-0,89 $\mu \mathrm{m}$, Infra-Vermelho Próximo), associadas às cores primárias azul, verde e vermelho, respectivamente. Com base na análise dessa imagem, foi feita uma classificação digital, usando um algoritmo de máxima verossimilhança (MAXVER) (Hernandez Filho et al., 1998) para a caracterização da cobertura e uso do solo da bacia.

A determinação da altimetria foi feita a partir da digitalização das linhas de curvas de nível das cartas topográficas do IBGE e da geração no SPRING de uma grade de Medida 
Numérica do Terreno (NMT) de 20 m de resolução com base no uso de funções no estado da arte de sistemas de informações geográficas disponibilizadas na versão do SPRING, V.3.6.03, http://www.dpi.inpe.br/spring/ (Câmara et al., 1996).

Foi realizado, em maio de 2007, trabalho de campo para observação in loco da paisagem, do uso e ocupação do solo com informações registradas por câmara digital e georreferenciadas com receptor GPS de navegação. Essas observações foram fundamentais para a análise das imagens de satélite no SPRING.

Com base no Mapa Pedológico de São Paulo, elaborado pelo IAC (Instituto Agronômico de Campinas) e pela EMBRAPA (Empresa Brasileira de Pesquisa Agropecuária), de 1999, escala de 1:500.000, os principais grupos de solo encontrados na bacia hidrográfica do rio Batedor foram identificados.

\section{RESULTADOS E DISCUSSÃO}

O tratamento das imagens de satélite e das cartas topográficas no aplicativo SPRING permitiram a geração de mapas e informações com as características hidrográficas da bacia do rio Batedor e do uso do solo. A imagem da bacia do rio Batedor com a delimitação dos seus limites (divisor de águas), da rede de drenagem, e ordem dos cursos d'água, classificado segundo Strahler (1956) pode ser observada na Figura 3. Parâmetros como a área da bacia $(A)$ ou área de drenagem, o perímetro $(P)$, o comprimento total dos cursos d'água $(L t)$, o comprimento do talvegue, aplicados às equações 1,2 e 3 possibilitaram o cálculo dos coeficientes de compacidade $(K c)$, de forma $(K f)$, densidade de drenagem $(D d)$ e sinuosidade do rio Batedor (Tabela 1 )

Os limites (divisores de água) da bacia do rio Batedor, sua rede de drenagem, classifica segundo Strahler, assim como os parâmetros físicos calculados incluindo a área da bacia $(A)$ ou área de drenagem, o perímetro $(P)$, o comprimento total dos cursos d'água $(L t)$ e o comprimento do talvegue do rio Batedor podem ser observados na Figura 3 e Tabela 1.

Observando a Figura 3 e o resultado da densidade de drenagem, pode-se afirmar que a bacia do rio Batedor, de quarta ordem segundo a classificação de Strahler (1956) é bem drenada (Figura 5.) e, portanto, tem menor capacidade de infiltrar água, proporcionando assim, maior escoamento superficial, fato este que está em acordo com as características de solos litólicos (Vieira, 1975). Embora seja uma bacia com área de 22,60 Km², o comprimento do rio principal é de apenas de 8,5 Km (Tabela 1). A Densidade de drenagem é de 2,82 $\mathrm{km} / \mathrm{km}^{2}$, o que indica ser uma bacia de boa densidade de drenagem (Targa, 2004), por situarse em área de escudos cristalinos, com pouca capacidade de infiltração e muito escoamento superficial (Villela e Matos, 1975) que somados aos aspectos climático e cobertura florestal fica explicado o fato da bacia ser responsável por 70\% do abastecimento do município de Cruzeiro, SP, com uma vazão de captação da ordem de 600m³/h (São Paulo, 2005).

A baixíssima sinuosidade do rio Batedor $(1,36)$ está relacionada com rios em topografias acidentadas (rios jovens), e poderia indicar um escoamento bastante rápido. Contudo, o coeficiente de compacidade $(K c)$ determinado para a bacia de 1,34 e o Fator de forma $(K f)$ de 0,31 indicam que a bacia do rio Batedor é pouco sujeita a enchentes (Villela e Matos, 1975).

A geração do mapa de uso do solo a partir da análise digital da imagem CBERS 2, no SPRING permitiu identificar quatro classes de uso de solo (Figura 4 e Tabela 2). Ao se observar a Tabela 2, percebe-se que a maior parte da bacia hidrográfica apresenta cobertura vegetal arbórea (78,8\%), seguida de pastagens ou pequenas culturas de subsistência (10,1\%), 
CURVELlo, R. T.; BATISTA, G. T.; TARGA. M. dos S. Estudo dos impactos da ocupação humana na microbacia do rio Batedor na Serra da Mantiqueira no município de Cruzeiro, SP, Brasil. Ambi-Agua, Taubaté, v. 3, n. 1, p. 91-107, 2008. (doi:10.4136/ambi-agua.45)

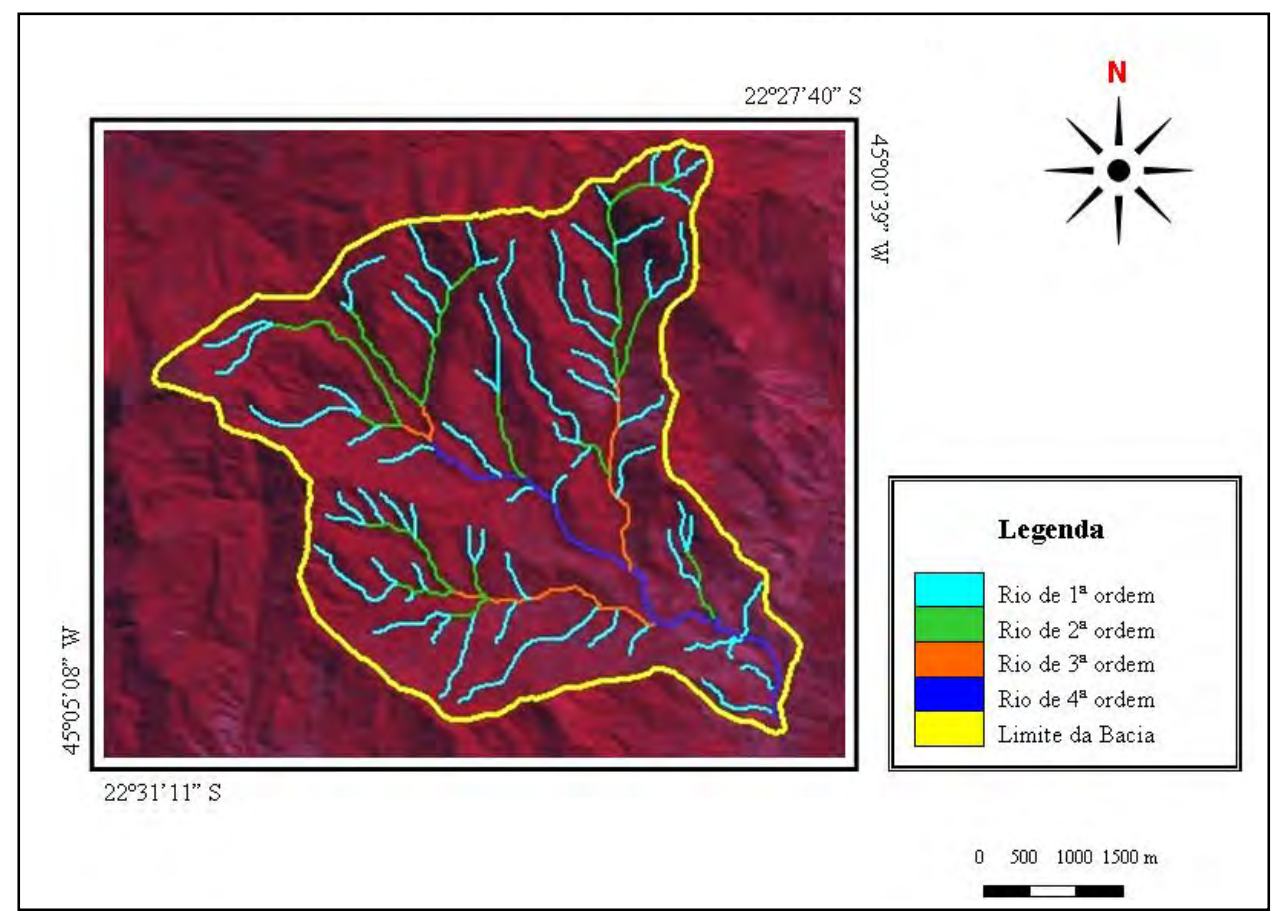

Figura 3. Limite, rede de drenagem, classificada segundo Strahler (1956) da bacia do rio Batedor sobre imagem CBERS de 2005.

Tabela 1. Características físicas da bacia hidrográfica do rio Batedor.

\begin{tabular}{l|c}
\hline Características Físicas & Bacia do Rio Batedor \\
\hline Área $(A)$ & $22,60 \mathrm{~km}^{2}$ \\
Perímeto $(P)$ & $22,47 \mathrm{~km}$ \\
Comprimento do talvegue $(L)$ & $8,50 \mathrm{~km}$ \\
Comprimento total dos cursos d'água $(L t)$ & $63,80 \mathrm{~km}$ \\
Coeficiente de compacidade $(K c)$ & 1,34 \\
Fator de forma $(k f)$ & 0,31 \\
Densidade de drenagem $(D d)$ & $2,82 \mathrm{~km} / \mathrm{km}^{2}$ \\
Sinuosidade & 1,36 \\
\hline
\end{tabular}

enquanto que a porção de solo exposto ou pequenas construções rurais correspondem a apenas $0,8 \%$. Tais dados indicam que a bacia do Batedor ainda está bem manejada, com uso não muito intenso, contudo não está isenta de ações antrópicas que podem ser prejudiciais à manutenção do solo e da qualidade de seu recurso hídrico.

A análise digital da imagem de satélite, com áreas de sombra, que correspondiam a $10 \%$ da área total da bacia foi prejudicada. Sombras freqüentes ocorrem devido ao fato da área de estudo localizar-se, em sua maior parte, em terrenos escarpados, nas encostas da Serra da Mantiqueira. Outra dificuldade encontrada foi a não identificação de algumas áreas pequenas de culturas de subsistência, como milho e mandioca. Essas áreas foram incluídas na categoria pasto. Essas dificuldades foram superadas com o levantamento de campo que permitiu a 


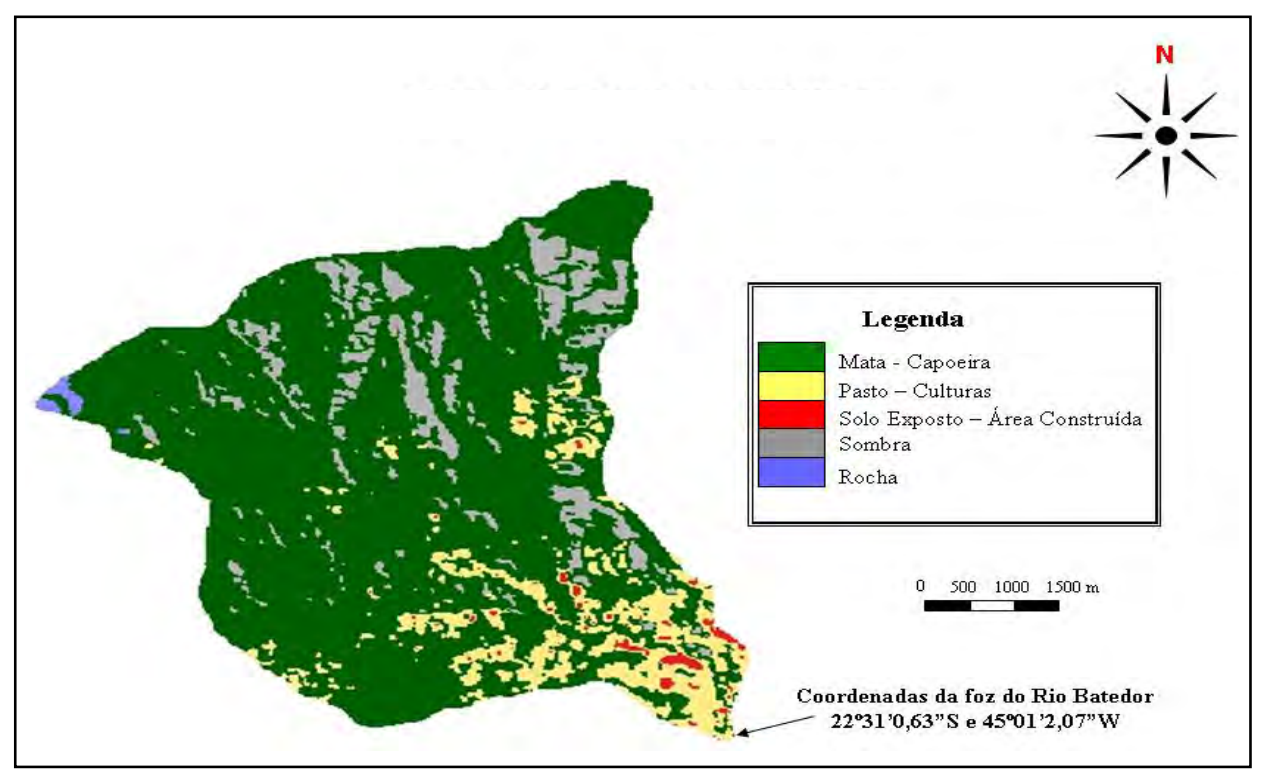

Figura 4. Cobertura e uso do solo na bacia do Batedor.

Tabela 2. Categorias de uso do solo na Bacia do rio Batedor.

\begin{tabular}{l|c|c}
\hline \multicolumn{1}{c|}{ Categorias } & Área $\left(\mathbf{K m}^{\mathbf{2}}\right)$ & Porcentagem $\mathbf{( \% )}$ \\
\hline Mata - Capoeira & 17,80 & 78,8 \\
Pasto - Culturas & 2,28 & 10,1 \\
Solo Exposto - Área Construída & 0,18 & 0,8 \\
Sombra & 2,26 & 10,0 \\
Rocha & 0,08 & 0,4 \\
\hline Total & $\mathbf{2 2 , 6 0}$ & $\mathbf{1 0 0 , 0}$ \\
\hline
\end{tabular}

constatação in loco que as áreas de sombra, por se tratarem de áreas mais escarpadas, sofreram pouca ação antrópica e possibilitou a constatação de que em, aproximadamente, $80 \%$ dessas áreas $\left(1,8 \mathrm{~km}^{2}\right)$ ocorre cobertura de mata ou capoeira e que em $20 \%$ encontra-se com plantios de bananas $\left(0,46 \mathrm{~km}^{2}\right)$. Com esse ajuste de campo, a percentagem da classe Mata-Capoeira sobe para 86,7\%.

Com base no trabalho de campo e no Mapa Pedológico de São Paulo, elaborado pelo IAC e EMBRAPA, três grandes grupos de solo foram identificados na bacia hidrográfica do rio Batedor (Figura 5). Os Neossolos Litólicos, encontrados na bacia hidrográfica do rio Batedor são por definição solos que apresentam reduzida profundidade efetiva. Essa condição limita seu uso com agricultura devido ao reduzido volume de terra disponível para o ancoramento das plantas e para a retenção de umidade. A maioria desses solos ocorre em relevos acidentados, portanto muito susceptíveis à erosão e apresentam sérias limitações de trafegabilidade. Seu uso requer cuidados especiais quanto aos tratos conservacionistas (Oliveira, 1999).

Já os Cambissolos, segundo Oliveira (1999), estão situados em relevo forte ondulado a escarpado. Apresentam severas restrições quanto ao uso agrícola, os localizados em terrenos escarpados apresentam limitações mesmo ao uso pastoril e florestal devido à sua capacidade de desagregação. Tais solos possuem elevada erodibilidade e forte limitação à trafegabilidade, à qual é aumentada com a pedregosidade e afloramentos de rocha e pela presença de solos 
rasos representados pelos Neossolos Litólicos. É comum a presença de solos apresentando horizonte $\mathrm{Cr}$ (saprolito) constituído por rocha parcialmente intemperizada a profundidades inferiores a $1,5 \mathrm{~m}$. Geralmente, tais saprolitos apresentam significativo estádio de intemperismo, sendo portanto de consistência branda, não oferecendo limitações ao sistema radicular das plantas.

Por outro lado, a classe dos Latossolos constitui o agrupamento de solos mais extenso do Estado de São Paulo. São, em geral, solos com boas propriedades físicas e situados, na maioria dos casos, em relevo favorável ao uso intensivo de máquinas agrícolas, com exceção dos solos em regiões serranas. Os Latossolos tendem a apresentar elevada porosidade e friabilidade, o que facilita seu manejo agrícola. O relevo, com exceção dos solos situados em região serrana, é pouco movimentado, com declividade geralmente inferior a 5\% qualifica os Latossolos como os mais adequados para a agricultura extensiva no Estado de São Paulo. Sua principal limitação é a baixa disponibilidade de nutrientes nos solos distróficos. Os Latossolos Vermelho - Amarelo argissólicos apresentam em geral relação textural ligeiramente superior aos Latossolos típicos, fato que lhes confere uma erodibilidade um pouco maior.

O conhecimento de propriedades do solo auxilia na seleção das áreas a serem utilizadas na exploração agrícola, bem como na determinação do tipo e do grau com que as práticas de conservação devem ser empregadas para reduzir a desagregação pela erosão hídrica do solo (Albuquerque et al., 2000). A erodibilidade do solo é uma característica utilizada nos planejamentos conservacionistas. As práticas de conservação devem ser mais intensas em solos com erodibilidade alta do que em áreas com erodibilidade baixa.

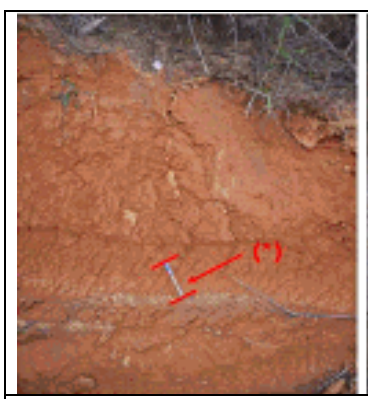

(a)

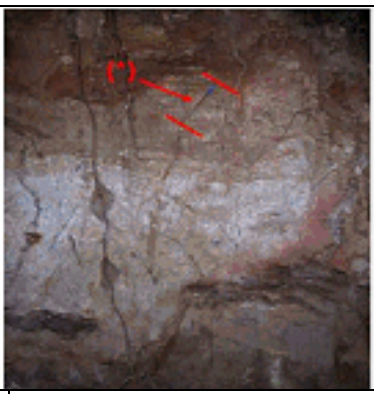

(b)

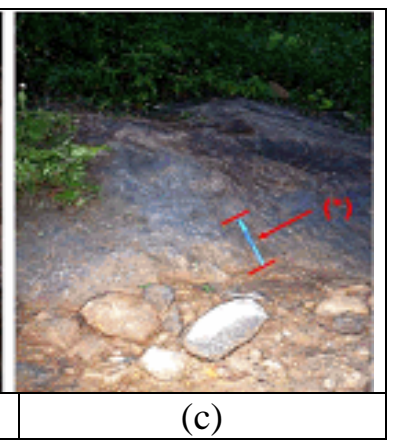

(c)

Figura 5. Tipos de solo encontrado na Bacia do Batedor: a) LatossoloVermelho Amarelo Distrófico; b) Cambissolo Háplico Distrófico; c) Neossolo Litólico com Afloramento de Rochas (fotos de campo dos autores).

As características dos solos encontrados na bacia do rio Batedor como baixa profundidade e grande quantidade de cascalho encontrada no cambissolo háplico e no neossolo litólico, bem como o relevo inclinado, condicionam sérios impedimentos à mecanização, o que limita atividades agrícolas na bacia. Essas características também estão associadas à maior susceptibilidade à erosão, principalmente, devido à baixa permeabilidade e à formação de sulcos pela enxurrada (EMBRAPA, 1999).

Com base na digitalização das curvas de nível, derivou-se um mapa altimétrico da bacia do rio Batedor (Figura 6). Pode-se notar uma elevada variação de altitude na área de estudo. A Figura 7 mostra o mapa de declividade que evidencia um elevado grau de declive do terreno, com média de declividade de $23^{\circ}$ com áreas em que a declividade chega a $80^{\circ}$.

A altitude varia de $625 \mathrm{~m}$ até $2.249 \mathrm{~m}$ com uma altitude média de $1291 \mathrm{~m}$. A variação de altitude é de $1.624 \mathrm{~m}$ em pouco mais de $8 \mathrm{Km}$ de distância. Tal variação altimétrica influencia significativamente as temperaturas locais e o regime pluviométrico da área estudada. 


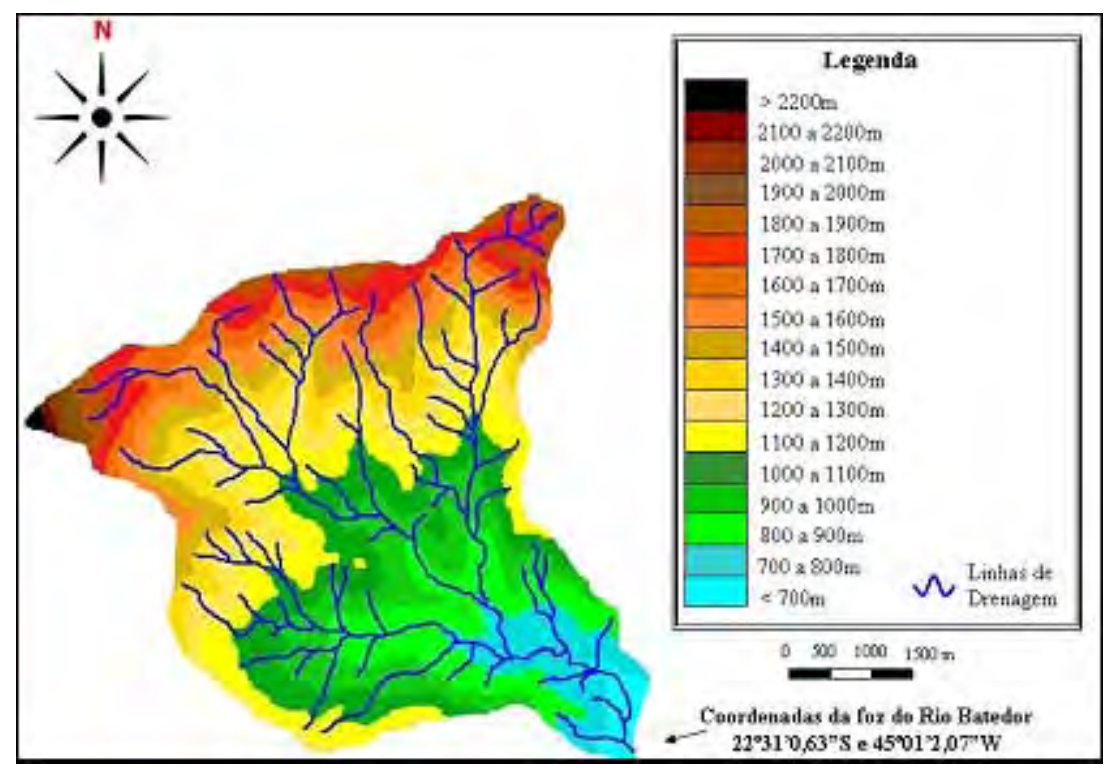

Figura 6. Hipsometria da bacia rio Batedor com intervalos de altitude de $100 \mathrm{~m}$.

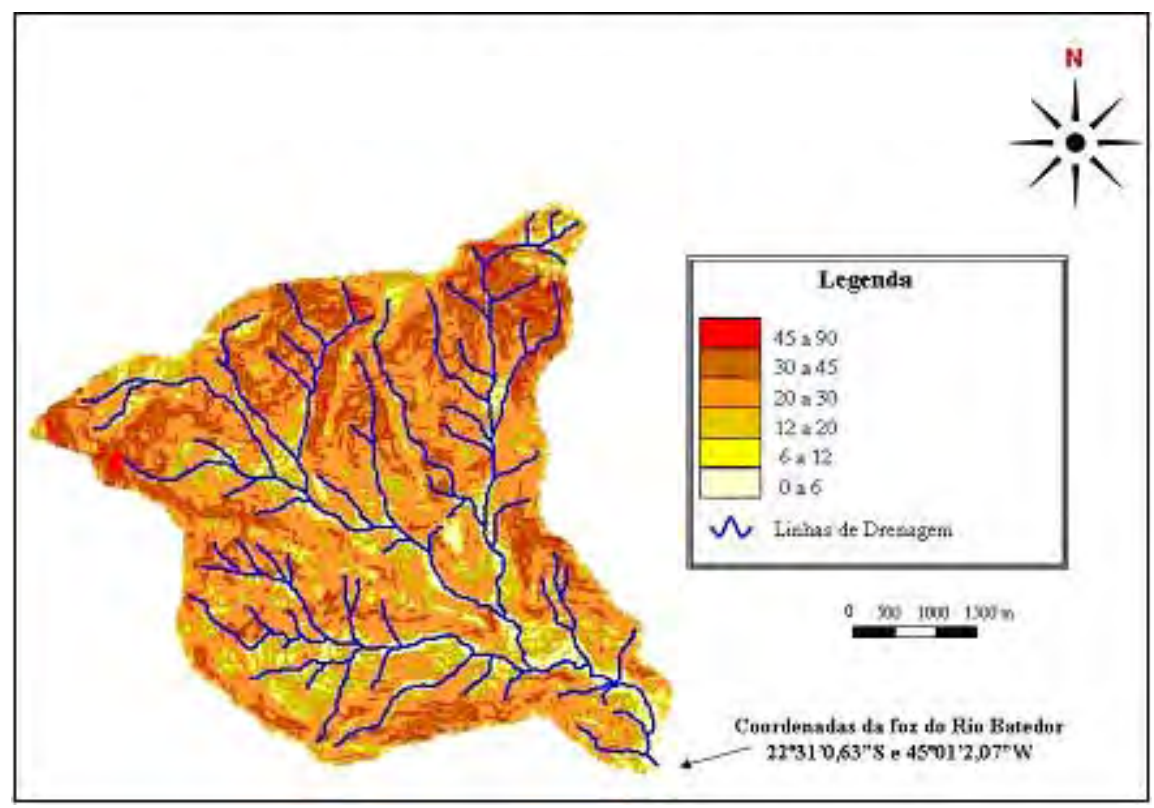

Figura 7. Declividade (em graus) da bacia do rio Batedor.

As pesquisas de campo revelaram ocupação humana irregular, envolvendo 96 famílias com aproximadamente 286 pessoas que utilizam métodos inadequados para o plantio de banana, milho e hortaliças que afetam a bacia devido à fragilidade do solo. O plantio de bananas tem provocado impacto negativo no solo, com retirada de água e nutrientes, além de fomentar o desmatamento em áreas de encostas, nascentes e margens, favorecendo o processo de desmoronamento.

Na observação em campo, constatou-se que as áreas de pastagem encontram-se bastante degradadas, sem nenhum tipo de manejo. Na bacia do rio Batedor é explorada pecuária leiteira extensiva de pequeno porte (Figura 8A), com superpastoreio que provoca erosão laminar (Figura 8B) e alto grau de pisoteio pelo gado (Figura 8C, seta laranja). Em algumas áreas de pastagem, o solo está exposto (Figura 8D, seta amarela) e em alguns casos, com 
CURVELlO, R. T.; BATISTA, G. T.; TARGA. M. dos S. Estudo dos impactos da ocupação humana na microbacia do rio Batedor na Serra da Mantiqueira no município de Cruzeiro, SP, Brasil. Ambi-Agua, Taubaté, v. 3, n. 1, p. 91-107, 2008. (doi:10.4136/ambi-agua.45)

início de erosão com ravinas e desmoronamentos de taludes (Figura 8C e 8D setas vermelhas).

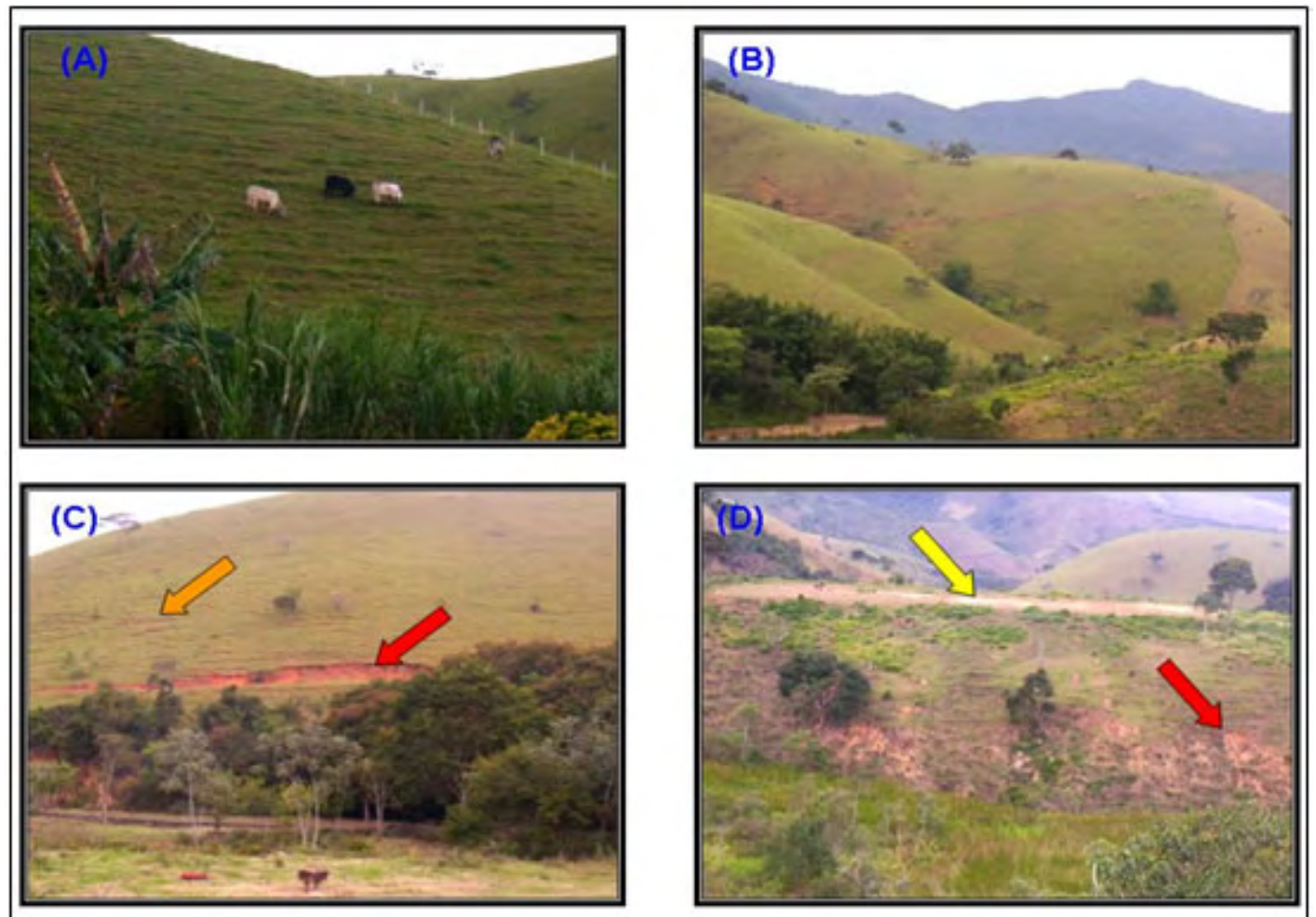

Figura 8. Aspectos da pastagem da bacia do Batedor, com evidências de diversos tipos de erosão.

As culturas temporárias existentes na área de estudo são basicamente mandioca, milho e hortaliças, de subsistência cujo excedente é eventualmente vendido no comércio local. Nessas culturas temporárias, pouco cuidado com o manejo e conservação do solo é exercido, não se faz plantio em curvas de nível nem manutenção de cobertura orgânica e muitas vezes o solo está exposto. Na Figura 9A (seta vermelha), observa-se área em declive onde ocorreu plantio recente. Na Figura 9B (seta vermelha), vê-se uma roça de milho abandonada após a colheita. Na Figura 9D, observa-se plantio de hortaliças dentro da bacia estudada.

A falta de manejo adequado, sem técnicas para conservação do solo, principalmente, em áreas de declividade, provoca erosão e perda do solo, em alguns casos, o início de voçorocas, que já caracteriza um processo erosivo avançado (Figura 9C). A erosão em sulcos caracterizase pelo escoamento superficial concentrado de uma lâmina d'água com tensão de cisalhamento suficiente para desagregar o solo, que deforma o sulco e altera as características hidráulicas do escoamento responsável pela dinâmica de formação dos sulcos (Albuquerque et al., 2000; Cantalice et al., 2005).

Espectralmente, a cultura de banana foi muito similar à classe de mata-capoeira, quando analisada na imagem CBERS 2. Contudo, o trabalho de campo permitiu identificar um grande plantio de bananas que na análise digital da imagem teria sido englobado na categoria matacapoeira (Figura 10, polígono laranja), em que se pode notar também afloramento rochoso em declividade elevada (Figura 10 polígono azul). Corrêa (2001), analisando a bacia do ribeirão Itaim no município de Taubaté, SP, que também contribui para o rio Paraíba do Sul, concluiu que a pouca cobertura florestal decorrente das atividades antrópicas é responsável pelo alto nível de sedimentação nos cursos d'água e que erosões ocasionam assoreamento do rio e 
CURVELlo, R. T.; BATISTA, G. T.; TARGA. M. dos S. Estudo dos impactos da ocupação humana na microbacia do rio Batedor na Serra da Mantiqueira no município de Cruzeiro, SP, Brasil. Ambi-Agua, Taubaté, v. 3, n. 1, p. 91-107, 2008. (doi:10.4136/ambi-agua.45)

iniciam-se, principalmente, a partir das estradas mal conservadas, do caminhamento do rebanho bovino e das alterações físicas da topografia pelas obras de engenharia.

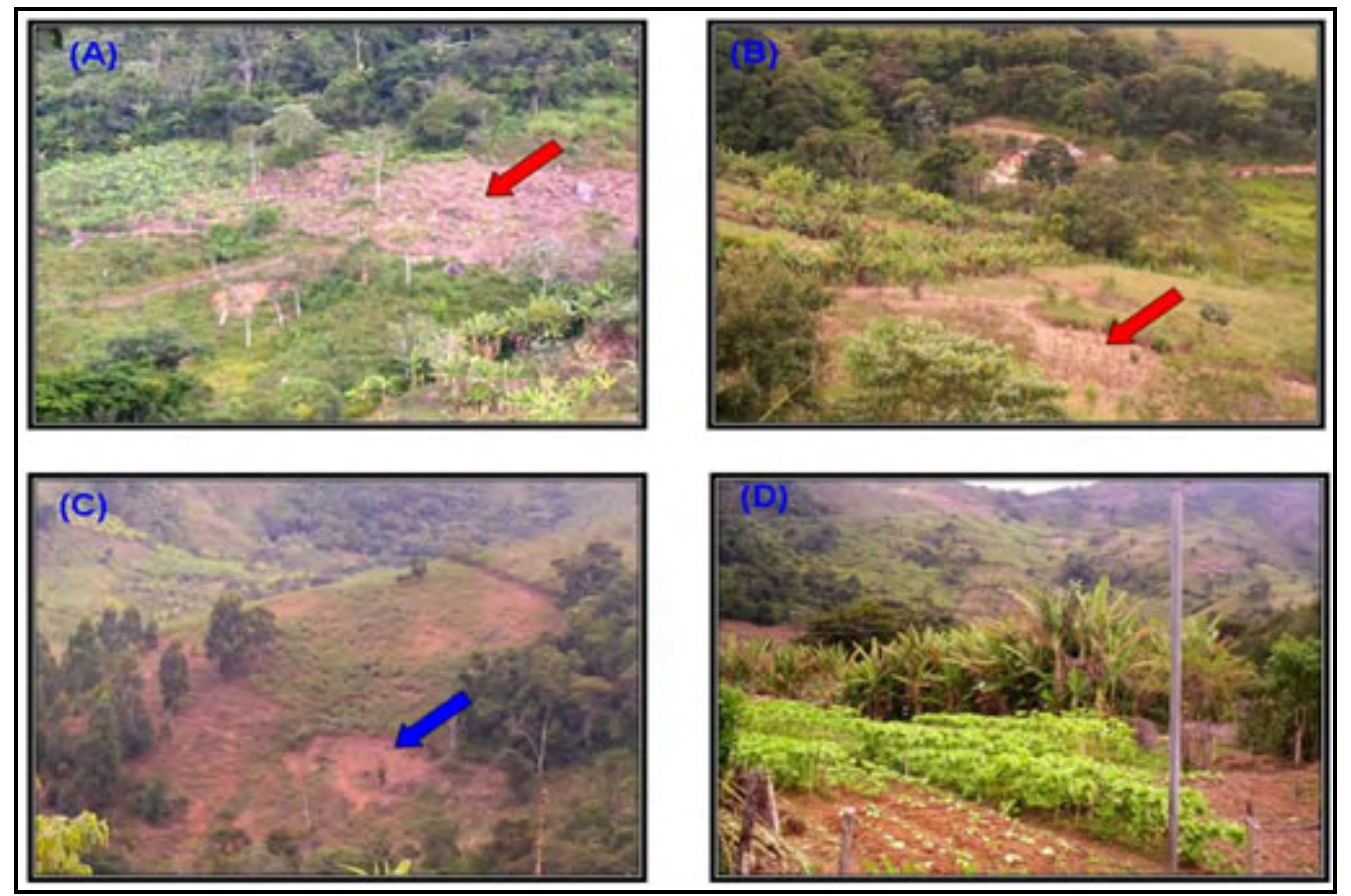

Figura 9. Culturas temporárias na bacia do Batedor.

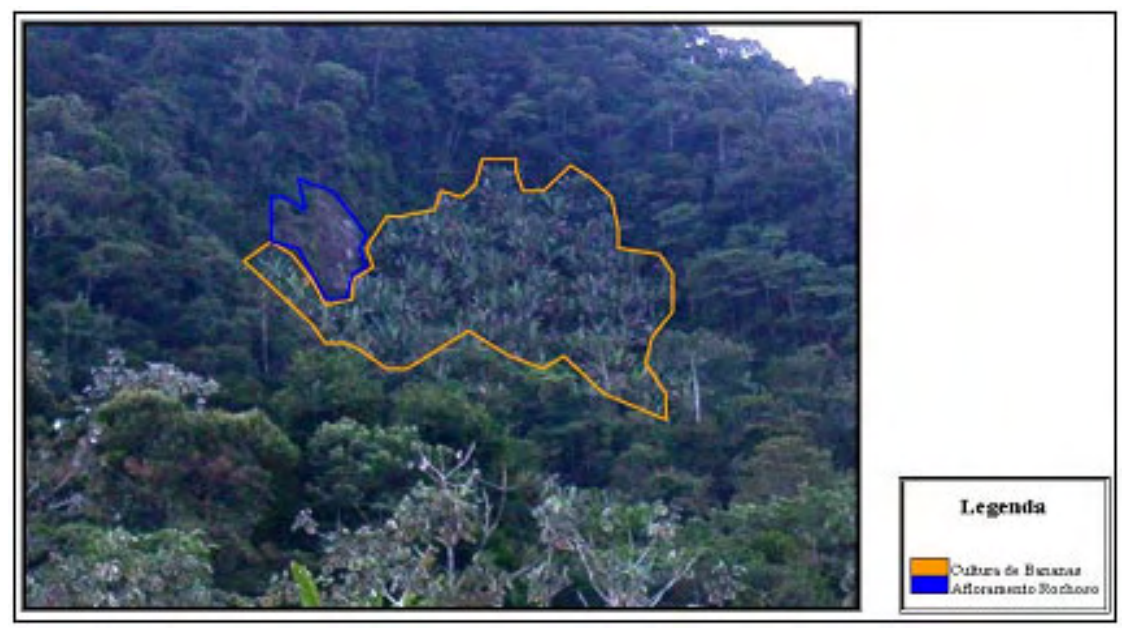

Figura 10. Plantio de banana e afloramento rochoso na encosta da bacia.

Apesar do plantio de banana ser uma cultura permanente, existem restrições quanto ao tipo de solo e à declividade do terreno e, em alguns casos, necessita-se de manejo de cultivo e práticas para a preservação do solo. Ressalta-se que os tipos de solo associados à topografia do terreno da área de estudo, não são dos mais qualificados para os tipos de culturas ali encontradas.

Segundo Borges e Souza (2007), a conservação do solo representa o conjunto de práticas agrícolas destinadas a preservar sua fertilidade química e também práticas mecânicas de controle de erosão. Eles recomendam as seguintes técnicas de manejo e conservação do solo no cultivo de bananas: 
a) Revolver o solo o mínimo possível. A quebra excessiva dos torrões, com a pulverização do solo deixa-o mais exposto ao aparecimento de crostas superficiais e, por conseguinte, à erosão;

b) Conservar o máximo de resíduos vegetais sobre a superfície. Os resíduos evitam ou diminuem o impacto de gotas de chuva na superfície do solo, também são empecilhos ao fluxo de enxurradas, pois a velocidade é reduzida diminuindo a capacidade de desagregação e transporte do solo. Atuam ainda na conservação da umidade e na amenização da temperatura do solo.

O cultivo de banana não é considerado adequado em solos onde o lençol freático está a menos de um metro de profundidade (Borges e Souza, 2007), o que ocorre no caso de plantio às margens de rios, freqüentemente observado junto à margem do rio Batedor, o que constitui inadequação à Lei 4771/65 (Código Florestal), que determina, no Artigo 2ª item “a”, as margens de rios como áreas de preservação permanente. Esse tipo de cultivo, não recomendado, promove a deposição de matéria orgânica das bananeiras, que pode vir a alterar a qualidade química da água ou causar modificações no fluxo de água do rio, provocando remansos e ainda o assoreamento em pontos específicos do rio. Ressalta-se que esse tipo de cultivo reduz a vegetação de floresta, principalmente, ciliar que entre outras funções melhora a qualidade e quantidade de água, hoje, já crítica para o abastecimento (Rebouças et al., 1999).

Por outro lado, no curso médio e inferior da bacia do rio Batedor prevalece o uso do solo como pastagem e, em alguns casos, a mata ciliar foi removida, e se nota pouca ou nenhuma ocorrência de vegetação às margens do rio, principalmente na saída da bacia (Figura 11).

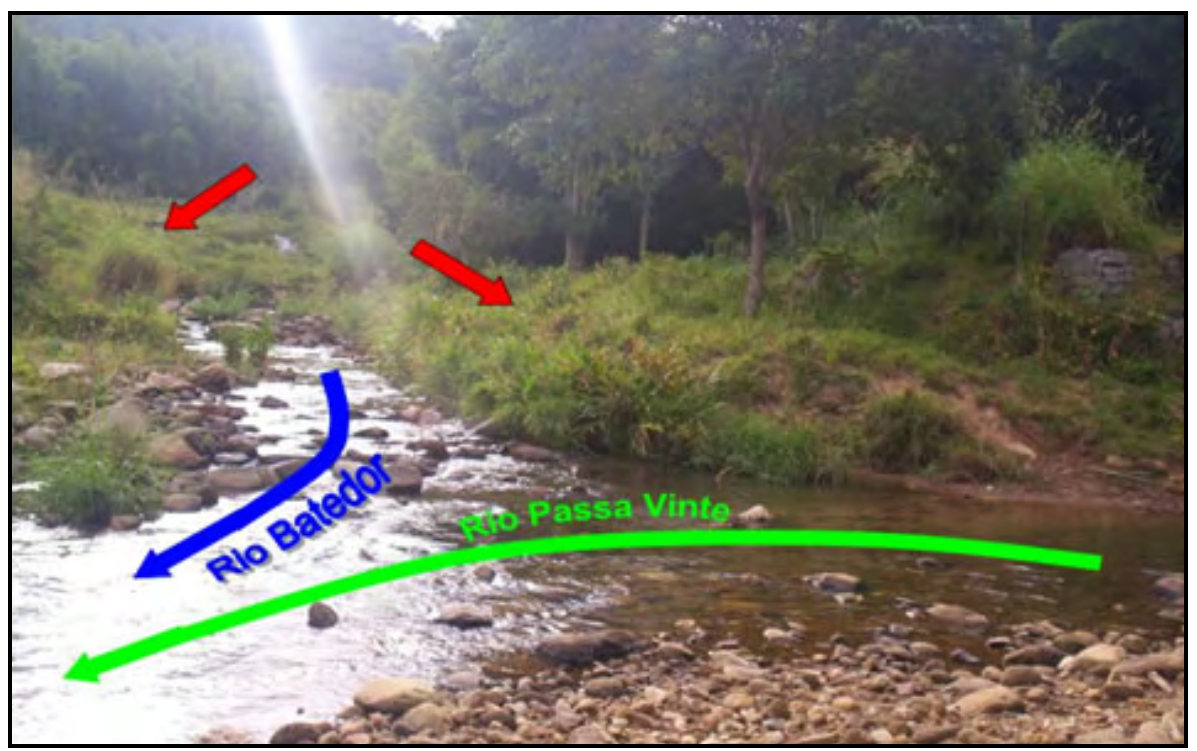

Figura 11. Foz do rio Batedor, afluente do Rio Passa Vinte.

A cobertura vegetal florestal nativa nessas Áreas de Preservação Permanente iria atenuar os efeitos erosivos e a lixiviação dos solos, contribuindo também para a regularização do fluxo hídrico, redução do assoreamento dos corpos d’água e reservatórios, bem como traria benefícios para a biodiversidade da fauna (Costa et al., 1996).

Observa-se na Figura 12, à esquerda, a barragem para captação de água do SAAE (Serviço Autônomo de Água e Esgoto) de Cruzeiro no rio Batedor, bem como as canaletas por onde flui a água (Figura 12, à direita) até os reservatórios e daí, por meio de dutos, para a estação de tratamento. 
Os cultivos e outras ocupações antrópicas observadas na bacia encontram-se a montante do local onde foi instalada a estação de captação de água, responsável por $70 \%$ do fornecimento de água do município de Cruzeiro, SP, e, por essa razão, podem causar impactos

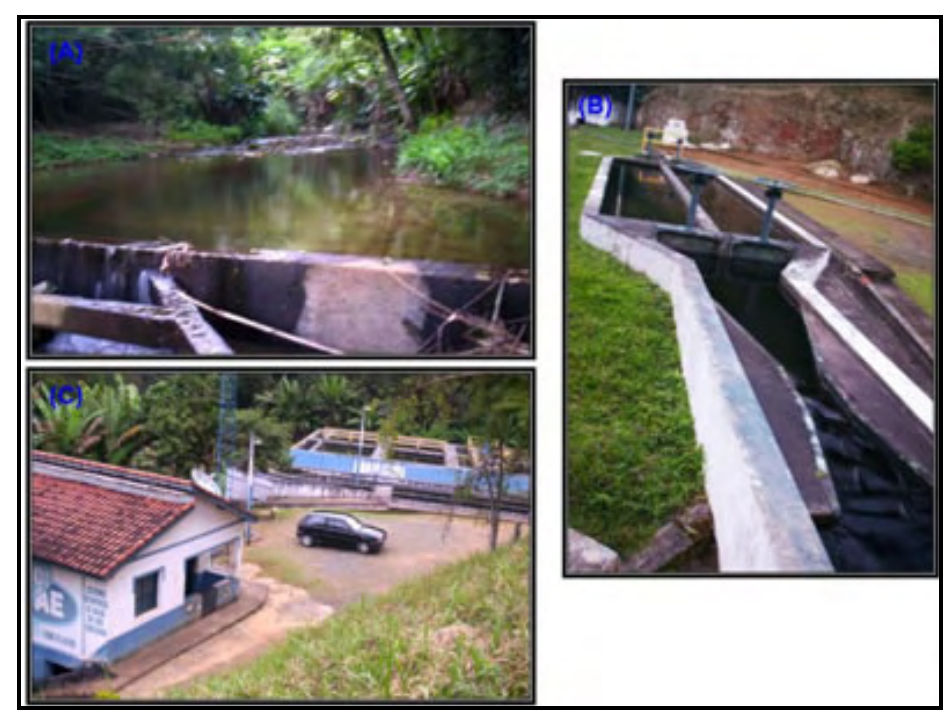

Figura 12. Aspecto da captação de água na bacia do Batedor.

ambientais nos aspectos físicos da bacia e nas características de qualidade e quantidade da água prejudicando o abastecimento de Cruzeiro, SP.

As ocupações que ocorreram após a desapropriação da Fazenda do Batedor podem ser consideradas irregulares ou clandestinas já que foram realizados à margem da legislação urbanística, ambiental, civil, penal e registrária. Embora, para que se possa consolidar um assentamento, seja necessário o acesso à água e à energia elétrica. Porém um aspecto bastante limitador para a consolidação desse assentamento, é o fato de que se localiza em áreas de preservação ambiental e, portanto, não podem ser regularizados (Pinto, 2003).

Verificou-se em campo que a maioria das casas tem acesso à energia elétrica regular, tornando confuso a caracterização de clandestinidade e uma eventual retomada de posse da área por parte da prefeitura municipal. Contudo, não há uma regra clara quanto à possibilidade ou não de ligação dos assentamentos ilegais às redes de energia elétrica, água, esgoto e telecomunicações. Na verdade, o Poder Público têm até estimulado a consolidação de loteamentos clandestinos, ao estabelecer para as concessionárias obrigações de atendimento a qualquer usuário e de universalização do acesso aos serviços. Muitas vezes, as empresas concessionárias preferem oficializar a combater as ligações clandestinas (Pinto, 2003).

Trata-se de um procedimento de regularização fundiária de intervenção pública, sob os aspectos jurídicos, físico e social, que objetiva legalizar a permanência de populações moradoras em áreas urbanas ocupadas em desconformidade com a lei para fins de habitação, implicando acessoriamente melhorias no ambiente urbano do assentamento, no resgate da cidadania e da qualidade de vida da população beneficiária (Alfonsin, 1999).

Em áreas de preservação ambiental como é o caso da bacia do rio Batedor, estudos para a adequação do uso da terra em função da legislação são de suma importância (Catelani et al., 2003) e podem contribuir com o poder público na adoção de ações de planejamento do uso e ocupação do solo e gerenciamento dos recursos hídricos da bacia do Batedor. A efetivação do planejamento, juntamente com projetos de Educação Ambiental, conforme proposto por Batista et al., (2005), podem, em longo prazo, manter ou minimizar os efeitos das ações antrópicas na bacia, garantindo que a qualidade e quantidade dos recursos naturais não sejam comprometidos no futuro. 


\section{CONCLUSÕES}

As técnicas de sensoriamento remoto e geoprocessamento, aliadas ao trabalho de campo provaram ser úteis e eficazes na caracterização física da bacia e na elaboração de mapa de uso de solo.

A bacia do rio Batedor apresenta características físicas favoráveis ao abastecimento hídrico por ser bem drenada, com grande disponibilidade hídrica, não apresentar risco de enchentes e estar situada em área de muitas nascentes, na encosta da Serra da Mantiqueira, e possuir cursos jovens, com pouca sinuosidade.

Observando os dados de uso do solo, conclui-se que se trata de uma bacia saudável, com 86,7\% da área ocupada por mata ou capoeira. Porém, por ser uma área de preservação ambiental (APA da Mantiqueira) e por ser área de manancial para captação de água para o município de Cruzeiro, qualquer interferência antrópica deve ser muito bem planejada visando reduzir os impactos ambientais sobre a bacia.

As principais ações antrópicas encontradas na bacia do rio Batedor estão relacionadas à ocupação irregular de áreas para moradias, desenvolvimento de agricultura de subsistência como a bananicultura em locais declivosos e margens do rio, pastagens degradadas, que denotam a inadequação do uso do solo à legislação ambiental e a redução da área florestal da bacia e que podem contribuir para o agravamento dos processos erosivos, causar perda de solo e assoreamento da calha do rio, podendo alterar as características de qualidade e quantidade de água.

\section{REFERÊNCIAS}

ALBUQUERQUE, J. A.; CASSOL, E. A.; REINERT, D. J. Relação entre a erodibilidade em entressulcos e estabilidade dos agregados. Revista Brasileira de Ciência do Solo, v. 24, n. 1, p. 141-151, 2000.

ALFONSIN, B. M. Políticas de regularização fundiária: justificação, impactos e sustentabilidade. In: Research Report - Lincoln Institute of Land Policy. Cambridge, 1999. Disponível em: <http://www.lincolinst.edu>. Acesso em maio 2007.

AULICINO, L. C. M.; RUDORFF, B. F. T.; MOREIRA, M. A.; MEDEIROS, J. S.; SIMI JR., R. Subsídios para o manejo sustentável da bacia hidrográfica do rio Una através de técnicas de geoprocessamento e de sensoriamento remoto. In: SIMPÓSIO LATINOAMERICANO DE PERCEPCIÓN REMOTA, 9., 2000, Puerto Iguazu. Anais... São José dos Campos: SELPER, 2000. p. 899-908.

BATISTA, G.T.; NETO, P. F.; DIAS, N. W.; TARGA, M. S.;OLIVEIRA, L. A. M. Educação ambiental voltada para recursos hídricos: um estudo de caso. 2005, 20p. In:_ Olhando para as águas do Ribeirão das Almas - Caieiras, <http://www.agro.unitau.br/caieiras>. Acesso em agosto de 2007.

BATISTA, G.T.; M. S. TARGA. Gerenciamento e Manejo de bacias hidrográficas. In: Gestão de Recursos Hídricos e Manejo de Bacias Hidrográficas. Curso de especialização por educação a distância. Targa, M. S. (Coord.). Universidade de Taubaté - UNITAU, Taubaté - SP, 24 p., 2004. 
CURVELlO, R. T.; BATISTA, G. T.; TARGA. M. dos S. Estudo dos impactos da ocupação humana na microbacia do rio Batedor na Serra da Mantiqueira no município de Cruzeiro, SP, Brasil. Ambi-Agua, Taubaté, v. 3, n. 1, p. 91-107, 2008. (doi:10.4136/ambi-agua.45)

BORGES, A. L.; SOUZA, L. S. Livro banana: exigências edafoclimáticas. Cap. 1 Disponível em: <http://www.agencia.cnptia.embrapa.br/recursos/Livro_Banana_Cap_1ID-NHDNBfwu. pdf $>$. Acesso em: março de 2007.

BRASIL Constituição Federal (1988). Cap. VI - Do Meio Ambiente, Artigo n 225. Disponível em: <www.lei.adv.br>. Acesso em: 25 jan. 2008.

BRASIL. Decreto n ${ }^{\circ}$ 91.304, de 3 de junho de 1985. Dispõe sobre a implantação de área de proteção ambiental nos Estados de Minas Gerais, Rio de Janeiro e São Paulo, e dá outras providências. Disponível em: <www.lei.adv.br>. Acesso em: 25 jan. 2008.

BRASIL. Instrução Normativa ${ }^{0}$ 12, de 10 de junho de 2005. Na produção, importação e comercialização de batata-semente, será utilizada a tabela de níveis de tolerância para pragas não-quarentenárias regulamentadas. Disponível em: <http://extranet. agricutura.gov.br/sislegis-consulta/servlet/VisualizarAnexo?id=11492>. Acesso em: maio de 2007.

BRASIL. Lei $\mathrm{n}^{\circ}$ 9.985, de 18 de julho de 2000. Regulamenta o art. 225, $\S 1^{\circ}$, incisos I, II, III, e VII da Constituição Federal, institui o Sistema Nacional de Unidades de Conservação da Natureza e dá outras providências. Disponível em: <www.lei.adv.br>. Acesso em: 25 jan. 2008.

BRASIL. Lei $\mathrm{n}^{\circ}$ 6.766, de 19 de dezembro de 1979. Dispõe sobre o Parcelamento do Solo Urbano e dá outras providências. Disponível em: <www.lei.adv.br>. Acesso em: 25 jan. 2008.

BRASIL. Lei $n^{0}$ 9.433, de 8 de janeiro de 1997. Institui a Política Nacional de Recursos Hídricos, cria o Sistema Nacional de Gerenciamento de Recursos Hídricos, regulamenta o inciso XIX do art. 21 da Constituição Federal, e altera o art. $1^{\circ}$ da Lei $n^{\circ} 8.001$, de 13 de março de 1990, que modificou a Lei $\mathrm{n}^{0}$ 7.990, de 28 de dezembro de 1989. Disponível em: <www.lei.adv.br>. Acesso em: 25 jan. 2008.

BRASIL, Lei n ${ }^{\circ}$ 9.795, de 27 de abril de 1999. Dispõe sobre a educação ambiental, institui a Política Nacional de Educação Ambiental e dá outras providências. Disponível em: <www.lei.adv.br>. Acesso em: 25 jan. 2008.

CÂMARA G.; SOUZA R. C. M.; FREITAS, U. M.; GARRIDO J.;. "SPRING: Integrating remote sensing and GIS by object-oriented data modelling" Computers \& Graphics, 20: (3) 395-403, May-Jun 1996. < http://www.dpi.inpe.br/geopro/trabalhos/spring.pdf >. Acesso 17 outubro 2007.

CANTAliCE, J. R. B.; CASSOL, E. A.; REICHERT, J. M.; BORGES, A. L. DE O. Hidráulica do escoamento e transporte de sedimentos em sulcos em solo franco-argiloarenoso. Revista Brasileira de Ciência do Solo, v. 29, p. 597 - 697, 2005.

CORRÊA, R. de C. Avaliação das atividades antrópicas sobre a Bacia Hidrográfica do Ribeirão Itaim-Taubaté, SP. 2001. 109f. Dissertação (Mestrado em Ciências Ambientais) - Departamento de Ciências Agrárias, Universidade de Taubaté, Taubaté, 2001.

COSTA, T.; COSTA, C.; SOUZA, M. G.; BRITES, R. S. Delimitação e caracterização de áreas de preservação permanente por meio de um sistema de informações geográficas (SIG). Revista Árvore, Viçosa, v. 20, n. 1, p. 129-135, 1996. 
CRUZEIRO. Decreto Municipal que Declara a Fazenda do Batedor no Município de Cruzeiro - SP área de utilidade pública nº145, de 8 de junho de 1964.

EMPRESA BRASILEIRA DE PESQUISA AGROPECUÁRIA - EMBRAPA. Sistema Brasileiro de Classificação de Solos. Brasília: EMBRAPA, 1999. 412p.

HERNANDEZ FILHO, P. H.; PONZONI, F. J.; PEREIRA, M. N. Mapeamento da fitofisionomia e do uso da terra de parte da bacia do Alto Taquari mediante o uso de imagens TM/Landsat e HRV/SPOT. Pesq. agropec. bras., Brasília, v.33, Número, p.1755-1762, out. 1998.

INSTITUTO BRASILEIRO DE GEOGRAFIA E ESTATÍSTICA - IBGE. Mapa de biomas do Brasil: primeira aproximação (mapa digital). 2004. 1 mapa. Escala 1: 5000000. Disponível em: <www. Ibge.gov.br/mapas/temáticos/mapas_ murais/biomas.pdf>. Acesso em: maio de 2007.

OLIVEIRA, J. B.; CAMARGO, M. N.; ROSSI, M.; CALDERANO FILHO, B. Mapa pedológico de São Paulo. Campinas: Instituto Agronômico/EMBRAPA - Solos, 1999. 1 mapa. Escala 1: 500.000.

OLIVEIRA, J. B. Solos do Estado de São Paulo: descrição das classes registradas no Mapa pedológico. Campinas: Instituto Agronômico, 1999. Boletim Científico, 45. 112p.

PINTO, V. C. Ocupação irregular do solo urbano: o papel da legislação federal. 2003. Disponível em: <www.senado.gov.br/conleg/artigos_direito.htm>. Acesso em: mar. 2007.

PONÇANO W. L., CARNEIRO C. D. R., BISTRICHI C. A. Mapa Geomorfológico do Estado de São Paulo, escala 1:1.000.000. IPT n.1.183 (Monografias 5), v. 1, 94p. 1981.

REBOUÇAS, A. C.; BRAGA, B.; TUNDISI, J. G. Águas doces no Brasil: capital ecológico, uso e conservação. São Paulo: Escrituras, 1999. 717p.

SÃO PAULO. Secretaria de Saneamento e Energia. Departamento de águas e energia elétrica - DAEE. Uso dos recursos hídricos do Estado de São Paulo. Disponível em: <www.daee.sp.gov.br>. Acesso em: set. de 2005.

SETZER, J. Atlas climático e ecológico do Estado de São Paulo. São Paulo, Comissão Estadual da Bacia Paraná-Uruguai, 1966. 61 p.

STRAHLER, A. N. Quantitative slope analysis. Bulletin of the Geological Society of América, Rochester, 67:596-671, 1956.

TARGA, M. dos S. Hidrologia de Superfície. In: Gestão de Recursos Hídricos em Bacias Hidrográficas. Curso de especialização por educação a distância. Targa, M. S. (Coord.). Universidade de Taubaté - UNITAU. Taubaté - SP, 63p. 2004.

VIEIRA, L.S. Manual da ciência do solo. São Paulo: CERES, 1975.

VILLELA, S. M.; MATOS, A. Hidrologia aplicada. 1 ed. São Paulo: McGraw-Hill do Brasil, 1975. 245p. 


ISSN = 1980-993X - doi:10.4136/1980-993X
www.agro.unitau.br/ambi-agua
E-mail: ambi-agua@agro.unitau.br
Tel.: (12) 3625-4116

\title{
Hydrogeology and hydrodynamics of Tremembé aquifer, São Paulo, Brazil
}

(doi:10.4136/ambi-agua.46)

\author{
Helio Nóbile Diniz ${ }^{1}$; Jair Santoro ${ }^{1}$; Getulio Teixeira Batista ${ }^{2}$; Nelson Wellausen \\ Dias $^{2}$; Marcelo dos Santos Targa ${ }^{2}$ \\ ${ }^{1}$ São Paulo State Geological Institute, Environmental Secretariat, Av.Miguel Stéfano, 3900, Água Funda, \\ 04301-903 - São Paulo, SP, Brazil \\ e-mail: \{heliodiniz; jairsantor\}@yahoo.com.br \\ ${ }^{2}$ Environmental Sciences Post-Graduate Program, University of Taubaté, Estrada Mun. Dr.José Luiz \\ Cembranelli, 5000, Bairro Itaim, 12081-010 - Taubaté, SP, Brazil \\ e-mail: \{getulio; mtarga; nelson\}@agro.unitau.br
}

\begin{abstract}
This paper shows the results obtained from several pump tests of two wells drilled 13.2 meters apart, in the Agrarian Sciences Department of the University of Taubaté farm, located in the Una river hydrographic basin, Taubaté municipality, State of São Paulo, Brazil. During well drilling some difficulties were encountered due to the presence of sandy grains without inter-granular cementation of the Tremembé Formation sandstones, Taubaté Group. The detailed description of the geologic profile obtained by sampling the perforated sedimentary layers shows the presence of persistent sandstone and conglomerate sequences, intercalated by layers of shale and claystone with limestone nodules. In order to determine the hydrodynamic parameters of the Tremembé aquifer, several pump tests were conducted during well perforation and the unconfined, leaky, water-table, and confined aquifer layers were sampled. Once the boreholes were completed, tests were conducted to determine maximum discharge rate, interference between wells and artificial recharge potential. In addition to establishing appropriated methodologies for the determination of aquifer hydrodynamics, this paper describes techniques for interpreting the effects of artificial recharge and interference between wells, and demonstrated the application of image well theory complemented with a new theory, the image well water-mirror.
\end{abstract}

Keywords: hydrogeology; well hydraulics; theory of the image well water-mirror.

\section{Hidrogeologia e hidrodinâmica do Aqüífero Tremembé, São Paulo, Brasil}

\section{RESUMO}

Este trabalho mostra os resultados obtidos com a perfuração e ensaios de bombeamento realizados em dois poços tubulares profundos, distanciados de 13,2m, na área do Departamento de Ciências Agrárias da Universidade de Taubaté, no Município de Taubaté. Os dados construtivos descritos demonstram as dificuldades encontradas com a perfuração dos poços, devido aos tipos litológicos da Formação Tremembé, do Grupo Taubaté, no local, onde os grãos arenosos das camadas terciárias não possuem cimentação intergranular. A descrição detalhada do perfil geológico, caracterizado por meio de testemunhos das sondagens, mostra a presença de seqüências arenosas e conglomeráticas persistentes, intercaladas por camadas de folhelhos, argilitos maciços e nódulos calcáreos. Durante a 
DINIZ, H. N.; SANTORO, J.; BATISTA, G. T.; DIAS, N. W.; TARGA, M. dos S. Hydrogeology and hydrodynamics of Tremembé aquifer, São Paulo, Brazil. Ambi-Agua, Taubaté, v. 3, n. 1, p. 108-137, 2008. (doi:10.4136/ambi-agua.46)

construção dos poços foram realizados testes de vazão em diferentes profundidades que mostraram a evolução hidrodinâmica dos aqüíferos atravessados pela perfuração, de livres, semi-livres, semi-confinados a confinados. Com os poços completados foram realizados testes de vazão máxima, de interferência entre poços e de recarga artificial. Adicionalmente às metodologias consagradas, são empregadas e demonstradas novas técnicas para interpretação hidrodinâmica da recarga artificial dos aqüíferos e da interferência entre os poços. São demonstrados os ensaios metodológicos da aplicação da teoria do poço imagem, complementados com um nova teoria, a do poço imagem espelho d'água.

Palavras-chave: hidrogeologia; hidráulica de poços; teoria do poço imagem espelho d’água.

\section{INTRODUCTION}

The aquifer cone of depression of a pumping well can be determined with reasonable accuracy if hydrodynamic parameters are known for a confined aquifer (transmissivity and coefficient of storage) as well as the pumping rate (Driscoll, 1989). The depression (or drawdown) cone shape is a function of $s \times r$, where $s$ is the depression observed at an $r$ distance from the well due to a $Q$ pumping rate maintained during a $t$ period measured from the beginning of well pumping. Usually the depression cone has transitory characteristics since several factors associated with groundwater flow and pumping activities change with time. The influence radius (or the interference area of the depression cone) is related to the distance that the depression cone could reach away from the well. This influence can be determined when some hydrodynamic parameters of the aquifer are known (Minnesota, 1991).

A method for calculating the percentage of the total pumping rate of two wells (built within the influence radius of each other) comes from groundwater flow distributed within the intersection of the influence circumference of both wells or from areas located outside of the region of intersection but within each well's influence area.

The confined aquifer transmissivity and coefficient of storage hydraulic parameters are aquifer characteristics that do not change during either extracting groundwater through pumping or recharging an aquifer through deep well injection. Based on this premise and applying the image well theory (on a horizontal mirror plane) a method for estimating the recharge cone associated with an injection well is proposed and demonstrated in this research. The study proposes methods considered more appropriate than the traditional methods used for solving this type of problem, such as the one proposed by Bouwer (1978).

The research focuses on analyzing the hydrogeological properties of the Tertiary sedimentary aquifers located in the Tremembé Formation (part of the Taubaté Group) within the Una River hydrographic basin, São Paulo State, Brazil.

The research was conducted based on the construction of two deep wells, one for the production of groundwater to supply the water demand for irrigation in the Department of Agrarian Sciences of the University of Taubaté. The other well was built to support the hydrogeologic research to allow measures of the interference between wells as well as other important observations. The main objective of this research is to develop a hydrogeologic model that explains the hydraulic properties of wells in the study area.

\subsection{Study area}

The study area is located in the Taubaté Municipal District (southeastern region of the State of São Paulo) and within Paraíba do Sul River Valley. The study area is distant approximately $160 \mathrm{~km}$ east of the city of São Paulo (Figure 1). Road access to Taubaté from São Paulo is provided by two highways, President Dutra and Carvalho Pinto. 
DINIZ, H. N.; SANTORO, J.; BATISTA, G. T.; DIAS, N. W.; TARGA, M. dos S. Hydrogeology and hydrodynamics of Tremembé aquifer, São Paulo, Brazil. Ambi-Agua, Taubaté, v. 3, n. 1, p. 108-137, 2008. (doi:10.4136/ambi-agua.46)

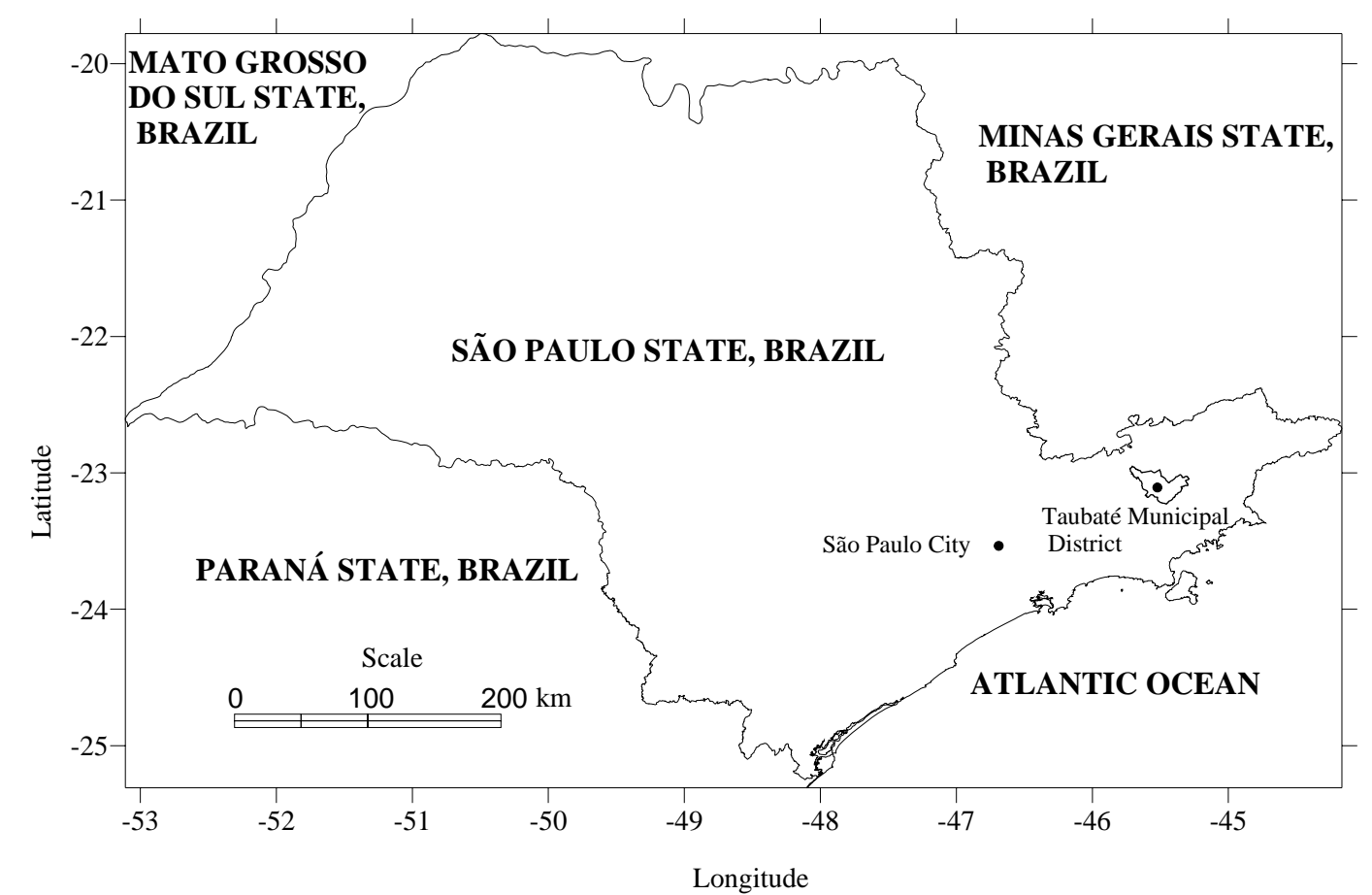

Figure 1. Taubaté Municipal District location in relationship to the state of São Paulo boundaries in Brazil.

Taubate municipality is located within the Paraíba do Sul river valley and bordered by two mountain chains, Serra da Mantiqueira and Serra do Mar. The district's terrain in the urban and surrounding rural areas is characterized mostly by flattened hills sustained by Tertiary sediments of the Taubaté Group. In the rural areas, away from the urban center, the terrain is predominantly rugged due to the higher hills of Serra do Mar in the southwestern portion of the territory, while in the northwestern portion the hills belong to Serra da Mantiqueira. Both areas are sustained by the Complex Embu crystalline rock formation. In the central portion of the district there is the occurrence of extensive floodplains associated with Paraíba do Sul River. The extent of the district's territory is $655 \mathrm{~km}^{2}$. The climate is tropical with dry winter, $21^{\circ} \mathrm{C}$ average annual temperature, and $1,400 \mathrm{~mm}$ average annual precipitation.

\subsection{Regional geology}

Taubaté sedimentary basin is formed by layers of Cenozoic and Tertiary sediments deposited within the Paraíba do Sul tectonic block, which is characterized by Embu and Apiaí Lands of the Precambrian crystalline complex. Those crystalline basement rocks are constituted by gneiss, granites, and migmatites with bands and different migmatization grades, intercalated with schist and granites of the Brasiliano cycle (Santoro et al., 1991). The Buquira Fault, at the north, and Alto da Fartura Fault, at the south, are the lateral boundaries of both sedimentary and crystalline rocks (Hasui and Ponçano, 1978).

The origin of Taubate sedimentary basin is associated with the reactivation of major ENE faults that comprise the São Paulo strike-slip fault zone (Hasui et al., 1978) represented by Monteiro Lobato Fault (Sadowski and Carneiro, 1974), Jaguari River Fault (Cavalcante and Kaefer, 1974), and Buquira and Bom Retiro Faults (Carneiro et al., 1976). Palmital, Parateí, São José, and Rio Comprido are normal faults described by Carneiro et al. (1976). Those are dip-slip faults associated with gravitational mudslides (Coltrinari, 1992) that characterize recent reactivations of old strike-slip faults. 
DINIZ, H. N.; SANTORO, J.; BATISTA, G. T.; DIAS, N. W.; TARGA, M. dos S. Hydrogeology and hydrodynamics of Tremembé aquifer, São Paulo, Brazil. Ambi-Agua, Taubaté, v. 3, n. 1, p. 108-137, 2008. (doi:10.4136/ambi-agua.46)

Taubaté sedimentary basin is part of a taphrogenic basin group, the so-called "system of Serra do Mar rifts" described by Almeida (1976) and, more recently, the "Southest Brazilian continental rift" described by Riccomini (1989). These tectonic processes occurred during the opening of the South Atlantic Plate that formed asymmetrical grabens with dumper to SE or NW filled with Tertiary sediments. It has an elongated format approximately $170 \mathrm{~km}$ long and $10 \mathrm{~km}$ to $20 \mathrm{~km}$ wide.

The thickness of the sediments varies reaching a maximum of $850 \mathrm{~m}$ in the Roseira subbasin, near Serra da Mantiqueira mountains (Hasui et al., 1978; Melo et al., 1986). Sedimentation occurred simultaneously with tectonics (Souza, 2004) producing typical gravel deposits originated from debris-flow processes in active folded edges of the basin. Sandstone and conglomerate deposits located in the central part of the basin are connected to alluvial and lacustrine systems.

For this research Hasui and Ponçano's (1978) stratigraphic column is the basis for describing both Tremembé and Caçapava Formations of the Taubaté Group. The names were initially proposed because of existing river channels and alluvial Tertiary plain deposits located in São José dos Campos and Caçapava municipality areas.

\subsection{Hydrogeology of the Paraíba do Sul river basin in the State of São Paulo}

In the Paraíba do Sul River Water Resource Management Unit, or "Unidade 2 de Gerenciamento de Recursos Hídricos" (UGRHI-2), there are two main aquifer systems: sedimentary (Cenozoic) and crystalline (Precambrian). The sedimentary terrains are responsible for the formation of the best aquifers of the region. The terrains are anysotropic and the aquifer characteristics vary according to the sedimentary formation lithology.

Franco Filho and Souza (1994) differentiated two units in the Taubaté sedimentary basin: 1) the Tremembé Formation at the base and 2) the Caçapava Formation at the top. Tremembé Formation consists of shale with lens of gray greenish pyrobetuminous argillites formed in a lacustrine environment and centimeter to decimeter sandstones, siltstones, and breccia inserts. Caçapava Formation consists of sandstones and siltstones originated in a fluvial environment with gray, yellow, and red pelite inserts.

Paraíba do Sul is an effluent river since groundwater flow discharges are responsible for supplying much of its water. Due to the increasing water demand for domestic and industrial uses, mainly in Jacareí, São José dos Campos, and Lorena municipalities, there are several pump wells with strong groundwater withdrawal that may be causing changes in groundwater flow patterns, such as induced aquifer recharge by wells drawdown, as observed by the Department of Water and Electric Energy studies (São Paulo, 1977a; São Paulo, 1977b). In several locations Paraíba do Sul river has become an influential river due to its recharging effect over the exploited aquifers.

According to São Paulo (1977a), most of the region is characterized by phreatic aquifers that show leaky conditions. Just in restricted areas there are confined aquifers that characterize artesian conditions.

\subsubsection{Paraíba do Sul Taubaté sedimentary aquifer system}

The groundwater flow model currently accepted for the Paraíba do Sul sedimentary aquifer system (Consórcio ICFKaiser-Logos, 1999) shows that the recharge associated with natural precipitation occurs throughout the basin area due to its permeable characteristics (Figure 2). These recharge areas are drained by the groundwater flow after the infiltrating rainwater reaches the phreatic aquifer. Hydrogeologic characteristics of the aquifers are closely related to the depositional environments. Based on this knowledge, two units with 
DINIZ, H. N.; SANTORO, J.; BATISTA, G. T.; DIAS, N. W.; TARGA, M. dos S. Hydrogeology and hydrodynamics of Tremembé aquifer, São Paulo, Brazil. Ambi-Agua, Taubaté, v. 3, n. 1, p. 108-137, 2008. (doi:10.4136/ambi-agua.46)

different hydraulic behavior can be distinguished in the region according to the environments in which the sediments were deposited. The first unit is located in the southeast and northwest portions of the Taubaté Sedimentary Basin (Jacareí/São José dos Campos and Lorena/Cachoeira Paulista municipal areas, respectively). This unit is associated with alluvial sedimentary environments that allow a high rate of well discharge (maximum of $200 \mathrm{~m}^{3} / \mathrm{h}$ and average of $50 \mathrm{~m}^{3} / \mathrm{h}$ ). The second unit is located in the region between Taubaté and

Recharge area

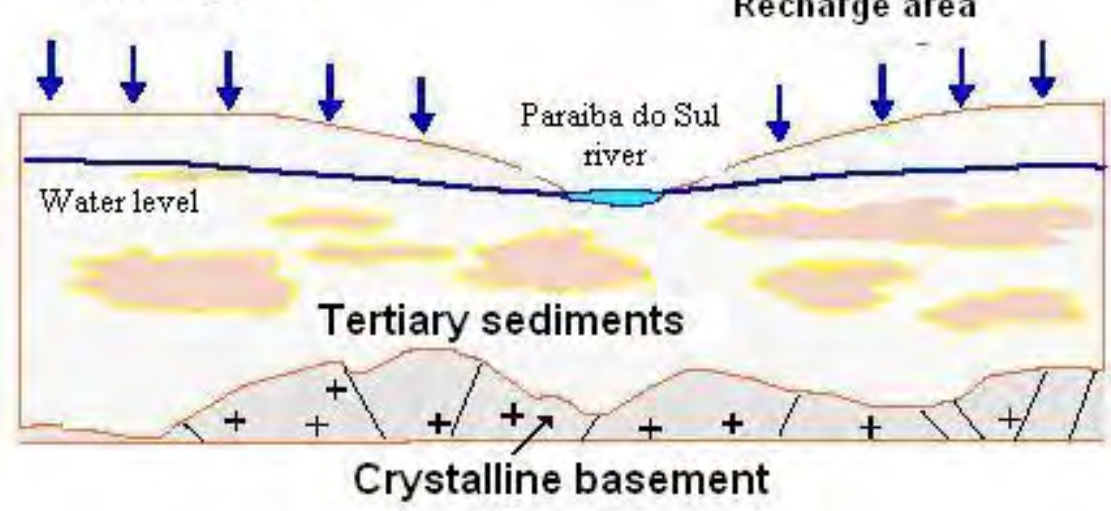

Figure 2. Regional circulation model for the sedimentary aquifer of the Taubaté Basin (modified of the Consórcio ICFKaiser-Logos, 1999).

Pindamonhangaba municipal areas near the central portion of the sedimentary basin. This unit is associated with lacustrine sedimentary environments and represents lower rates of well discharge (in the order of $20 \mathrm{~m}^{3} / \mathrm{h}$ to $30 \mathrm{~m}^{3} / \mathrm{h}$ and transmissivity between $10 \mathrm{~m}^{3} /$ day and 50 $\mathrm{m}^{3} /$ day).

\section{MATERIAL AND METHODS}

Two tubular deep wells were constructed using rotary drill in the Department of Agrarian Sciences, University of Taubaté, in cooperation with the Geological Institute, State of São Paulo Secretariat of the Environment. These wells were built with the objective of providing an analytical mechanism to describe the hydrogeologic behavior of the Tremembé Formation hydraulic sedimentary aquifer. And, at the same time, providing drilled sediment samples for characterizing the stratigraphy, palinology, paleontology, and mineralogy of the Tremembé Formation.

In order to determine the hydrodynamic parameters of Tremembé aquifer several pump tests were conducted during well perforation. Once completed, tests were conducted to determine maximum discharge rate, interference between wells, and artificial recharge potential.

The first drilled well, called Extracting/Injection well, has being used to irrigate crops planted in approximately 2 hectare test fields that belong to the Department of Agrarian Science. This well also has equipment associated to it that could allow the artificial recharge of the Tremembé aquifer. This well was tested (with pump tests) when the drilling was in the depths of $48 \mathrm{~m}, 66 \mathrm{~m}$, and $115 \mathrm{~m}$.

The Extracting/Injection well was built at $19.5 \mathrm{~m}$ of a food factory building that belong to the Department of Agrarian Sciences, and $3 \mathrm{~m}$ below the building's floor quota (Figure 3).

The data obtained with the pump tests indicate that the aquifer has the following characteristics (in sequence): unconfined, leaky, water-table, and confined. The first saturated sedimentary sequence was an unconfined aquifer (between $9 \mathrm{~m}$ and $16 \mathrm{~m}$ ), followed by a 
DINIZ, H. N.; SANTORO, J.; BATISTA, G. T.; DIAS, N. W.; TARGA, M. dos S. Hydrogeology and hydrodynamics of Tremembé aquifer, São Paulo, Brazil. Ambi-Agua, Taubaté, v. 3, n. 1, p. 108-137, 2008. (doi:10.4136/ambi-agua.46)

leaky aquifer (between $16 \mathrm{~m}$ and $48 \mathrm{~m}$ ), a water-table (between $48 \mathrm{~m}$ and $66 \mathrm{~m}$ ), and a confined aquifer (between $66 \mathrm{~m}$ and $115 \mathrm{~m}$ ). The static level stood at around $8 \mathrm{~m}$ between the depths of $40 \mathrm{~m}$ and $115 \mathrm{~m}$. The phreatic water table stood at around $9 \mathrm{~m}$ indicating that the head potential of the deep aquifer is around $1 \mathrm{~m}$ above the water table.

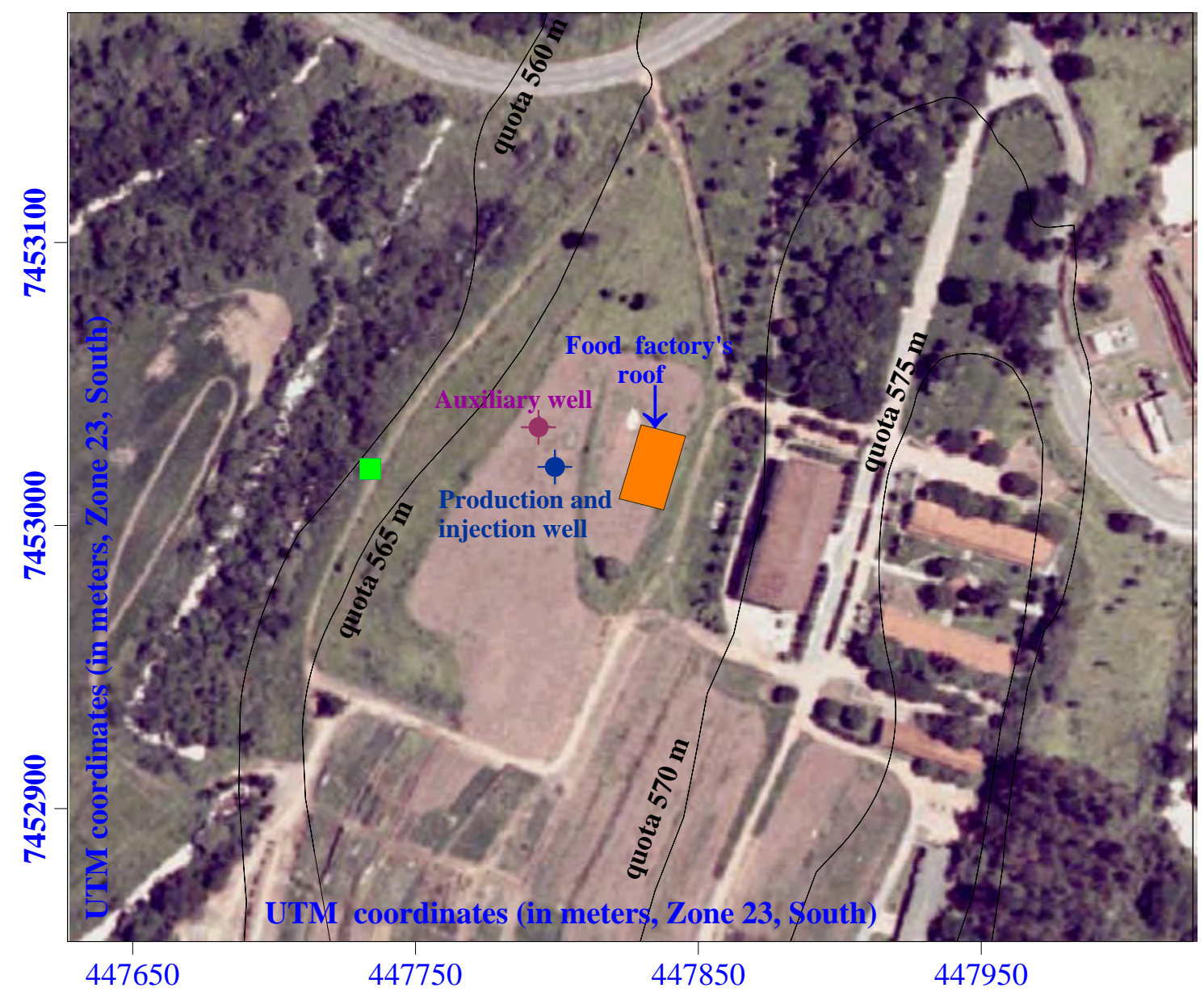

Figure 3. Digital ortophoto showing a portion of the Department of Agrarian Sciences area and the location of the food factory (roof) and the two wells.

The second well, called Auxiliary well, was drilled $13.2 \mathrm{~m}$ away from the first well. Pump tests were conducted in this well when drilling was at $49 \mathrm{~m}$ and $91.7 \mathrm{~m}$ deep. This borehole was used as observation well to measure the water levels during Production/Injection well pump tests, for the analysis of interference between wells, and for water injection during artificial recharge tests. This well enabled an important assessment of sedimentary aquifer hydrodinamic parameters.

For the interpretation of hydrodinamics aquifer parameters the following aquifer models were used: Theis (1935) for confined aquifer, Hantush (1956) for leaky aquifer, and Neuman (1972) for water-table aquifer. Models were selected according to the data obtained during drawdown $\times$ time pump tests at different depths during drilling.

\subsection{Theory of the image well and image well water-mirror}

The pumping well cone of depression, of a well constructed in a negative barrier neighborhood, is controlled by the effect known as well image (Fitts, 2002; Custodio and Llamas, 1983; Walton, 1970). The resulting cone of depression is equal to the individual sum 
DINIZ, H. N.; SANTORO, J.; BATISTA, G. T.; DIAS, N. W.; TARGA, M. dos S. Hydrogeology and hydrodynamics of Tremembé aquifer, São Paulo, Brazil. Ambi-Agua, Taubaté, v. 3, n. 1, p. 108-137, 2008. (doi:10.4136/ambi-agua.46)

of well effects (real well) and the well image pumping (image well). The image well is an imaginary well equidistant from the real well from which the image obtained from a vertical mirror located at the intersection between the depression cone and the negative barrier axes is compared with the real well (Figure 4).

The depression cone of well with lateral impermeable boundary

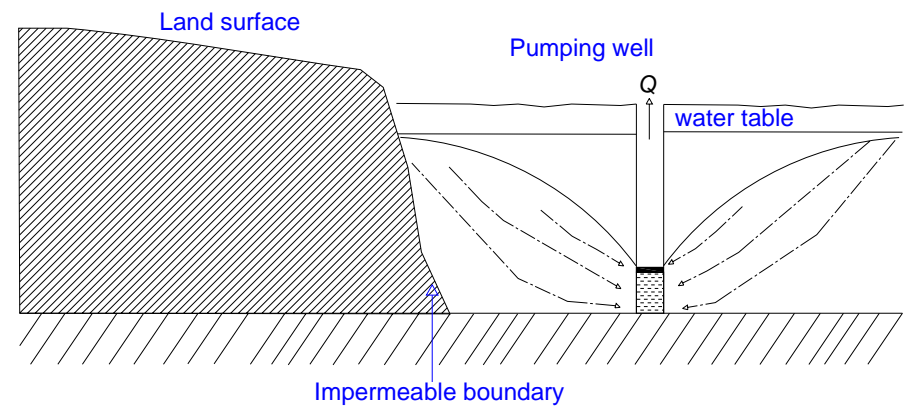

The effects of real and image well drawdown sum

$Q$ Image well with negative discharge

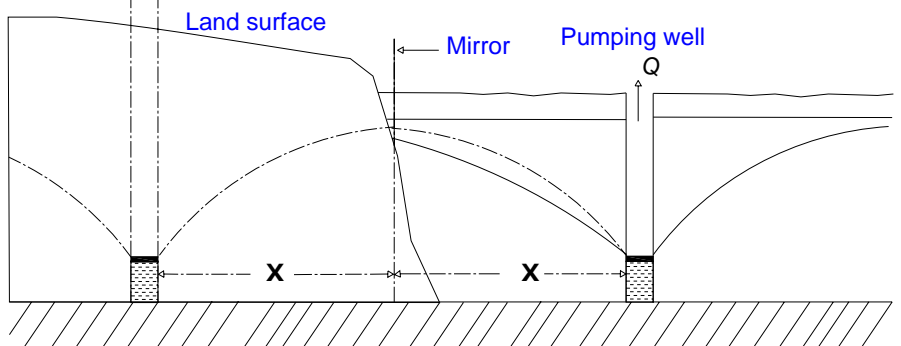

Figure 4. Schematic representation of a image well controlled by a negative barrier effect (modified from Custodio and Llamas, 1983).

In the case of a positive barrier (e.g. formed by the recharge from a river within the area affected by a well cone of depression), according to the theory of well image, the river can be replaced by a recharging well symmetrical to the real well located at the river edge and with an equal inflow (Custodio and Llamas, 1983). The drawdown observed at each point is the algebraic sum of drawdown and recoveries caused by each well (real and image), as represented in Figure 5.

The image well theory is useful for the interpretation of drawdown data of well boundary conditions by its comparison to the optical reflection.

In both cases, cone of depression effects due to negative barriers or recharge boundary, results are fictitious since they are simulated through image wells obtained by an imaginary vertical plane mirror. The well image effect is a geometric condition which practical implementation was effectively demonstrated by many implementations of pumping well drawdown solutions.

Another condition imposed to the interpretation of well drawdown is the horizontal boundary influence. Two scenarios can exemplify this influence: when a negative barrier is formed by the horizontal surface of the water table in a phreatic aquifer and the need to determine what is the effect when the pump well is stopped (beginning of the recovery); and when it is necessary to determine the effect of a horizontal recharge boundary formed by the same water table in a recharge well. 
In the first scenario, the effect of a negative barrier formed by the horizontal water table of a phreatic aquifer and the effect when the pump well stops can be determined by the resulting effect (cone of ascension) similar to the well cone of depression but inverted by a horizontal mirror. In the second scenario, when the boundaries are in the touchline and when the boundary is horizontal (top of aquifer) the image well theory is also valid.

The depression cone of well with recharge boundary

Real groundwater profile
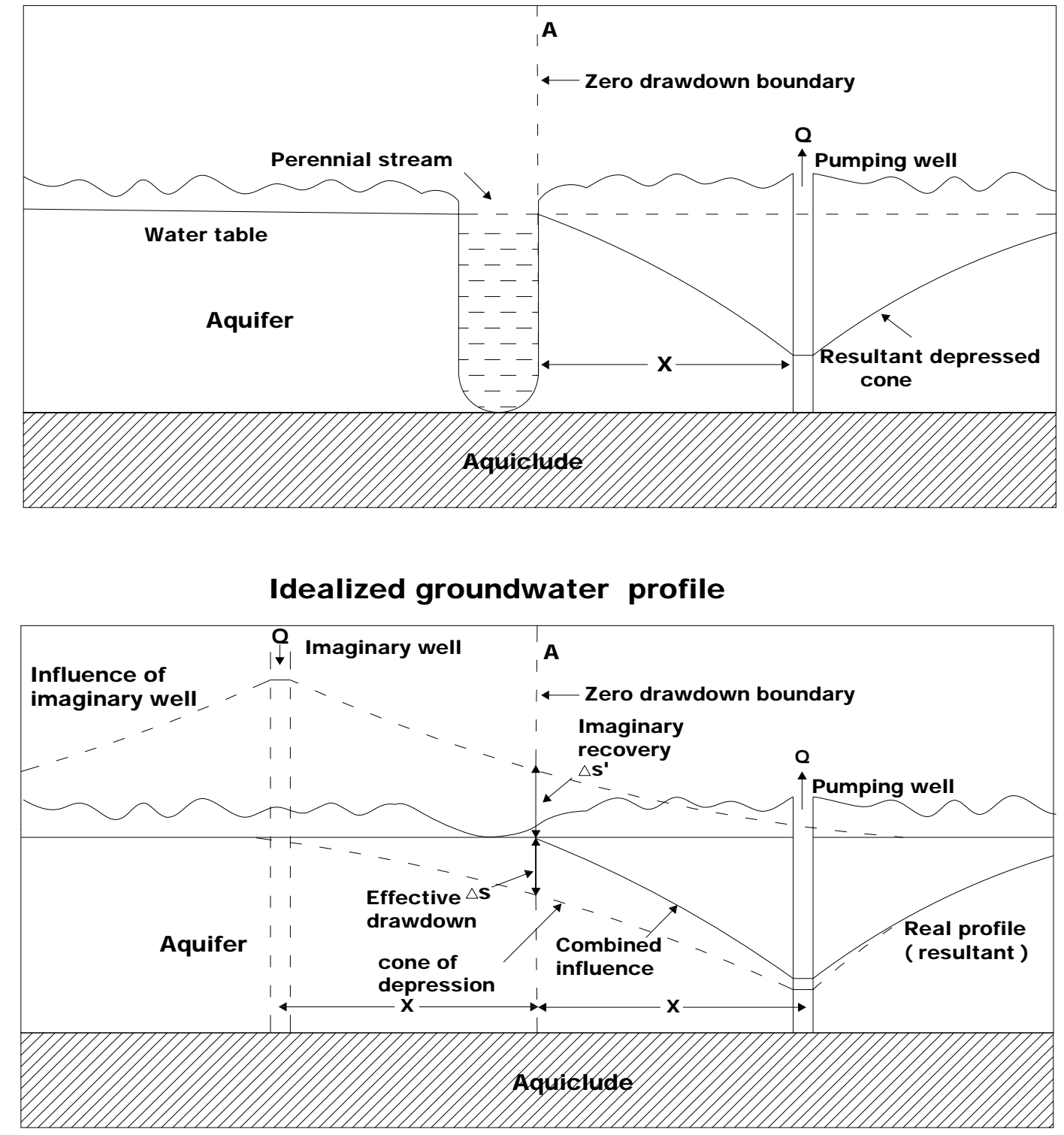

Figure 5. Schematic representation of the well image effect when the cone of depression finds a recharge boundary (modified from U.S. Geological Survey, 1977).

Therefore, when the pumping stops the cone of ascension will be symmetrical to the cone of depression but with an inverted image (negative barrier) produced by a well water-mirror. It is symmetrical to the cone of depression but inverted. Thus, the recharge rate is equal to the discharge rate with changed signal (Figure 6). 
DINIZ, H. N.; SANTORO, J.; BATISTA, G. T.; DIAS, N. W.; TARGA, M. dos S. Hydrogeology and hydrodynamics of Tremembé aquifer, São Paulo, Brazil. Ambi-Agua, Taubaté, v. 3, n. 1, p. 108-137, 2008. (doi:10.4136/ambi-agua.46)

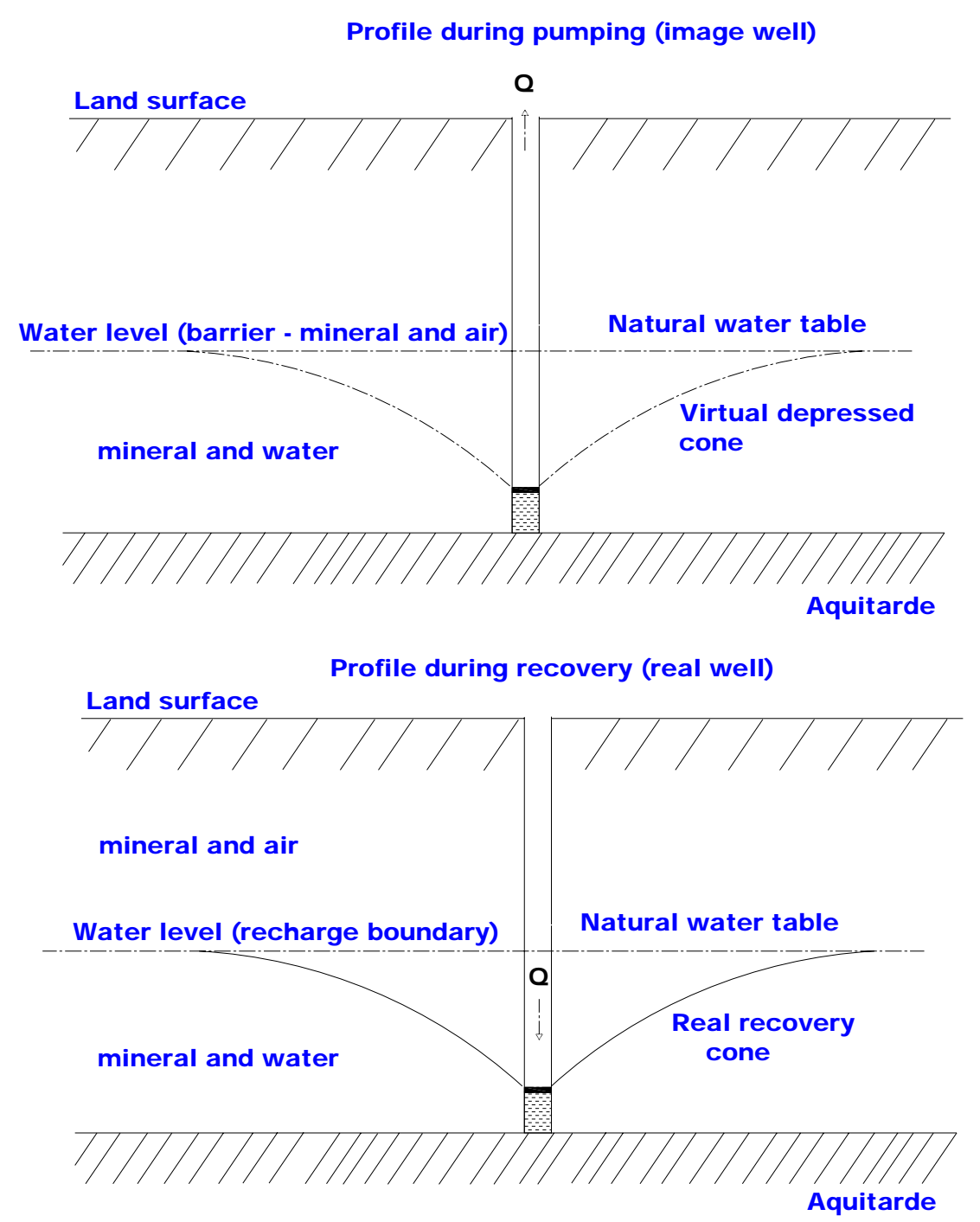

Figure 6. The well cone of ascension after well pumping stopped and the effect of an image well water-mirror.

When water injection occurs in a recharge well (phreatic aquifer) the water table effect is a positive barrier to the cone of ascension. The resulting effect is a cone symmetrical to the cone of depression for an equal discharge rate, but with opposite sign, reflected in a watermirror (horizontal plane mirror), as represented in Figure 7.

The image well water-mirror (horizontal mirror) theory has two important applications:

1 ) In the analysis of pump tests results - recovery $\times$ time data (real cone of ascension) will be similar to the drawdown $\times$ time data (virtual well - image well water-mirror), thus all methods used in the analysis of well hydraulics are applicable, such as Theis (1935) for confined aquifers, Hantush (1956) for leaky aquifers, and Neuman (1972) for water table aquifers with delayed drainage. In this scenario the situation is analogous to the descriptive geometry theory of projection planes for a line-of-sight.

2) In the analysis of well hydraulics - usually this analysis when applied to pump tests uses models that consider the discharge rate constant. In reality this rarely happens because during well pumping water level lowering occurs and, consequently, the hydraulic potential varies affecting the efficiency of the extraction equipment so that the discharge rate decreases over time. This effect, 
DINIZ, H. N.; SANTORO, J.; BATISTA, G. T.; DIAS, N. W.; TARGA, M. dos S. Hydrogeology and hydrodynamics of Tremembé aquifer, São Paulo, Brazil. Ambi-Agua, Taubaté, v. 3, n. 1, p. 108-137, 2008. (doi:10.4136/ambi-agua.46)

however, doesn't occur during recovery because well flow rate restoration is equivalent to the average pump test discharge rates. Therefore, the use of pump test recovery data rather than pump test drawdown data is more accurate for the interpretation of aquifer hydraulic parameters.

\section{Recharge well}

$Q$

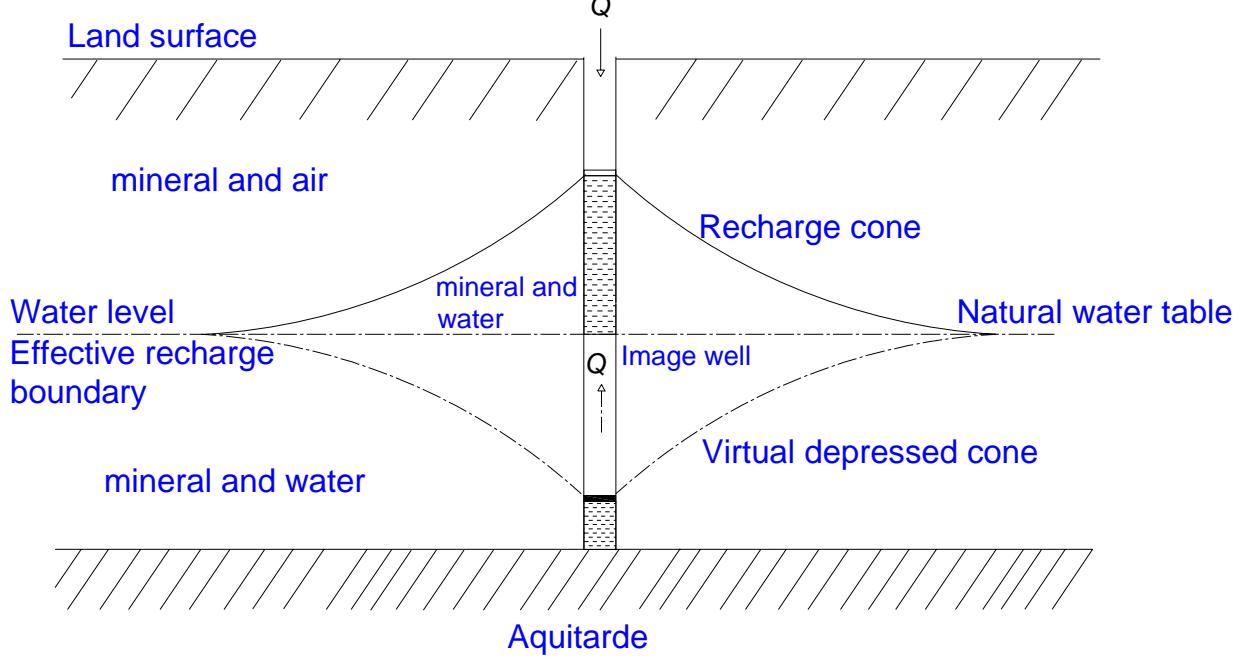

Figure 7. Well image recharge effect representation with positive barrier boundary.

The average discharge rate (equal to the injection rate with an opposite signal) is given by Equation [1]:

$$
Q_{m}=\frac{\sum_{i=1}^{i=n} Q_{i} \cdot\left(t_{i}-t_{i-1}\right)}{t_{\text {total }}}
$$

where $Q_{\mathrm{i}}$ is the discharge rate obtained for a period equal to $t_{\mathrm{i}}-t_{\mathrm{i}-1}$ and $t_{\text {total }}$ is the total pump test time.

\subsection{Well interference}

For an aquifer considered infinite the well pumping discharge rate comes from a circular area whose radius $(r)$ is known as the well radius of influence.

The well radius of influence is controlled by the aquifer hydrodynamic parameters transmissivity $(T)$ and coefficient of storage $(S)$, as shown in Figure 8 (Freeze and Cherry, 1979). Another important variable is the discharge rate.

At any point within the radius of influence the drawdown is given by the following equations:

$s=\frac{Q}{4 \pi T} W(u)$ for confined aquifers (Theis, 1935),

$s=\frac{Q}{4 \pi T} W\left(u, \frac{r}{\mathrm{~B}}\right)$ for leaky aquifers (Hantush, 1956),

$s=\frac{Q}{4 \pi T} W\left(u_{A}, u_{B}, \Gamma\right)$ for water table aquifers (Neuman, 1972), 


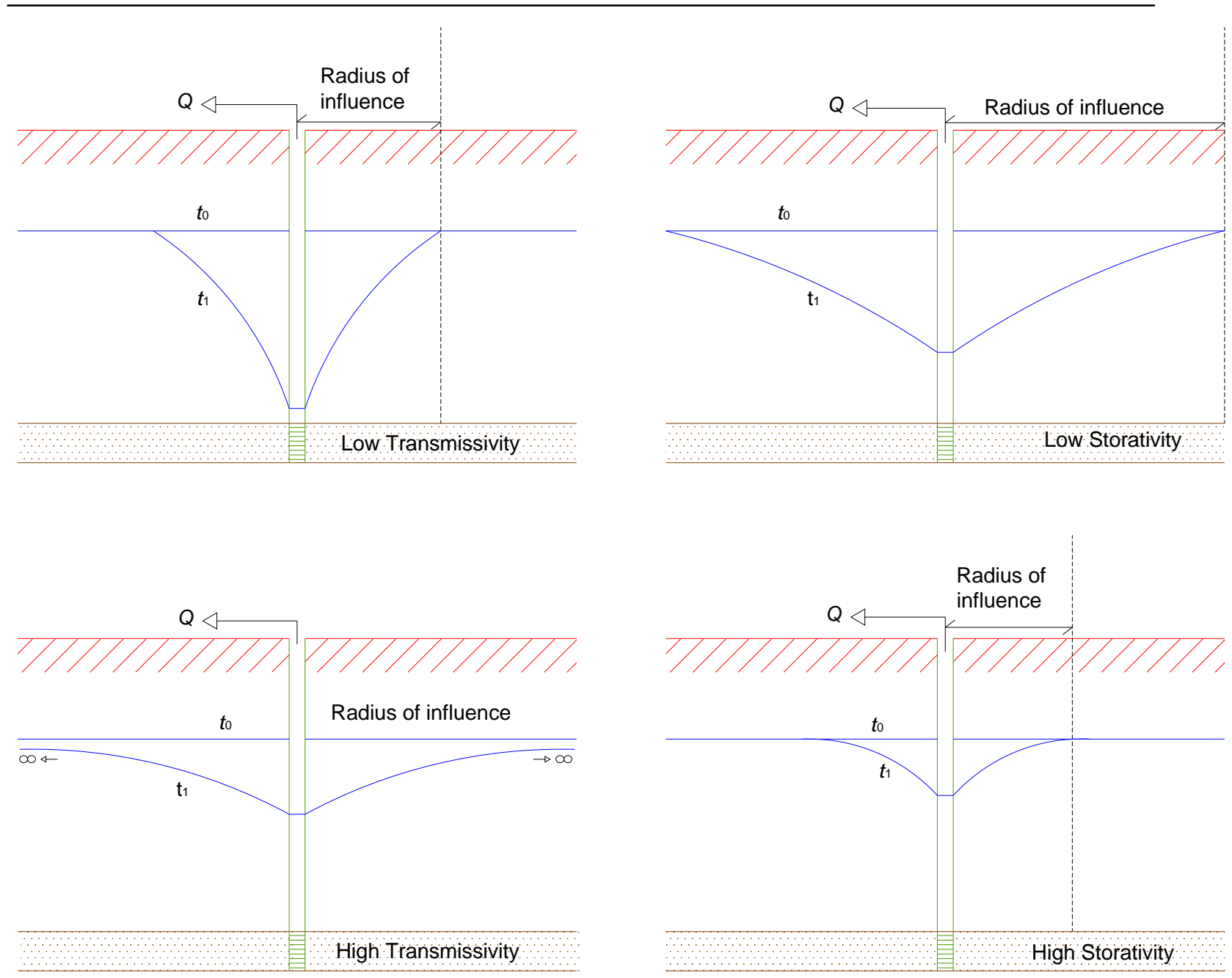

Figure 8. Extension and depth of the well radius of influence depending on the aquifer transmissivity and coefficient of storage values.

In the above equations there is a consistent relationship, that is, the direct proportionality between discharge rate $(Q)$ and transmissivity $(T)$ for any observed drawdown.

When another well is constructed within a well's radius of influence and pumped, interference occurs between them. In this case each well's radius of influence ( $r_{1}$ and $\left.r_{2}\right)$ becomes an intervenient, as represented in Figure 9. Therefore, the effect of one well drawdown $\left(s_{1}\right)$, produced by the discharge rate $Q_{1}$, is added to the radius of influence of the other pumping well's drawdown $\left(s_{2}\right)$ produced by a discharge rate $Q_{2}$. This results in a total drawdown ( $\left.s^{\prime}\right)$ that is equal to the sum of $s_{1}$ and $s_{2}$.

In pumping tests performed in one well and measurements of dynamic water level made in another well, the application of Equations [2], [3] or [4] is appropriate. Especially for calculating transmissivity $(T)$ since this is an aquifer parameter and not a well specific parameter.

When there is interference between wells, because both are pumping and they are within the radius of influence of each other, in one well there will be a drawdown $\left(s_{1}\right)$ due to this well's pumping and the influence of the other well's drawdown $\left(s_{2}\right)$, caused by the interference. The total well drawdown ( $\left.s^{\prime}\right)$ is the sum of both, more than only $s_{1}$.

An interference pump test is done by pumping two wells simultaneously from time $t_{0}$ and a discharge rate dependent on the equipment power and the dynamic head. In one of the 
pumping wells it could be determined the relationship $s^{\prime} \times t$ for a constant discharge rate $Q^{\prime}$. This discharge rate will be lower than the discharge rate $Q$ obtained without the interference between wells.

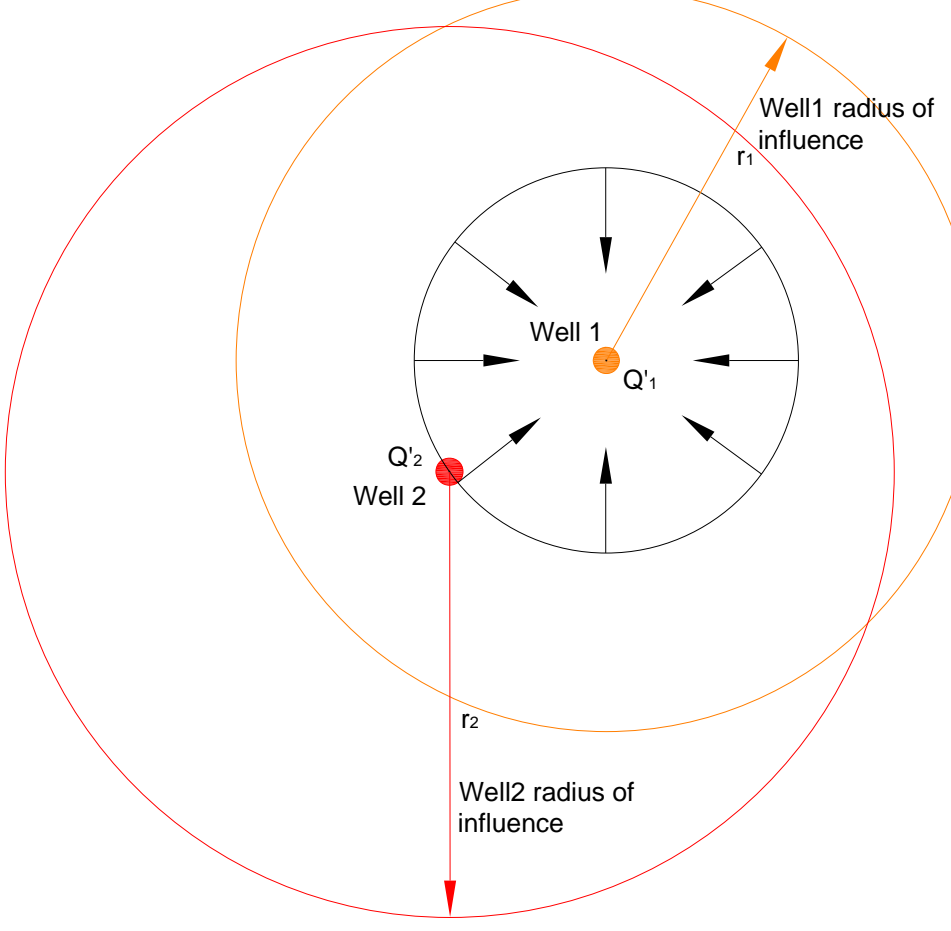

Figure 9. Well interference representation when two wells are constructed within each other's radius of influence.

This is because, for the same equipment, the dynamic head would be higher due to the lowering water level caused by the influence of the other pumping well and, consequently, by the decreasing efficiency of the pumping equipment.

Values of the relationship $s^{\prime} \times t$ for the discharge constant rate $Q^{\prime}$ when plotted in a logarithmic graphic using methods proposed by Theis given by Equation [2], Hantush given by Equation [3], or Neuman given by Equation [4], considering the characteristic of a given aquifer, the apparent transmissivity $\left(T^{\prime}\right)$ value is obtained. The value of transmissivity is apparent because the drawdown is measured under the influence of the other well interference.

As already mentioned, one relationship is consistent, that is, the direct proportionality between discharge rate and transmissivity value. From this the following can be said:

$$
\frac{Q}{T}=\frac{Q^{\prime}}{T^{\prime}}
$$

where $Q$ and $T$ are obtained for one well during pumping test without interference, while $Q$ ' and $T^{\prime}$ ' are obtained during an interference pumping test.

Thus, $Q^{\prime} \times T=Q \times T^{\prime}$. Where $Q, T$ and $T^{\prime}$ can be obtained from pump test results interpretation with or without interference, from which $Q^{\prime}$ can be determined. The discharge rate $Q$ comes from the aquifer area located within the well radius of influence ( $r_{1}$ for Well 1 in Figure 9). The discharge rate $Q_{\mathrm{i}}$ (interference discharge rate) is equal to $Q-Q^{\prime}$, since this discharge comes from the water contained within the aquifer circular area located between one well and its interfering well. The discharge rate $Q_{\mathrm{i}}$ is related to the aquifer area whose radius is equal to the distance between the wells (see Figure 9). 
DINIZ, H. N.; SANTORO, J.; BATISTA, G. T.; DIAS, N. W.; TARGA, M. dos S. Hydrogeology and hydrodynamics of Tremembé aquifer, São Paulo, Brazil. Ambi-Agua, Taubaté, v. 3, n. 1, p. 108-137, 2008. (doi:10.4136/ambi-agua.46)

\section{RESULTS AND DISCUSSION}

\subsection{Wells drilling}

The Production/Injection well was built at the site of UTM coordinates E $447798 \mathrm{~m}$ and N 7453025 m, Zone 23, South. The well design and geological log are shown in Figure 10.

The construction of this well had several problems, especially related to the geological characteristics of the drilled terrain. As the soil is composed predominantly by sandy material with little cohesion and high porosity it absorbed large amount of perforation fluid (water and bentonite) causing collapses as drilling progressed.

To prevent loss from borehole collapses, the drilling started with large-diameter $(\phi=$ 24 ”) down to $5.60 \mathrm{~m}$ depth, then, $\phi=17$ ” down to $16 \mathrm{~m}$ depth. Additionally, a steel pipe with $\phi=15$ " and thickness of 1/8" was introduced to prevent collapses. The space between the 17" diameter borehole and the external pipe surface of $\phi=15$ " was filled with cement grout. Thus, the entire geological section where the phreatic aquifer occurs, from $7.8 \mathrm{~m}$ (depth of the water table) to $16 \mathrm{~m}$ (maximum depth of the soil) was completely isolated, preventing the mixing of phreatic and confined aquifer waters. From $16 \mathrm{~m}$ down to $48 \mathrm{~m}$ the well was drilled with 14" steel drill bit. Between $48 \mathrm{~m}$ and $52.5 \mathrm{~m}$, the well was drilled with a 10" drill bit. After this depth down to $115 \mathrm{~m}$, an 8" drill bit was used. Borehole collapse and fragments fall occurred between $87 \mathrm{~m}$ and $115 \mathrm{~m}$. Thus, the well was protected with 8” and 6” PVC pipes and mechanic filtering tubes down to $87.1 \mathrm{~m}$ depth. Between $87.1 \mathrm{~m}$ and $115 \mathrm{~m}$ depth, fragment falls filled the borehole.

An Auxiliary well was built $13.2 \mathrm{~m}$ away from the Extracting/Injection well. The Auxiliary well design and the geological log are shown in Figure 11. For the Auxiliary well construction the same method employed in the drilling of the Production/Injection well was used. Thus, to avoid loss of drilling fluid and borehole fragment falls, a large diameter $(\phi=$ 24") drill bit was used down to $5 \mathrm{~m}$ and the extent of the borehole was secured by iron rings welded one after the other. After completing this path, the drilling progressed with a bit of 17 " in diameter down to the depth of $13.66 \mathrm{~m}$, and a steel pipe of $\phi=15$ ” and thickness of $1 / 8$ " was inserted into the borehole. The empty space was filled with cement grout. Thus, the entire geological section, where the phreatic aquifer occurs (beginning at $7.8 \mathrm{~m}$ depth of the water table down to $13.66 \mathrm{~m}$ that was the maximum depth of the soil at this site, has been completely isolated, preventing the mixing of phreatic and confined aquifer waters.

The drilling continued down to $64.26 \mathrm{~m}$ depth, in the Tertiary sediments of Tremembé formation, using a bit of $\phi=10$ ". After a trial to perform the hydraulic characteristics of the sedimentary aquifer, a collapse of this sedimentary layer occurred. Thus, a reopening of the borehole with $\phi=14$ " rotating drill bit was performed down to $18.1 \mathrm{~m}$ depth.

From $0.67 \mathrm{~m}$ above the ground surface down to $19.1 \mathrm{~m}$ depth, a steel pipe with $\phi=10 "$ and 1/4" thickness was introduced. At $18.1 \mathrm{~m}$ deep, a holding tab ( $\phi=14$ ”) was welded to hold the 10" internal pipes.

The drilling continued to $91.3 \mathrm{~m}$ depth and the extent between $47.7 \mathrm{~m}$ to $64.63 \mathrm{~m}$ was protected with PVC pipes ( $\phi=8$ "), and the interval between $51.03 \mathrm{~m}$ to $91.03 \mathrm{~m}$ with pipes and screens (PVC, $\phi=6$ ”). The opening of screen slots was $0.75 \mathrm{~mm}$ and filter pack of 1 to 5 $\mathrm{mm}$. 
DINIZ, H. N.; SANTORO, J.; BATISTA, G. T.; DIAS, N. W.; TARGA, M. dos S. Hydrogeology and hydrodynamics of Tremembé aquifer, São Paulo, Brazil. Ambi-Agua, Taubaté, v. 3, n. 1, p. 108-137, 2008. (doi:10.4136/ambi-agua.46)

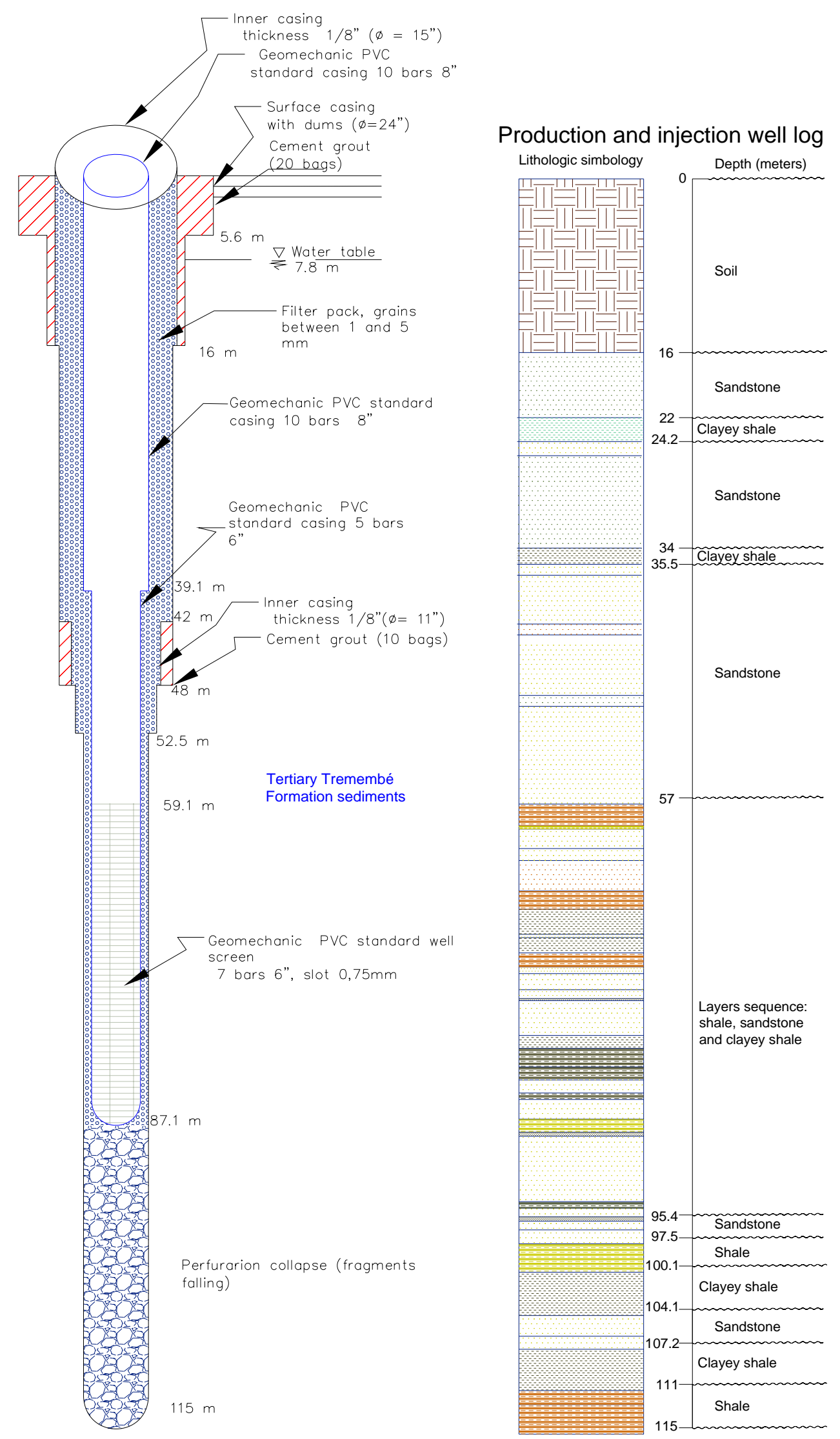

Figure 10. Agrarian Sciences Department of Taubaté University Production/Injection well design and geologic log. 
DINIZ, H. N.; SANTORO, J.; BATISTA, G. T.; DIAS, N. W.; TARGA, M. dos S. Hydrogeology and hydrodynamics of Tremembé aquifer, São Paulo, Brazil. Ambi-Agua, Taubaté, v. 3, n. 1, p. 108-137, 2008. (doi:10.4136/ambi-agua.46)

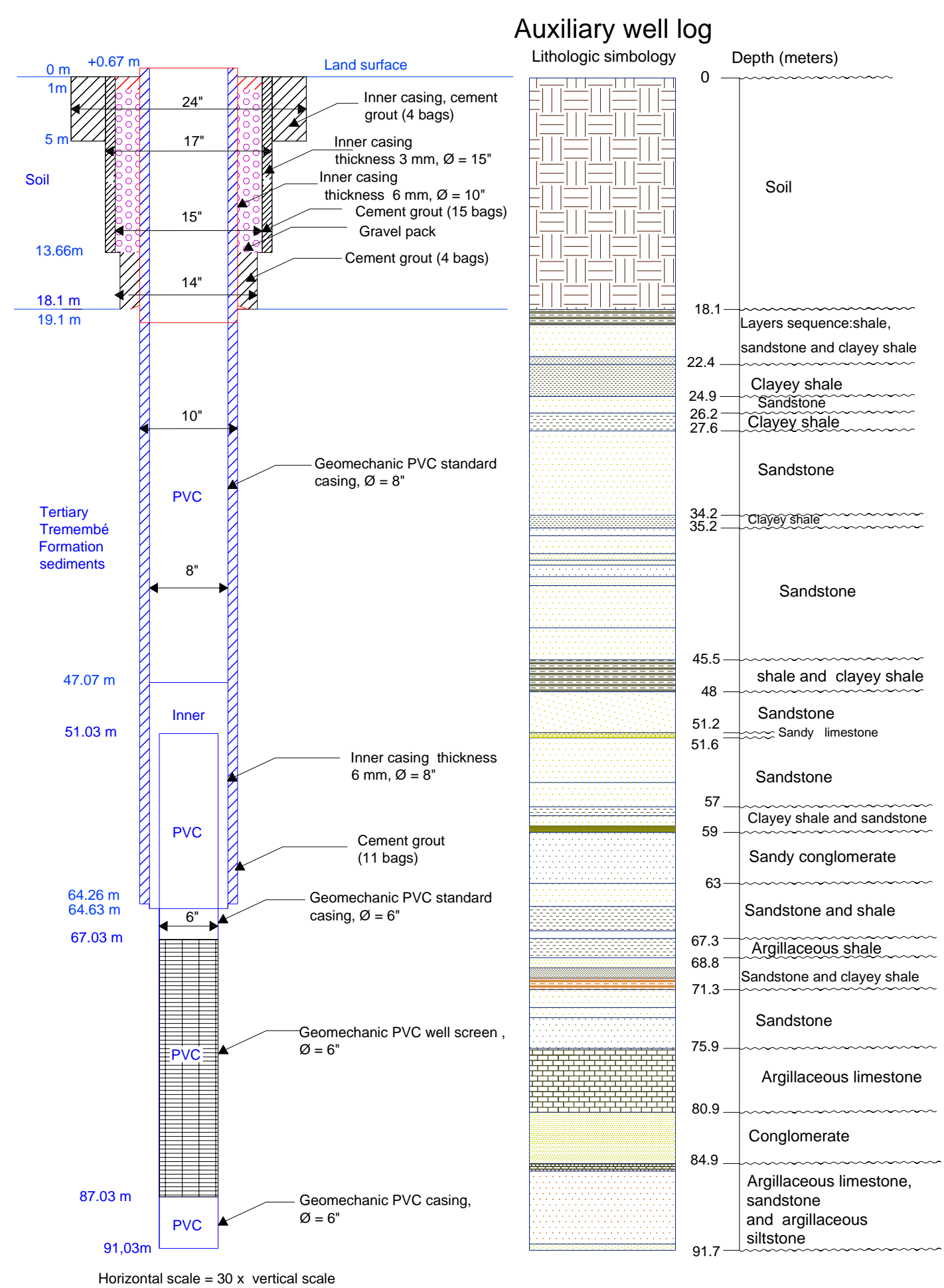

Figure 11. Agrarian Sciences Department of Taubaté University Auxiliary well design and geologic log.

\subsection{Geological characteristics}

The dominant soil type in the Una river hydrographic basin is the red yellow latosol (argisol) with thickness varying from $10 \mathrm{~m}$ in the floodplains up to $20 \mathrm{~m}$ in the hill tops. The soil profile is composed of fine to coarse sand from the surface down to $1 \mathrm{~m}$; by sandy clay loam from 1 to $2 \mathrm{~m}$; and by fine to coarse sand from $2 \mathrm{~m}$ to the maximum soil depth. In the Production/Injection well the latosol extended down to $16 \mathrm{~m}$ depth. 
DINIZ, H. N.; SANTORO, J.; BATISTA, G. T.; DIAS, N. W.; TARGA, M. dos S. Hydrogeology and hydrodynamics of Tremembé aquifer, São Paulo, Brazil. Ambi-Agua, Taubaté, v. 3, n. 1, p. 108-137, 2008. (doi:10.4136/ambi-agua.46)

Underneath the soil, the Taubaté basin Tertiary sediments occur until, at least, the depth of Production/Injection well $(115 \mathrm{~m})$. It is characterized by a succession of Tertiary layers formed by river and lake depositions during a semi-arid climate. The layers are comprised of shale, argillaceous limestone, calcareous and quartzitic sandstone, and conglomerate (Figures 10 and 11).

In the Production/Injection well, from 16 to $57 \mathrm{~m}$ depth, horizontal layers of Tremembé Formation Tertiary sandstones (Taubaté Group) predominantly occurs, formed during a fluvial depositional environment. Between $57 \mathrm{~m}$ to $115 \mathrm{~m}$, deposits of clayey shale dominate. However, they are intercalated with quartzitic micaceous sandstone and argillaceous shale formed in depositional environment originated from lakes with a lot of submerged animal and plant life. This explains the black organic matter found in the argillaceous shale layers.

\subsection{Hydrogeologic characterization}

During the Production/Injection well construction, an initial pump test was conducted at the depth of $48 \mathrm{~m}$ (Figure 12). The pump test data showed that the aquifer was leaky according to Hantush (1956) and was supplied from the aquitarde storage, an argillaceous sandstone layer located at a high aquifer level, and there was dynamic water level stabilization with 1.028 $\mathrm{m}^{3} / \mathrm{h}$ pumping rate. Measured transmissivity was $0.58 \mathrm{~m}^{2} / \mathrm{h}$.

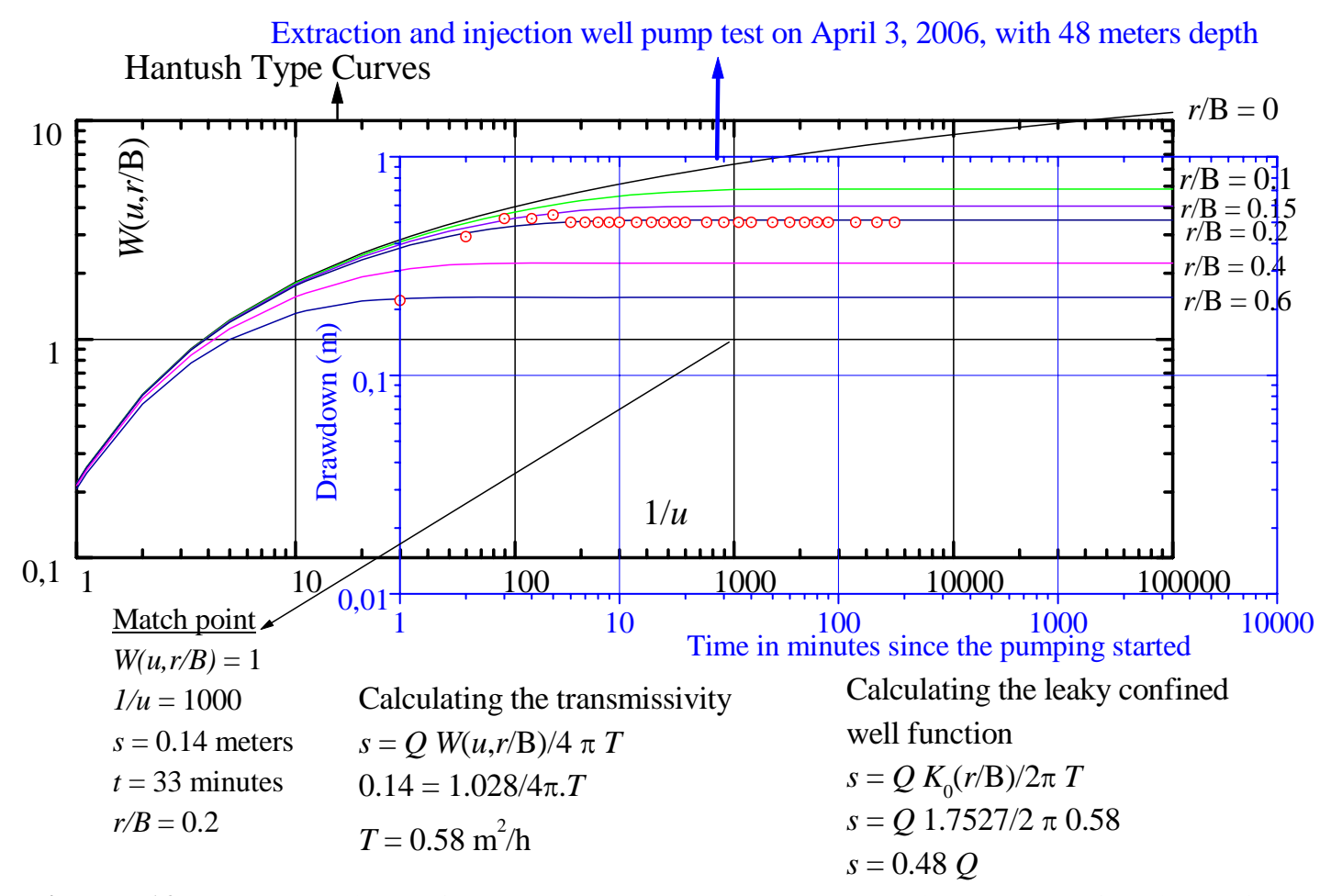

Figure 12. Interpretation of pump test data conducted during the perforation of the Production/Injection well at $48 \mathrm{~m}$ depth.

A second pump test was conducted when the borehole was at $66 \mathrm{~m}$ (Figure 13). This pump test had the purpose of checking possible hydrogeological variations given that the water level rose while the perforation went from $48 \mathrm{~m}$ to $66 \mathrm{~m}$, what indicates a clear change in aquifer behavior. The field drawdown data indicated that the aquifer changed its behavior, from leaky to delayed gravity response (Neuman, 1972), but the value of transmissivity did not change $\left(0.58 \mathrm{~m}^{2} / \mathrm{h}\right)$.

From the depth of this pump test $(66 \mathrm{~m})$ down to the final depth of the borehole $(115 \mathrm{~m})$ sandstones with intercalations of argillaceous shale occur and form aquicludes that confine the aquifer layers. The well was completed with $87.1 \mathrm{~m}$ and the interpretation of the final 
DINIZ, H. N.; SANTORO, J.; BATISTA, G. T.; DIAS, N. W.; TARGA, M. dos S. Hydrogeology and hydrodynamics of Tremembé aquifer, São Paulo, Brazil. Ambi-Agua, Taubaté, v. 3, n. 1, p. 108-137, 2008. (doi:10.4136/ambi-agua.46)

pump test (Figure 14) shows that the aquifer type changed to confined with transmissivity of $8 \mathrm{~m}^{2} / \mathrm{h}$ and storage coefficient of 0.002 .

Production and injection well drawdown pump test on April 28, 2006, with 66 meters depth and 6.83 meters of the static water level

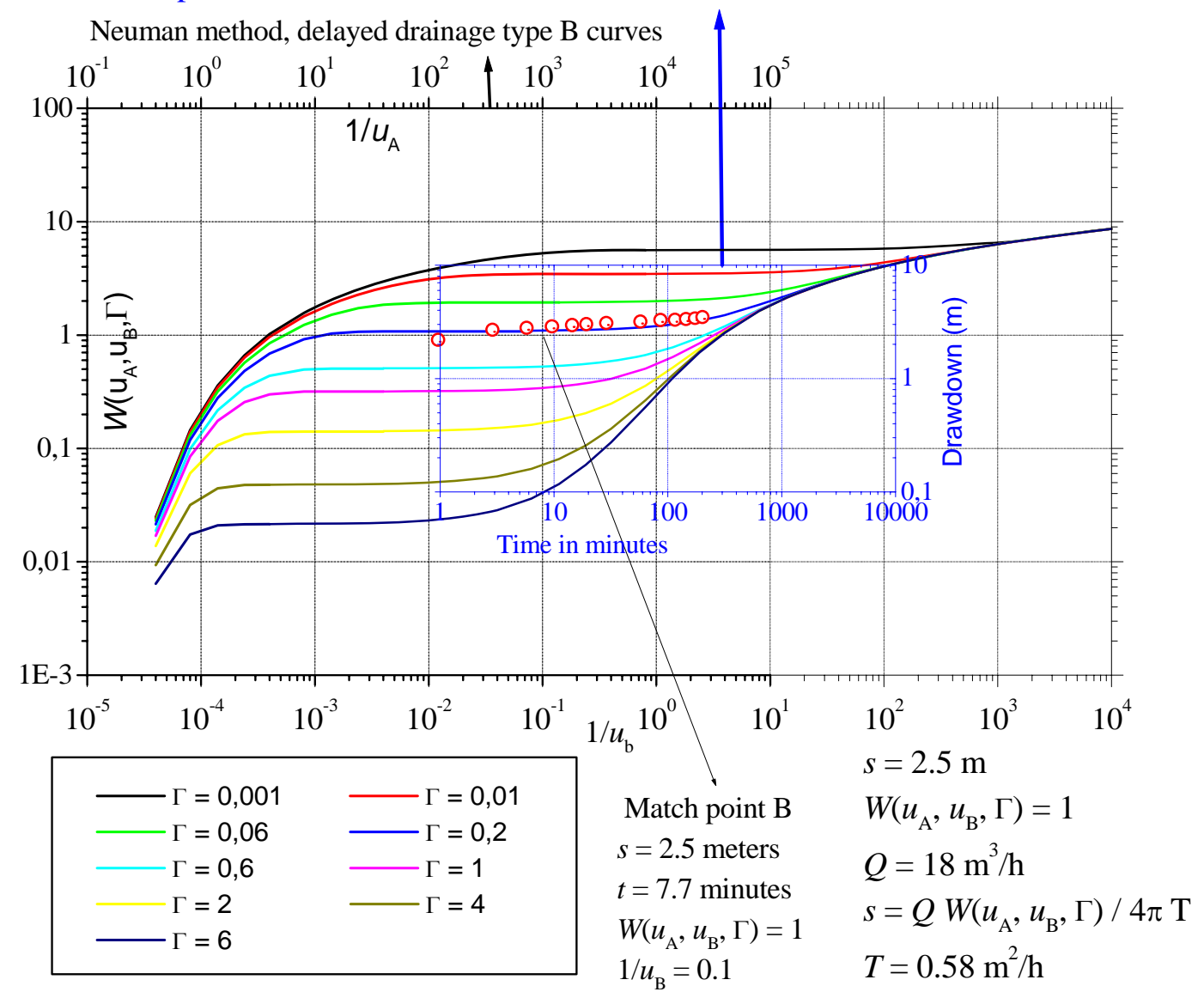

Figure 13. Matching late drawdown data to a type B curve (water-table aquifer).

The Production/Injection well, with the hydraulics characteristics, shown in Figure 14, can provide a very good discharge rate. For example, if the well is continuously pumped at $120 \mathrm{~m}^{3} / \mathrm{h}$ rate, after 2 years the dynamic level will be $35 \mathrm{~m}$, or equal to the static level (8.33 $\mathrm{m}$ ) plus the drawdown (26.59 m, Eq. 5) obtained from the Cooper and Jacob (1946) equation, therefore $8.33+26.59=34.92 \cong 35 \mathrm{~m}$.

The drawdown above was calculated as described: $r=14 " / 2=7 ”=0.18 \mathrm{~m}$; and $t=2$ years $=2 \times 365$ days $\times 24$ hours $/$ day $=17520$ hours.

$$
s=\frac{2.3 Q}{4 \pi T} \log \left(\frac{2.25 T t}{r^{2} S}\right) \Rightarrow s=\frac{2.3 \cdot 120}{4 \pi \cdot 8} \log \left(\frac{2.25 \cdot 8 \cdot 17520}{(0.18)^{2} \cdot 0.002}\right) \Rightarrow s=26.59 m
$$


DINIZ, H. N.; SANTORO, J.; BATISTA, G. T.; DIAS, N. W.; TARGA, M. dos S. Hydrogeology and hydrodynamics of Tremembé aquifer, São Paulo, Brazil. Ambi-Agua, Taubaté, v. 3, n. 1, p. 108-137, 2008. (doi:10.4136/ambi-agua.46)

Production and injection well drawdown data point on October 17, 2006

Theis Type Curve Confined Aquifer

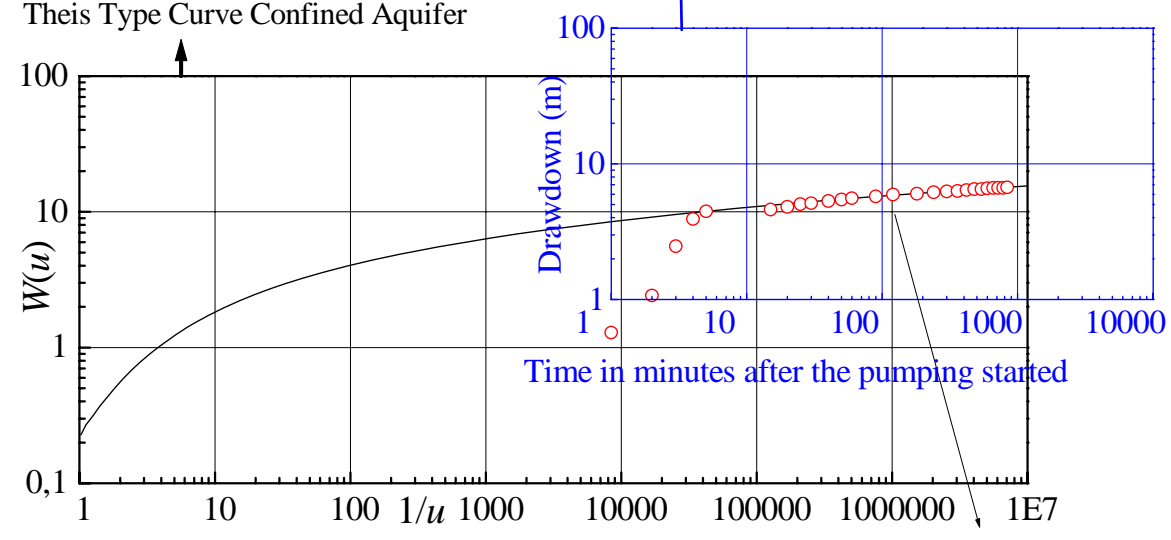

$$
\begin{array}{llll}
1 / u=4 T t / r^{2} S & Q=44.47 \mathrm{~m}^{3} / \mathrm{h} & r=0.18 \mathrm{~m} & \underline{\text { Match point }} \\
S=4 T t / r^{2} 1 / u & T=Q W(u) / 4 \pi \mathrm{s} & r^{2}=0.032 \mathrm{~m}^{2} & t=120 \text { minutes } \\
S=2 \times 10^{-3} & T=44.47 \times 10 / 4 \pi \times 4.43 & Q=44.47 \mathrm{~m}^{3} / \mathrm{h} & t=2 \text { hours } \\
& T=8 \mathrm{~m}^{2} / \mathrm{h} & T=8 \mathrm{~m}^{2} / \mathrm{h} & s=4.43 \text { meters } \\
& & S=0.002 & 1 / u=1000000 \\
& & W(u)=10
\end{array}
$$

Figure 14. Interpretation of the final pump test data of Production /Injection well.

\subsection{Advanced hydrogeological characterization}

After completion of the Production/Injection and Auxiliary wells, several pump tests were conducted in July and August, 2007. Interpretation of a pump test in the Production/Injection well with constant discharge rate of $36 \mathrm{~m}^{3} / \mathrm{h}$ and measurement of dynamic water level in the Production/Injection well is shown in Figure 15. Figure 16 shows the drawdown at the Auxiliary well.

Production and injection well (pumping well) drawdown data point on July 25, 2007,

in Taubate University Departament of Agronomy pump test

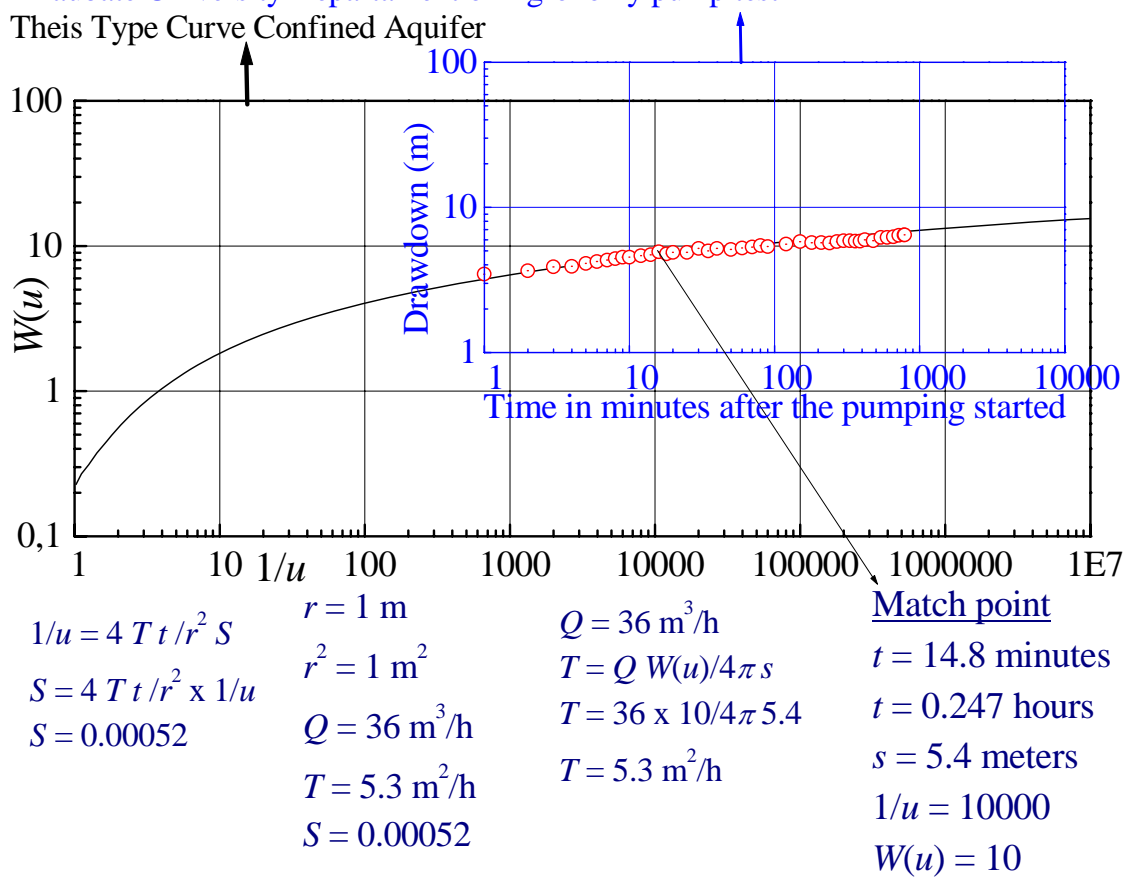

Figure 15. Interpretation of pump test conducted in the Production/Injection well with drawdown data measured at the same pumped well. 
Auxiliary well (observation well) drawdown data point on July 18, 2007, of the Production and injection well pump test

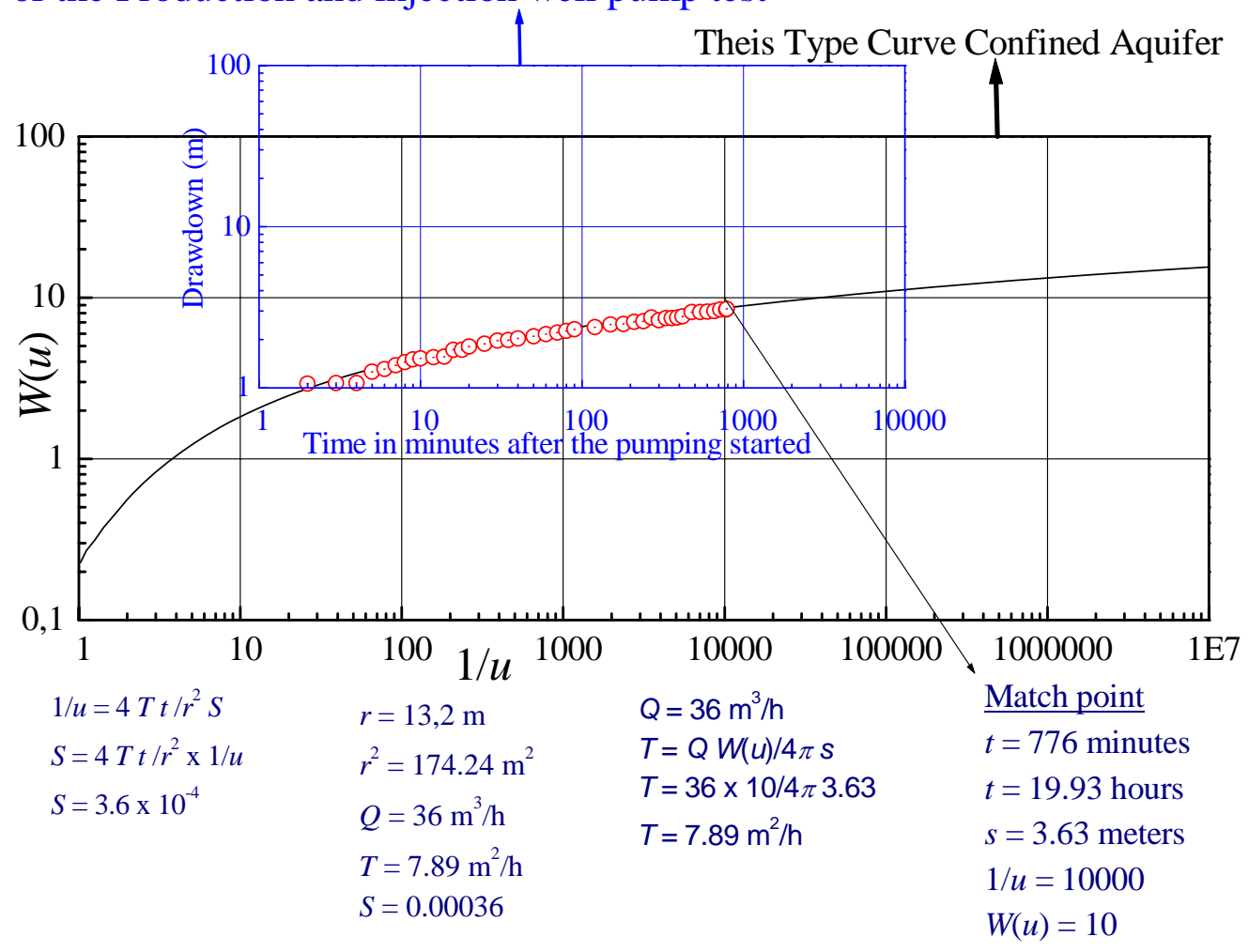

Figure 16. Interpretation of pump test conducted in the Production/Injection well with drawdown data measured at the auxiliary well (observation well) 13.2 m away.

Production and injection well (pumping well) recovery data point on July 25, 2007

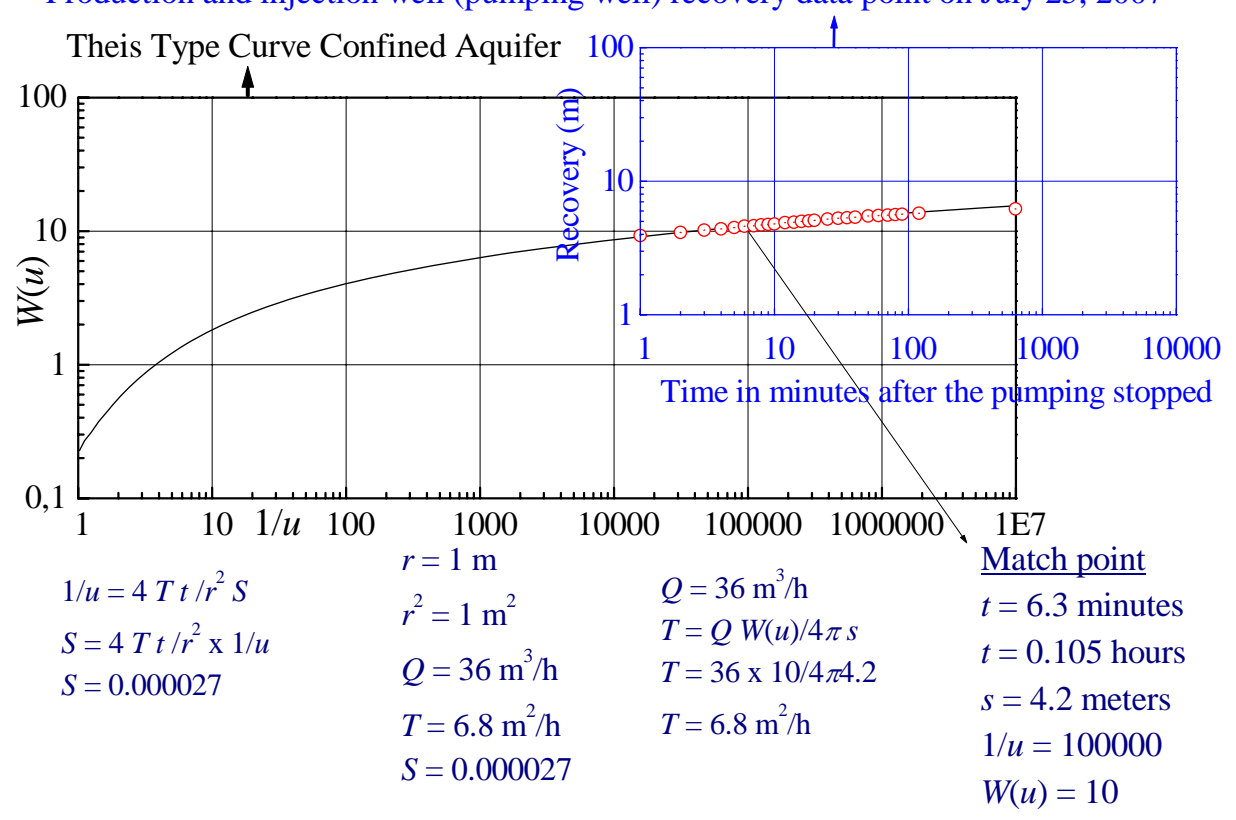

Figure 17. Interpretation of recovery test conducted in the Production/Injection well with recovery data measured at the same well pumped. 
According to the theory of image well water-mirror (horizontal plane mirror), as described in section 2.1 (Figure 6), the interpretation model that applies to the recovery data can also be used for the drawdown data, and therefore, Theis curve type (Theis, 1935) was used. The recovery test data measured in the Production/Injection well with $36 \mathrm{~m}^{3} / \mathrm{h}$ of the restored flow rate are shown in Figure 17 and measured recovery in the Auxiliary well (observation well) in Figure 18.

The interpretation of Production/Injection well pump test with discharge rate of $36 \mathrm{~m}^{3} / \mathrm{h}$ indicated $6.75 \mathrm{~m}^{2} / \mathrm{h}$ for the average transmissivity and 0.00033 for the average coefficient of storage.

Auxiliary well recovery data point (observation well) in Production and injection well pump test, on July 25, 2007

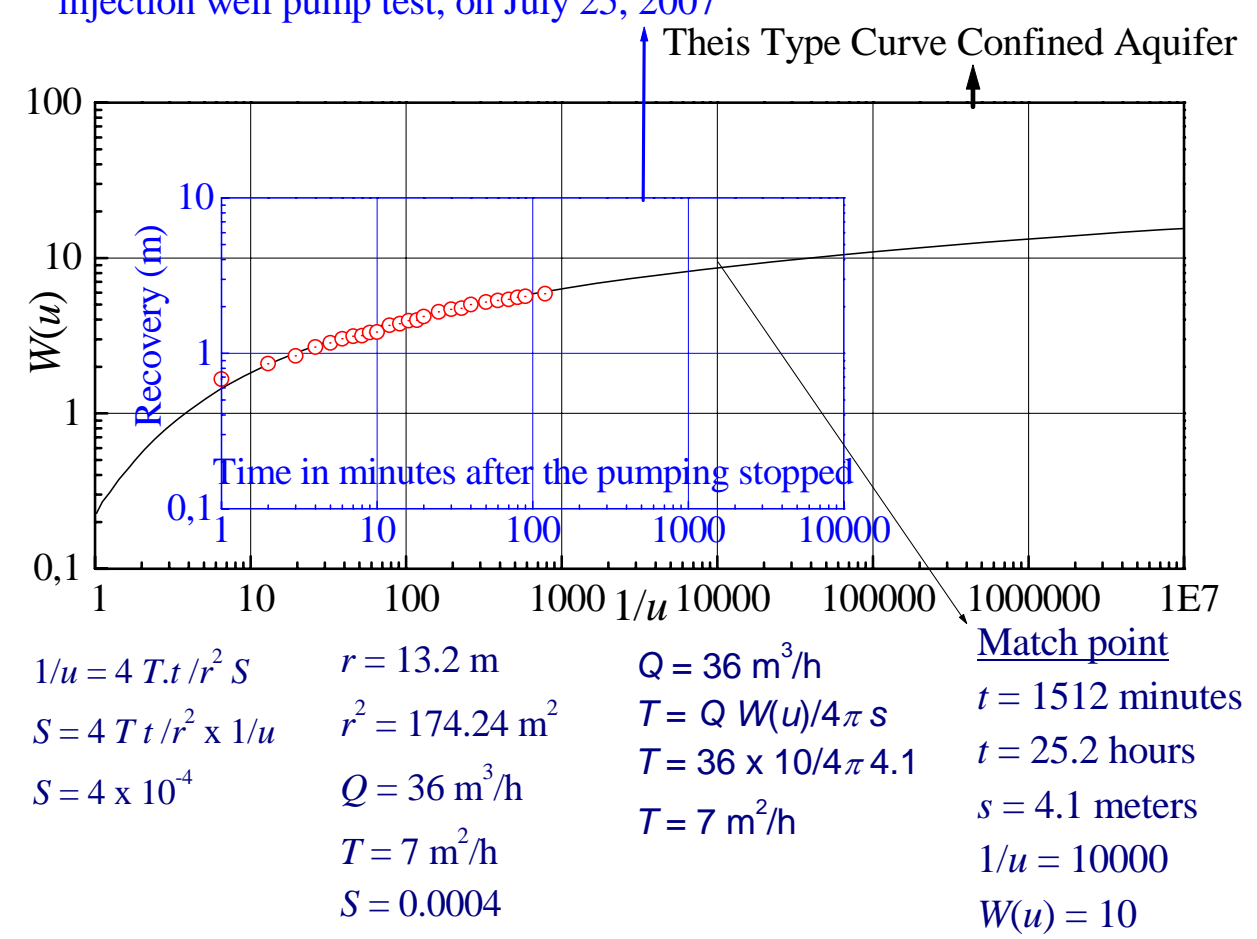

Figure 18. Interpretation of pump test conducted in the Production/Injection well with recovery data measured at the Auxiliary well (observation well).

Other pump tests were conducted in the Auxiliary well with $84 \mathrm{~m}^{3} / \mathrm{h}$ discharge rate and drawdown data measured in both in the pumped well (Figure 19) and in the Production/Injection well (observation well, Figure 20). 
DINIZ, H. N.; SANTORO, J.; BATISTA, G. T.; DIAS, N. W.; TARGA, M. dos S. Hydrogeology and hydrodynamics of Tremembé aquifer, São Paulo, Brazil. Ambi-Agua, Taubaté, v. 3, n. 1, p. 108-137, 2008. (doi:10.4136/ambi-agua.46)

Auxiliary well drawdown (pumping well) on July 18, 2007

Theis Type Curve Confined Aquifer

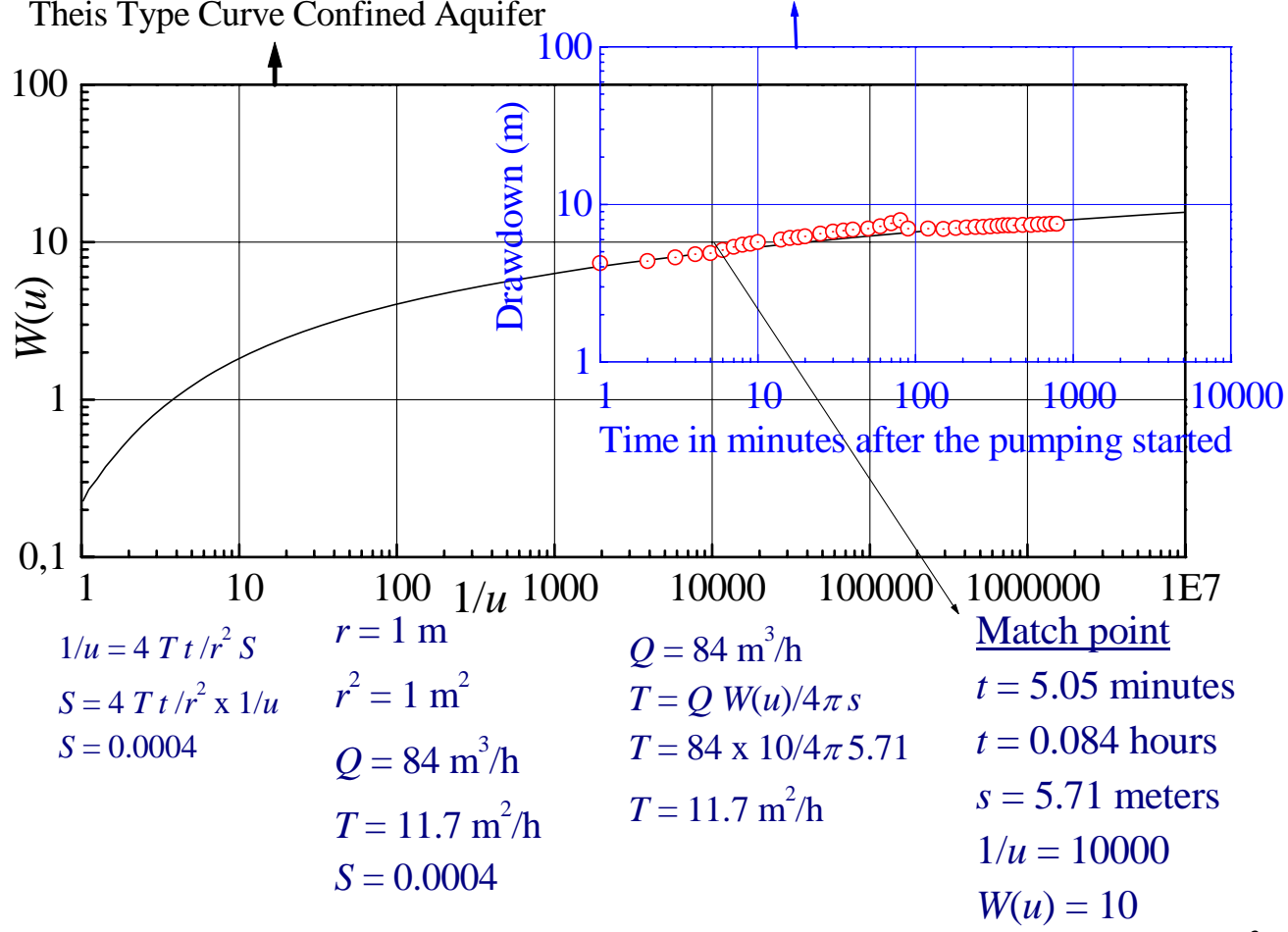

Figure 19. Interpretation of pump test conducted in the Auxiliary well with $84 \mathrm{~m}^{3} / \mathrm{h}$ discharge rate and drawdown measured in the same pumped well.

Production and injection well drawdown data point (observation well) of the Auxiliary well pump test, on July 18, 2007

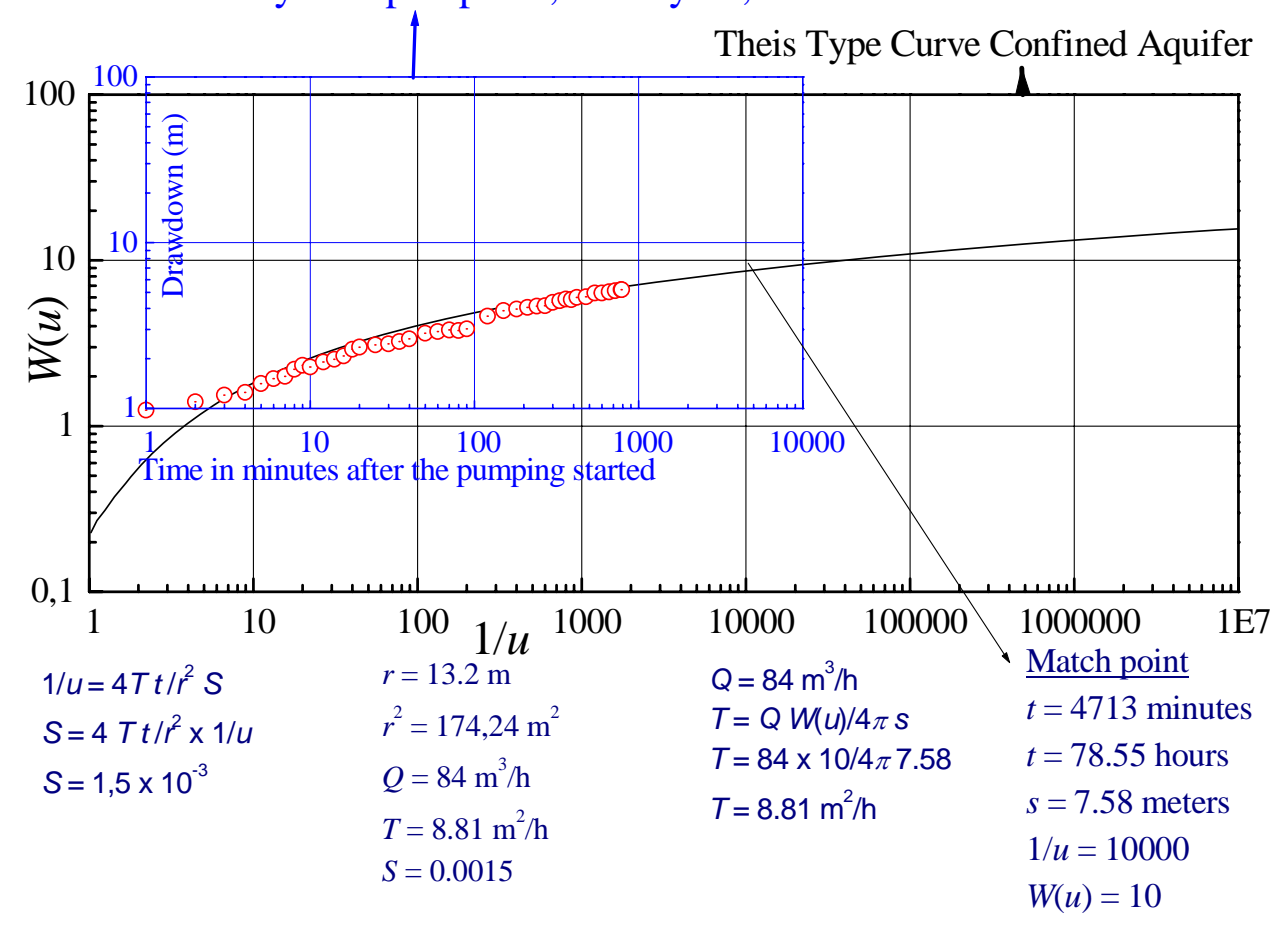

Figure 20. Interpretation of pump test conducted in the Auxiliary well with 84 $\mathrm{m}^{3} / \mathrm{h}$ discharge rate and drawdown measured in the Production/Injection well (observation well). 
DINIZ, H. N.; SANTORO, J.; BATISTA, G. T.; DIAS, N. W.; TARGA, M. dos S. Hydrogeology and hydrodynamics of Tremembé aquifer, São Paulo, Brazil. Ambi-Agua, Taubaté, v. 3, n. 1, p. 108-137, 2008. (doi:10.4136/ambi-agua.46)

The recovery data in the Auxiliary well (pumped well) test are shown in Figure 21 and in the Production/Injection well (observation well) are shown in Figure 22.

Auxiliary well (pumped well) recovery data point on July 18, 2007

Theis Type Curve Confined Aquifer

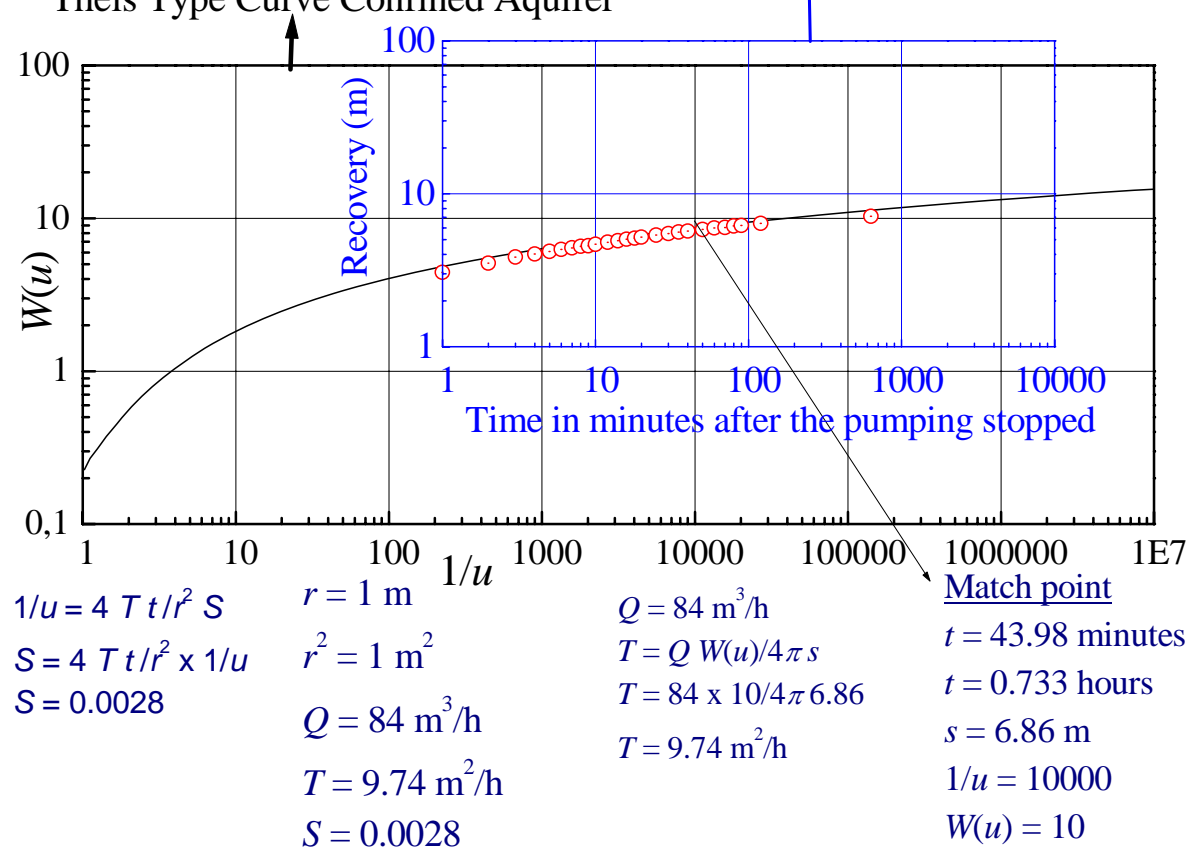

Figure 21. Interpretation of pump test conducted in the auxiliary well with $84 \mathrm{~m}^{3} / \mathrm{h}$ reinstated flow rate and recovery data measured in the same well (extraction well).

Production and injection well recovery data point (observation well) in Auxiliary well pump test, on July 18, 2007

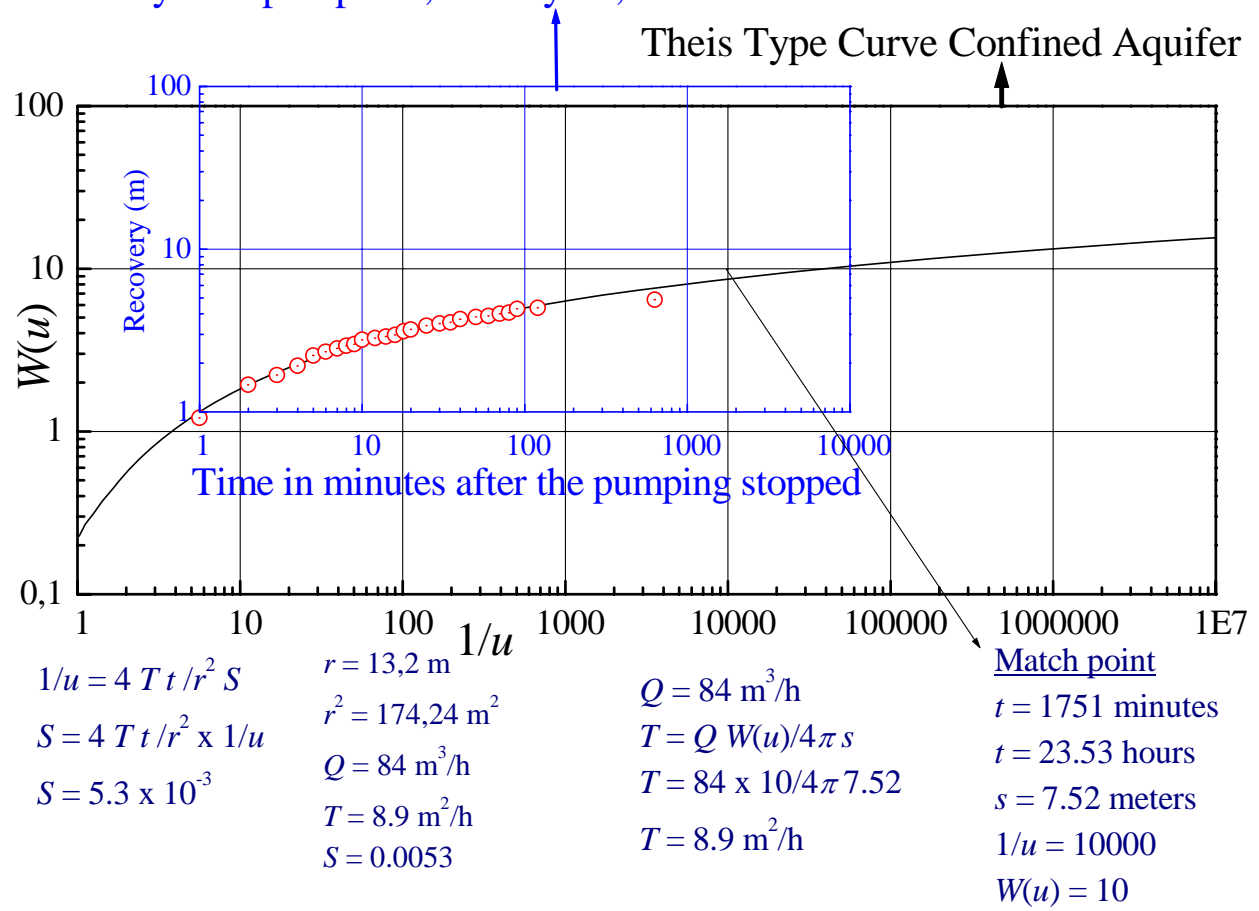

Figure 22. Interpretation of pump test conducted in the auxiliary well with 84 $\mathrm{m}^{3} / \mathrm{h}$ reinstated flow rate and recovery data measured in the Production/Injection well (observation well). 
DINIZ, H. N.; SANTORO, J.; BATISTA, G. T.; DIAS, N. W.; TARGA, M. dos S. Hydrogeology and hydrodynamics of Tremembé aquifer, São Paulo, Brazil. Ambi-Agua, Taubaté, v. 3, n. 1, p. 108-137, 2008. (doi:10.4136/ambi-agua.46)

The interpretation of pump tests data with discharge rate of $84 \mathrm{~m}^{3} / \mathrm{h}$ in the Auxiliary well, indicated $9.8 \mathrm{~m}^{2} / \mathrm{h}$ for the average transmissivity and 0.0025 for the average coefficient of storage.

The higher values found for both transmissivity and storage coefficient for a higher discharge rate demonstrate that when groundwater extraction increases other aquifer layers contribute to discharge rate, because the Tremembé Aquifer is confined with multi-layers (sandstone layers intercalated with argillaceous shale).

\subsection{Artificial recharge tests}

After the pump tests in the Production/Injection well and Auxiliary well were conducted on July 26, 2007, a recharge test in the Auxiliary well, with ascent water level (water injection) and drawdown (water injection stopped) was performed in both recharge wells, Auxiliary well and Production/Injection well.

The recharge test was conducted by pumping water from a container of $15.4 \mathrm{~m}^{3}$ that was filled with water previously extracted from the well at $27 \mathrm{~m}^{3} / \mathrm{h}$ recharge rate for 30 minutes (Figure 23).

According to the theory of image well shown in Figure 7 (section 2.1), during water injection (recharge rate $=-Q$ ) in a tubular deep well, the water level acts as a positive barrier and the increasing cone of the recharge water is equal to the cone of depression (discharge rate $=Q$ ) as an image reflected in a water-table mirror (horizontal mirror plane). Thus, for rise level data or drawdown after the water recharge stopped, the Theis model can be used for hydrodynamics' parameter determination when the aquifer is confined.

Data from rising water level observed in the Production/Injection well, with water injection in the Auxiliary well, are shown in Figure 24. And the drawdown data in the Production/Injection well, after the water injection stopped, are shown in Figure 25. Hydrodynamic parameters obtained during artificial recharge tests in the Tremembé Aquifer in the Department of Agrarian Sciences, University of Taubaté, are quite consistent with those obtained by pump tests.

Ascent water-level in recharge well (Auxiliary well), artificial recharge test on July 26, 2007

Theis Type Curve Confined Aquifer

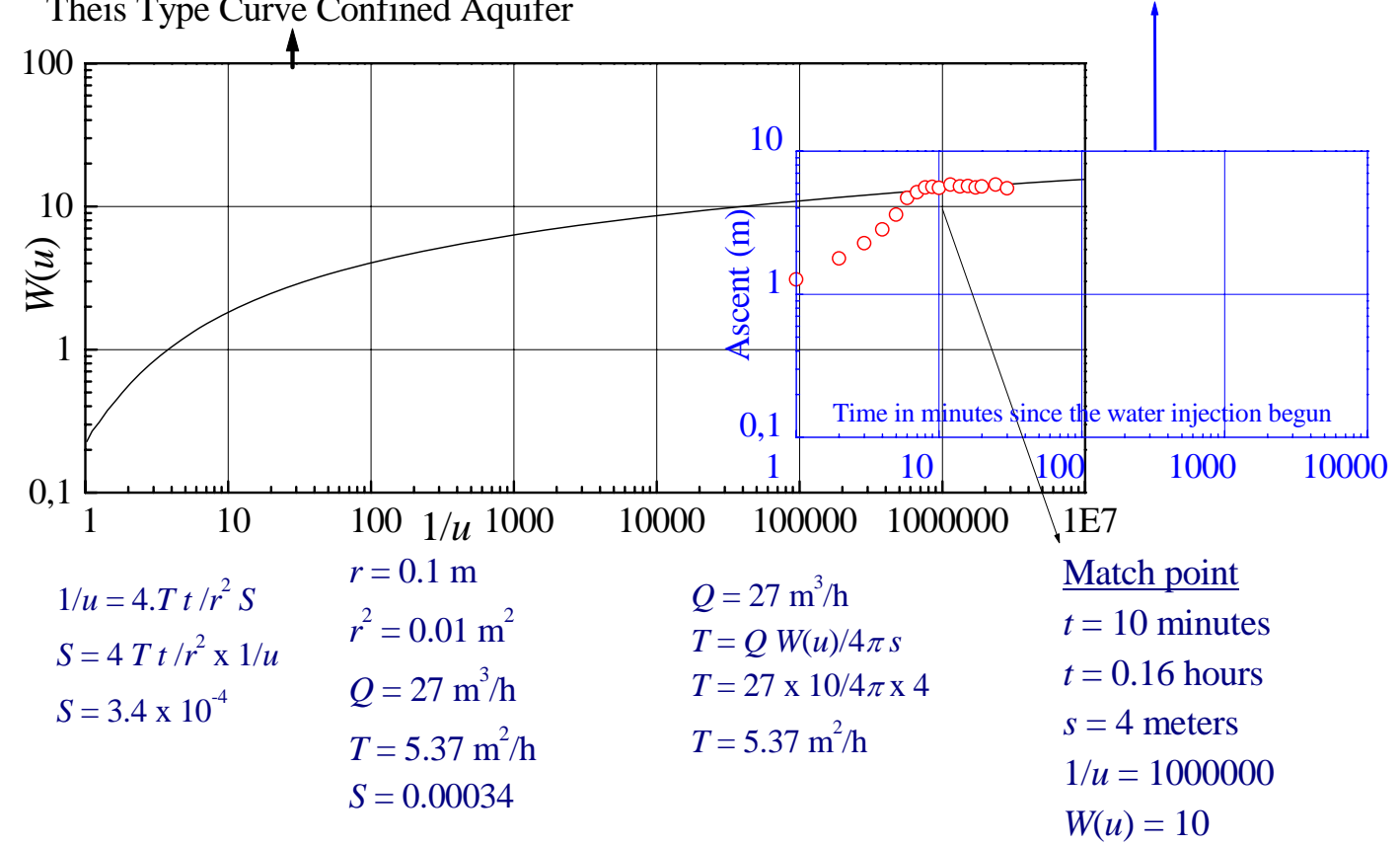

Figure 23. Artificial recharge test conducted in Auxiliary well, with $27 \mathrm{~m}^{3} / \mathrm{h}$ injection rate and ascent measures obtained in the same well (auxiliary well). 
DINIZ, H. N.; SANTORO, J.; BATISTA, G. T.; DIAS, N. W.; TARGA, M. dos S. Hydrogeology and hydrodynamics of Tremembé aquifer, São Paulo, Brazil. Ambi-Agua, Taubaté, v. 3, n. 1, p. 108-137, 2008. (doi:10.4136/ambi-agua.46)

Ascent water level in observation well (Production and injection well) from recharge test in Auxiliary well on July 26, 2007

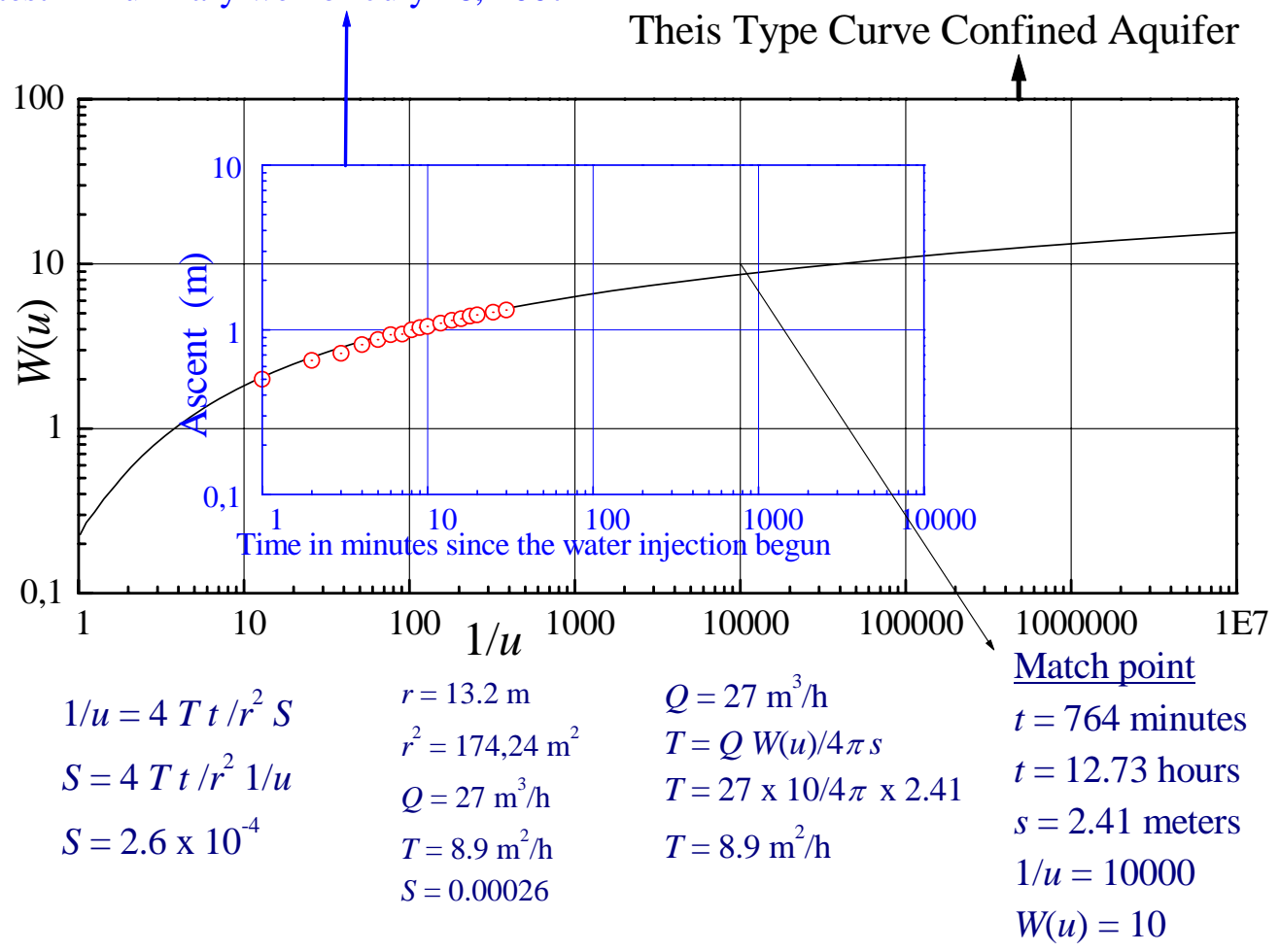

Figure 24. Artificial recharge test conducted in Auxiliary well, with $27 \mathrm{~m}^{3} / \mathrm{h}$ injection rate and ascent measures obtained in Production/Injection well (observation well).

Water level drawdown in Production and Injection well (observation well) in recharge

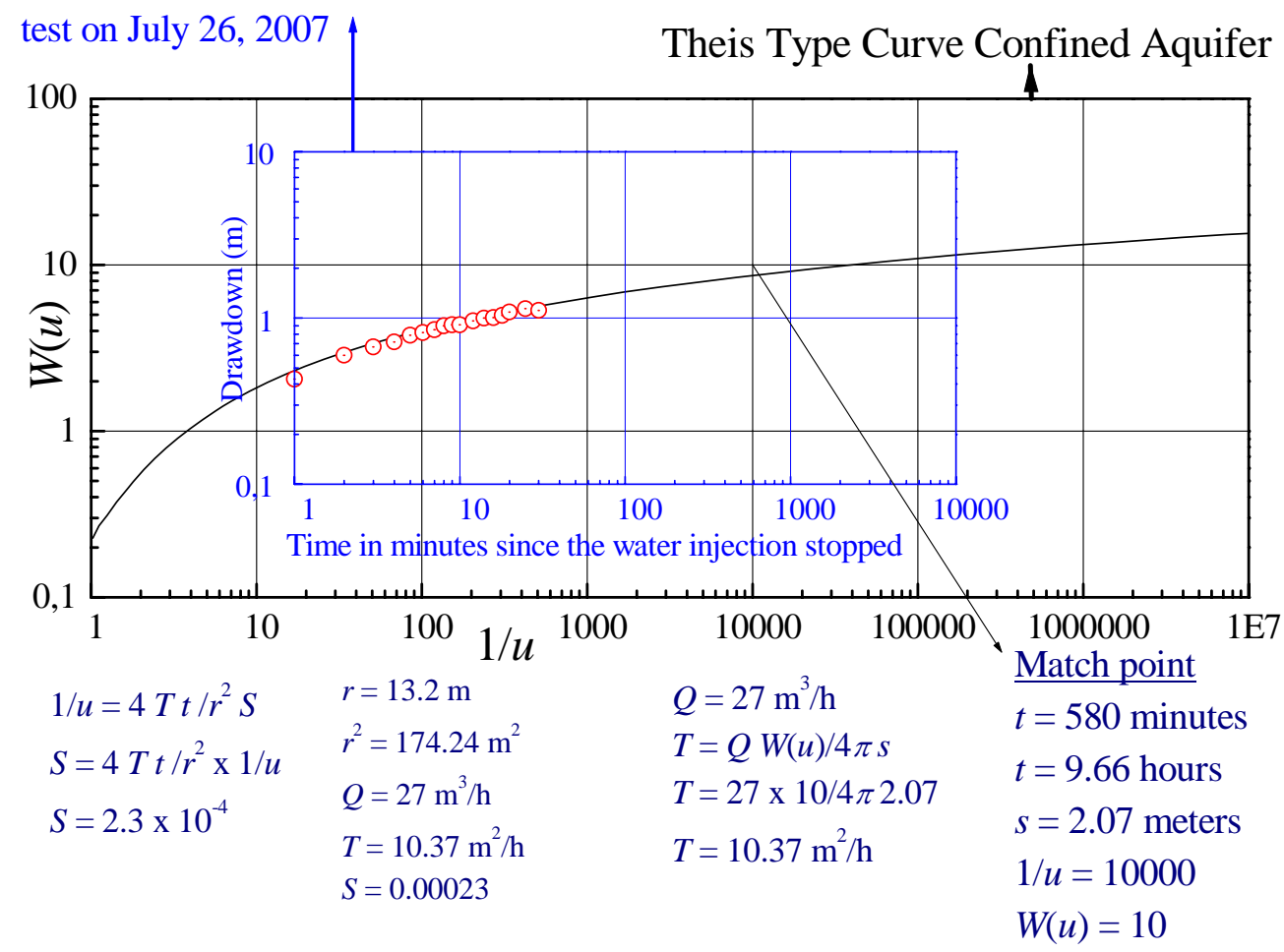

Figure 25. Artificial recharge test conducted in auxiliary well, after the $27 \mathrm{~m}^{3} / \mathrm{h}$ injection rate water stopped and drawdown measures obtained in Production/Injection well (observation well). 
DINIZ, H. N.; SANTORO, J.; BATISTA, G. T.; DIAS, N. W.; TARGA, M. dos S. Hydrogeology and hydrodynamics of Tremembé aquifer, São Paulo, Brazil. Ambi-Agua, Taubaté, v. 3, n. 1, p. 108-137, 2008. (doi:10.4136/ambi-agua.46)

The potentiometric water level of Tremembé Aquifer is approximately $8 \mathrm{~m}$ depth in the wells sites. Applying this value for drawdown in the Cooper and Jacob (1946) equation, a radius of 7" (half-diameter of borehole $\Rightarrow r=14 " / 2=7 "=0,18 \mathrm{~m}$ ), and a time of water injection of 24 hours (rainfall of 24 hours), to Equation [7], considering $T=8 \mathrm{~m}^{2} / \mathrm{h}$ and $S=$ 0,002 , shows that the maximum recharge rate by gravity, without extravasation of the injected water, is equal to $60 \mathrm{~m}^{3} / \mathrm{h}$.

$$
s=\frac{2,3 Q}{4 \pi T} \log \left(\frac{2,25 T t}{r^{2} S}\right) \Rightarrow 8=\frac{2,3 \cdot Q}{4 \pi \cdot 8} \log \left(\frac{2,25 \cdot 8 \cdot 24}{(0,18)^{2} \cdot 0,002}\right) \Rightarrow Q=60 \mathrm{~m}^{3} / \mathrm{h}
$$

In the Taubaté region rarely occurs 24 hour rains with intensities greater than $60 \mathrm{~mm}$. Therefore, with $60 \mathrm{~m}^{3} / \mathrm{h}$ flow rate, all water can be infiltrated by gravity in a single well, this corresponds to the water collected in a roof area of $24,000 \mathrm{~m}^{2}\left(60 \mathrm{~m}^{3} / \mathrm{h} \times 24 \mathrm{~h} / 0,006 \mathrm{~m}=\right.$ $24,000 \mathrm{~m}^{2}$ ). Thus, a well drilled in the region is quite effective for the injection of water captured in $24,000 \mathrm{~m}^{2}$ roofs for artificial recharge of aquifers.

\subsection{Wells interference}

After pump and recharge tests in the Production/Injection and Auxiliary wells, various tests for measuring interference between the wells were performed on August 8, 2007 (Figures 26, 27, 28 and 29).

The procedure for the interference tests was: pumping begun simultaneously in both wells (Production/Injection and Auxiliary) with maximum flow rate lower than the maximum discharge rate of individual well pump tests and limited by equipment power loss due to interference; and pumping stopped in both wells at the same time to begin the recovery tests in both wells.

Production and injection well drawdown data point in the interference pump test with Auxiliary well, on August 08, 2007

Theis Type Curve Confined Aquifer

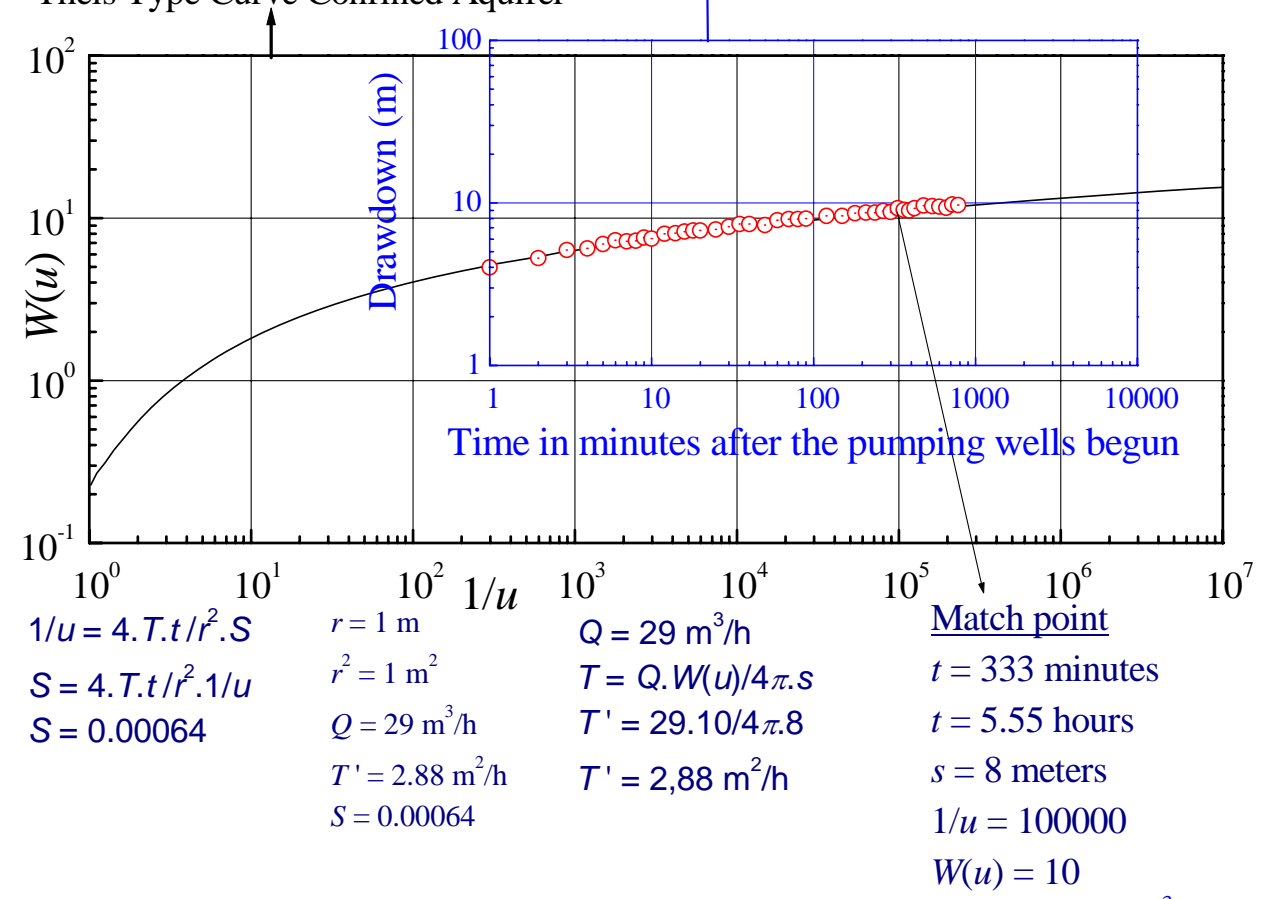

Interference data: $Q \times T^{\prime}=Q^{\prime} \times T$ or, $36 \times 2.88=Q^{\prime} \times 7.89$, thus $Q^{\prime}=13.14 \mathrm{~m}^{3} / \mathrm{h}$

Figure 26. Interference test (Production/Injection well drawdown) during the Production/Injection and Auxiliary wells pumping. 
DINIZ, H. N.; SANTORO, J.; BATISTA, G. T.; DIAS, N. W.; TARGA, M. dos S. Hydrogeology and hydrodynamics of Tremembé aquifer, São Paulo, Brazil. Ambi-Agua, Taubaté, v. 3, n. 1, p. 108-137, 2008. (doi:10.4136/ambi-agua.46)

The radius of influence found for the Production/Injection well pump test (Figure 16) with the obtained hydrodynamic parameters $\left(7.89 \mathrm{~m}^{2} / \mathrm{h}\right.$ for transmissivity and 0.00036 for coefficient of storage) without interference between wells, and for the time duration of the pumping (13 hours) with $36 \mathrm{~m}^{3} / \mathrm{h}$ constant discharge rate, is approximately $800 \mathrm{~m}$.

The interference test results of the Production/Injection well drawdown (Figure 26) show that $13.14 \mathrm{~m}^{3} / \mathrm{h}$ of the total discharge rate of the Production/Injection well pump test, without interference between the wells $\left(36 \mathrm{~m}^{3} / \mathrm{h}\right)$, comes from a radial area equal to the distance between the Production/Injection and Auxiliary wells $(13.2 \mathrm{~m})$. The withdraw flow rate in that area corresponded to $36.5 \%$ of the discharge rate of the Production/Injection well pump test without interference $\left(36 \mathrm{~m}^{3} / \mathrm{h}\right)$.

Considering the recovery data obtained in the Production/Injection well during the interference test (Figure 27), the reinstated flow rate in the area of $13.17 \mathrm{~m}^{3} / \mathrm{h}$ represents $37.8 \%$ of the Production/Injection well reinstated flow rate without interference $\left(36 \mathrm{~m}^{3} / \mathrm{h}\right)$ as shown in Figure 18.

Production and injection well recovery data point in the interference recovery test with Auxiliary well, on August 08, 2007

Theis Type Curve Confined Aquifer

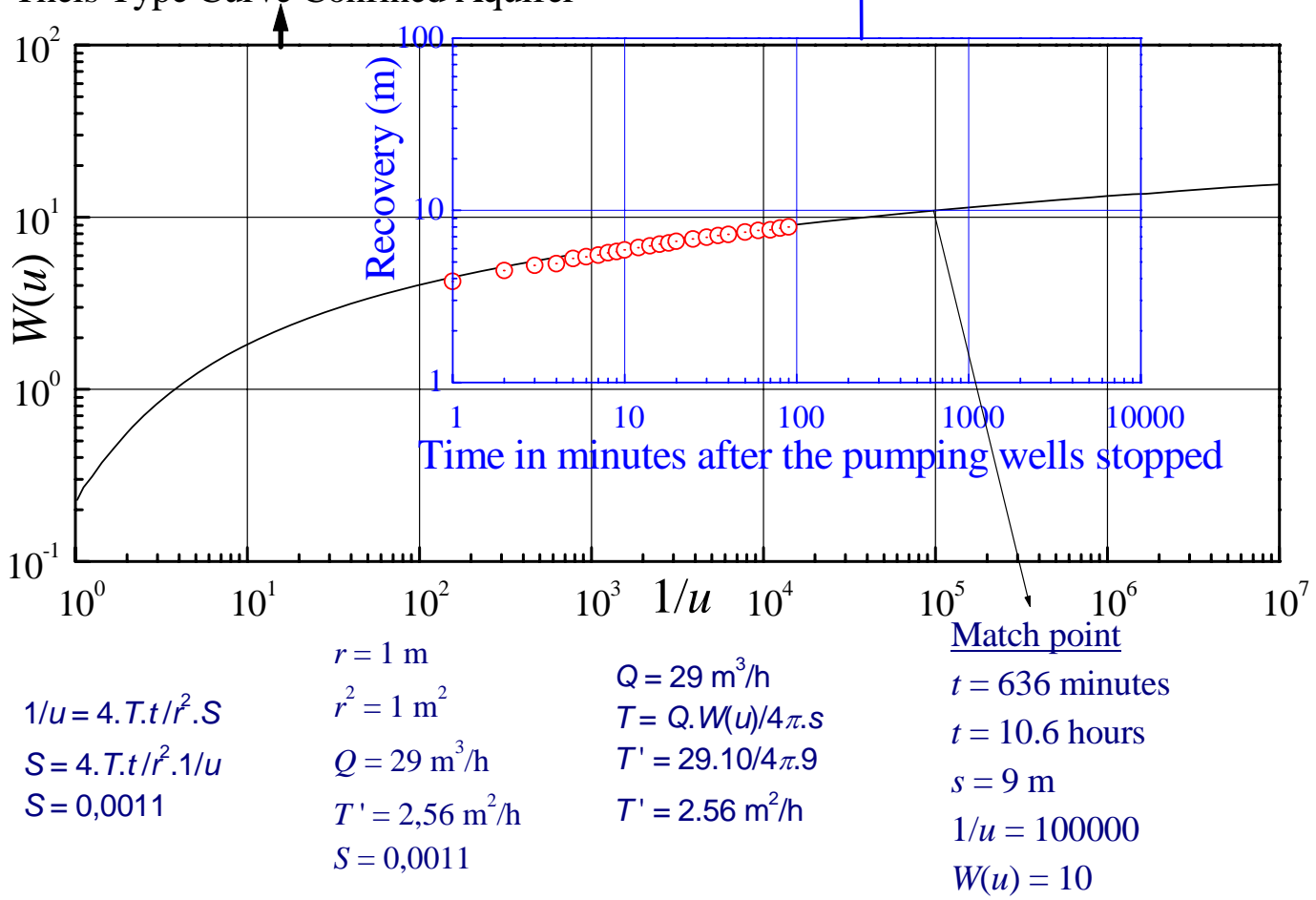

Interference data: $Q \times T^{\prime}=Q^{\prime} \times T$, thus $36 \times 2.56=Q^{\prime} \times 7$, or $Q^{\prime}=13.17 \mathrm{~m}^{3} / \mathrm{h}$

Figure 27. Interference test (Production/Injection well recovery test) during the Production/Injection and Auxiliary wells reinstated flow rate.

The radius of influence found for the Auxiliary well pump test (Figure 20) with the obtained hydrodynamic parameters $\left(8.81 \mathrm{~m}^{2} / \mathrm{h}\right.$ for transmissivity and 0.0015 for storage coefficient) without interference between wells, and for the pumping time duration (13 hours) with $84 \mathrm{~m}^{3} / \mathrm{h}$ constant discharge rate, is approximately $415 \mathrm{~m}$.

The interference test results of the Auxiliary well drawdown (Figure 28) show that 52.2 $\mathrm{m}^{3} / \mathrm{h}$ of the total discharge rate of the Auxiliary well pump test, without interference between the wells $\left(84 \mathrm{~m}^{3} / \mathrm{h}\right)$, comes from the area whose radius is equal to the distance between the Production/Injection and Auxiliary wells $(13.2 \mathrm{~m})$. The flow rate withdraw in the considered 
DINIZ, H. N.; SANTORO, J.; BATISTA, G. T.; DIAS, N. W.; TARGA, M. dos S. Hydrogeology and hydrodynamics of Tremembé aquifer, São Paulo, Brazil. Ambi-Agua, Taubaté, v. 3, n. 1, p. 108-137, 2008. (doi:10.4136/ambi-agua.46)

area corresponds to $62.1 \%$ of the discharge rate of the Auxiliary well pump test without interference $\left(84 \mathrm{~m}^{3} / \mathrm{h}\right)$ and the rest $(37.9 \%)$ of the flow rate $\left(84 \mathrm{~m}^{3} / \mathrm{h}-52.2 \mathrm{~m}^{3} / \mathrm{h}=31.8 \mathrm{~m}^{3} / \mathrm{h}\right)$ comes from the area between $13.2 \mathrm{~m}$ (distance between the wells) and $415 \mathrm{~m}$ (radius of influence of the Auxiliary well pump test without interference).

Considering the recovery data obtained in the Auxiliary well during the interference test (Figure 29), the reinstated flow rate in the area of $45.4 \mathrm{~m}^{3} / \mathrm{h}$ represents $54 \%$ of the Auxiliary well reinstated flow rate without interference $\left(84 \mathrm{~m}^{3} / \mathrm{h}\right)$ as shown in Figure 21.

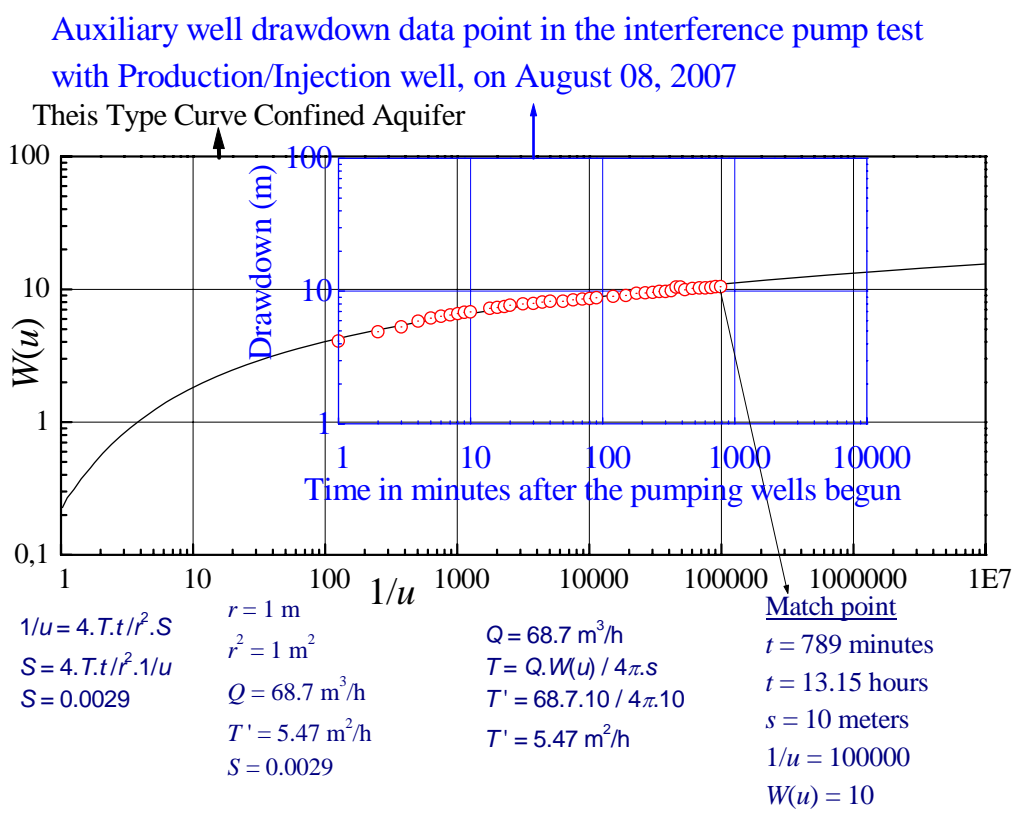

Interference data $: Q \times T^{\prime}=Q^{\prime} \times T$, thus $84 \times 5.47=Q^{\prime} \times 8.81$, or $Q^{\prime}=52.2 \mathrm{~m}^{3} / \mathrm{h}$

Figure 28. Interference test (Auxiliary well drawdown) during the Production/Injection and Auxiliary wells pumping.

Auxiliary well recovery data point in the interference recovery test with Production/Injection well, on August 08, 2007

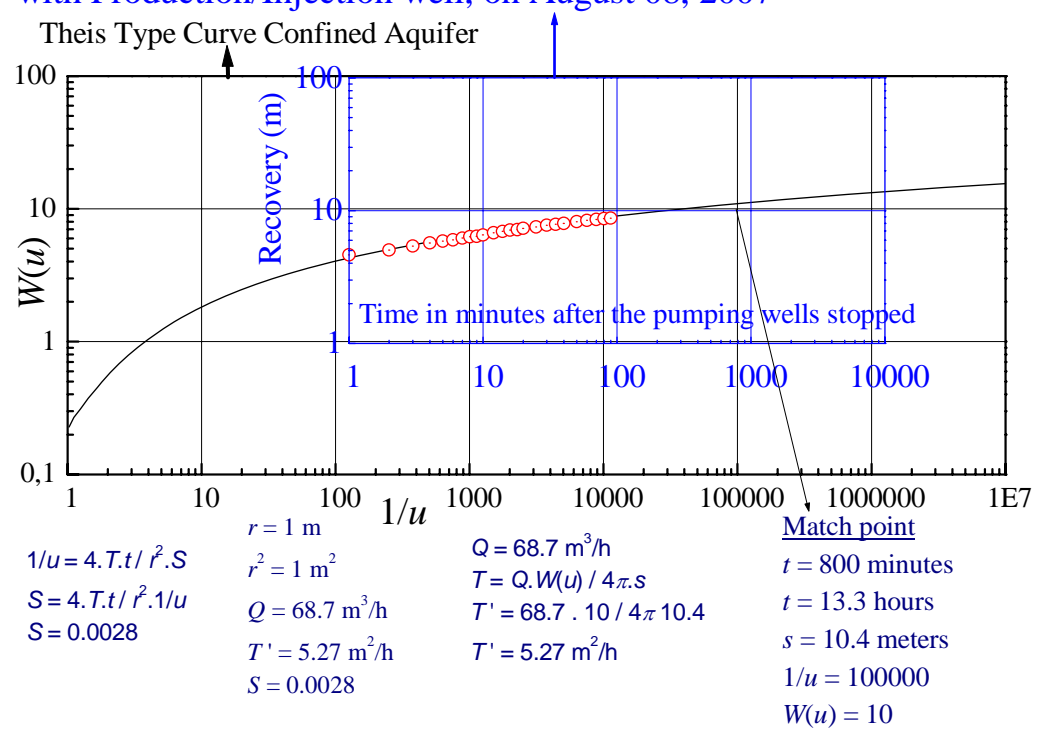

Interference data: $Q \times T^{\prime}=Q^{\prime} \times T$, thus $84 \times 5.27=Q^{\prime} \times 9.74$, or $Q^{\prime}=45.4 \mathrm{~m}^{3} / \mathrm{h}$

Figure 29. Interference test (Auxiliary well recovery test) during the Production/Injection and Auxiliary wells reinstated flow rate. 
DINIZ, H. N.; SANTORO, J.; BATISTA, G. T.; DIAS, N. W.; TARGA, M. dos S. Hydrogeology and hydrodynamics of Tremembé aquifer, São Paulo, Brazil. Ambi-Agua, Taubaté, v. 3, n. 1, p. 108-137, 2008. (doi:10.4136/ambi-agua.46)

\section{CONCLUSIONS}

The two wells drilled within the property of the Department of Agrarian Sciences, University of Taubaté, allowed improving the current geological and hydrogeological knowledge about Tremembé Formation (Taubaté Group).

Analysis of sedimentary layer samples collected during well drilling allowed characterizing Tremembé Formation lithology, stratigraphy, and paleontology. Several pump tests were conducted to verify the hydrogeological evolution in different depths of the sedimentary layers.

Tremembé Formation samples obtained at the depth between $16 \mathrm{~m}$ and $18 \mathrm{~m}$ showed the presence of red-yellow latosol soils that contained the phreatic aquifer and around $9 \mathrm{~m}$ the water table was observed. It was found between $18 \mathrm{~m}$ and $48 \mathrm{~m}$ a succession of sandstone and conglomerate layers formed by Tremembé Formation Tertiary sediments. These layers constitute a leaky aquifer due to the intercalation of shale argillaceous layers and associated slow vertical leakage. Predominantly sandstone and conglomerate layers were observed between $48 \mathrm{~m}$ and $66 \mathrm{~m}$ that, associated with upper layers water contribution, form an unconfined aquifer with delayed response with transmissivity around $0.6 \mathrm{~m}^{2} / \mathrm{h}$ and water level located $8 \mathrm{~m}$ deep.

From $66 \mathrm{~m}$ depth towards the end of the Production/Injection well drilling (at $115 \mathrm{~m}$ ) a succession of sandstone, conglomerate, shale, argillaceous shale, mudstone, and dolomite layers occurs. These layers constitute a confined aquifer with an $8 \mathrm{~m}$ water level depth, and around $8 \mathrm{~m}^{2} / \mathrm{h}$ transmissivity, and $1 \times 10^{-4}$ coefficient of storage. With these hydrodynamic characteristics this well can provide discharge rates up to $150 \mathrm{~m}^{3} / \mathrm{h}$.

The construction of an Auxiliary well located at $13.2 \mathrm{~m}$ from the Production/Injection well enabled several pumping tests with drawdown and recovery measurements in both, the pumping and observation wells.

The interpretation of pump tests (drawdown and recovery), as well as recharge tests, were developed by applying the theory of image well water-mirror (horizontal mirror) that can be applied in two situations:

a) In the analysis of pumping test results, where the recovery $\times$ time data (real well) are considered similar to the drawdown $\times$ time (virtual well - image well water-mirror), due to the similarity between the cones of depression and ascension. When the tested aquifer is classified as confined, the Theis method could be applied to obtain the hydrodynamic parameters associated with drawdown and recovery behavior.

b) During pumping tests, the theory of image well water-mirror enabled to determine that well recovery is associated with the average (weighted by the time factor) of the pumping flow rates, so that recovery $\times$ time is more accurate for determining the aquifer hydrodynamic parameters than the drawdown $\times$ time because the recovery flow rate is always constant.

The application of image well water-mirror theory showed that the water injected by artificial recharge also have a similar cone of depression behavior. A flow rate $Q$ (for a drawdown $h$ ) can be extracted and the same flow rate $Q$ (for a rise $h$ ) injected in a well if water extravasation does not occur, which is limited by the recharge dynamic level when it reaches the well head.

The contribution of the aquifer circular area, between interfering wells, in the discharge rate of a well was determined by multiplying the aquifer transmissivity and the interference 
DINIZ, H. N.; SANTORO, J.; BATISTA, G. T.; DIAS, N. W.; TARGA, M. dos S. Hydrogeology and hydrodynamics of Tremembé aquifer, São Paulo, Brazil. Ambi-Agua, Taubaté, v. 3, n. 1, p. 108-137, 2008. (doi:10.4136/ambi-agua.46)

flow rate. The discharge rate of a well without interference was determined by multiplying the apparent transmissivity and the discharge rate without interference.

\section{ACKNOWLEDGEMENTS}

The authors wish to express their gratitude to the Geological Institute of the State of São Paulo Secretariat of Environmental and to the Graduate Program in Environmental Sciences of the University of Taubate for their support to this research. They also wish to thank the State of São Paulo Research Support Foundation - FAPESP for funding this research.

\section{REFERENCES}

ALMEIDA, F. F. M. The system of continental rifts bordering the Santos Basin, Brazil. Anais Academia Brasileira de Ciências, Rio de Janeiro, n. 48 (supl.), p.15-26, 1976.

BOUWER, H. Groundwater hydrology. New York: McGraw-Hill, 1978. 480 p.

CARNEIRO, C. D. R.; HASUI, Y.; GIANCURSI, F. D. Estrutura da bacia de Taubaté na região de São José dos Campos. In: CONGRESSO BRASILEIRO DE GEOLOGIA, 29., 1976, Ouro Preto. Anais... Ouro Preto: SBG, 1976. v. 4, p. 247-256.

CAVALCANTE, J. C.; KAEFER, L. Q. Geologia da folha de Santos (parcial). In: CONGRESSO BRASILEIRO DE GEOLOGIA, 28., 1974, Porto Alegre. Anais... Porto Alegre: SBG, 1974. v. 4, p. 227-245.

COLTRINARI, L. Geomorfologia e dinâmica quaternária no sudeste do Brasil. Revista do Departamento de Geografia da FFLCH/USP, São Paulo, v. 6, p. 7-16, 1992.

CONSÓRCIO ICFKAISER-LOGOS. Projeto qualidade das águas e controle da poluição hídrica na bacia do Rio Paraíba do Sul: meta I. São Paulo: SRHSO-SEPURB/MPOBIRD-PNUD, may/1999. Stencilled.

COOPER JR., H. H.; JACOB, C. E. A generalized graphical method for evaluating formation constants and summarizing well-field history. American Geophysics Union Transaction, Washington, n. 27, p. 526-534, 1946.

CUSTODIO, E.; LLAMAS, M. R. Hidrologia subterrânea. Barcelona: Omega, 1983. Tomo I, 1157 p.

DRISCOLL, F. G. Groundwater and wells. 2.ed. St. Paul: Johnson Filtration Systems, 1989. $1089 \mathrm{p}$.

FITTS C. R. Groundwater science. London: Academic Press, 2002. 450 p.

FRANCO FILHO, F. W. B.; SOUZA, J. C. S. Explotação de água subterrânea em São José dos Campos: efeitos observados ao longo do tempo. In: CONGRESSO BRASILEIRO DE ÁGUAS SUBTERRÂNEAS, 8., dez.1994, Recife. Anais... Recife: ABAS, 1994. v. 1, p.113-123.

FREEZE, R. A.; CHERRY, J. A. Groundwater. Englewood Cliffs: Prentice-Hall, 1979. 604 p.

HANTUSH, M. S. Analysis of data from pumping tests in leaky aquifers. American Geophysical Union Transaction, Washington, v. 37, n. 6, p. 702-714, 1956. 
HASUI, Y.; GIMENEZ, A. F.; MELO, M. S. Sobre as bacias tafrogênicas do sudeste brasileiro. In: CONGRESSO BRASILEIRO GEOLOGIA, 30., 1978, Recife. Anais... Recife: SBG, 1978. v. 1, p. 382-392.

HASUI, Y.; PONÇANO, W. Organização estrutural e evolução da bacia de Taubaté. In: CONGRESSO BRASILEIRO GEOLOGIA, 30., 1978, Recife. Anais... Recife: SBG, 1978. v. 1, p.368-381.

MELO, M. S.; CAETANO, S. L .V.; COIMBRA, A. M. Tectônica e sedimentação nas áreas das bacias de São Paulo e Taubaté. In: CONGRESSO BRASILEIRO DE GEOLOGIA, 34., 1986, Goiânia. Anais... Goiânia: SBG, 1986. v. 1, p. 321-336.

MINNESOTA. Departament of Natural Resources. Division of Waters. Criteria and guidelines for assessing geologic sensitivity of ground water resources in Minnesota. St. Paul: DNR, Division of Waters, 1991.

NEUMAN, S. P. Theory of flow in unconfined aquifers considering delayed response of the water table. Water Resources Research, n. 8, p. 1031-1045, 1972.

RICCOMINI, C. O rift continental do sudeste do Brasil. 1989, 256f. Tese (Doutorado em Geociências) - Instituto de Geociências, Universidade de São Paulo, São Paulo, 1989.

SADOWSKI, G. R.; CARNEIRO, C. D. R. O charnoquito de São Francisco Xavier, São Paulo. In: CONGRESSO BRASILEIRO DE GEOLOGIA, 28., Porto Alegre, 1974. Anais... Porto Alegre: SBG, 1974. v. 4, p. 207-211.

SANTORO, E.; ENS H. H.; NAGATA, N. Geologia das folhas Jacareí, Tremembé, Taubaté e Pindamonhangaba. São Paulo, Parte 1: embasamento setentrional da bacia de Taubaté. In: SIMPÓSIO GEOLOGIA DO SUDESTE, 2., 1991, Rio de Janeiro. Atas... São Paulo: SBG, p. 481-489.

SÃO PAULO. Secretaria do Meio Ambiente. Departamento de Águas e Energia Elétrica DAEE. Estudo de águas subterrâneas: região administrativa 3 - S.J. dos Campos e faixa litorânea. São Paulo: Enco/DAEE, 1977a. v. 1, 112 p. (text).

SÃO PAULO. Secretaria do Meio Ambiente. Departamento de Águas e Energia Elétrica DAEE. Estudo de águas subterrâneas: região administrativa 3 - S.J. dos Campos e faixa litorânea. São Paulo: Enco/DAEE, 1977b. v. 5, 160 p. (maps and tables).

SOUZA, J. C. S. Estudo hidrogeológico da região de Lorena. 2004, 174f. Tese (Dutorado em Geociências) - Instituto de Geociências, Universidade de São Paulo, São Paulo, 2004.

THEIS, C. V. The relation between the lowering of piezometric surface and the rate and duration of discharge of a well using ground-water storage. American Geophysical Union Transaction, Washigton, Part II p. 519-524. 1935.

U. S. GEOLOGICAL SURVEY. Ground water manual. Washington: Government Printing Office, 1977. $480 \mathrm{p}$.

WALTON, W. C. Groundwater resource evaluation. New York: Ed.McGraw-Hill, 1970. $664 \mathrm{p}$. 